University of South Florida

DIGITAL COMMONS

Digital Commons @ University of

@ UNIVERSITY OF SOUTH FLORIDA

South Florida

\title{
Enhancing the Connectivity of High Speed Rail in the Orlando- Tampa Corridor with Local Public Transportation Systems: Issues and Opportunities
}

CUTR

Follow this and additional works at: https://digitalcommons.usf.edu/cutr_nctr

\begin{abstract}
Recommended Citation
"Enhancing the Connectivity of High Speed Rail in the Orlando-Tampa Corridor with Local Public Transportation Systems: Issues and Opportunities," National Center for Transit Research (NCTR) Report No. CUTR-NCTR-RR-2010-01, Center for Urban Transportation Research, University of South Florida, 2011. DOI: https://doi.org/10.5038/CUTR-NCTR-RR-2010-01

Available at: https://scholarcommons.usf.edu/cutr_nctr/131
\end{abstract}

This Technical Report is brought to you for free and open access by the National Center for Transit Research (NCTR) Archive (2000-2020) at Digital Commons @ University of South Florida. It has been accepted for inclusion in Research Reports by an authorized administrator of Digital Commons @ University of South Florida. For more information, please contact digitalcommons@usf.edu. 
National Center

for Transit Research

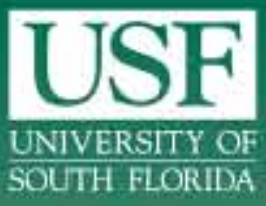

Enhancing the Connectivity Of High Speed Rail in the Orlando-Tampa Corridor with Local Public Transportation Systems: Issues and Opportunities

January 2011

Final Report

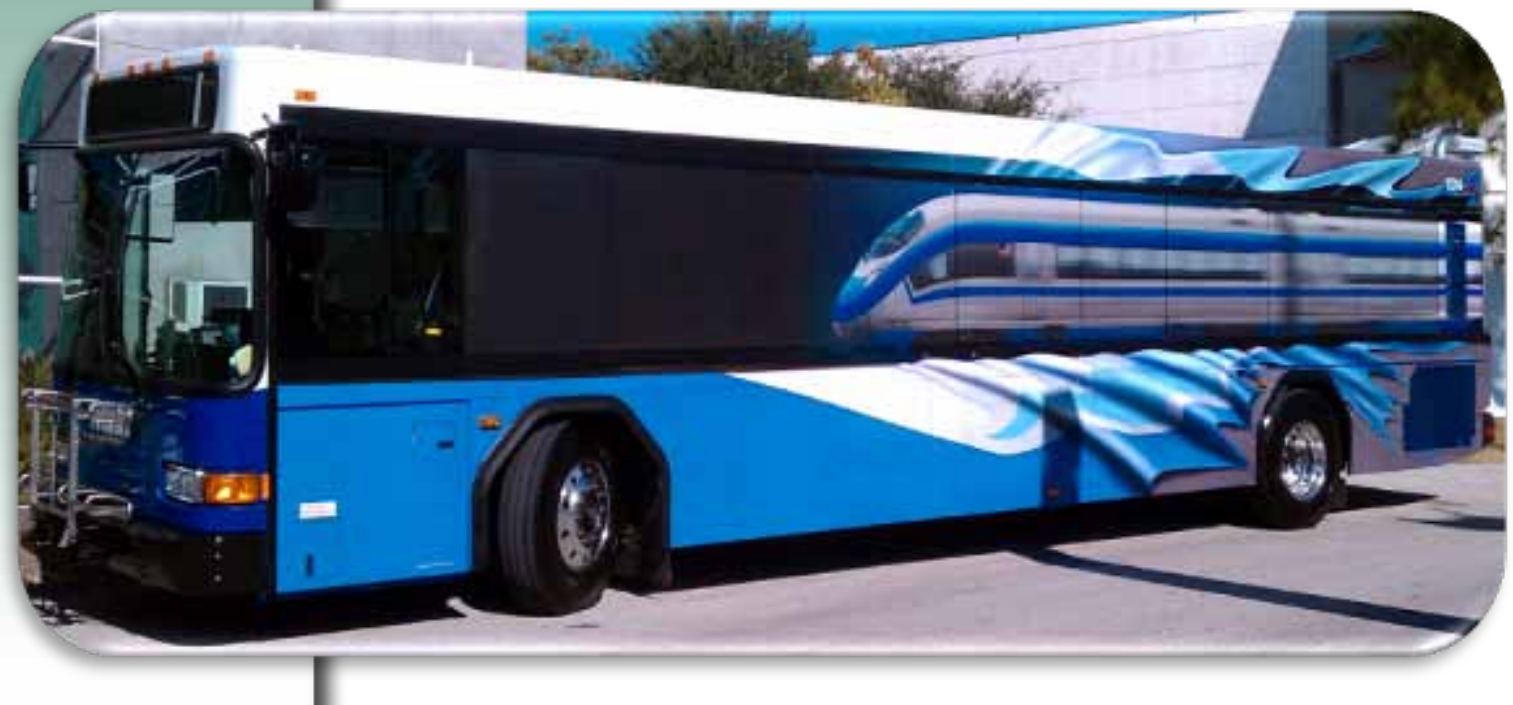

Funded by

Florida Department of Transportation

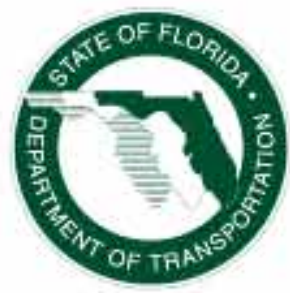




\section{DISCLAIMER}

The contents of this report reflect the views of the authors, who are responsible for the facts and the accuracy of the information presented herein. This document is disseminated under the sponsorship of the Department of Transportation University Transportation Centers

Program and the Florida Department of Transportation, in the interest of information exchange. The U.S. Government and the Florida Department of Transportation assumes no liability for the contents or use thereof. 


\title{
Enhancing the Connectivity Of High Speed Rail in the Orlando-Tampa Corridor with Local Public Transportation Systems: Issues and Opportunities
}

\author{
Final Report
}

Prepared for

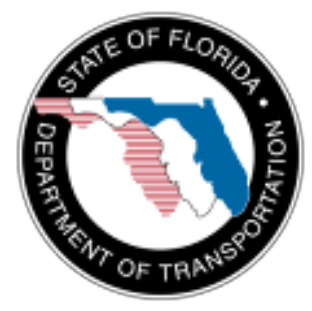

State of Florida Department of Transportation

Public Transit Office

605 Suwannee Street, MS 30

Tallahassee, Florida 32399-0450

\section{Project Manager: \\ Nazih Haddad \\ Prepared by}

(Rob Gregg and Justin Begley)

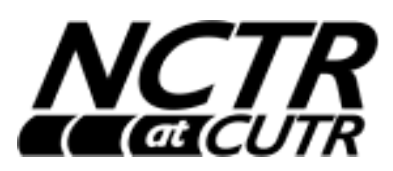

National Center for Transit Research

Center for Urban Transportation Research (CUTR)

University of South Florida

4202 East Fowler Avenue, CUT100

Tampa, Florida 33620-5375

January 2011

BDK85, RPWO \#977-24 


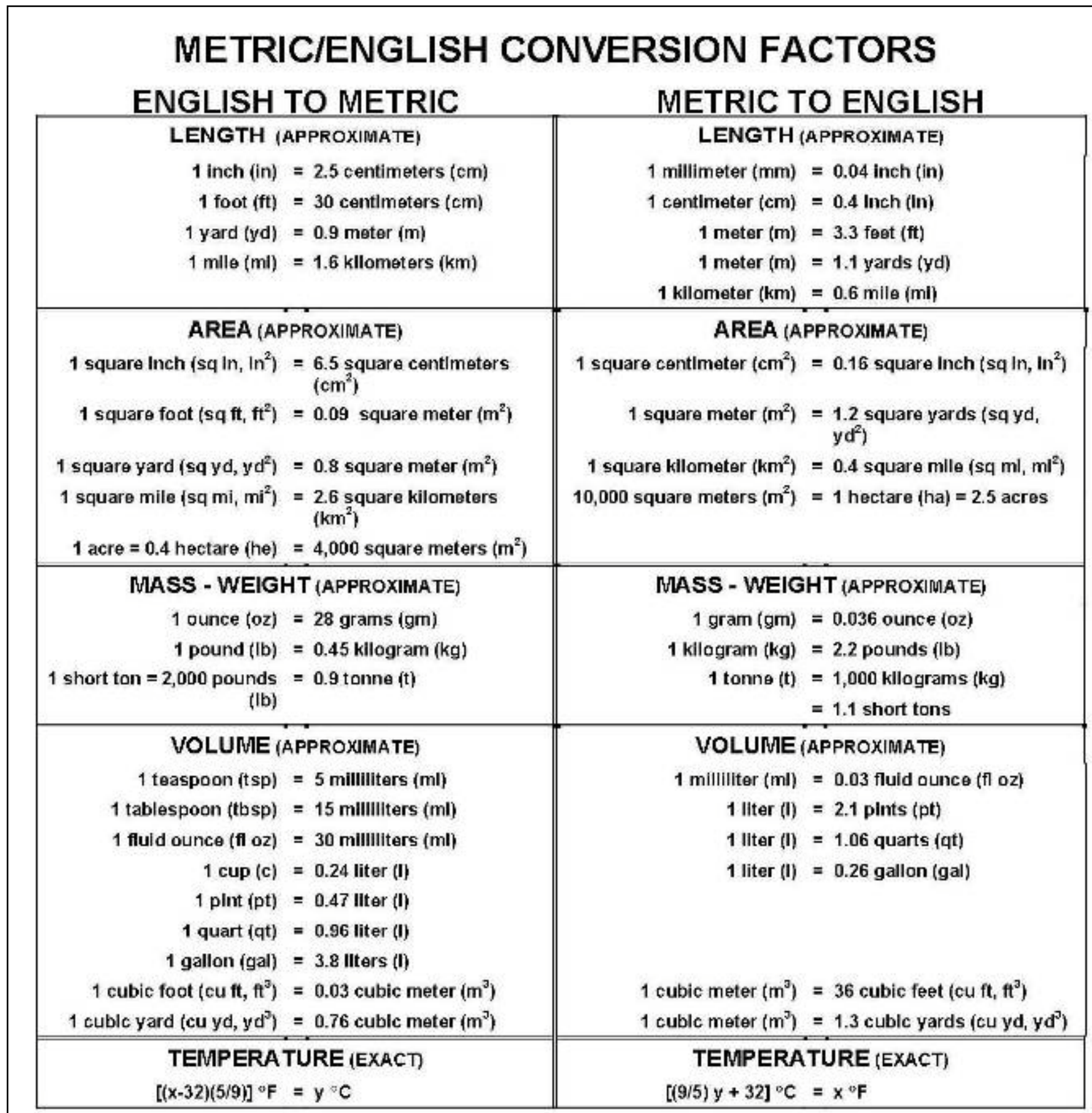

\section{QUICK INCH - CENTIMETER LENGTH CONVERSION}

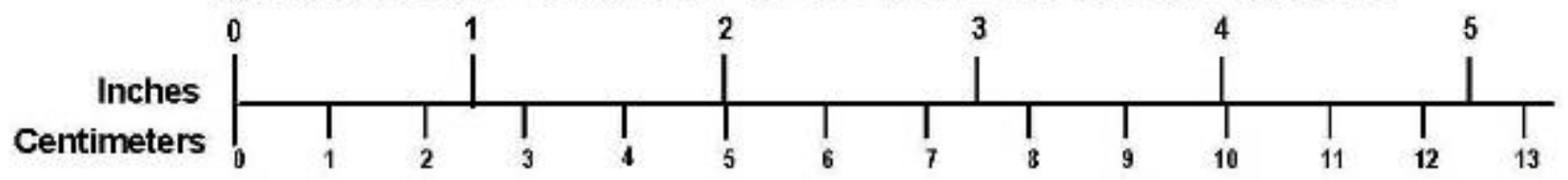

\section{QUICK FAHRENHEIT - CELSIUS TEMPERATURE CONVERSION}

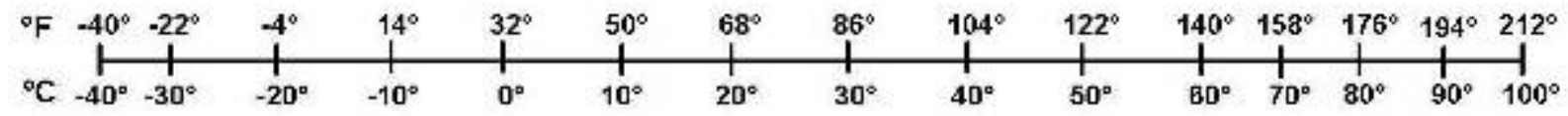

For more exact and or other conversion factors, see NIST Miscellaneous Publication 226, Units of Wieights and Measures. Price $\$ 2.50$ SD Catalog No. C13 10286 


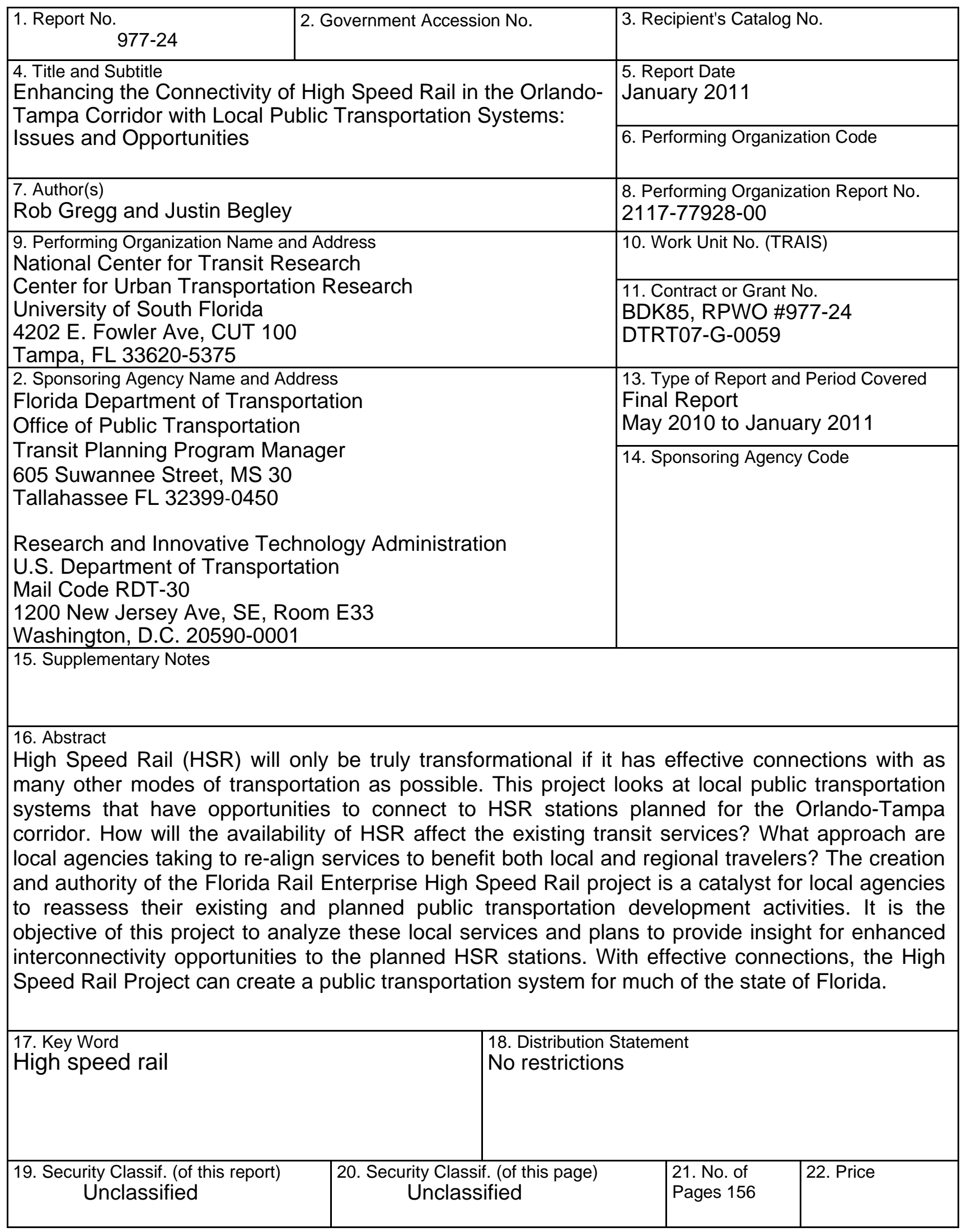


This page intentionally left blank. 


\section{EXECUTIVE SUMMARY}

The Tampa to Orlando corridor of Florida High Speed Rail (HSR) is expected to launch in 2015 to much anticipation as what will be the initial line of a national HSR service network. A 2003 market study of the proposed system stated the 'travel experience is impacted by each contact point' along an end-to-end HSR trip. It has been publicly argued that currently the least understood element of the Tampa to Orlando HSR line is the viability of connecting 'to and from' transportation options. The purpose of this study is to evaluate public transportation services within this corridor and identify opportunities for enhancement of HSR connectivity through mass transit. Prospects for increasing the use of connecting public transportation systems were found to be influenced by HSR station locations and meeting the needs of intercity travelers through provision of convenient and travel time competitive services.

\section{Transit Markets and High Speed Rail Station Integration to Local Transit Systems}

In Chapter 2, background is provided with a look to what has been learned through the operation of international HSR systems. Those existing HSR systems have traditionally catered to business travelers, whereas the projected primary users of the FHSR Phase I line may be a more balanced business/commuter and leisure/recreational trip purpose mix.

Central city HSR station locations tend to encourage travel on other transit systems when colocated with high capacity fixed guideway transit (such as local rail) and be more difficult to access by an automobile. As private cars are expected to be the primary competitor to a trip made on HSR, the degree to which station placement discourages use of any segment of an end-to-end HSR trip should not be understated. The costs to bring increased levels of local transit service to a HSR urban core station are typically lower than suburban stations, where less service exists. Walk up and cycling accessibility are more likely to be components of end to end trip utilizing transit than autos and have less potential outside of urban core areas. Two conditions identified for making suburban stations successful include the need to create a connection to a local rail network and to integrate fares, schedules, and information.

\section{Factors Affecting the Use of Connecting Bus Service for Intercity Travelers}

- Availability of express bus services for riders of particular trip purposes

- The amount of reduction of travel time between available mode options

- Frequency of service, including off-peak, late-night and weekends

- Competition with other mode choices in an open market

- Pick up and drop off locations adjacent to connecting transportation

- Ability to make seamless connections between the two riding platforms

- Provision of baggage handling strategies and complementary service 


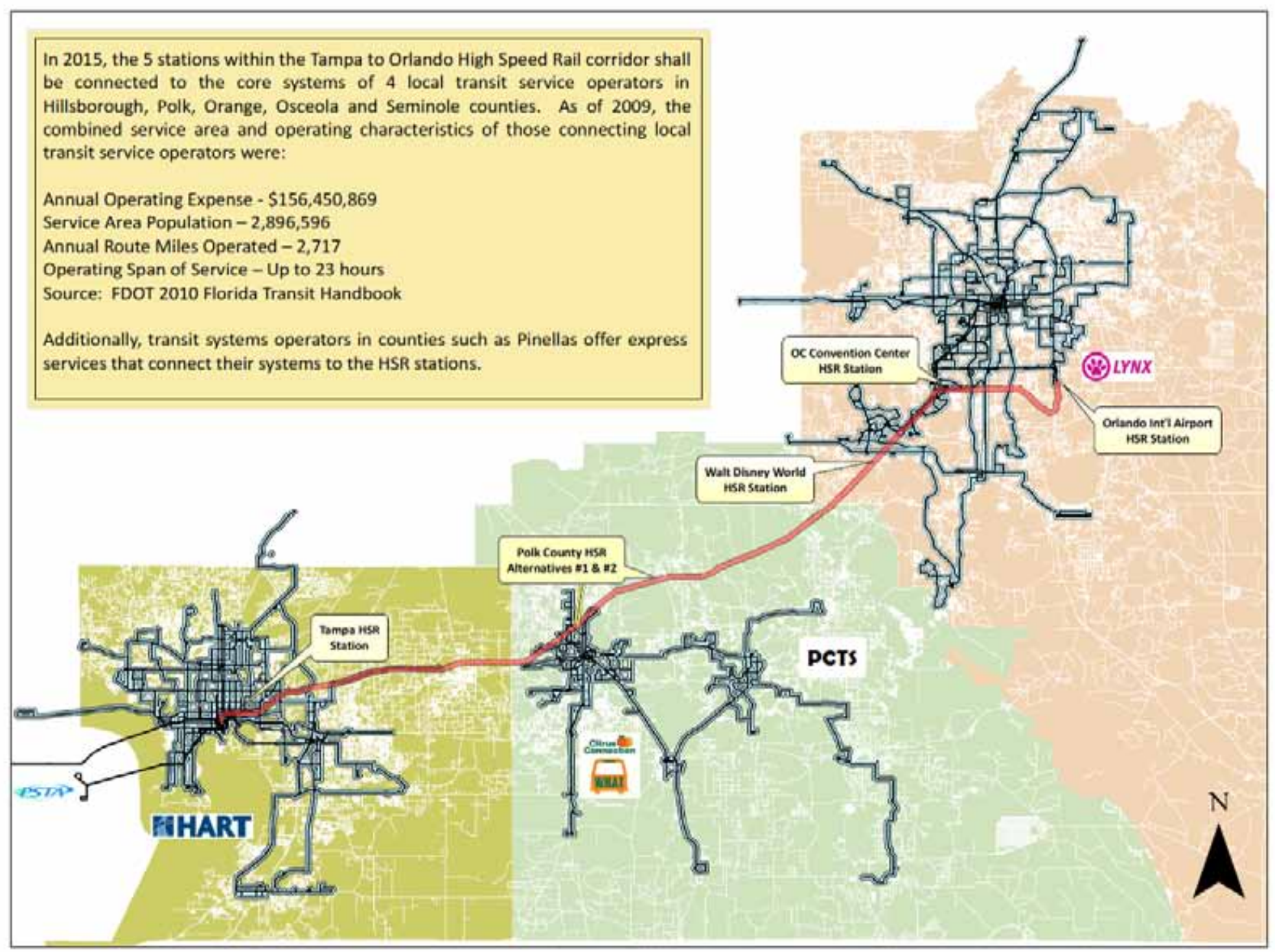

Figure ES- 1: Tampa to Orlando HSR Line and Connecting Public Transit Systems 


\section{Defining Quality Levels of Transit Service to Future HSR Stations}

In Chapter 3, existing (2010) transit service levels in the Tampa to Orlando HSR corridor were assessed for how effective they might be to provide trip connectivity. The following criteria for defining a quality connecting service were established:

- A quality public transportation connecting route has a matching span of service to HSR

- A quality public transportation connecting route serves a HSR station with at least 2 vehicles per hour/30 minute frequency

- A quality public transportation connecting route takes passengers to/from their trip generator in no more than $200 \%$ of a comparable auto travel trip time

- A quality public transportation connecting service should reduce uncertainty and emphasize convenience by eliminating the need for bus-to-bus transfers to reach major trip generators

The findings in Chapter 4 concluded that from the three future Orlando area HSR stations served by LYNX, a limited amount of destinations were connected with a relatively high quality of service. Those directly served generators were located primarily south of downtown. Polk County's existing transit service levels connected few generators with quality service on weekdays and Saturdays while late night and Sunday service was non-existent. Hillsborough County's transit system, HART, connected more generators with multiple bus lines but had mixed levels of service on late nights and weekends.

\section{Year 2015 Public Transportation Systems Level of Service Overview}

Chapter 5 begins to look forward, as to what future local transit levels of service would be leading up to 2015 and beyond. A major restructuring of LYNX's fixed route bus services is ongoing in response to a reduction in funding. A Five-Year Service Plan was created with a primary goal of planning the development of premium transit, Bus Rapid Transit (BRT) and other supporting services in a financially constrained environment. Efforts have been ongoing to unite Lakeland Area Mass Transit District (LAMTD), Winter Haven Area Transit (WHAT) and Polk County Transit Services (PCTS) under a single governing body, the Polk Transit Authority (PTA), to plan and operate all transit services for Polk County. New HSR connecting bus routes have been planned for both the Kathleen Road and Williams DRI site locations. A primary goal for HART through 2015 is to protect core services, which constitute the top 15 performing bus routes in the system.

\section{Public Transportation and Long Range Plans}

Beyond the 2015 line opening date, there is great potential for FHSR to have regional transportation benefit. Today's supporting transit networks have been conceived to be greatly expanded by transportation planning agencies into multi-county systems connected with commuter rail, light rail, BRT and other bus services to create an auto-independent environment for mobility. Long-range plans were found to have better integrated HSR and incorporated supporting transit networks in connectivity plans. 


\section{Opportunities to Enhance HSR Connectivity}

Chapter 7 summarizes a set of strategies and detailed service plans to provide increased opportunities for success in connecting HSR to local public transportation. They include:

- Targeting HSR station serving routes for frequency, span and days of service improvements

An analysis in Chapter 6 reveals opportunities to enhance local transit system connections with improvements in frequencies, operating span and weekend service on routes with a significant number of potential HSR trip generators.

- Extend or deviate nearby bus routes into HSR stations

Analysis of existing services provides some insight into the environment for connectivity at the time of HSR line opening. With minor deviations, non-direct HSR connected routes could serve the stations directly.

- Consider enhancement of existing lines and new express bus services to emerging generators and unserved communities. Specific opportunities include:

\begin{tabular}{|c|c|c|}
\hline System & $\underline{\text { Route }}$ & Opportunity \\
\hline HART & 5 & Enhance Span \& Frequency to Serve USF \& Busch Gardens \\
\hline HART & 18 & Enhance Span \& Frequency to Serve USF \& Busch Gardens \\
\hline HART & $96 \& 97$ & Enhance Span to Match HSR, Serve Downtown Tampa \\
\hline HART & $200 x$ & Enhance Span and Frequency to Match HSR \& Connect Pinellas County \\
\hline HART & NEW & Express Bus from HSR to Tampa International Airport \\
\hline HART & NEW & Express Bus from HSR to MacDill Air Force Base \\
\hline LAMTD & 12 & Deviate into HSR (Location \#2) and Match Span and Frequency of Service \\
\hline LAMTD & 50 & Deviate into HSR (Location \#2) and Match Span and Frequency of Service \\
\hline LAMTD & 51 & Deviate into HSR (Location \#2) and Match Span and Frequency of Service \\
\hline LAMTD & 56 & Deviate into HSR (Location \#2) and Match Span and Frequency of Service \\
\hline LAMTD & NEW & Express Bus from HSR (Location \#1) to Downtown Lakeland \\
\hline LYNX & NEW & Express Bus from Poinciana to Disney HSR to Walt Disney World \\
\hline LYNX & NEW & Express Bus from Orlando International Airport HSR to Lake Nona \\
\hline LYNX & NEW & Express Bus from Orlando International Airport HSR to University of Central Florida \\
\hline LYNX & NEW & Express Bus from Orlando International Airport HSR to SunRail Sand Lake Station \\
\hline $\begin{array}{c}\text { Polk } \\
\text { County }\end{array}$ & NEW & Express Bus from HSR (Location \#1) to Downtown Winter Haven \\
\hline $\begin{array}{l}\text { Polk } \\
\text { County }\end{array}$ & NEW & Express Bus from HSR (Location \#1) to Legoland Theme Park \\
\hline PSTA & $100 x$ & Enhance Span and Frequency to Match HSR \& Connect Pinellas County \\
\hline PSTA & $300 x$ & Enhance Span and Frequency to Match HSR \& Connect Pinellas County \\
\hline
\end{tabular}




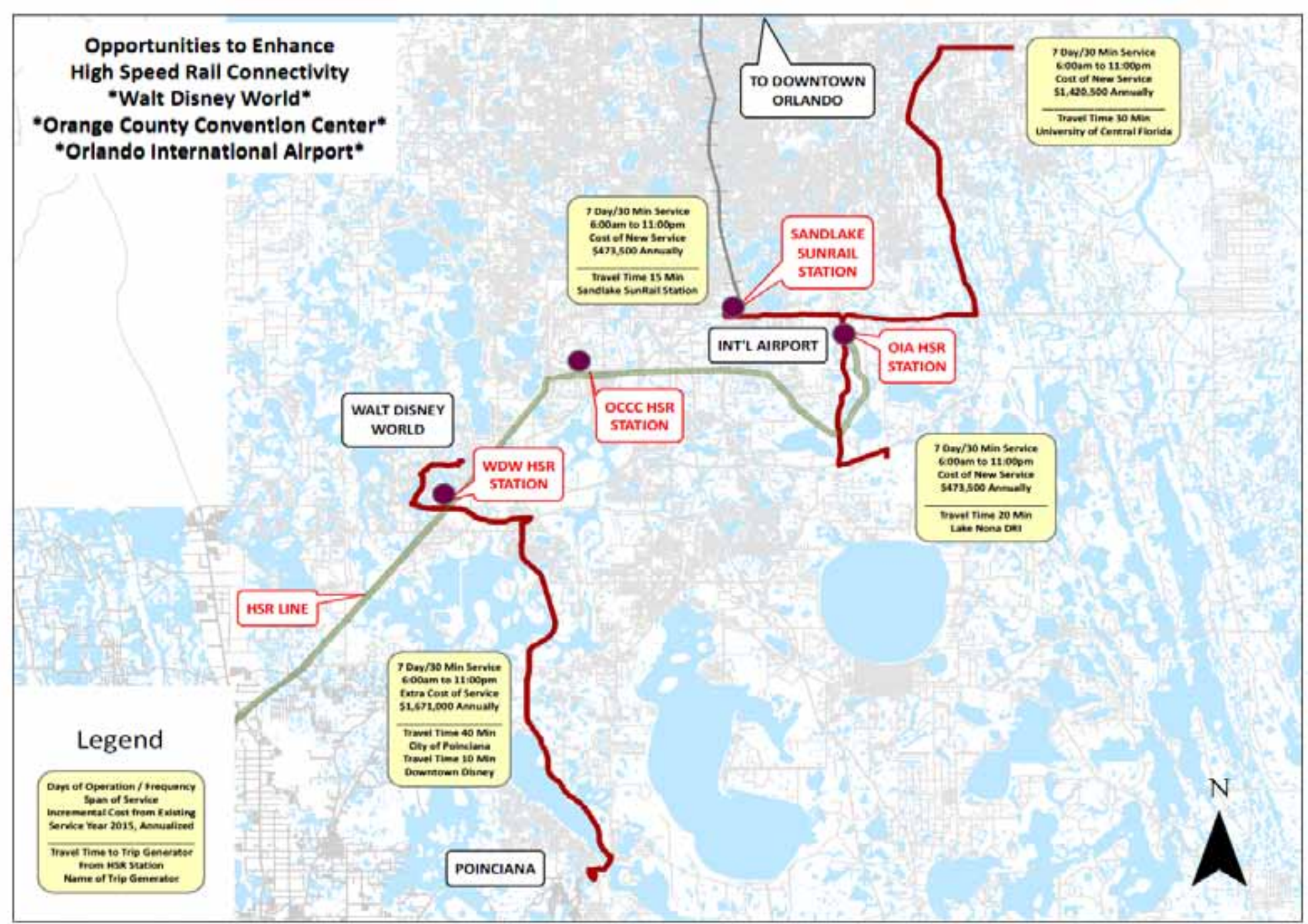

Figure ES- 2: Opportunities to Enhance Metro Orlando HSR Connectivity 


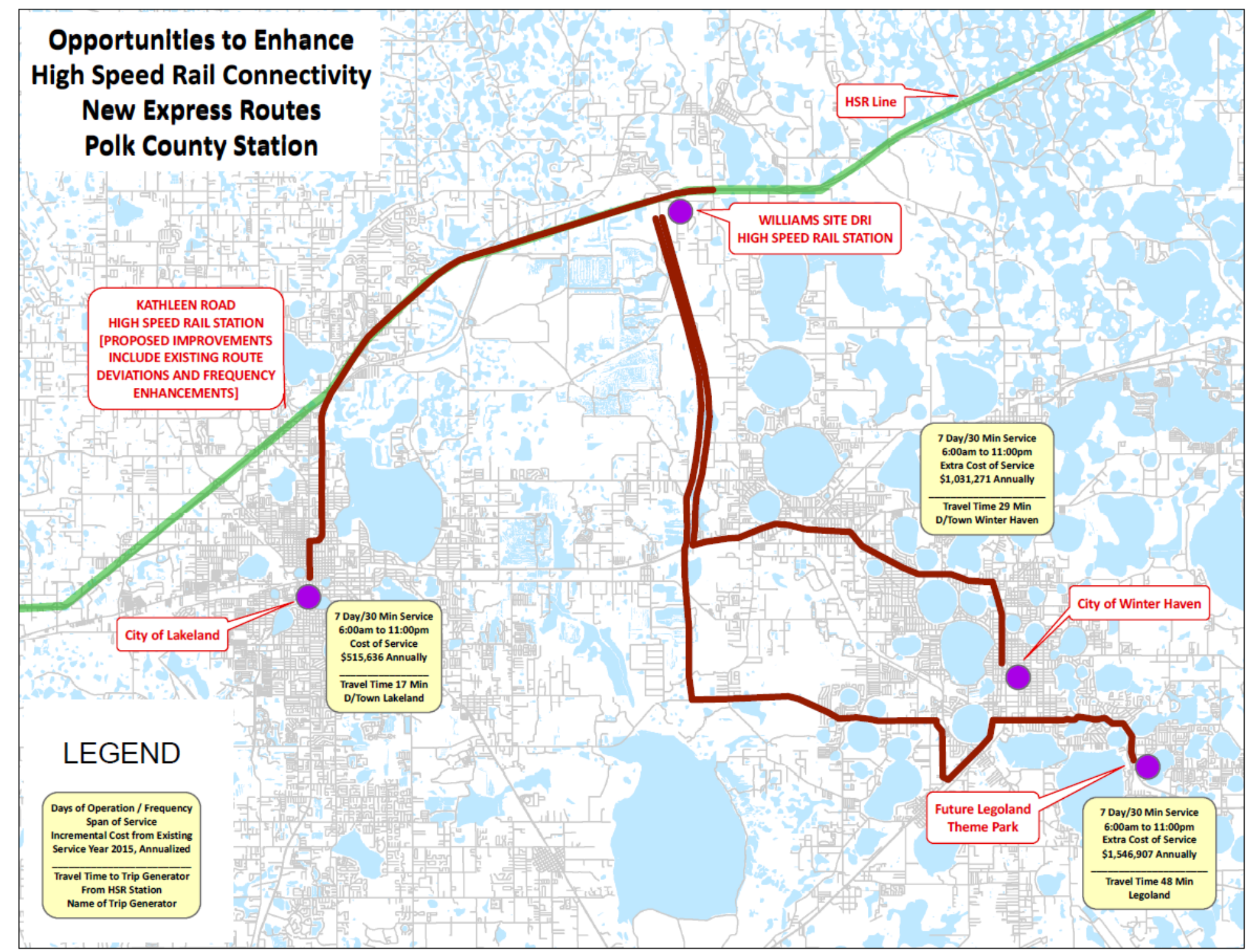

Figure ES- 3: Opportunities to Polk County HSR Connectivity 


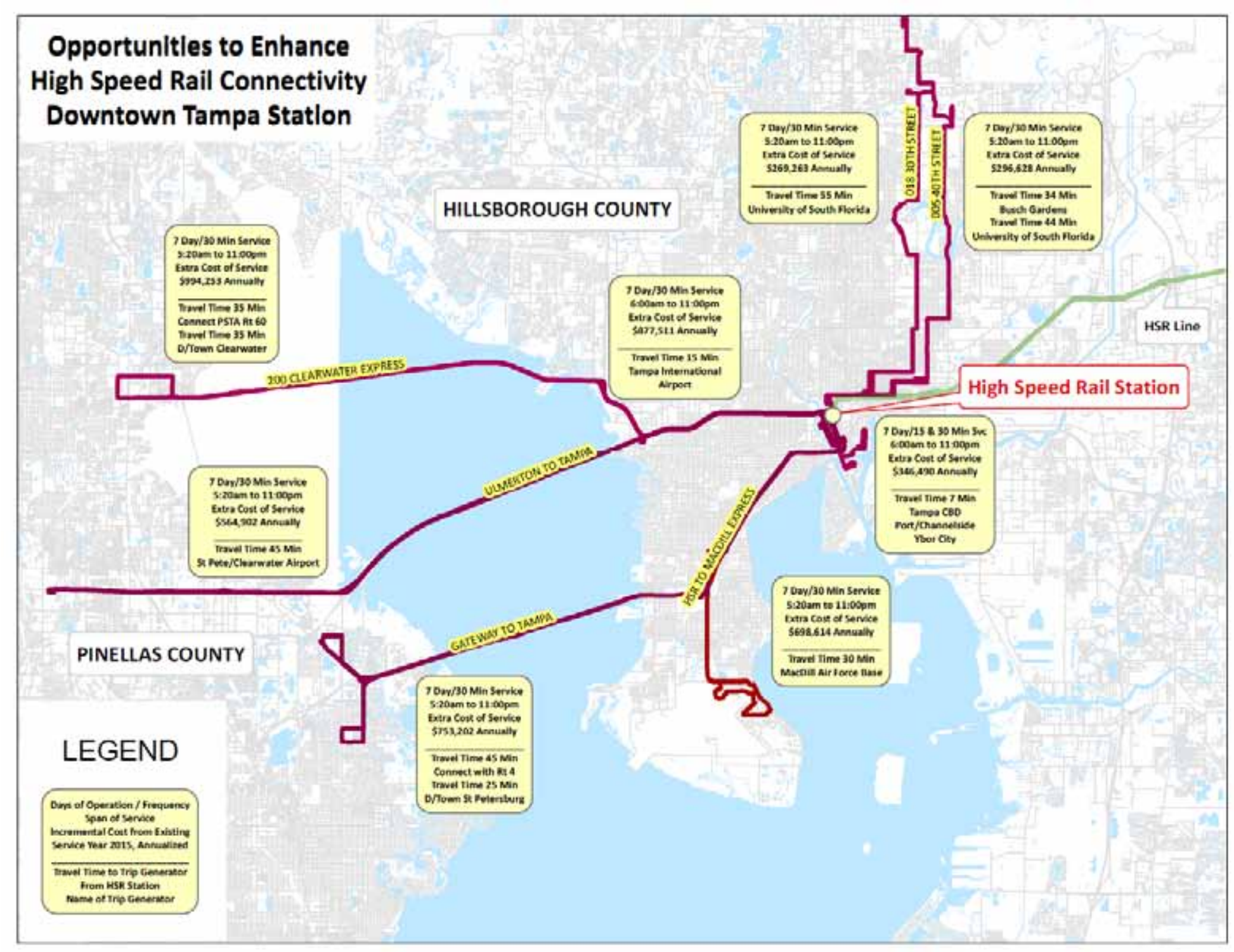

Figure ES- 4: Opportunities to Enhance Tampa Bay HSR Connectivity 
This page intentionally left blank 


\section{TABLE OF CONTENTS}

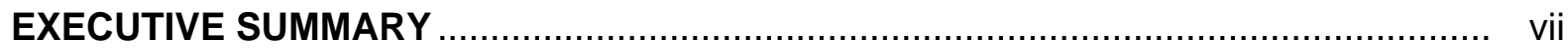

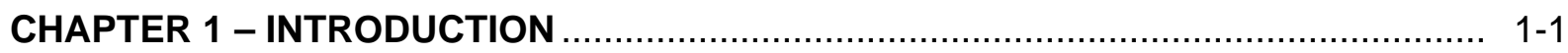

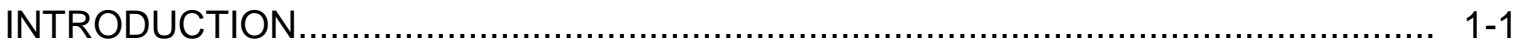

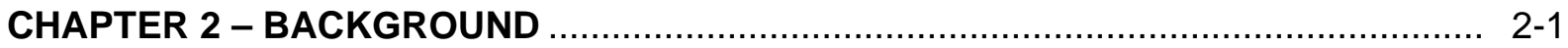

DESCRIPTION OF THE TAMPA - ORLANDO FHSR PHASE ........................... $2-1$

Phase I Operating Characteristics ...................................................... 2-2

DESCRIPTION OF FHSR PHASE I CONNECTING PUBLIC TRANSPORTATION

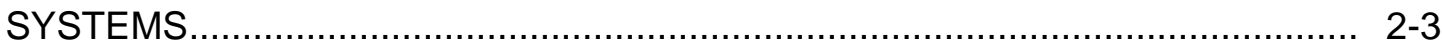

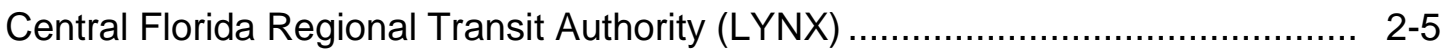

Hillsborough Area Regional Transit Authority (HART) ................................... 2-5

Lakeland Area Mass Transit District (LAMTD/Citrus Connection) ........................ 2-5

Polk County Transit Services/Winter Haven Area Transit (PCTS \& WHAT) ......... 2-6

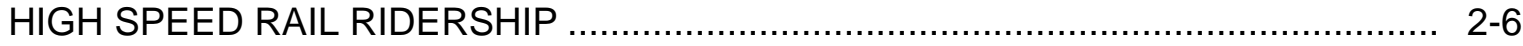

HSR STATION ACCESS FOR CONNECTING PUBLIC TRANSPORTATION ........... 2-7

Issues Raised in Research Related to HSR Station Access .............................. 2-7

SURROUNDING STATION LAND USE AND ACCESSWAYS ............................. $2-9$

Orlando International Airport Station ............................................................ $2-9$

Orange County Convention Center Station ................................................ $2-9$

Walt Disney World Station ............................................................................. 2 $2-9$

Polk County Site Alternative \#1 - Williams Site/Future USF Polytechnic............. 2-10

Polk County Site Alternative \#2 - Kathleen Road ........................................... 2-12

Downtown Tampa Intermodal Center ........................................................... 2-14

Urban Core and Urban Periphery FHSR Stations and Mass Transit................... 2-14

DEFINING EFFECTIVE CONNECTING PUBLIC TRANSPORTATION SERVICE ...... 2-16

Transit Service Planning ...................................................................... 2-16

CHARACTERISTICS AND ISSUES IN MAKING SUCCESSFUL INTERCITY

TRAVELER CONNECTION WITH PUBLIC TRANSPORTATION ...................... 2-19

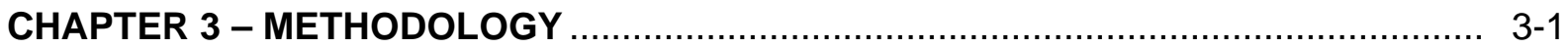

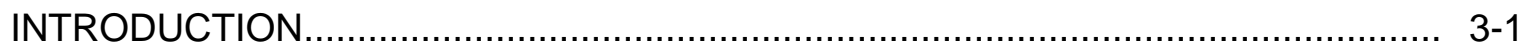

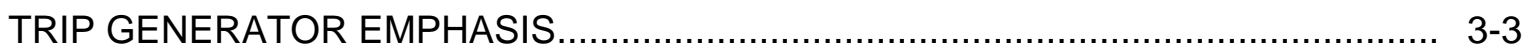

CHAPTER 4 - YEAR 2010 PUBLIC TRANSPORTATION SERVICE LEVELS

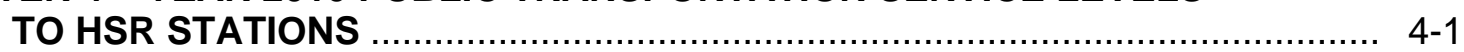

2010 TRANSIT CONNECTIVITY TO FUTURE HSR STATION LOCATIONS ............ 4 4-1

Route 8: W. Oak Ridge Rd/Int'I Dr ...................................................... $4-4$

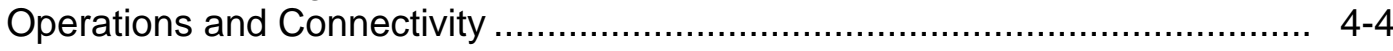


Origins and Destinations

4-4

Route 11: S. Orange Ave/Orlando Int'l.......................................................... 4-4

Operations and Connectivity ................................................................ 4-4

Origins and Destinations .................................................................. 4-4

Route 38: Downtown Orlando/Int'I Dr......................................................... 4-5

Operations and Connectivity.................................................................... 4-5

Origins and Destinations...................................................................... 4-5

Route 41: SR 436 Crosstown................................................................. 4-5

Operations and Connectivity....................................................................... 4-5

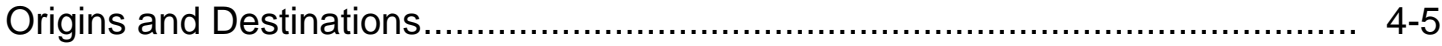

Route 42: Int'l D/Orlando Int'l Airport ............................................................ 4-6

Operations and Connectivity.................................................................. 4-6

Origins and Destinations............................................................................. 4-6

Route 50: Downtown Orlando/Magic Kingdom ………….................................... 4-6

Operations and Connectivity ...................................................................... 4-6

Origins and Destinations ............................................................................. 4-6

Route 51: Conway/Orlando Int'l Airport......................................................... 4-7

Operations and Connectivity....................................................................... 4-7

Origins and Destinations........................................................................ 4-7

Route 55: West US 192/Four Corners …………......................................... 4-7

Operations and Connectivity................................................................... 4-7

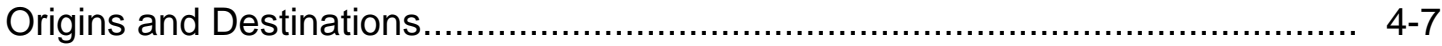

Route 56: West US 192/Magic Kingdom............................................................ 4-8

Operations and Connectivity................................................................. 4-8

Origins and Destinations....................................................................... 4-8

Route 58: Shingle Creek Circulator................................................................ 4-8

Operations and Connectivity................................................................. 4-8

Origins and Destinations....................................................................... 4-8

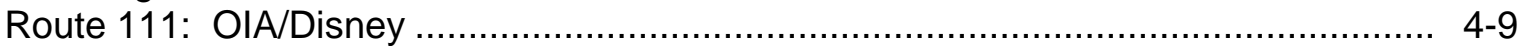

Operations and Connectivity...................................................................... 4-9

Origins and Destinations............................................................................... 4-9

Route 301: 3D-Pine Hills/Animal Kingdom...................................................... 4-9

Operations and Connectivity.................................................................. 4-9

Origins and Destinations........................................................................ 4-9

Route 306: Poinciana/Magic Kingdom ……………….................................... 4-10

Operations and Connectivity..................................................................... 4-10

Origins and Destinations....................................................................... 4-10

Route 641: Williamsburg Circulator.................................................................. 4-10

Operations and Connectivity ………………………................................ 4-10

Origins and Destinations ............................................................................... 4-10

Route Greenline: I-Drive Trolley ........................................................................ 4-11

Operations and Connectivity ...................................................................... 4-11

Origins and Destinations .............................................................................. 4-11

Route Redline: I-Drive Trolley ……………………......................................... 4-11

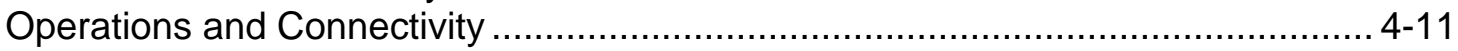

Origins and Destinations ........................................................................... 4-11

Route 50: Kathleen/Providence ……….......................................................... 4-13

Operations and Connectivity …………………………............................. 4-13

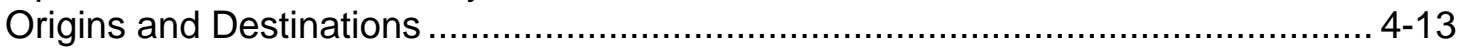

Route 51: North 98/Duff Rd........................................................................... 4-13 


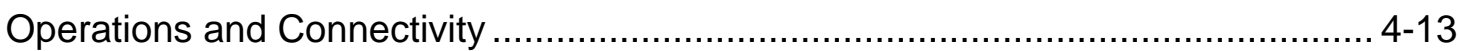

Origins and Destinations ............................................................................ 4-14

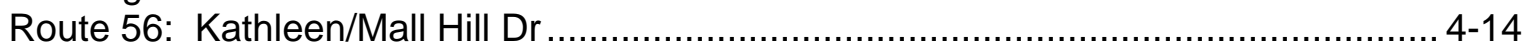

Operations and Connectivity ..................................................................... 4-14

Origins and Destinations ........................................................................... 4-14

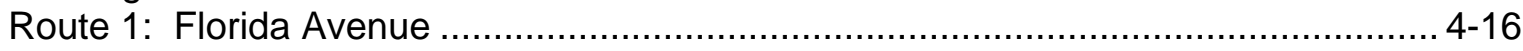

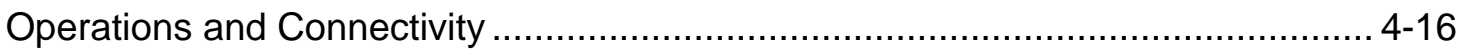

Origins and Destinations ........................................................................... 4-16

Route 2: Nebraska Avenue .......................................................................... 4

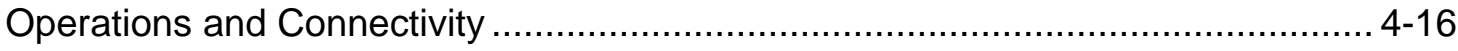

Origins and Destinations ........................................................................... 4-17

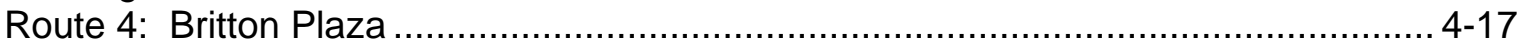

Operations and Connectivity ................................................................... 4-17

Origins and Destinations ........................................................................... 4-17

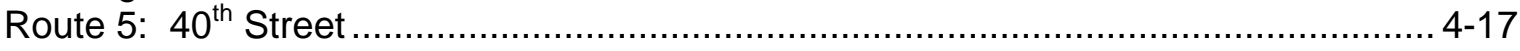

Operations and Connectivity .................................................................... 4-17

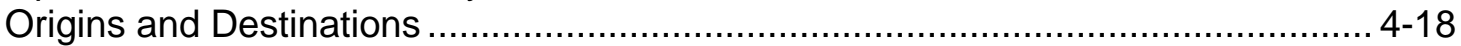

Route $6: 56^{\text {th }}$ Street .................................................................................... 4-18

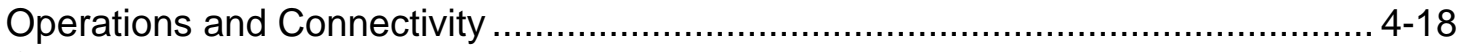

Origins and Destinations ....................................................................... 4-18

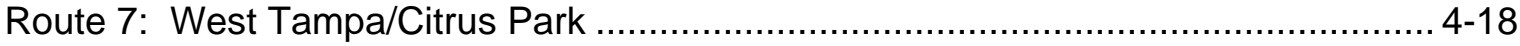

Operations and Connectivity .................................................................... 4-18

Origins and Destinations ........................................................................ 4-19

Route 8: Progress Village/Brandon ................................................................. 4-19

Operations and Connectivity ...................................................................... 4-19

Origins and Destinations ......................................................................... 4-19

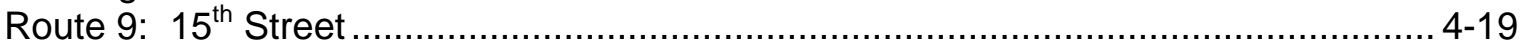

Operations and Connectivity ..................................................................... 4-19

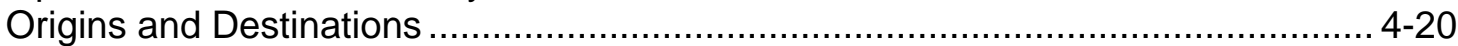

Route 10: Cypress Street............................................................................ 4-20

Operations and Connectivity .................................................................... 4-20

Origins and Destinations ....................................................................... 4-20

Route 12: $22^{\text {nd }}$ Street ................................................................................. $4-20$

Operations and Connectivity ............................................................. 4-20

Origins and Destinations ......................................................................... 4-20

Route 14: Armenia Avenue ...................................................................... 4-21

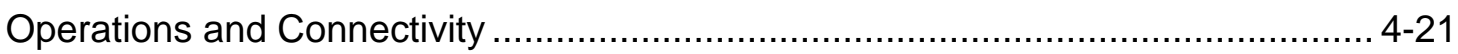

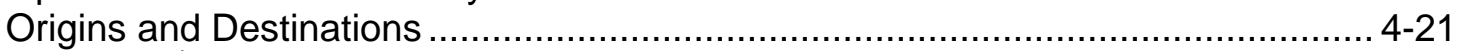

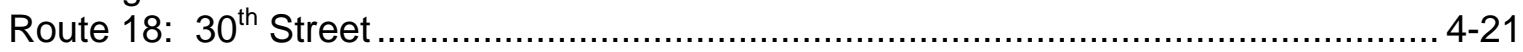

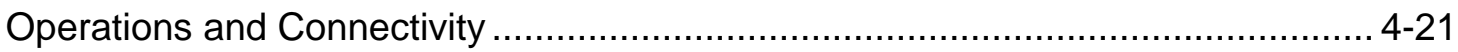

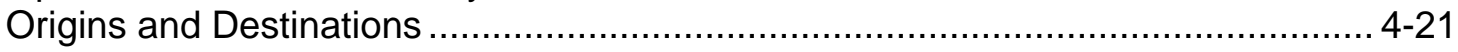

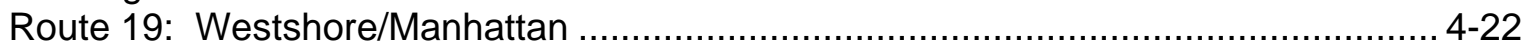

Operations and Connectivity ................................................................ $4-22$

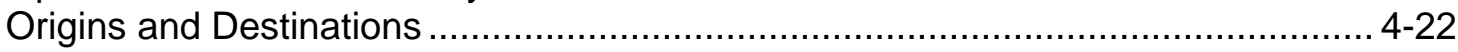

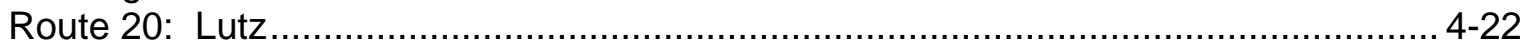

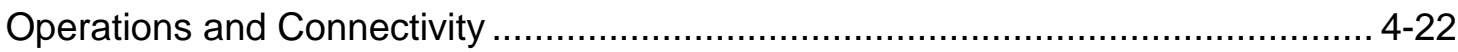

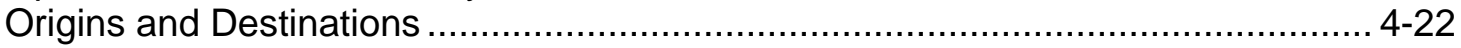

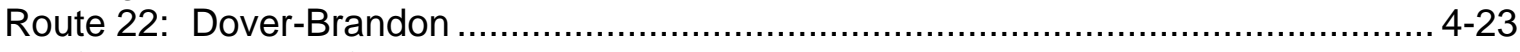

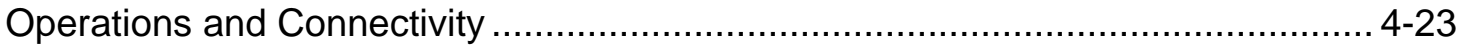

Origins and Destinations ............................................................................. $4-23$ 
Route 23: Temple Terrace ……………...................................................... 4-23

Operations and Connectivity ........................................................................ 4-23

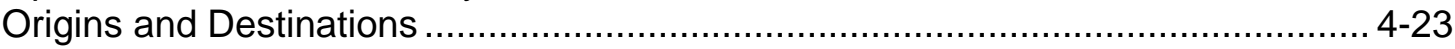

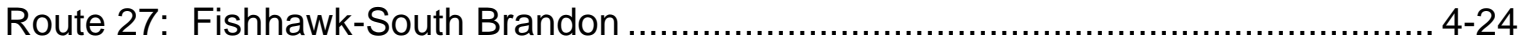

Operations and Connectivity ...................................................................... 4-24

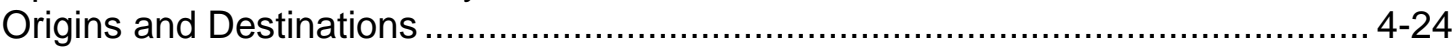

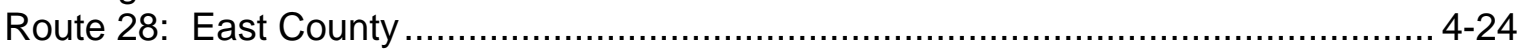

Operations and Connectivity ........................................................................ 4-24

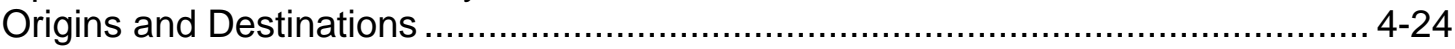

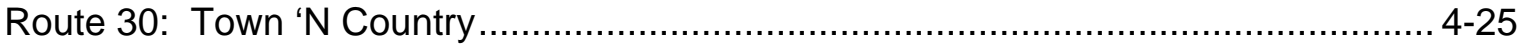

Operations and Connectivity ...................................................................... 4-25

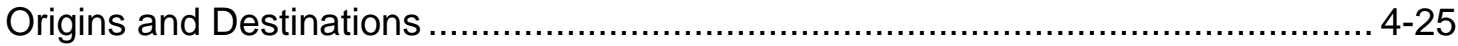

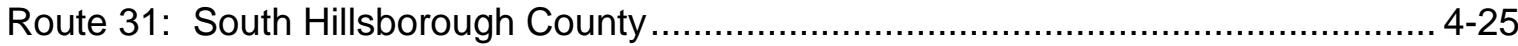

Operations and Connectivity ........................................................................... 4-25

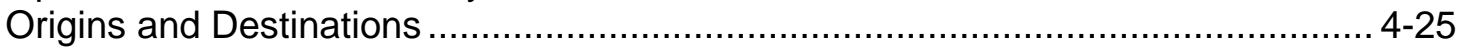

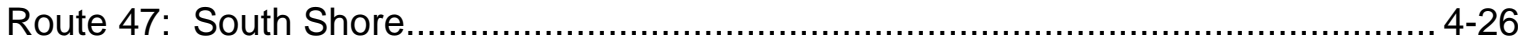

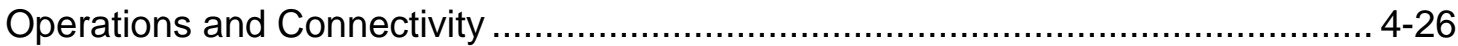

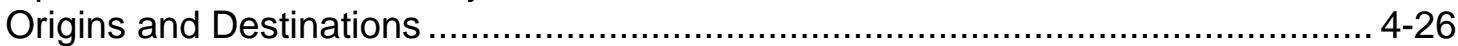

Route 50: Citrus Park-Carrollwood .................................................................. 4-26

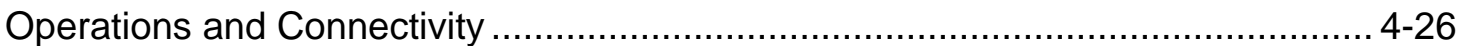

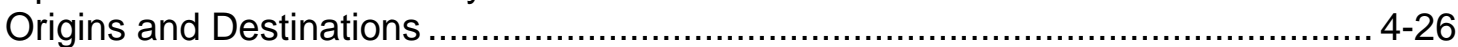

Route 51: New Tampa .............................................................................. 4-27

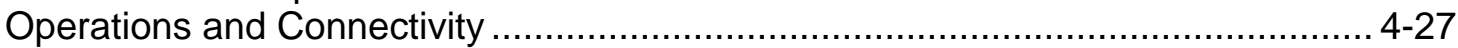

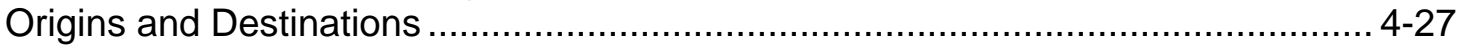

Route 59: Westchase-Town 'N Country ............................................................ 4-27

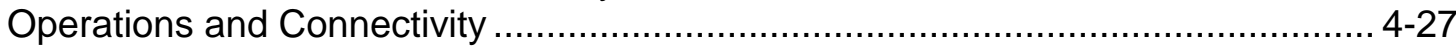
Origins and Destinations ........................................................................... 4-27

Route 96: Downtown Purple Line.................................................................. 4-28

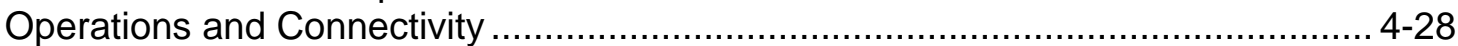

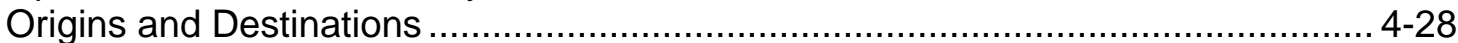

Route 97: Downtown Green Line .................................................................... 4-28

Operations and Connectivity ........................................................................ 4-28

Origins and Destinations ............................................................................. 4-28

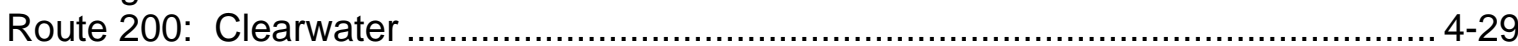

Operations and Connectivity ..................................................................... 4-29

Origins and Destinations .............................................................................. 4-29

Premium Transit Capital Projects................................................................... 4-29

Tampa - Streetcar Extension...................................................................... 4-29

Tampa - HART Northwest and West Corridors AA .............................................. 4-31

Pinellas County - Alternative Analysis ................................................................... 4-33

Metro Orlando - 'SunRail' Commuter Rail System .................................................. 4-35

Tampa - North/South and East/West Bus Rapid Transit (BRT) ................................. 4-36

Orlando - Lymmo BRT Expansion...................................................................... 4-38

CHAPTER 5 - YEAR 2015 PUBLIC TRANSPORTATION SYSTEMS LEVEL OF SERVICE ............................................................................... 5

YEAR 2015 PUBLIC TRANSPORTATION SYSTEMS LEVEL OF SERVICE ............. 5-1 Hillsborough Area Regional Transit Authority (HART) ……................................ 5-1 Lakeland Area Mass Transit District (LAMTD), Winter Haven Area Transit 
(WHAT), and Polk County Transit Services (PCTS) ............................. $5-3$

Central Florida Regional Transit Authority (LYNX) ...................................... $5-5$

PUBLIC TRANSPORTATION AND LONG RANGE PLANS ................................ $5-11$

Metro Orlando Long-Range Transit Plans .............................................. 5-11

Commuter Rail ................................................................................. 5-11

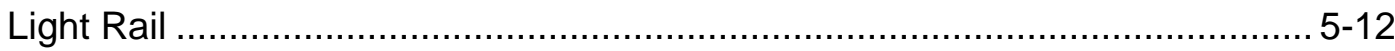

BRT and Circulators ....................................................................... 5-12

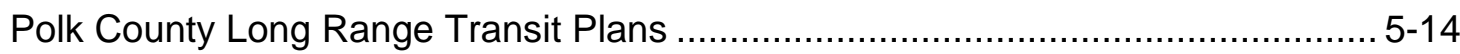

Tampa Bay Region Long Range Transit Plans ............................................ 5-17

CHAPTER 6 - APPLICATION OF METHODOLOGY TO 2010 SERVICE LEVELS

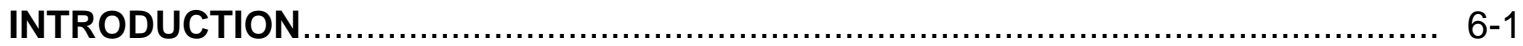

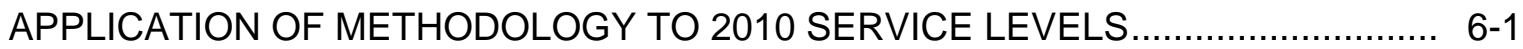

Observations for Weekday Service ........................................................... $6-6$

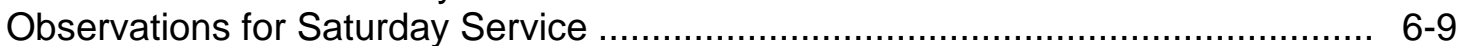

Observations for Sunday Service ......................................................... 6-12

CHAPTER 7 - OPPORTUNITIES TO ENHANCE HSR CONNECTIVITY .................... $7-1$

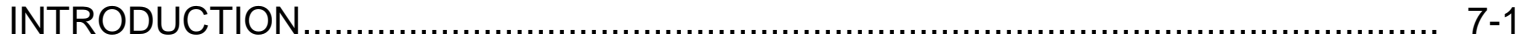

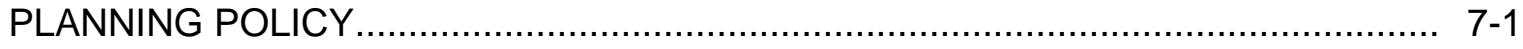

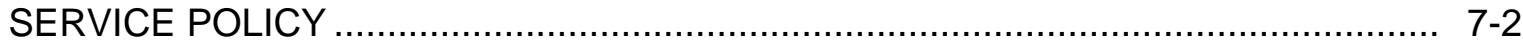

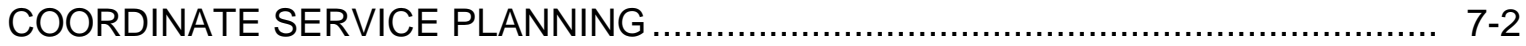

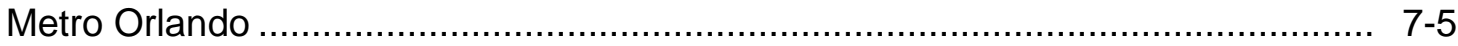

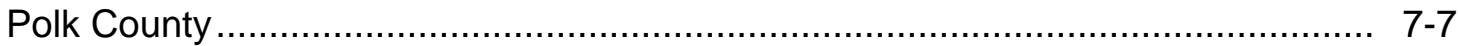

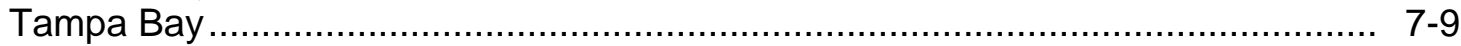

Deploy Traveler Information Systems That Inform Riders of Real-Time Arrival and Departure Times...................................................................... $7-9$

Consider Bus Specifications to Serve the Needs of HSR Travelers ..................... $7-10$

Integrate Fare Collection Across Transportation Systems ................................ 7-11

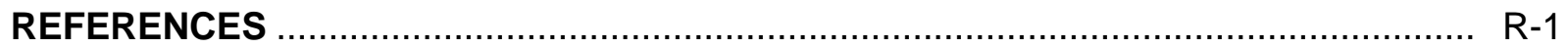

\section{APPENDICES}

APPENDIX A 2010 Public Transportation Services Levels By Transit Agency ...... A-1

APPENDIX B AGENCY INTERVIEW .......................................................... B-1 


\section{FIGURES}

\section{Chapter 4}

Figure 4-1 Timeline of Various Premium Capital Projects ................................... 4-40

\section{Chapter 7}

Figure 7-1 Interior of a Public Transit Vehicle with Overhead Storage ...................... 7-11 


\section{MAPS}

\section{CHAPTER 2}

Map 2-1 Florida High Speed Rail Phase I with Connecting Public Transportation

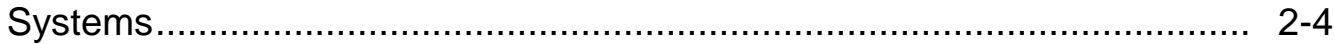

Map 2-2 Williams Project Future Land Use Map ............................................... 2-11

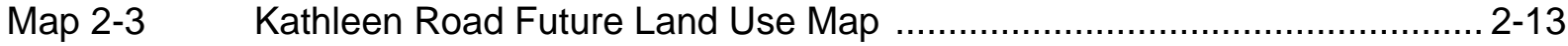

\section{CHAPTER 4}

\begin{tabular}{|c|c|}
\hline Map 4-1 & Route Analyses for Metro Orlando HSR Station …................................. 4 -3 \\
\hline Map 4-2 & Route Analyses for Polk County HSR Station $\ldots \ldots \ldots \ldots \ldots \ldots \ldots \ldots \ldots \ldots \ldots \ldots \ldots \ldots$ \\
\hline Map 4-3 & Route Analyses for Tampa International Center HSR Station.... \\
\hline Map 4-4 & TECO Line Streetcar System .................................... \\
\hline Map 4-5 & HART AA - Northeast Corridor Alignments ...... \\
\hline Map 4-6 & HART AA - West Corridor Alignments ................ \\
\hline Map 4-7 & Pinellas County Alternatives Analysis ..... \\
\hline Map 4-8 & 61-mile/17 Station Commuter Rail System Map.. \\
\hline Map 4-9 & HART Transit Emphasis Corridors Study .............. \\
\hline Map 4-10 & Lymmo Expansion Study Area \\
\hline
\end{tabular}

\section{CHAPTER 5}

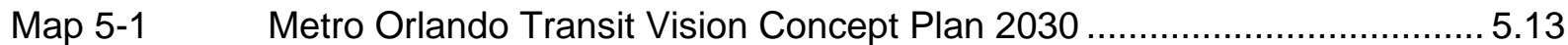

Map 5-2 Draft Polk County Transit Plan 2035 …............................................ 5-16

Map 5-3 Tampa Bay Region Initial Transit Projects ......................................... 5-19

Map 5-4 Tampa Bay Region Long Range Supporting Transit Network.................... 5-20

\section{Chapter 7}

Map 7-1 Opportunities to Enhance High Speed Rail Connectivity *Walt Disney World**Orange County Convention Center **Orlando International

Airport* ................................................................................... $7-4$

Map 7-2 Opportunities to Enhance High Speed Rail Connectivity *New Express Routes* *Polk County Station* ............................................ 7-6

Map 7-3 Opportunities to Enhance High Speed Rail Connectivity - Downtown

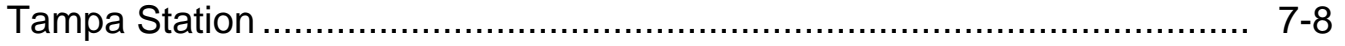




\section{TABLES}

\section{CHAPTER 2}

Table 2-1 Examples of HSR Schedule at 55-Minute Operating Travel Time

\section{CHAPTER 6}

Table 6-1 2010 Weekday Levels of Public Transportation Service Connecting

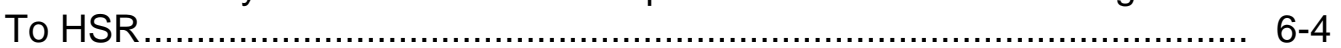

Table 6-2 2010 Saturday Levels of Public Transportation Service Connecting

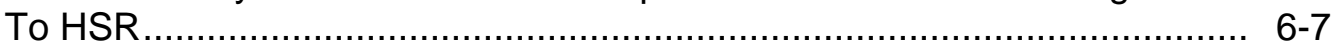

Table 6-3 2010 Sunday Levels of Public Transportation Service Connecting

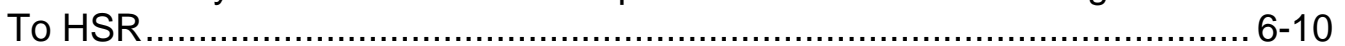




\section{CHAPTER 1 \\ INTRODUCTION}

\section{INTRODUCTION}

The Tampa to Orlando corridor of Florida High Speed Rail (HSR) is expected to launch in 2015 to much anticipation as it might be the initial line of a national HSR service network. A 2003 market study of the proposed system stated the 'travel experience is impacted by each contact point' along an end-to-end HSR trip. It has been publicly argued that currently the least understood element of the Tampa to Orlando HSR line is the viability of connecting 'to and from' other transportation services. There are numerous private mobility options being discussed for the stations including taxi cabs, hourly and daily car rentals, and shuttle services. These modes offer varying levels of convenience for particular segments of the ridership market. The purpose of this study is to evaluate public transportation services within this initial corridor and identify opportunities for enhancement of HSR connectivity through mass transit.

Internationally, HSR lines have had success connecting dense urban population centers, each typically with robust mass transit systems. In contrast, the Tampa-Polk County-Orlando HSR line connects a rapidly developing region with local public transportation systems that currently serve almost 2800 square miles with primarily bus services. Though these local bus services offer flexibility to satisfy yet-to-be confirmed travel patterns to and from stations, they lack permanence, which instills a sense of reliability and trust. In part, how riders reach the stations to board and connect to their final destinations will partially determine the success of the HSR line. If there are not a number of quality options to support a HSR trip connection, a potential user may instead opt for an auto trip. Benefits realized from high-speed train travel may be lost should connecting services not be travel-time competitive and convenient.

FDOT and local transit providers are on the cusp of providing improved mobility options such as regional and local rail and Bus Rapid Transit (BRT) to the cities of Tampa and Orlando. Several capital projects for introducing these premium transit services by the time HSR line operations are underway and will be described. Others, currently in varying degrees of planning, will fulfill the vision of a multi-modal supporting public transportation network that will feed and distribute from the HSR system. Five-year outlooks for Central Florida transit agencies are varied. LYNX, the metro-Orlando transit provider, is in the first year of a five-year program to significantly restructure its bus services. Polk County and Hillsborough County transit operators have each had unsuccessful referendum outcomes in a search for new dedicated funding streams to supplement or replace declining local revenues. How each of the transit properties intends to address service planning in light of these events over the next five years will be explored. 
This study evaluates the connecting local public transportation services with respect to their eventual interaction with HSR travelers and their trips. Local service plans, ten year Transit Development Plans, regional mid-range, and long range transportation plans have also been reviewed. Through the analysis of current service levels and proposed short, mid and long range transit plans, the case for public transportation as a viable alternative to serve HSR can be made. A methodology to evaluate the quality of connecting services to HSR stations will be described. A quality connection is defined as a service that is lower cost than private modes while not degrading the overall HSR trip competitiveness. The connecting lines should directly serve identified HSR trip generators and cities with short travel times with sufficient frequency with a span of operation matching the train system.

Combinations of opportunities have been identified that include suggested policies for existing local bus systems that serve HSR stations to consider. Also described are opportunities to create new express bus services to cities and destinations where a demand for travel is expected. Operating hours of connecting local bus lines and the frequency with which they arrive to carry patrons are identified to promote an end- to-end ride experience that is both consistent and reliable. Local transit system operators are unique in the conventions for naming and branding services but can collaborate on developing certain elements that can be common across jurisdictions. Enhancing connectivity must also consider other qualities of the ride experience. A simple, but accountable method of fare payment should consider the user's need to not possess media for or pay multiple fares within a single trip. A connecting rail or bus trip should be on well maintained, appropriately-sized, and equipped vehicle that complements the HSR ride experience. 


\section{CHAPTER 2}

\section{BACKGROUND}

\section{DESCRIPTION OF THE TAMPA - ORLANDO FHSR PHASE}

To understand the relationship between Florida High Speed Rail (FHSR) and its connectivity to local transit systems, a brief summary of local transit supportive factors is provided. The FHSR Record of Decision from the Federal Railroad Administration describes this first phase of the eventual Tampa - Orlando - Miami line. From east to west, the line will originate at a yet to be constructed Orlando International Airport multi-modal center. This center has been dubbed the 'transportation hub for the state' due to its central location and the high number of planned modes expected to connect within it. Given the type of expected passenger destinations with close proximity to the station, this is expected to be a very active transfer center.

The HSR line will operate on newly constructed track with the large majority of it within the median envelope of Interstate 4. From the terminus at Orlando International Airport, the line will generally follow State Road 528, the Beachline Expressway, to the second of three Metro Orlando stations to serve the destinations around the Orange County Convention Center (OCCC). This station, located at what was formerly named the Canadian Court Intermodal Center, is located close to many potential trip origins and destinations, and as its name implies, will serve as a connecting point to other modes of transportation. Within the immediate area around the planned station is the OCCC, one of the nation's three largest, as well as numerous hotels and connecting transit services with direct lines to the tourist destinations of International Drive and downtown Orlando.

Heading southwest, the line enters the I-4 corridor and proceeds towards the area of Walt Disney World (WDW). This third Orlando stop, at the WDW station, will be south of State Road 192 also known as Irlo Bronson Memorial Highway. Land to construct the stop has been made available and of all the Orlando area stations, this location has the least amount of developed property around it. The station is currently planned to have fewer connecting modes than the other Orlando locations, but is expected to have high levels of both public and private bus services, to connect visitors to theme parks, hotels, and timeshare residences.

As the line continues southwest, then eventually west within the I-4 median, one station will be constructed in Polk County. The FHSR Record of Decision describes potential locations at the western terminus of State Road 570 (Polk Parkway) near the jurisdictional boundary between Hillsborough and Polk County as well as Kathleen Road in Lakeland, a location closer to the urban center of Polk County. However, language within the Record of Decision allows other locations to be considered with the appropriate level of study (USDOT, 2010). An alternate location that has been endorsed by the Polk County Transportation Planning Organization 
(PCTPO) is the Williams site Development of Regional Impact (DRI). The University of South Florida Polytechnic Institute will be constructed on this site. For the purposes of this study, public transportation connectivity to HSR and the opportunities to enhance it will focus on the Kathleen Road and Williams DRI in Polk County.

The final stop of the FHSR Phase I project will be in the downtown Tampa area, in a yet to be constructed intermodal center adjacent to the current site of the local transit operator's main transfer hub, the Marion Transit Center. The station is just to the north of Tampa's central business district (CBD) and to the north and west of entertainment destinations and a cruise port.

\section{Phase I Operating Characteristics}

Current proposals describe a passenger rail service with a span of service from 6:00 am to 11:00pm, 7 days a week. The system would operate 16 end-to-end intercity round trips daily with a travel time of between 55 to 64 minutes accommodating stops at all 5 stations (USDOT, 2010).

\begin{tabular}{|l|r|r|r|r|r|}
\hline & \multicolumn{1}{|c|}{ TPA } & \multicolumn{1}{c|}{ LKL } & \multicolumn{1}{c|}{ DSN } & \multicolumn{1}{c|}{ OCC } & \multicolumn{1}{c|}{ MCO } \\
\hline TPA & & $23: 00$ & $37: 30$ & $46: 00$ & $55: 30$ \\
\hline LKL & $23: 00$ & & $12: 30$ & $21: 00$ & $30: 30$ \\
\hline DSN & $37: 30$ & $12: 30$ & & $06: 30$ & $16: 00$ \\
\hline OCC & $46: 00$ & $21: 00$ & $06: 30$ & & $07: 30$ \\
\hline MCO & $55: 30$ & $30: 30$ & $16: 00$ & $07: 30$ & \\
\hline
\end{tabular}

Table 2-1: Example of HSR schedule at 55-minute operating travel time Source: www.floridahighspeedrail.org

Trains will be equipped with amenities that rival any found on mass transportation systems. Most notably, there will be wireless internet connectivity and real time information systems that will allow a passenger to spend a travel trip productively if they choose. Elements of comfort will also be provided via food and drink cars and well apportioned seating. It is important to note the ride experience elements of comfort, convenience, and travel time savings as significant attractors in the HSR trip. Any connecting transportation service should be evaluated against the standards of the train ride and its strengths and weaknesses identified. 


\section{DESCRIPTION OF FHSR PHASE I CONNECTING PUBLIC TRANSPORTATION SYSTEMS}

Currently, there are four public transportation systems positioned to directly serve the five HSR stations:

- Central Florida Regional Transit Authority (LYNX), serving Orange (Orlando), Osceola and Seminole Counties

- Hillsborough Regional Transit Authority (HART) serving Tampa \& Hillsborough County

- Lakeland Area Mass Transit District (Citrus Connection) serving the greater Lakeland area of Polk County

- Polk County Transit Services/Winter Haven Area Transit (PCTS \& WHAT), serving Winter Haven and Polk County

Additionally, a fifth transit provider, Pinellas Suncoast Transit Authority, connects Pinellas County to the downtown Tampa station via two (2) express bus routes. The I-Drive trolley in Orlando operates under a public/private partnership with the City of Orlando and businesses along International Drive. The two Trolley routes would link the OCCC HSR station to the International Drive corridor.

The following map provides some statistics about the connecting transit service areas and overlays the FHSR over the network of existing supportive feeder networks. A quarter mile buffer is generated around the transit networks and is for the purposes of the study, the 'transit access' area to use the systems. 


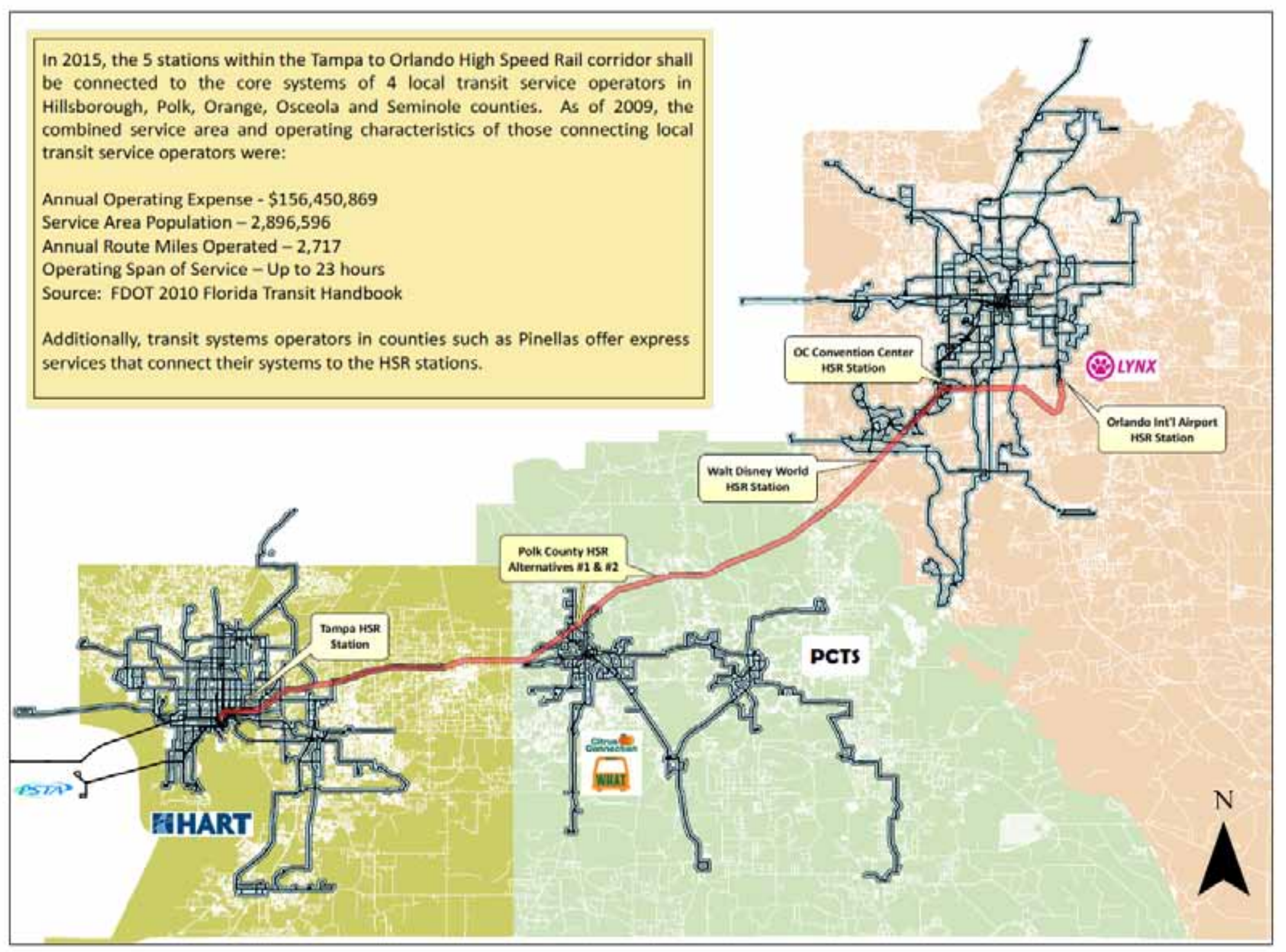

Map 2-1: Florida High Speed Rail Phase I with Connecting Public Transportation Systems 


\section{Central Florida Regional Transit Authority (LYNX)}

LYNX is an independent authority that provides a variety of bus services to Orange County (cities include Orlando, Winter Park, Maitland), Osceola County (cities include Kissimmee and St. Cloud), and Seminole County (cities include Altamonte Springs, Casselberry and Sanford). In 2009, LYNX operated 298 buses in peak service across nearly 1300 route miles. LYNX provided approximately 24 million passenger trips in 2009, with a span of service up to 23 hours on weekdays (FDOT, 2010).

Of the four transit systems, LYNX has the most geographically dispersed service area. The downtown Orlando transit center serves as the system hub, with many of the north-south routes connecting there. To the north of the downtown are residential and business centers and to the south of downtown are clusters of tourist destinations and developing educational and research institutions. Notably, the HSR line is to be constructed well south of the downtown area and much of the existing LYNX fixed operates to its north.

\section{Hillsborough Area Regional Transit Authority (HART)}

HART is an independent authority serving the City of Tampa, City of Temple Terrace, and unincorporated Hillsborough County. In 2009, HART operated 197 vehicles in peak service on 978 route miles. HART supplied over 13 million passenger trips in 2009 with a weekday span of 21.5 hours of service (FDOT, 2010).

The bulk of HART's service area is concentrated to the north and west of its downtown center. The majority of the system's north-south routes originate or end at the location of the future HSR station. Due to the geography of the service area and lack of east-west thoroughfares, few of the east-west traveling routes currently serve the downtown transfer center. Hillsborough County has a considerable number of suburban residential developments, which makes providing high levels of service challenging.

\section{Lakeland Area Mass Transit District (LAMTD/Citrus Connection)}

LAMTD is an independent district that serves the greater Lakeland area with fixed-route bus services. In 2009, LAMTD operated 24 vehicles in peak service across 220 route miles. In 2009, LAMTD provided 1.45 million passenger trips with a weekday span on some routes of up to 14 hours (FDOT, 2010).

LAMTD operates the majority of its service within the most urbanized area in Polk County, the City of Lakeland. Lakeland also provides intercity express routes to the cities of Bartow and Winter Haven; however, the majority of LAMTD's service is concentrated around the urban core. The proposed HSR station on Kathleen Road is approximately three miles north of the downtown transfer area, where a significant number of the bus routes connect. There are currently three LAMTD routes that pass by the Kathleen Road location. At the present time, LAMTD does not provide service in or around the Williams DRI. 


\section{Polk County Transit Services/Winter Haven Area Transit (PCTS \& WHAT)}

PCTS is a division of Polk County government that functions as the Administrative Agent and Project Manager for the WHAT system. PCTS operates two fixed bus routes and contracts with Citrus Connection to jointly operate fixed route bus service for Winter Haven. PCTS \& WHAT combined to operate 21 vehicles in peak service in 2009, over 223 route miles. The two systems served almost half a million passenger trips last year.

PCTS and WHAT bus routes primarily serve the western half of the county, operating on county facilities, connecting the smaller cities and unincorporated areas with the Winter Haven. Although there is an intercity express route to Lakeland, the PCTS or WHAT bus services do not operate near either of the two proposed HSR stations.

\section{HIGH SPEED RAIL RIDERSHIP}

In order to assess and design connecting public transportation services to complement high speed rail, there should be an understanding of the nature of trips and ultimate goals of the traveler. With the exception of the Amtrak Acela service in the Northeast US, there are no existing fast rail transit lines operational in the US to review for ridership analysis. Levinson writes that internationally, the business market segment has traditionally been a primary focus for HSR. Early lines built in France and Japan were constructed to connect the largest near-by cities with an alternative to a restrictive air travel market. Well developed local public transit systems were already in use and serving as a connecting mode for business travelers.

The maturing French HSR system has since proposed and implemented some extensions into leisure driven areas, with Metzler noting the highest ridership peak travel on the French TGV line to be Friday afternoons. This stratification is significantly different than the expected trip purpose projected for the Florida HSR system. The Florida Intercity Passenger Rail Vision Plan from 2006 describes a breakdown of trip purpose to be $25 \%$ for business travel, $20 \%$ for commuter travel and 55\% for social and recreational travel. These numbers are in line with another well studied, historically planned HSR system in California. Similarly, the California High Speed Rail Authority reports projected ridership trip purposes to be $55 \%$ business and commute trips and 45\% personal and leisure trips (University of California, 2010).

Ultimately, the existing local transit systems that will connect to FHSR are better designed and suited to serve certain HSR passenger trips more than others:

\section{Who the local transit systems are likely to serve:}

- Commuter or leisure traveler local to Central Florida, who is a current user of at least one local transit system

- An individual lacking personal transportation

- Someone who places a premium on cost over convenience and/or travel time

- An individual whose start of trip and end of trip location is a major trip generator served with express bus or quality level of transit 
- International tourists who may be more inclined to ride transit due to personal experiences with public transportation from their country of origin

\section{Who the local transit systems are less likely to serve:}

- An individual who places a premium on convenience over cost, i.e. business traveler.

- Large groups or families visiting an area where a private service can be more accommodating and cost effective

- Individuals who require at least one end of their trip to be a door-to-door service

- An individual or individuals with multiple destinations after alighting the HSR

- Someone who has rarely or never used local bus transit systems

\section{HSR STATION ACCESS FOR CONNECTING PUBLIC TRANSPORTATION}

A significant factor in determining the success of local public transit connectivity to HSR stations will be the station location relative to existing and proposed transit lines. Existing lines that were designed to connect trip origins and destinations and serve the needs of the local transit system rider will be more diverse than that of the inter and intra-city HSR traveler. The six potential station locations along the Tampa-Orlando corridor all possess unique attributes that present different strengths and opportunities for local mass transit connections. These opportunities are largely related to the potential for intermodal connectivity, existing and future land-use development, and the urban and suburban environments they lie within. Each of the station locations will be reviewed with respect to these elements.

\section{Issues Raised in Research Related to HSR Station Access}

A mature HSR system in France has been the subject of study for determining the implications of station placement and the associated impacts on local transit connections. FacchinettiMannone analyzed the local transit system connectivity to a HSR line extension in mid-sized French cities. The focus of the study was to preserve travel time savings achieved on a HSR trip through quality connections to local transit service. The analysis classifies stations as either being placed within the urban core of a city or the urban periphery. The relevant portions of this study to the Tampa - Orlando corridor are the mid-size city case studies and variety of station locations, both within the urban centers and outlying areas.

The findings in this study illustrate the differences between what could be expected by the differing station locations on the FHSR Phase I line. The central city station locations tend to encourage intermodality because of the higher amount of existing transit services that are typically already found there. High capacity fixed guideway transit systems are more likely to have been built and operating in urban centers. Urban center locations were found to be more difficult to access by an automobile. As private autos are expected to be the primary competition for HSR trips, the degree to which station placement discourages use of a private vehicle on any segment of a HSR trip should not be understated. The more the use of an auto is required to use the HSR, the less likely it may be that the user will opt for a HSR trip at all. Additionally, 
the costs to bring higher levels of local transit service to a HSR urban core station would be lower than to peripheral stations where less service exists (Facchinetti-Mannone, 2010).

Urban center station placement challenges are largely related to costs and the development of land surrounding the area. Station costs are higher if the land is to be procured. The issue of a restricted footprint and limited access roads may have an impact on the number of local bus lines that could access the station to make connections. The uses of the land surrounding the station would be more likely to already be defined and the expected value increase from proximity to HSR might make them prohibitive to acquire for redevelopment into desirable HSR supportive properties (Facchinetti-Mannone, 2010).

Conversely, the benefits and challenges of urban periphery station locations are clear. Suburban stations are more likely to have lower levels of public transit service and the costs will be higher to connect larger parts of the local transit service area to HSR. Suburban stations were found to require more trips by private automobile to reach, thereby introducing additional volume onto the local roads leading up to them. Walk up and cycling accessibility, which are more likely to be components of end to end trips utilizing transit than autos, have less potential outside of urban core areas (Facchinetti-Mannone, 2010).

There is a case to be made for constructing stations outside urban centers with regards to land use and development. As stations are constructed farther outside developed urban centers, more of the surrounding land is less likely to be developed. Transit Oriented Development, zoning, and land use modifications may face fewer hurdles in becoming reality because the intensity of development may be defined from a clean slate and not that of redevelopment or infill on a parcel-by-parcel basis.

There were two conditions identified for making suburban stations successful. The first is the need to create a connection to a local rail network, thereby still serving the urban centers that local systems operate within. The second is the requirement to integrate fares, schedules, and information to reduce wait times between modes and offer public transit services to major destinations with service that is competitive with private cars (Albalate \& Bel, 2010).

Reinforcing these findings was a review by Shin of the recent experience and prospects for HSR in Korea. The Korea Train Express (KTX) went into operation in 2004, following systems in Japan, France, Germany, and Spain. One of the reasons the Korean government pursued HSR was to balance regional development, thereby necessitating the need to build both urban core and peripherally located stations. For Korean the government, developing a system to do more than just connect large nearby cities was a priority, thereby dispersing the over-concentration of the nation's functions in the Metro Capital Seoul region (Shin, 2005).

Initial line ridership numbers came in at less than half of what expected, due in part to the inconvenience of getting to KTX stations. While many factors influenced these early ridership numbers, including an economic slowdown and partial completion of the line, station location and access play a role in determining ridership in the Korean example (Shin, 2005). The author cites improving accessibility and connectivity of HSR stations as a pressing need. Connecting 
HSR stations to airports with local rail lines and expanding intermodal connection opportunities, including bus transit, are points of emphasis in the study.

\section{SURROUNDING STATION LAND USE AND ACCESSWAYS}

\section{Orlando International Airport Station}

The HSR preferred alternative calls for a location for the HSR platform at a new Southern Terminal Intermodal Station. Here, the Intermodal Station will be bordered to the north by the north airport terminal complex and attached parking garages and airport runway to the east. As the HSR platform is proposed to be built just to the south of the existing airport facility, it will be well integrated to the airport terminal services and access ways. The station will be within the heart of the Aviation Authority; therefore, land use opportunities will be within the guidelines and permitting of the Authority. The surrounding areas are largely made up of airplane runways, staging areas and taxiways, as well as drainage basins. The Orlando Aviation Authority is a significant landowner in the undeveloped surrounding areas, most notably to the south. Opportunities for development include a mixed-use proposal to the south on what is currently a wetland mitigation site, adjacent to the developing Lake Nona area that contains a number of emerging medical and research facilities. There are two primary access roads into the airport and future HSR station. From the north, Airport Blvd circulates through the facility connecting to toll road 528. To the south, South Access Road is a four-lane divided roadway that connects Boggy Creek and the Central Florida Greenway.

\section{Orange County Convention Center Station}

The 20 acre station area envelope is bordered by International Drive to the west and Beachline Expressway to the south. There is a large amount of surface parking in the area, primarily existing to serve the expansive Convention Center to the northwest and abundant hotels surrounding the site. Theme park properties such as Universal Studios and Sea World occupy significant developed parcels in the area. Residential communities and resort properties are also within the immediate vicinity of this well-developed land around the station. Undeveloped areas include a mix of environmentally sensitive lands to the south and to the north and east, just north of Universal Blvd.

\section{Walt Disney World Station}

Walt Disney World has allocated up to 50 acres for station development at the site adjacent to US 192 and the I-4 corridor that the HSR line will operate within. The future station site design is conditioned upon approval by WDW and the ability of that private enterprise to operate the station and construct facility parking. On the eastern side of I-4 is the master planned urban development of Celebration and an adjacent water basin. There is a great deal of undeveloped property surrounding the station, owned by the WDW Corporation, which surrounds the station and could potentially be developed with their approval. Access ways to the site are provided by an interstate exit from I-4, US 192 and World Drive to the west. This site will require construction of new access roads from the existing arterials and local roads to enter the station. 


\section{Polk County Site Alternative \#1 - Williams Site/Future USF Polytechnic}

The Williams DRI site, at the eastern intersection of I-4 and the Polk Parkway, lies next to the proposed USF Polytechnic campus, Polk Commerce Centre, and Lake Myrtle Sports Complex. The 2800 acre DRI is centrally located to Polk County, approximately 8 miles from downtown Lakeland.

The USF campus will occupy 570 acres and has an expected capacity of 16,000 students. The Williams property owner is offering 20 acres within their site for the HSR station (Gernert, 2010).

A summary of the DRI project includes:

- 4,300 residential units

- 1.3 million square feet of commercial space

- A research/development park with 2.9 million square feet of space

- 350 hotel rooms

- A village center

Future land use indicates another quarter of the property is dedicated for environmental preservation with the remaining $50 \%$ serving a variety of uses. As the massive Green Swamp area occupies all areas to the north, future land development around the station would be concentrated southward. Given the need for future public transportation services to this site, it is important to note that two roadways are proposed to be constructed off SR 33 from the west and north as well as an access ramp east off Polk Parkway. These include the Pace Road interchange project on the Polk Parkway and completion of the four-lane highway connecting the Pace Road interchange on the east and State Road 33 on the west. The county has completed construction of the four-lane Pace Road from Berkley Road to the interchange. This roadway will serve the University and potential HSR station. Bus service will be routed into the property from the west and south on these roads connecting cities such as Lakeland, Bartow, Winter Haven, and the future Legoland theme park. 


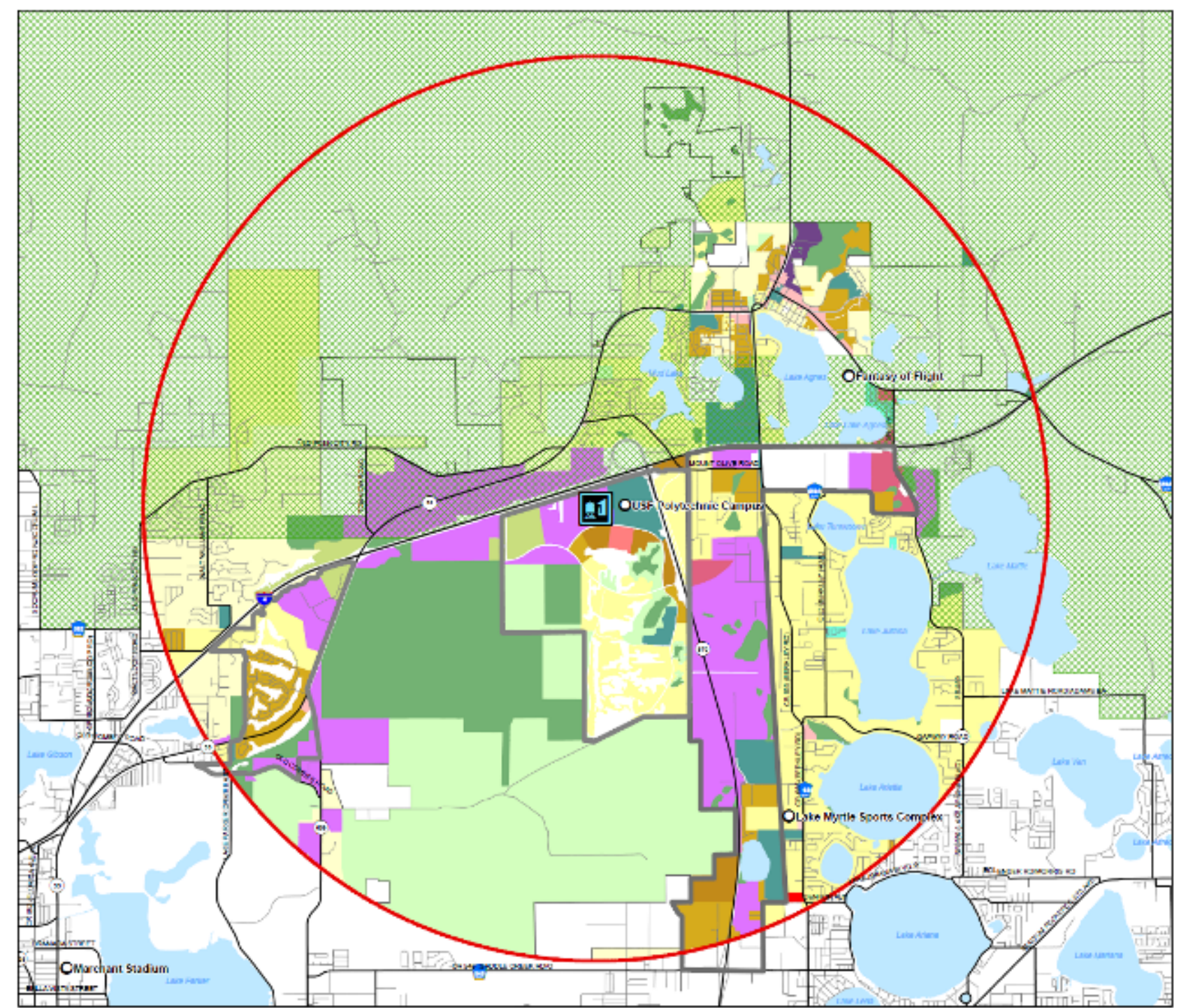

PROPOSED

WILLIAMS

HIGH SPEED

RAIL STATION

Approved for

Further Study

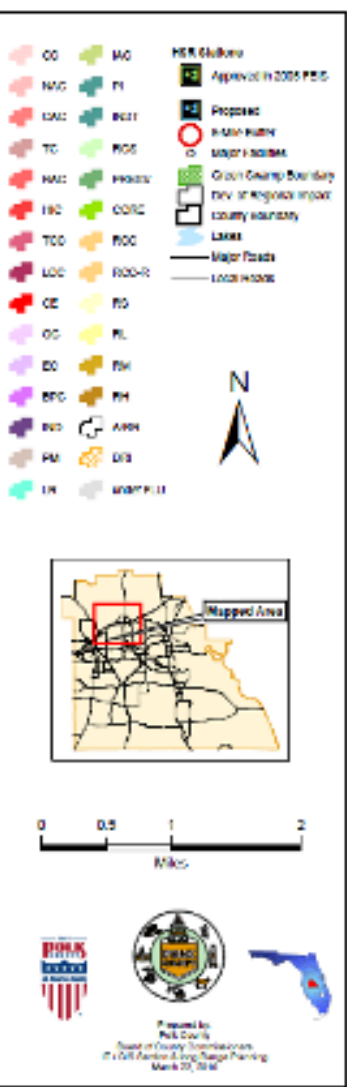

Map 2-2: Williams Project Future Land Use Map - Source Polk County TPO 


\section{Polk County Site Alternative \#2 - Kathleen Road}

This proposed station location lies just to the north of I-4 and is within three miles of downtown Lakeland. An I-4 interchange exists to the south of the station location at Kathleen Road. The proposed 20-acre HSR station site is bordered by Kathleen Road, a four-lane divided roadway to the west, Mall Hill Drive, a two-lane road with center turn lane to the north, and Griffin Road, a four-lane divided roadway to the east.

An analysis by the City of Lakeland identified over 500 acres available in the immediate area for infill development and 680 acres of land for potential development (Studiale, 2010). There is a significant amount of residentially zoned property between downtown and the HSR location. Several large lakes exist to the east. Existing commercial, office space and undeveloped land immediately border the station location to the north and east. 


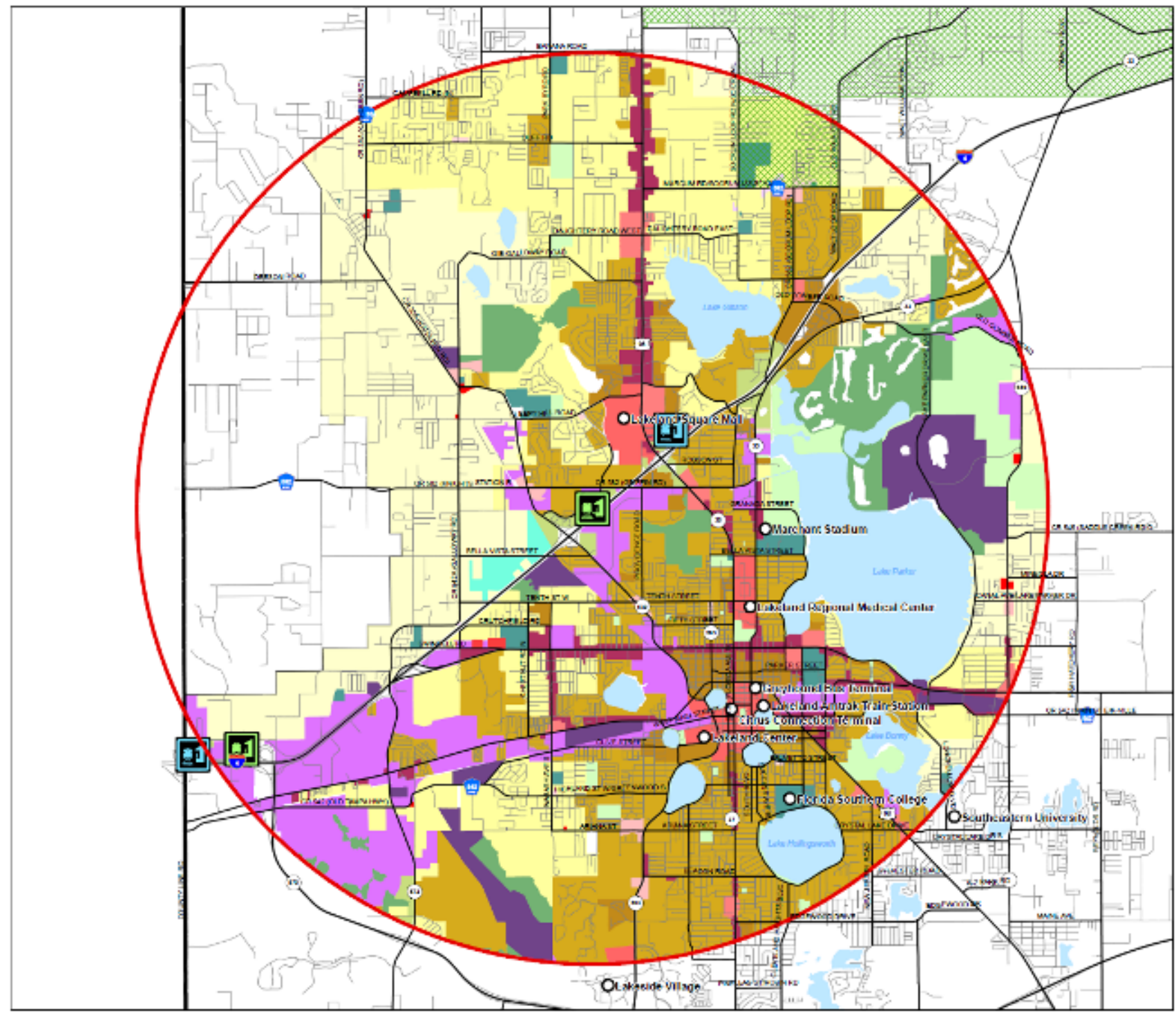

PROPOSED KATHLEEN

HIGH SPEED

RAIL STATION

Approved in $2005 \mathrm{FEIS}$

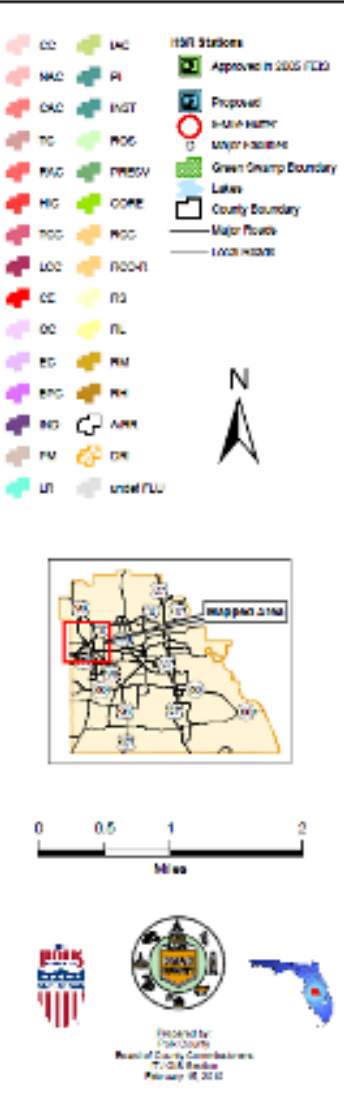

Map 2-3: Kathleen Road Future Land Use Map - Source Polk County TPO 


\section{Downtown Tampa Intermodal Center}

The western terminus of the Tampa - Orlando corridor will be at a to-be constructed intermodal center just north of the downtown business district, and cultural and entertainment centers. The eight (8) acre site for the station will be primarily made up of the former Morgan Street jail site, HART's Marion Transit Center main bus transfer hub, several buildings, and surface parking lots. Access to the area from Interstate 275 currently exists via two exits for vehicles, one coming from the west (from the direction of the Tampa International Airport and Pinellas County) and one coming from the east from an interchange with I-4. Several north-south arterials currently run through the future station footprint that could allow bus access into the HSR station. They include Tampa Street, Florida Avenue, Franklin Street, and Marion Street. From the west, Laurel Street enters the proposed HSR station site. The City of Tampa plans to improve Perry Harvey Park on N. Orange Avenue, including pedestrian access to link the Tampa Riverwalk from the HSR station. A gateway from Franklin Street to the site is in development in addition to several Comprehensive Plan amendments to update land uses to support all rail transportation around stations.

An urban redevelopment project at the former Central Park Village housing complex is ongoing less than one mile east of the station. It is a 30 acre, mixed-use complex that should be one of the first infill projects completed by the 2015 HSR line opening. The Tampa Downtown Partnership reports interest in redevelopment in other areas up to one half mile away of the proposed station (Jackovitz, 2010).

\section{Urban Core and Urban Periphery FHSR Stations and Mass Transit}

The six proposed FHSR station sites all exist within locations that possess varying degrees of local transit service integration, from an urban center with a main transfer terminal in Tampa, to the currently unserved Williams site in Polk County. Opportunities to provide the levels of connecting public transit needed to preserve HSR travel time savings and provide an end to end trip competitive with private autos will be influenced by each station's accessibility to desired trip origins and destinations. The cost of service improvements between HSR stations and trip generators will be higher where lower levels of transit exist today. The stations will be reviewed with respect to their proximity to urban environments and existing levels of public transit system integration.

The Orlando International Airport station is currently connected to the local transit network via five (5) of the system routes. Of note is the Link 111, which operates on an alignment very similar to that of the HSR line, connecting Disney, the Convention Center and Airport with 30 minute frequency. This Link also runs along Sand Lake Road, where the southern terminus of the commuter rail line 'SunRail' is expected to be completed by 2013. Link 41 connects communities north of Orlando to the airport along SR 436. It is currently the only bus route that operates north of downtown Orlando with a direct connection to any of the three metro area HSR stations. The strength of this station location will be the many intermodal links that are proposed to be made here. Roadway access is channeled down from two east-west toll roads, 417 and 528, into two four lane divided access roads from the north and south. Demand for 
access to the station from the south will likely increase with development around Lake Nona, and projects such as the Boggy Creek/417 interchange improvement will relieve associated congestion.

The Orange County Convention Center station area is served by seven (7) of the LYNX system's $60+$ bus routes, called 'Links' as well as the two I-Drive trolley routes which operate on a headway based schedule. Outside the urban core of downtown Orlando, the OCCC station is accessible to the CBD via Interstate 4. Additionally, six LYNX Disney-serving express bus routes pass to the west on I-4 and could connect to HSR with minimal re-routing. A flex route operates to the south of the station, that could bring individuals from the residences in the Williamsburg area from their door to HSR with a pre-arranged pickup. There is a significant amount of roadway accessibility to the future site including the north/south running I-4, International Drive, and Universal Blvd, and east/west running Beachline Expressway and Central Florida Parkway. This location has the opportunity to realize significant public transportation use due to the amount of existing service at or around the site that can provide competitive trip travel times to the auto, the Convention Center, hotels, and visitor attractions in the immediate area and adjoining roadway capacity.

In the Orlando metro area, the WDW station location lies the farthest outside the urban environment. It is within close proximity to two local transit routes that are likely candidates for deviations into this site. Those two routes follow a somewhat similar pattern, limiting the coverage area for direct HSR access connecting Kissimmee to Disney World and the Lake County/Polk County Lines. Public transportation opportunities here are the lowest of all the Orlando sites and may involve extension of the 300 series express routes beyond the Downtown Disney transfer center. Considerations for increased public transit service levels are somewhat cost prohibitive, as the number of communities and trip generators beyond Disney are few. This station will have strong links to the Disney World complexes via the private WDW transportation network.

The Williams DRI location for the Polk County HSR stop currently has no public transportation within the area. Of the two Polk candidates, the William DRI location is the more centrally located within the county, but has no current generators to operate service to. It is the farthest outside the urban areas of all station locations and will be dependent on roadway building and enhancements to be accessible. Transit service will be brought here in the future to serve the USF campus and associated development around the Williams DRI site project. Although it is centrally located within the county, there will be few generators that will connect to the station via transit service with a low, auto competitive travel time. This would drive the number of auto trips required to access the station higher as a proportion to public transit than any of the other stations. Using public transit as a means to reach the station is a long- term proposition, anticipating the required density and trip purpose needed to grow around the largely undeveloped area to make it beneficial.

The Kathleen Road site in Polk County lies within close proximity to the urban center of Polk County, just north of Lakeland. However, current service levels in the immediate area of the site are low, with the majority of the transit network to the south and east. Three routes operating 
between US 98 and Kathleen Rd are candidates for minor deviations into the HSR stations. All three routes connect at the downtown Lakeland transfer terminal with auto competitive travel times. Of the three metro areas served by the FHSR Phase I line, the Polk County station will likely have the greatest reliance on at least one bus to bus transfer to bring individuals to and from the station. A sprawling geography and relatively low levels of local transit create a challenge in connecting communities with direct HSR station service. The short travel times to make downtown connections will be offset somewhat by the transfer waiting times to reach final destinations. This location's close proximity to the urban environment would be beneficial, as fewer resources would be needed to extend services.

The HSR station with the highest levels of existing public transit service is the Tampa location. Nearly two thirds of HART's bus lines directly serve the Marion Transit Center, including HART's most productive core routes. The Marion Street Transitway gives dedicated bus-only access north/south through the downtown to serve the transfer facility. There is ample access to the site for other non-direct CBD-serving routes via Florida Avenue, Laurel Street, and Cass Street. Having the location just north of the downtown center, it is spared some of the vehicular traffic experienced in peak commute periods and for events at the St Pete Times Forum and Riverfront areas. This station is the only one of the six within an urban center close to existing Amtrak and intercity bus travel. The Metrorapid BRT line and alignments considered in an Alternatives Analysis will serve the HSR station. While this location has relatively strong prospects for access by public transportation systems, it will still be easily accessible by auto from I-4 and local streets. A funded road project to connect the Crosstown Expressway to I-4 will increase the accessibility of the station, particularly from the South Tampa area where access is currently limited.

A more detailed analysis of all current public transportation access to the proposed HSR station sites is found in Chapter 4.

\section{DEFINING EFFECTIVE CONNECTING PUBLIC TRANSPORTATION SERVICE}

In order to identify opportunities to enhance public transportation connectivity to HSR stations, there must be some background on both the basis for the design of the existing transit service as well as the characteristics of successful transit connections for intercity travelers.

\section{Transit Service Planning}

TCRP Report 55, Guidelines for Enhancing Suburban Mobility Using Public Transportation, provides some principles for transit planning in the mixed density environments that comprise the majority of the service areas of the FHSR connecting systems (Urbitran Associates, Multisystems \& SG Associates, 1999). These elements will be expanded upon to better illustrate local conditions of the FHSR supporting networks.

- Develop Service Around Focal Points 
All of the local transit networks operate through downtown transfer terminals in Orlando, Winter Haven, Lakeland, and Tampa, with the majority of their respective bus routes connecting into them. Elsewhere in the service area are smaller transfer centers, superstops, and focal points where multiple routes meet and transfer passengers between routes. There are both natural focal points, such as shopping malls and other areas of commerce, as well as specifically designed transfer centers that keep the systems tied together away from the downtown terminals. HSR stations will be a focal point much like an airport, with potentially large numbers of intermodal transfer opportunities.

- Operate along moderately dense suburban corridors, and connect land use mixes that consist of all-day trip generators

As bus routes emerge from the central downtown terminals, they primarily operate on major urban to suburban corridors that host a service area's trip generators with mixed land uses including commercial and residential properties. This is where a local transit system can be more effective by serving the most densely populated corridors. A larger challenge is presented where the passenger needs to travel beyond these corridors into unserved neighborhoods.

- Serve transit's more traditional markets such as low income, blue collar neighborhoods

The local transit networks have a significant ridership base in the low income, transit dependent passenger segment. Service exists to neighborhoods and trip generators that this population frequents in part because it drives ridership. In order to receive federal funds, a transit agency must demonstrate that their service provision does not disproportionally exclude access by minority populations. Any changes to local transit routes that are designed to serve what will be a different passenger market segment in HSR connecting trips should not negatively affect the service to existing rider populations.

- Link suburban transit services, especially local circulators and shuttles, to the broader regional line haul network

Due to the expansive service area for each system operating through mixed densities and lacking a geographical concentration of generators, a variety of bus services are employed to maximize resources across a challenging environment. Flex routes, circulators, shuttles, and express routes are all provided to complement the fixed bus route core line haul network. These complementary services tend to be less cost efficient per passenger to the system as a whole, but are appropriately scaled to provide a level of service for certain rider markets where an allday local service cannot effectively do so. Opportunities for HSR connectivity should consider these types of bus service.

\section{- $\quad$ Target Markets Appropriately}

This principle is the foundation of the previous one, linking transit services. Those services to be linked are created to operate in the secondary markets that require non-traditional public transportation. It can also be used to justify the potential for a new connecting mode type, 
commuter rail. The idea is that there is an unserved market in daily commuter work trips that is not met through local or express bus services. The SunRail alignment and alternative alignments for the HART AA connect major generators and cities with a level of service not present in today's transit networks.

\section{- Economize on Expenses}

Transit agencies will always be working to provide higher service levels with fewer resources wherever possible. This can take the form of sharing facilities such as transfer centers or maintenance yards. Connecting many modes and routes at HSR stations can increase efficiencies, particularly where the cost to extend service to those locations is low. New focal points can emerge from the stations, with land uses that lower the need for auto trips.

- Adapt vehicle fleets to customer demand

Standard 40-foot transit coaches may not always be the best fit for each type of service. Neighborhood streets where demand is low and noise can be an issue may warrant a smaller vehicle. New services may be marketed with a reduced environmental impact utilizing alternative fuel and propulsion buses. Any new HSR connecting service could consider a range of options that attempt to preserve the fast train experience by featuring clean vehicles, smaller buses, wireless internet connectivity, branding, and traveler information not found on all local buses.

- Creatively adapt transit service practices to the landscape

The optimum connecting transit service to HSR may not have been conceived yet, as this mode has no domestic lineage to study for successes in this type of environment. Creative adaptation may come from trial and error, benefitting from the flexibility of bus services. This study attempts to define some elements that service should possess such as span of service, frequency of service, travel time, and convenience; however, service should be adapted to demand over time.

- Obtain private sector support

Transit operators should explore opportunities to work with local communities or private enterprise where higher levels of service are sought than the agency is able to provide with public funding. The primary local example is the I-Drive Trolley, which has a dedicated purpose for bringing area visitors to businesses along International Drive in Orlando. The private funding and operations through public mechanisms is one example of a model for future application.

- Plan with the community and update goals and objectives

One condition discovered during this study was the different degrees to which planning for future transit services with HSR was conducted. HSR had long been planned by the State, but until funding was identified to construct the system, only a limited amount of discussion was had 
about how to serve it with local transit systems. All short, mid- and long- range plans will be updated to reflect the inclusion of HSR as a new regional transportation option.

\section{CHARACTERISTICS AND ISSUES IN MAKING SUCCESSFUL INTERCITY TRAVELER CONNECTIONS WITH PUBLIC TRANSPORTATION}

The HSR stations have been referred to as 'mini-airports', in part due to the types of amenities and services they are built to accommodate. TCRP reports $62 \& 83$, titled Improving Public Transportation Access to Large Airports' and Strategies for Improving Public Transportation Access to Large Airports respectively, describe effective service and connectivity plans to meet the needs of the intercity traveler.

These studies first consider the use of connecting local rail systems to serve intercity travelers. It is important to note, in review of the plans for local public transportation providers in FHSR Phase I, there are currently no local rail (heavy, light, or commuter) systems proposed to directly serve any of the five stations at the time of line opening in 2015. However, both Tampa and Orlando have near to mid-term plans to introduce rail lines. The Orlando metro area's commuter rail project, 'SunRail', does not currently have a HSR station served in any of its three proposed phases but a short eastern deviation from the southern end of its first phase has been discussed to be extended to the Orlando International Airport. HART is in the process of identifying its Locally Preferred Alternative (LPA) from an ongoing Alternatives Analysis. Both candidate alignments for the LPA have a terminus at the Tampa HSR station/Intermodal Center. A preferred technology has not been formally identified, yet indications among HART Board members imply that depending on cost, light rail is a suitable technology. Finally, an Alternatives Analysis underway in Pinellas County is considering a rail connection to the area of the downtown Tampa Intermodal Center.

For the purposes of this evaluation, rail will be referenced as a connecting mode with a future expectation to serve HSR stations. At the time of line opening, buses will be the primary public transportation mode linking to HSR. Many of the same principles, successful regional and local rail systems use in serving intercity travelers at airports can be applied to the concept of using buses to serve intercity travelers at HSR stations.

TCRP 83 describes the elements of successful bus service to meet the needs of intercity travelers. A market analysis in major airport markets, which included Orlando and Tampa, found a majority of the users of connecting multi-stop bus services to airports were not business travelers (Leigh Fisher Associates, Coogan \& Marketsense, 2002). Areas with high trip end densities that were closer to the airport have the most successful connecting bus lines in operations (Leigh Fisher Associates, Coogan \& Marketsense, 2002).. Other characteristics of quality bus services that were found in operation included the following:

- Express Bus Services - In order to preserve travel time savings that the HSR will generate, dedicated point to point bus lines using interstate highways where available provide the greatest ability to enhance connectivity 
- Reduced Regional Travel Time - Bus services that provide the fastest and most direct service to airports were found to be the most successful. In the markets studied this included use of High Occupancy Vehicle lanes, transit preferential traffic signal treatments, stops only at major activity centers, and providing single seat trips that require no transfers.

- Consistently High Levels of Service Frequency - This requires the institution of off peak, night, and weekend service that generally is less productive. There needs to be an image of reliability of the connecting service to encourage use of the system. The traveler must trust that the connecting bus service will be there to meet them and this is harder to achieve with infrequent service.

- Competition with Other Mode Choices - The HSR system would become more attractive as a trip option with increased options available to connect to that rail line. Transit service only becomes a viable option for connectivity when it provides convenience, competitive travel time, and cost savings that would allow a potential user to consider transit as a trip segment.

- Pick up and Drop Off Locations - Station access for HSR connector services should allow bus loading and unloading to be closest to the entry to the train to create the shortest walk trip.

TCRP 62 outlines four elements of successful bus connections to airports that share the previous ideas and expand upon the non-motorized elements of the travel trip (Leigh Fisher Associates, Coogan \& Marketsense, 2000).

- Seamless Connections to the Two Riding Platforms - The user must be able to easily find the connecting service or HSR entry point, and understand the required walking distance to make the connection, as well as the number of levels required to traverse. Single level walking trips, potentially including baggage, are the easiest for the traveler to make.

- Baggage Handling Strategies, Services and Availability - There are numerous examples of this on the private transportation side, as the mature air travel markets have implemented the most cost effective, convenient policies for their customers. These should be reviewed for their applicability to HSR vis-à-vis local transit transfers. Public transportation operations policies may need to be updated to reflect this potential demand.

- Headway Minimization and Line Speed - This reinforces the importance of the earlier discussed idea that a fast, direct, and frequent local connecting service stands the best chance to be successful in serving intercity travelers that arrived via a similarly characterized service. 
- Understanding the Market Segment and Serving it Well - The broad distribution of end to end trips for HSR riders makes door to door service difficult for the suburban residential areas. Infrequent, multi-stop bus service is likely too slow to satisfy the business traveler. Therefore, a market segment (business, commuter, leisure) should be identified and served with the appropriate amount of resources.

Finally, TCRP 62 identifies issues affecting the use of connecting bus services. One challenge lies in knowing the ultimate number of intercity passengers with trip ends outside the downtown or other areas with low levels of transit service. It was first noted that even in some of the larger US airport serving cities, trip ends in the downtown CBD were low compared to international counterparts (Leigh Fisher Associates, Coogan \& Marketsense, 2000). Trip origins and destinations tended to be highly dispersed. Given the development patterns in the areas around HSR stations and split distribution of business/commute trips to leisure trips, the design of connecting services should include a mix of options flexible enough to adapt over time.

The difference in travel time among available connecting mode options can make some much more viable than others, even when they are at a much higher cost. Non-express public transportation services will continuously be at a disadvantage to those who place a premium on travel time over cost. Conversely, when the price of parking, taxis, or rental vehicles are factored in, public transportation holds a distinct cost advantage. 
This page intentionally left blank 


\section{CHAPTER 3 \\ METHODOLOGY}

\section{INTRODUCTION}

This chapter defines a methodology for defining a desirable connecting public transportation service line based on the study background. It can be used to assess current service (as will be demonstrated in Chapter 6) and develop future HSR connecting services that will provide viable options in mode choice segments both leading up to and exiting an HSR trip. The elements in this methodology consist of span of service, frequency of service, travel time preservation, and convenience to major destinations. Two other issues that may emerge as the FHSR system is built out and potentially increases local ridership are; capacity and cost. In most cases, vehicles in local transit networks have sufficient capacity to handle an increase in passengers driven by $\mathrm{HSR}$ ridership. The cost to a rider for a connecting bus trip or future commuter rail trip should be reviewed in future studies for impacts on mode choice decision making.

The HSR is the trunk of the trip and connecting local transit services must be direct to as many high use locations as possible in order for travelers to choose the service over an auto trip. The private auto is perceived as the primary competitor to FHSR in the area as air travel is too costly, time consuming, and inconvenient. The need to understand end-to-end trip timings is important. As rail trip distances shorter than 100 miles are found to be more difficult to compete with the auto, connecting services must be designed to eliminate the auto from as much of the trip wherever possible, remain travel time competitive, and provide convenience similar to a HSR ride.

With such a large investment needed to build out a public transit network to connect all destinations to each station, initial opportunities will be in standardizing service characteristics to emphasize the largest trip generators and urban centers. A benefit exists where an individual using HSR can locate a rail or bus line that serves one of these generators or urban centers and take that single trip to the destination.

\section{A Quality Public Transportation Connecting Route has a Matching Span of Service}

The operating Span of Service of the FHSR Phase I line provides a starting point in which to assess quality of service of connections. The line has been conceived to operate 17 hours daily, potentially between 6:00am and 11pm, seven days a week. In order for a connecting public rail line or bus route to provide a reliable, trustworthy option to the rider, at minimum it should serve the station between those hours. Should the HSR train arrive, and service by a connecting line has ended for the day, then that line obviously does not truly meet the needs of the HSR rider. 
Local transit systems will push users into alternative modes if they do not provide service to meet the riders' needs during all hours of operation.

A situation that could take place is one in which a commuter relies on transit service to connect them to the HSR line for a work trip home in the evening. Regularly, a particular line meets the need at a certain time of day to make the connection. However, should a work day be extended and no transit service is available to make the connection, a user is left with options such as a taxicab or an emergency ride service to reach the HSR line. Another potentially trust damaging scenario is a connecting line's service day ends before the last HSR trip arrives stranding outof-town passengers at the station who are unfamiliar with local transportation options. Routes with high HSR trip generation should have a matching service span to be considered a reliable service option.

\section{A Quality Public Transportation Connecting Route Serves a HSR Station with at Least Two Vehicles per Hour/30-Minute Frequency}

A rail or bus line with vehicles arriving every 15 minutes or less is typically reflective of a high level of service for that line. It is usually warranted by increasing ridership demands and in the case of the FHSR supporting transit systems, infrequently used due to the high cost and diminishing return on investment for all but the top 1-2\% of routes. The nature of vehicle scheduling and ability for passengers to understand when a vehicle will arrive is important to consider when devising an optimum frequency for connecting HSR service.

The average vehicle route frequency in 2009 for both HART and LYNX was just less than 30 minutes, while the Polk County system exceeded 30 minutes. Though 15-minute service is desirable, but largely cost ineffective for the FHSR line supporting systems. However, anything that exceeds 30 minutes does not ensure more than one servicing vehicle from a line in an hour and becomes less reliable in preserving travel time of an end to end trip. Additionally, there is an unknown amount of time required to transfer a passenger from the HSR train to a local line at the station that would deter the need for excessively high frequencies. Eastbound and west bound trains will be arriving at stations at different times, and 30-minute service would help ensure a minimal wait time no matter what direction the passenger is going.

\section{A Quality Public Transportation Connecting Route Takes Passengers to/from Their Trip Generator in no More than $\mathbf{2 0 0 \%}$ of a Comparable Auto Travel Trip Time}

The HSR trip between any two stations will have a travel time improvement over that of a private auto trip performing the same segment. That travel time benefit can easily be lost in HSR to local service transfer wait times and more significantly, indirect, multi-stop routes that slow a waiting passenger's time of arrival. Rail, Bus Rapid Transit (BRT), and Express Bus Routes provide the greatest opportunity to preserve travel time savings as they are designed to move riders more quickly to major destinations. However, much of the existing transit service networks are made up of local, multi-stop routes that are less effective at achieving travel time savings, focusing instead on greater coverage across a mix of land uses and generators. 
As a baseline, a public transportation trip could perform no better than matching (100\%) a comparable auto travel time segment. That assumes a single stop on the route aside from the HSR station while operating on the same roadways, including interstates. Public transportation is highly inefficient in performing these types of services. A more likely scenario is for transit service to provide 'competitive' travel time. If the standard for transit service to be provided to generators in $150 \%$ of an auto travel time, the majority of destinations could not be served. This is particularly relevant the farther away a generator is from the station. Private autos make use of the roadways with the highest speeds, whereas transit routes are typically structured to pick up and drop off the highest number of passengers. As the distance grows between the station and generator, the effect of this is compounded resulting in only the most select generators, in close proximity to the HSR station, being served in $150 \%$ of an auto travel trip time. Given the location of the stations and the distance away from many of the generators, a reasonable number of existing routes and improvements to future routes could be made to get passengers to and from generators by transit in $200 \%$ of auto time or less given the current levels of local transit service.

\section{TRIP GENERATOR EMPHASIS}

In order to structure an assessment of travel time competitiveness between transit and an auto, the top trip generators for each service area expected for use by HSR riders were listed as a sample for analysis. A more detailed, statistical analysis should be undertaken for further study, especially once the line opens and actual trip starts and ends can be evaluated. The trip generators used were developed through discussions with local transit agencies and their experiences in service operations and planning, identification of major tourist destinations, existing locations with high levels of service, and transit system marketing literature. Additionally, trip generators were developed from potential markets for HSR trip ends in business districts, government, education, health care, and military installations. Generators more likely to be served by private transportation providers with shuttles or bus systems were also included.

\section{A Quality Public Transportation Connecting Service Should Reduce Uncertainty and Emphasize Convenience by Eliminating the Need for Bus to Bus Transfers to Reach Major Trip Generators}

HSR trips that use public transit connections become less competitive and more difficult to navigate when bus-to-bus transfers are required. Arriving at a HSR station with a single rail line or bus ride to reach a final destination is of notable convenience for visitors to the area, particularly those that may be unfamiliar with where a transfer will take place. Travel time reliability is also greatly diminished as transfer wait times and indirect connecting routes increase overall trip travel times and make the HSR end-to-end trip longer. While it is impossible to serve every destination with a direct line (as private auto rentals and taxis are designed to meet this need), those locations with the highest amount of trip generation should be targeted with a direct HSR-serving route. 
In conclusion, to meet the definition as established here of a 'quality' local connecting service line, a route should possess the following criteria:

- A span of service operation that at minimum matches the HSR line

- A frequency of 30 minutes

- Carry passengers to major trip generators or city centers in no more than $200 \%$ of a comparable auto trip time and without requiring a bus to bus transfer

Once these criteria are applied to local transit lines, opportunities can be identified for improvements to connect the HSR station to the local service areas. 


\section{ChAPTER 4 \\ YEAR 2010 PUBLIC TRANSPORTATION SERVice LeVELS to HSR StAtions}

\section{TRANSIT CONNECTIVITY TO FUTURE HSR STATION LOCATIONS}

This chapter presents a route-by-route analysis of HSR-serving transit lines that are in operation in Year 2010. Current levels of service are not necessarily reflective of what will be available in 2015, the year the HSR line will open. However, many of these local transit lines are long established, productive routes that will likely continue operating into the future. This section is also intended to provide insight into the inner transit network connectivity by providing information about the number and locations of bus to bus transfer opportunities.

The 2010 connecting transit coverage areas are provided in separate maps, with color-coded service types. Circles are drawn around the portions of the service areas with the most complete access to the fixed-route transit network for each area. A one-quarter mile transit access area is shaded gray to illustrate standard walk distances to and from the routes. Each HSR-serving route is described with a route name, classification of the service, peak operating frequency, weekday hours of operation, and one-way travel time to the end of a route. Major points of interest are identified for the intercity traveler. Routes defined as 'non-HSR' serving would likely not directly serve stations under current alignments and are accessible only via busto-bus transfers. Locations for transfer to non-HSR serving routes are listed. Origins and destinations along the routes are outlined with approximate travel times provided from the stations.

The bus route classifications are presented below.

- Circulator Routes- Typically short bus routes that often take the form of one-way loops. Circulators often operate as fixed routes to connect a number of locations in close proximity to each other in a zone or district.

- Connector Routes - Lines designed to connect two significant points of interest, with multi-stop bus service in between the two.

- Express Routes - Bus lines that connect one or more locations utilizing an alignment and speed designed to rival an auto trip. These routes may be targeted toward commuters or other ride types that place a premium on travel time and convenience. 
- Limited Stop Routes- Routes that have more stops than Express lines, but fewer than local multi-stop routes. Limited stop service is designed to speed trips between locations and may also overlay on portions of local routes, but provide faster travel speeds.

- Local Bus Routes - Multi-stop bus service designed to connect the largest number of origins and destinations possible, often starting and ending at designed bus transfer locations.

- Shuttle Services - Transit routes that operate between two major points of interest with a sole purpose of connecting the two locations directly either on demand or as frequently as possible. 


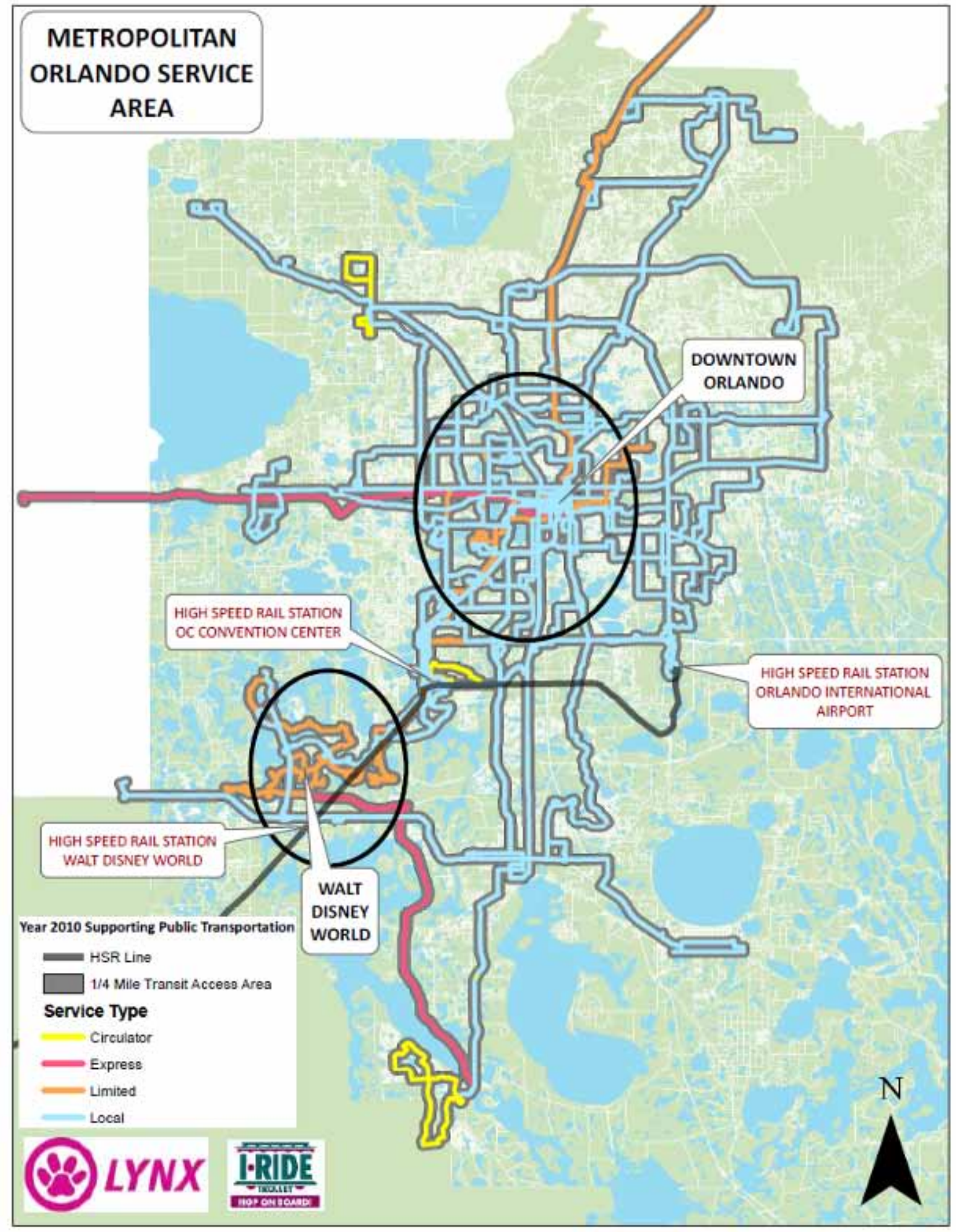

Map 4-1: Route Analyses for Metro Orlando HSR Stations 


\begin{tabular}{|c|c|c|}
\hline \multicolumn{2}{|l|}{ Route 8: W. Oak Ridge Rd/Int'I Dr. } & Type: Local \\
\hline 15 min & 22 & 85 min \\
\hline Peak Frequency & Daily Hours in Operation & One-way Travel Time \\
\hline
\end{tabular}

Operations and Connectivity:

Link 8 operates north and south between the Orlando Premium Outlets on International Drive to the downtown LYNX central transfer station. This line connects to non-HSR serving routes at Prime Outlets (24,305), Rio Grande Ave (304), Holden Ave (4), Parramore Ave (300) and all routes serving the downtown LYNX transfer center.

Origins and Destinations:

Route 8 will connect riders from the OCCC HSR station to Premium Outlets in 16-minute travel time. Sea World is served with an eight-minute travel time, Wet ' $n$ Wild in a $12-$ minute travel time, Prime Outlets in a 12 minute travel time, and the Amway Arena and downtown in 68minute travel time.

\begin{tabular}{|c|c|l|}
\hline \multicolumn{2}{|l|}{$\begin{array}{l}\text { Route 11: S. Orange Ave/Orlando Int'I } \\
\text { Airport }\end{array}$} & \multicolumn{1}{l|}{ Type: Local } \\
\hline 30 min & 20 & 41 min \\
\hline Peak Frequency & Daily Hours in Operation & One-way Travel Time \\
\hline
\end{tabular}

Operations and Connectivity:

Link 11 operates north and south between the Orlando International Airport and downtown Orlando. The route has several one-way travel patterns on it, traveling primarily on the Beachline Expressway and Orange Ave. Non-HSR serving routes are connected at Hansel Ave $(7,18)$, Michigan St $(40)$ and the downtown central transit terminal.

Origins and Destinations:

From the OIA HSR station there is a travel time of 30-minutes to the Orlando Regional Medical Center and Arnold Palmer Hospital. The Lucerne Medical Center is served in a 33- minute travel time and downtown Orlando and Amway Arena in a 40-minute travel time. 


\begin{tabular}{|c|c|c|}
\hline Route 38: Downtown Orlando/Int'I Dr. & Type: Circulator \\
\hline $15 \mathrm{~min}$ & 12 & 50 min \\
\hline Peak Frequency & Daily Hours in Operation & One-way Travel Time \\
\hline
\end{tabular}

Operations and Connectivity:

Link 38 is termed a circulator route that operates as an express between the OCCC HSR station location and downtown Orlando. The north and south traveling route operates along Interstate 4 (I-4) southbound and returns north on International Dr, Kirkman Rd and I-4. Non-HSR serving route connections are at Wet ' $\mathrm{n}$ Wild (37) and the downtown central terminal. The 50-minute travel time is to complete the entire loop.

Origins and Destinations:

Passengers originating from downtown to the future OCCC Intermodal Center would have a 20minute travel time, with a 30-minute travel time from the HSR location back to downtown. There would be a 12-minute travel time from the OCCC site to Wet ' $n$ Wild.

\begin{tabular}{|c|c|c|}
\hline \multicolumn{2}{|l|}{ Route 41: SR 436 Crosstown } & Type: Local \\
\hline 30 min & 19 & 102 min \\
\hline Peak Frequency & Daily Hours in Operation & One-way Travel Time \\
\hline
\end{tabular}

Operations and Connectivity:

Link 41 connects the Orlando International Airport to cities north of downtown including the eastern edge of Winter Park, Casselberry, Altamonte Springs and ending in Apopka. One of the longest routes in the LYNX system operates along Semoran Blvd/436. Non-HSR serving routes are connected at Gatlin Ave $(3,6)$, Lake Underhill Rd $(6,28)$, Colonial Dr $(29,30)$, Aloma Ave (13), Orlando Ave (12), Wymore Rd (1), Brantley Square $(23,434)$ and the Apopka Superstop $(17,44,405)$.

Origins and Destinations:

Link 41 is the only HSR serving line that operates north of downtown Orlando. Winter Park is served in 42-minute travel time, Casselberry in 63-minute travel time, Altamonte Springs in 83minute travel time and Apopka in 102-minute travel time. 


\begin{tabular}{|c|c|c|}
\hline Route 42: Int'I Dr/Orlando Int'I Airport & Type: Local \\
\hline 30 min & 20 & 96 min \\
\hline Peak Frequency & Daily Hours in Operation & One-way Travel Time \\
\hline
\end{tabular}

Operations and Connectivity:

Link 42 operates between two of the HSR station locations at OIA and OCCC. The route originates from OIA, westbound along Sand Lake Rd, where it would make a future connection with the SunRail commuter rail line. The line also operates on Oak Ridge Rd and International Dr. Non-HSR serving routes are connected at Florida Mall $(4,7,37,111)$ and John Young Pkwy (305).

Origins and Destinations:

Points of interest on Route 42 will be connected to HSR from two Orlando-area HSR station locations. From OIA, these include retail shopping at Florida Mall in 23 minutes and Premium Outlets in 51 minutes.

\begin{tabular}{|c|c|c|}
\hline \multicolumn{2}{|l|}{$\begin{array}{l}\text { Route 50: Downtown Orlando/Magic } \\
\text { Kingdom }\end{array}$} & Type: Limited \\
\hline 30 min & 19 & 63 min \\
\hline Peak Frequency & Daily Hours in Operation & One-way Travel Time \\
\hline
\end{tabular}

Operations and Connectivity:

Link 50 is a limited stop express route connecting the downtown LYNX central station to Disney World. The route travels along I-4 into the OCCC proposed HSR station, then onto the Downtown Disney West Side Transfer Center and ticketing center. Route 50 will connect with non-HSR serving routes at the LYNX Disney Super Stop $(300,303,304,305)$ and Vista Blvd (56).

Origins and Destinations:

From the future OCCC station, downtown Orlando would be served in a 20-minute travel time, Downtown Disney would be served with a 26-minute travel time, Sea World in a seven-minute travel time and the WDW Ticket and Transportation Center served in a 43-minute travel time. 


\section{\begin{tabular}{|c|c|c|}
\hline \multicolumn{2}{|c|}{ Route 51: Conway/Orlando Int'I Airport } & Type: Local \\
\hline 60 min & 17 & 50 min \\
\hline Peak Frequency & Daily Hours in Operation & One-way Travel Time \\
\hline
\end{tabular}}

Operations and Connectivity:

Link 51 connects Orlando International Airport to downtown Orlando via Hoffner Ave, South Conway Rd, and Curry Ford Rd. Non-HSR route serving connections are made at Curry Ford $\mathrm{Rd}(15)$ and the downtown central transfer terminal.

Origins and Destinations:

The Amway arena and downtown Orlando are connected from the OIA HSR station location in 52-minutes.

\begin{tabular}{|c|c|c|}
\hline \multicolumn{2}{|c|}{ Route 55: West US 192/Four Corners } & Type: Local \\
\hline 30 min & 17 & $44 \mathrm{~min}$ \\
\hline Peak Frequency & Daily Hours in Operation & One-way Travel Time \\
\hline
\end{tabular}

Operations and Connectivity:

Link 55 originates in the Osceola Square Mall in Kissimmee and operates along US 192 into Lake County at the Four Corners Wal-Mart. This route could be slightly deviated to serve the WDW HSR station and connect to destinations along the route. Non-HSR serving routes are connected to Link 55 at the Osceola Square Mall $(4,10,18,26,57)$.

Origins and Destinations:

Points of interests along Link 55 are served from the proposed WDW HSR station. The Town of Celebration would be connected in less than 10 minutes and Kissimmee in approximately 32 minutes. 


\begin{tabular}{|c|c|c|}
\hline \multicolumn{2}{|c|}{ Route 56: West US 192/Magic Kingdom } & \multirow{2}{*}{$\begin{array}{l}\text { Type: Local } \\
45 \text { min }\end{array}$} \\
\hline 30 min & 18 & \\
\hline Peak Frequency & Daily Hours in Operation & One-way Travel Time \\
\hline
\end{tabular}

Operations and Connectivity:

Link 56 operates similarly to Link 55, originating in Kissimmee at the Osceola Square Mall traveling on US 192. The same deviation proposed for the 55 would bring the route into the WDW HSR stations and connect with the WDW transportation services that will use the station. Rather than continuing on US 192, the route travels north on World Dr toward the Magic Kingdom cast bus station. All non-HSR route connections are made at Osceola Mall and the WDW Ticket and Transportation Center.

Origins and Destinations:

Kissimmee and Celebration would be connected to HSR the same as with the 55. The WDW Ticket and Transportation Center within Disney World connection would require less than 10 minutes travel time and Disney University and Magic Kingdom Bus Station connections would require less than 15 minutes.

\begin{tabular}{|c|c|c|}
\hline \multicolumn{2}{|l|}{ Route 58: Shingle Creek Circulator } & Type: Circulator \\
\hline 30 min & 13 & 11 min \\
\hline Peak Frequency & Daily Hours in Operation & One-way Travel Time \\
\hline
\end{tabular}

Operations and Connectivity:

Link 58 is a short-line circulator that connects Canadian Court to the Rosen Shingle Creek Resort. The trip pattern operates on International Dr, Pointe Plaza Ave, and Universal Blvd.

Origins and Destinations:

The 11-minute total trip time connects the resort, UCF Rosen College of Hospitality, Westin Village of Imagine, Rosen Plaza Hotel, and Rosen Centre Hotel to the OCCC HSR station. 


\begin{tabular}{|c|c|c|}
\hline \multicolumn{2}{|l|}{ Route 111: OIA/Disney } & Type: Local \\
\hline 30 min & 19 & $79_{\text {min }}$ \\
\hline Peak Frequency & Daily Hours in Operation & One-way Travel Time \\
\hline
\end{tabular}

Operations and Connectivity:

Link 111 connects WDW to the International Airport via Destination Parkway along Sand Lake $\mathrm{Rd}$, SR 528 and I-4. Link 111 follows a route pattern that somewhat follows the future HSR line and will likely serve the future SunRail station at Sand Lake Road. The line connects with nonHSR serving routes at the Florida Mall Superstop $(4,7,37)$ and LYNX Downtown Disney Superstop (300 series routes).

Origins and Destinations:

The significant destination along the route will be the SunRail Phase I southernmost terminus at Sand Lake. If the route were deviated into the new OCCC station, Sun Rail connections could be made from the east and west on HSR. Approximate travel times to connect with SunRail from Orlando International Airport would be 10 minutes and from the OCCC station would take 25 minutes.

\begin{tabular}{|r|c|c|}
\hline \multicolumn{2}{|c|}{ Route 301: 3D-Pine Hills/Animal Kingdom } & Type: Limited \\
\hline $2_{\text {trips }}$ & 5 & 90 min \\
\hline Peak Frequency & Daily Hours in Operation & One-way Travel Time \\
\hline
\end{tabular}

Operations and Connectivity:

Link 301 is a limited-operation express route designed to carry employees to WDW with 1 morning trip and two evening trips. The route originates at the Park Promenade Superstop to the west of downtown Orlando and serves multiple theme park locations throughout WDW. It operates in the vicinity of WDW HSR station and could possibly be deviate to serve areas not otherwise directly provided access by other routes. Non-HSR route connections are made at Park Promenade $(37,44,443)$, and West Gate Plaza $(48,125)$.

Origins and Destinations:

The north end of the line would serve near Ocoee in approximately 80 minutes. Destinations within WDW such as Animal Kingdom, Epcot, and the Pop Century hotel would all be served in less than 10 minutes travel time. 


\begin{tabular}{|r|c|c|}
\hline \multicolumn{2}{|l|}{ Route 306: Poinciana/Magic Kingdom } & Type: Limited \\
\hline $1_{\text {trip }}$ & 2 & 45 min \\
\hline Peak Frequency & Daily Hours in Operation & One-way Travel Time \\
\hline
\end{tabular}

Operations and Connectivity:

Link 306 is a service connecting Poinciana to WDW that could be deviated into the new HSR station WDW. One morning and afternoon trip connect these two locations.

Origins and Destinations:

The growing residential community of Poinciana straddles the Osceola and Polk County lines. This service brings Poinciana residents to work at WDW with a stop mid trip at the Poinciana High School.

\begin{tabular}{|c|c|l|}
\hline \multicolumn{2}{|l|}{$\begin{array}{l}\text { Route } 641: \text { Williamsburg Circulator } \\
\text { (pickupline) }\end{array}$} & \multicolumn{1}{l|}{ Type: Flex } \\
\hline 60 min & 13 & 10 min \\
\hline Peak Frequency & Daily Hours in Operation & One-way Travel Time \\
\hline
\end{tabular}

Operations and Connectivity:

Route 641 is a flex service, with a pick up and drop off area covering the Williamsburg community. This flex zone is just to the south of the future OCCC HSR station. Connections to route 58 and 111 take place at the Destination Parkway Superstop.

Origins and Destinations:

From HSR, Pickupline 641 connects the International Resort and Spa, Aquatica, Sea World, the Renaissance Orlando Resort, and two golf clubs. Travel times are variable due to the nature of flex service route deviations. 


\begin{tabular}{|c|c|c|}
\hline \multicolumn{2}{|l|}{ Route Greenline: I-Drive Trolley } & Type: Local \\
\hline 30 min & 10.5 & $\mathrm{~N} / \mathrm{A}_{\text {min }}$ \\
\hline Peak Frequency & Daily Hours in Operation & One-way Travel Time \\
\hline
\end{tabular}

Operations and Connectivity:

The Green Line begins service in the Major Boulevard area Hampton Inn, travels along Universal Boulevard and then follows the Red Line Trolley Route on South International Drive. Green Line Trolleys arrive approximately every 30 minutes. This is a headway-based service that does not have published arrival times.

Origins and Destinations:

The Green Line's stops serve numerous hotels, tourist attractions, retail shopping outlets, nightlife and dining options.

\begin{tabular}{|c|c|c|}
\hline \multicolumn{2}{|l|}{ Route Redline: I-Drive Trolley } & Type: Local \\
\hline 30 min & 10.5 & $\mathrm{~N} / \mathrm{A}_{\text {min }}$ \\
\hline Peak Frequency & Daily Hours in Operation & One-way Travel Time \\
\hline
\end{tabular}

Operations and Connectivity:

The Red Line begins at the north end of International Drive at Prime Outlets Orlando and travels the majority of International Drive to Sea World and services south on International Drive ending at Orlando Premium Outlets. Red Line trolleys arrive approximately every 20 minutes. The IDrive Trolley operates within the vicinity of the OCCC HSR station.

Origins and Destinations:

The Red Line's 77 stops serve more than 50 hotels, numerous tourist attractions, retail shopping outlets, nightlife and dining options on International Drive. 


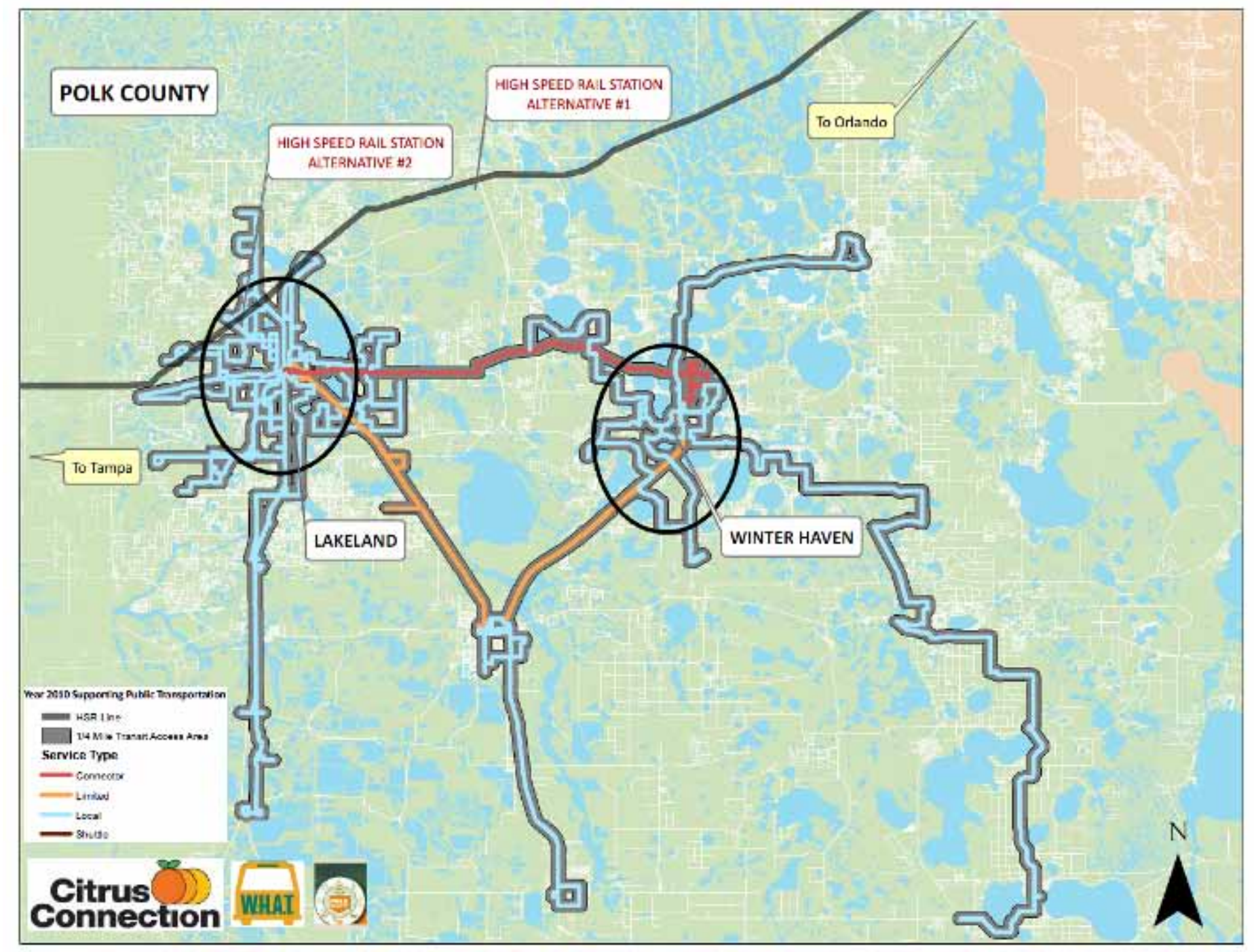

Map 4-2: Route Analyses for Polk County HSR Station 
Polk County Station Alternative 1 at the site of the Williams DRI currently has no local transit service operations within one mile of the proposed HSR station.

Polk County Station Alternative 2 at the Kathleen Road site has the following bus routes operational within a close proximity to the proposed station location, although roads to access the site have not yet been constructed.

\begin{tabular}{|c|c|c|}
\hline \multicolumn{2}{|l|}{ Route 50: Kathleen/Providence } & Type: Local \\
\hline 60 min & 14 & 22 min \\
\hline Peak Frequency & Daily Hours in Operation & One-way Travel Time \\
\hline
\end{tabular}

Operations and Connectivity:

Route 50 is a line that generally runs north and south, connecting the Lakeland Square Mall to the downtown Lakeland Central Bus Terminal. From this terminal, connections can be made to all but 4 of the Citrus Connection routes.

Origins and Destinations:

With a deviation into the proposed HSR station, Route 50 will be able to serve downtown Lakeland in approximately 20 minutes and the Lakeland Square Mall in approximately 5 minutes. Route 50's connections at the downtown terminal provide transit system access via one bus transfers to the cities of Auburndale, Bartow, and Winter Haven as well as all points of interest in the Citrus Connection service area.

\begin{tabular}{|c|c|c|}
\hline \multicolumn{2}{|l|}{ Route 51: North 98/Duff Rd. } & Type: Local \\
\hline 30 min & 13 & 19 min \\
\hline Peak Frequency & Daily Hours in Operation & One-way Travel Time \\
\hline
\end{tabular}

Operations and Connectivity:

Route 51 operates north and south from the central downtown terminal to Northside Village, primarily on Florida Ave/US-98 North. Two deviations off of US-98 on the inbound trip to downtown occur in order to serve the Super Wal-Mart and Lakeland Square Mall, both of which are not served on the outbound trip. 
Origins and Destinations:

With a deviation into the proposed HSR station, Route 51 will be able to serve the Lakeland Square Mall in approximately 5 minutes and downtown terminal in approximately 15 minutes. Route 51's connections at the downtown terminal provide transit system access via one bus transfers to the cities of Auburndale, Bartow, and Winter Haven as well as all points of interest in the Citrus Connection service area.

\begin{tabular}{|c|c|c|}
\hline \multicolumn{2}{|l|}{ Route 56: Kathleen/Mall Hill Dr. } & Type: Local \\
\hline 60 min & 13 & 25 min \\
\hline Peak Frequency & Daily Hours in Operation & One-way Travel Time \\
\hline
\end{tabular}

Operations and Connectivity:

Route 56 operates north and south from the central downtown terminal to Lakeland Square Mall, along Martin Luther King Jr. Blvd, $10^{\text {th }} \mathrm{St}$, and Kathleen Rd.

Origins and Destinations:

With a deviation into the proposed HSR station, Route 56 will be able to serve the Lakeland Square Mall in approximately 10 minutes and the downtown terminal in approximately 20 minutes. Route 56's connections at the downtown terminal provide transit system access via one bus transfers to the cities of Auburndale, Bartow, and Winter Haven as well as all points of interest in the Citrus Connection service area. 


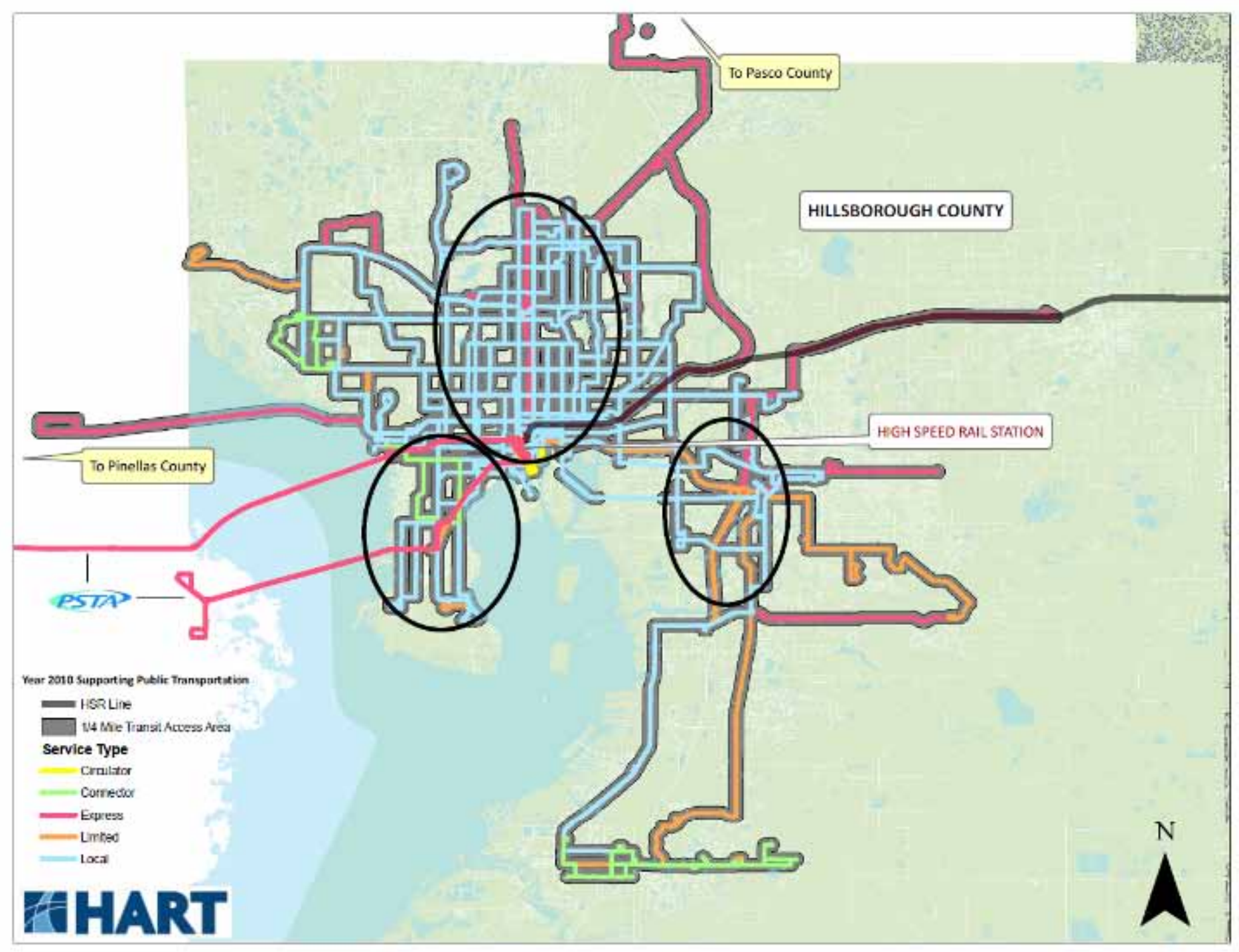

Map 4-3: Route Analyses for Tampa Intermodal Center HSR Station 


\begin{tabular}{|c|c|c|}
\hline \multicolumn{2}{|l|}{ Route 1: Florida Avenue } & Type: Local \\
\hline 20 min & 21 & 55 min \\
\hline Peak Frequency & Daily Hours in Operation & One-way Travel Time \\
\hline
\end{tabular}

Operations and Connectivity:

Route 1 runs primarily north and south on Florida Avenue, just to the west of Interstate 275. It is one of the core, main trunk lines of the HART bus route network operations between the Marion Transit Center downtown to the University Area Transit Center (UATC) in north central Tampa. The route offers connections to bus lines at both UATC and the Yukon Transfer Center. The Yukon Transfer Center also functions as a Park-and-Ride facility in the central Tampa area.

Origins and Destinations:

The route serves within the vicinity of a cluster of educational institutions including the Stetson Law School and Brewster Vocational Technical School. The route better serves these locations with respect to HSR connectivity on the inbound trip as the route travels along the one-way Tampa St heading south, each with an approximate travel time to HSR of less than 5 minutes. The outbound trip from the HSR station would be practical to a rider that visited these locations if they alighted on the one-way north traveling Florida Avenue at Palm Avenue and walked a block west to the schools.

\begin{tabular}{|c|c|c|}
\hline \multicolumn{2}{|l|}{ Route 2: Nebraska Avenue } & Type: Local \\
\hline 15 min & 20 & 48 min \\
\hline Peak Frequency & Daily Hours in Operation & One-way Travel Time \\
\hline
\end{tabular}

Operations and Connectivity:

Route 2 is one of HART's highest frequency and most productive routes serving the urban corridor of Nebraska Avenue from Cass Street to Fletcher Avenue. Major connection points with east and west traveling routes not directly serving the HSR station are made at Busch Blvd (39), Sligh Ave (41), Hillsborough Ave (34), Martin Luther King Jr. Blvd (32) and Columbus Ave (15). 
Origins and Destinations:

This route provides a direct connection from the urban neighborhood of Seminole Heights to downtown Tampa in 14 minutes. The travel time to the Tampa Greyhound Dog Track is approximately 20 minutes. The corridors traveled along Route 2 are also in the final design stages of a Bus Rapid Transit (BRT) line set to open in 2013.

\begin{tabular}{|c|c|c|}
\hline \multicolumn{2}{|l|}{ Route 4: Britton Plaza } & Type: Local \\
\hline 60 min & 15 & 58 min \\
\hline Peak Frequency & Daily Hours in Operation & One-way Travel Time \\
\hline
\end{tabular}

Operations and Connectivity:

Route 4 operates at an hourly frequency, generally travelling north and south between downtown Tampa and the northern border of the MacDill Air Force Base (AFB). The line connects mid route with the Britton Plaza Transfer Center and meets with non-HSR serving routes 36 and 89 with a 30 -minute travel time.

Origins and Destinations:

The inbound trip to HSR serves Hyde Park Village, the Tampa Convention Center, and St Pete Times Forum as it returns on Platt St from MacDill AFB. Travel times from those locations are less than 15 minutes. The outbound trip travels on Cleveland Street and requires walking south to reach those locations.

\begin{tabular}{|c|c|c|}
\hline \multicolumn{2}{|l|}{ Route 5: 40th Street } & Type: Local \\
\hline 30 min & 17 & 54 min \\
\hline Peak Frequency & Daily Hours in Operation & One-way Travel Time \\
\hline
\end{tabular}

Operations and Connectivity:

Route 5 is a north and south traveling line with operations along $40^{\text {th }}$ St, ending at UATC. It connects with non-HSR serving routes at Columbus Dr (15), Martin Luther King Jr. Blvd (32), Hillsborough Ave (34), Hanna St (41), and Busch Blvd (39). 
Origins and Destinations:

Major points of interest connected to HSR via Route 5 include Busch Gardens/Adventure Island with a 34-minute travel time, the University of South Florida, Moffitt Cancer Center and Shriner's Children's Hospital with an approximate 45-minute travel time and Veterans Administration Hospital at a 50-minute travel time.

\begin{tabular}{|c|c|c|}
\hline \multicolumn{2}{|l|}{ Route 6: 56 th Street } & Type: Local \\
\hline 30 min & 21 & 65 min \\
\hline Peak Frequency & Daily Hours in Operation & One-way Travel Time \\
\hline
\end{tabular}

Operations and Connectivity:

Route 6 outbound from HSR travels east and then north to UATC at a 30-minute frequency. It connects with a number of non-HSR serving routes in the NetPark Transfer Center at a 30minute travel time, including routes: $15,32,34,37,39,41$ and 57.

Origins and Destinations:

The line serves the City of Temple Terrace with a 45-minute travel time, the Museum of Science and Industry in 51 minutes, the USF Sun Dome in 55 minutes and University Community Hospital in 60 minutes.

\begin{tabular}{|c|c|c|}
\hline \multicolumn{2}{|c|}{ Route 7: West Tampa/Citrus Park } & Type: Local \\
\hline 30 min & 17 & 60 min \\
\hline Peak Frequency & Daily Hours in Operation & One-way Travel Time \\
\hline
\end{tabular}

Operations and Connectivity:

Route 7 is a line that operates on several one way streets, with its end-of-line turn around at the Citrus Park Super Wal-Mart in the northwestern area of Hillsborough County. The line segment north of Martin Luther King Jr. Blvd only operates on selected trips. Non-HSR line connections are made at Martin Luther King and Armenia Ave $(32,45)$, Habana Ave (41), Hillsborough Ave (34), Waters Ave (16), Henderson Rd (39), and the West Tampa Transfer Center $(32,36,41,45)$ with a 30-minute travel time. 
Origins and Destinations:

Multiple trip generators are found along Route 7 including the Performing Arts Center and Children's Museum at five- minute travel time, the University of Tampa at eight- minute travel time, Argosy University at 10 minutes, St. Joseph's Hospital at 24 minutes, Raymond James Stadium at 30 minutes, and Hillsborough Community College at 35 minutes.

\begin{tabular}{|c|c|c|}
\hline \multicolumn{2}{|l|}{ Route 8: Progress Village/Brandon } & Type: Local \\
\hline 30 min & 19 & 68 min \\
\hline Peak Frequency & Daily Hours in Operation & One-way Travel Time \\
\hline
\end{tabular}

Operations and Connectivity:

Route 8 travels eastbound from the Marion Transit Center through Ybor City, Palm River, and Progress Village with the end of line at Westfield Brandon Mall. Non-HSR route connections are made at Broadway Ave and $50^{\text {th }}$ St $(15), 78^{\text {th }}$ St and Causeway Blvd (46), and Westfield Brandon Mall $(37,46,35 \mathrm{LX})$.

Origins and Destinations:

The line serves the majority of its connected trip generators close to the downtown station. It directly serves the St Pete Times Forum and Tampa Bay History Center in less than 10 minutes. It also makes a connection with the TECO streetcar system that will bring riders to the Channelside Entertainment Complex, Florida Aquarium, and cruise Port of Tampa. Route 8 connects to Ybor City in 13 minutes.

\begin{tabular}{|c|c|c|}
\hline \multicolumn{2}{|l|}{ Route 9: 15 th Street } & Type: Local \\
\hline 30 min & 17 & 66 min \\
\hline Peak Frequency & Daily Hours in Operation & One-way Travel Time \\
\hline
\end{tabular}

Operations and Connectivity:

Route 9 originates from downtown, running north and south on $15^{\text {th }}$ St and Rowlett Park Drive through several residential neighborhoods in central Tampa. The line connects at Yukon Transfer Center with a 39-minute travel time and ends at UATC. Route 9 connects with nonHSR serving routes at $17^{\text {th }}$ Ave (15), Martin Luther King Jr. Blvd (32), Hillsborough Ave (34), Yukon Transfer Center/Park-and-Ride (16, 39), and UATC $(18,33,45,57)$. 
Origins and Destinations:

The route serves a connection to Amtrak at Tampa Union Station in less than five-minute travel time, the western end of Ybor City with a 6-minute travel time, Hillsborough Community College Ybor campus at 8-minute travel time, and the Tampa Greyhound Dog Track in 35 minutes.

\begin{tabular}{|c|c|c|}
\hline \multicolumn{2}{|l|}{ Route 10: Cypress Street } & Type: Local \\
\hline 30 min & 14 & 28 min \\
\hline Peak Frequency & Daily Hours in Operation & One-way Travel Time \\
\hline
\end{tabular}

Operations and Connectivity:

Route 10 is a relatively short bus line that travels east and west almost exclusively along Cypress St out to Cypress Point Park. The line connects to non-HSR serving routes at Dale Mabry Hwy (36), Lois Ave (45), and Westshore Blvd (15, 45, 89).

Origins and Destinations:

This route connects the HSR station to the center of the Westshore business district in approximately 20 minutes. Tampa's Performing Arts Center, Museum of Art, and Children's Museum are all served with a 6-minute travel time. On the western end of the route is the MacDonald Training Center with a travel time of 25 minutes.

\begin{tabular}{|c|c|c|}
\hline \multicolumn{2}{|l|}{ Route 12: 22nd Street } & Type: Local \\
\hline 20 min & 21 & 56 min \\
\hline Peak Frequency & Daily Hours in Operation & One-way Travel Time \\
\hline
\end{tabular}

Operations and Connectivity:

Route 12 operates north and south along $22^{\text {nd }}$ St and Rowlett Park Dr from Marion Transit Center to UATC. Non-HSR lines are connected at $17^{\text {th }}$ Ave and Columbus Dr (5), Martin Luther King Jr. Blvd (32), Hillsborough Blvd (34), Busch Blvd (39), University Mall (45), and UATC.

Origins and Destinations:

Amtrak at Tampa's Union Station is less than 5 minutes from the HSR station on Route 12. Hillsborough Community College at Ybor City travel time is 9 minutes. The University Mall in north central Tampa is served by Route 12 originating at the future HSR station in a travel time of 38 minutes. 


\begin{tabular}{|c|c|c|}
\hline \multicolumn{2}{|l|}{ Route 14: Armenia Avenue } & Type: Local \\
\hline 60 min & 16 & 55 min \\
\hline Peak Frequency & Daily Hours in Operation & One-way Travel Time \\
\hline
\end{tabular}

Operations and Connectivity:

Route 14 is a north and south running line from downtown Tampa to Yukon Transfer Center/Park-and-Ride, operating primarily along North Blvd and Armenia Ave. Non-HSR lines are connected to Route 14 at Hyde Park and Plant Ave (46), Columbus Dr (15), Martin Luther King Jr. Blvd (32, 45), Hillsborough Ave (34), Sligh Ave (41), Waters Ave (16), and Busch Blvd (39).

Origins and Destinations:

Route 14 serves the University of Tampa in 8-minute travel time.

\begin{tabular}{|c|c|c|}
\hline \multicolumn{2}{|l|}{ Route 18: 30th Street } & Type: Local \\
\hline 30 min & 17 & 64 min \\
\hline Peak Frequency & Daily Hours in Operation & One-way Travel Time \\
\hline
\end{tabular}

Operations and Connectivity:

Route 18 runs north and south mainly along $29^{\text {th }}$ St and $30^{\text {th }} \mathrm{St}$, with a near end of route stop at UATC and end of line at Sinclair Hills Rd. Non-HSR serving routes are connected at $17^{\text {th }}$ Ave (15), Sligh Ave (41), Busch Blvd (39), and UATC $(33,45,57)$.

Origins and Destinations:

The route proceeds north leaving downtown and serves the Tampa General Hospital Health Park with a 22 minute travel time. The western end of the Busch Gardens theme park is served with a 32-minute travel time. The 18 passes the Veterans Administration Hospital and UATC in 44 minutes from downtown. The route then enters the University of South Florida from its western-most entrance and serves the USF Medical Center in a 54-minute travel time. Finally, the University Community Hospital is served in a 60-minute travel time. 


\begin{tabular}{|c|c|c|}
\hline \multicolumn{2}{|l|}{ Route 19: Westshore/Manhattan } & Type: Local \\
\hline 30 min & 21 & 69 min \\
\hline Peak Frequency & Daily Hours in Operation & One-way Travel Time \\
\hline
\end{tabular}

Operations and Connectivity:

Route 19 serves South Tampa traveling south and west from downtown Tampa with several one-way street patterns near route origin. An alternating trip segment occurs on Manhattan Blvd and Westshore Blvd. Non-HSR serving routes connections are made at Britton Plaza Transfer Center to routes 36 and 89 .

Origins and Destinations:

Several hospitals are served along Route 19. The Davis Islands neighborhood and Tampa General Hospital is a 17-minute travel trip on Route 19 to the Marion Transit Center. Tampa's $\mathrm{SOHO}$ district is served in a 25-minute travel time. The Memorial Hospital is connected in 27 minutes and Kindred Hospital in 55 minutes.

\begin{tabular}{|c|c|c|}
\hline \multicolumn{2}{|l|}{ Route 20: Lutz } & Type: Express \\
\hline 40 min & 3 & 33 min \\
\hline Peak Frequency & Daily Hours in Operation & One-way Travel Time \\
\hline
\end{tabular}

Operations and Connectivity:

The Route 20 Express originates from the First Baptist Church Park-and-Ride in the north central area of Hillsborough County serving daily commuters with a limited number of peak-hour only trips to downtown Tampa. Routes 33 and 83 do not directly connect to the future HSR station but transfer to the Route 20 at Fletcher Ave and Nebraska Ave.

Origins and Destinations:

Riders are from the communities of the surrounding areas of Lutz, Land O' Lakes, and Central Pasco County. They are likely auto dependent to either drive to or be dropped off at the facility. Currently, there are not supportive transit options in this low density area. 


\begin{tabular}{|c|c|c|}
\hline \multicolumn{2}{|l|}{ Route 22: Dover - Brandon } & Type: Express \\
\hline 30 min & 3 & 57 min \\
\hline Peak Frequency & Daily Hours in Operation & One-way Travel Time \\
\hline
\end{tabular}

\section{Operations and Connectivity:}

Route 22 operates as a commuter express service from the eastern Hillsborough County suburban area along State Road 60 and utilizes the Crosstown Expressway to bring riders to the downtown transit hub. A limited number of peak hour weekday trips are provided.

Origins and Destinations:

The unincorporated areas of Dover, Valrico, and Brandon are served with stops at two Parkand-Ride facilities located at Dover Park and Rogers Field. A third stop is made at an expressonly stop at the SR $60 \mathrm{Kmart}$ in Brandon. There is a limited amount of supporting transit service in the area to feed the Park-and-Ride facilities but no direct connections to the Route 22.

\begin{tabular}{|c|c|c|}
\hline \multicolumn{2}{|l|}{ Route 23: Temple Terrace } & Type: Express \\
\hline 40 min & 3 & $42 \mathrm{~min}$ \\
\hline Peak Frequency & Daily Hours in Operation & One-way Travel Time \\
\hline
\end{tabular}

Operations and Connectivity:

Route 23 operates north and south, primarily along $56^{\text {th }}$ Ave to the northeast of downtown Tampa. The route enters I-4 at $50^{\text {th }}$ Street and travels into Marion Transit Center. It is a peak hour commuter express service with a limited number of weekday trips.

Origins and Destinations:

The line originates at the City of Temple Terrace City Hall Park-and-Ride and makes one stop at the Terrace Plaza Express location before its progression into downtown. This serves the City of Temple Terrace residential neighborhoods and University of South Florida area. 


\section{\begin{tabular}{|c|c|c|}
\hline \multicolumn{2}{|l|}{ Route 27: Fishhawk-South Brandon } & Type: Limited \\
\hline 20 min & 3 & 60 min \\
\hline Peak Frequency & Daily Hours in Operation & One-way Travel Time \\
\hline
\end{tabular}}

Operations and Connectivity:

Route 27 is a commuter limited-stop express service in the southeastern Hillsborough County area that operates along several local corridors and the Crosstown Expressway. It is a peak hour, weekday-only service with a limited number of daily trips.

Origins and Destinations:

Three Park-and-Ride facilities are served in the communities of FishHawk, Bloomingdale, and Brandon. There are a significant number of residential planned urban developments in this area of the county with a limited amount of supporting transit service.

\begin{tabular}{|c|c|c|}
\hline \multicolumn{2}{|l|}{ Route 28: East County } & Type: Express \\
\hline 30 min & 3 & 50 min \\
\hline Peak Frequency & Daily Hours in Operation & One-way Travel Time \\
\hline
\end{tabular}

Operations and Connectivity:

Route 28 is a commuter express that operates along I-4 from Thonotosassa Rd, onto I-75 and the Crosstown Expressway into downtown Tampa. It is a peak hour, weekday-only service with a limited number of daily trips.

Origins and Destinations:

Route 28 originates in the rural community of Thonotosassa at the Mount Zion Church Parkand-Ride. It makes one stop before reaching the future HSR station at Burnett Park, also a Park-and-Ride facility in the east Tampa/Seffner area. 


\begin{tabular}{|c|c|c|}
\hline \multicolumn{2}{|l|}{ Route 30: Town 'N Country } & Type: Local \\
\hline 15 min & 21 & 67 min \\
\hline Peak Frequency & Daily Hours in Operation & One-way Travel Time \\
\hline
\end{tabular}

Operations and Connectivity:

Route 30 emerges from downtown toward the north and west along Kennedy Blvd and the Veterans Expressway. Every trip enters into the Tampa International Airport (TIA) with selected trips Operations to the north, serving connections at the Northwest Transfer Center (NWTC). Non-HSR serving bus routes are connected to Route 30 at Hyde Park Ave and Plant Ave (46), MacDill Ave (89), Dale Mabry Hwy (36), Westshore Plaza Transfer Center (15, 45), and Northwest Transfer Center $(16,34,39,88)$.

Origins and Destinations:

Route 30 operates at a relatively high frequency to serve TIA with a published travel time of 27 minutes from downtown. The Westshore business district and retail shopping center, Westshore Plaza are served in 23 minutes. The International Mall is served with a 25-minute travel time. This route also connects future HSR to the TECO Streetcar line, which serves the downtown Central Business District, Channel District, and Ybor City.

\begin{tabular}{|c|c|c|}
\hline \multicolumn{2}{|c|}{ Route 31: South Hillsborough County } & Type: Local \\
\hline 120 min & 14 & 118 min \\
\hline Peak Frequency & Daily Hours in Operation & One-way Travel Time \\
\hline
\end{tabular}

Operations and Connectivity:

Route 31 is the longest mileage local route in the HART bus network. It connects the southern most communities of Hillsborough County primarily via Highway 41 and Providence Rd. It connects multiple non-HSR serving routes in Ybor City (46), Westfield Brandon Mall $(35,37)$, Riverview Oaks (24), and Ruskin (87). This line is also fed by a flex route that will bring passengers from their door to connect to the route.

Origins and Destinations:

Route 31 serves communities in Ruskin (110 minutes), Apollo Beach (95 minutes), Gibsonton (79 minutes), Riverview (63 minutes), and Brandon (44 minutes) to downtown Tampa future HSR. 


\begin{tabular}{|c|c|c|}
\hline \multicolumn{2}{|l|}{ Route 47: South Shore } & Type: Limited \\
\hline 30 min & 4 & 76 min \\
\hline Peak Frequency & Daily Hours in Operation & One-way Travel Time \\
\hline
\end{tabular}

Operations and Connectivity:

Route 47 is a limited stop express route from Sun City Center to downtown Tampa, with operations on Highway 41, I-75, and the Crosstown Expressway. It follows a similar pattern to Route 31 , but only stops at major pick-up points and uses the highways instead of local roads to achieve travel time savings. A limited number of peak-hour only trips are provided.

Origins and Destinations:

Route 47 makes a total of four stops from Sun City Center (75 minutes), Apollo Beach (45 minutes), and Gibsonton (29 minutes).

\begin{tabular}{|c|c|c|}
\hline \multicolumn{2}{|l|}{ Route 50: Citrus Park-Carrollwood } & Type: Express \\
\hline 30 min & 3 & 55 min \\
\hline Peak Frequency & Daily Hours in Operation & One-way Travel Time \\
\hline
\end{tabular}

Operations and Connectivity:

This line is a commuter express originating in the central/northwest Carrollwood community. It operates primarily on Gunn Hwy and Interstate 275 into downtown Tampa. Route 50 is a service limited to peak -hour weekday trips only.

Origins and Destinations:

The route makes 3 stops at Park-and-Rides in Carrollwood (48 minutes), Citrus Park (43 minutes) to the west, and on Orange Grove $\operatorname{Dr}(25$ minutes) as it approaches I-275 into downtown. 


\begin{tabular}{|c|c|c|}
\hline \multicolumn{2}{|l|}{ Route 51: New Tampa } & Type: Express \\
\hline 30 min & 3 & 75 min \\
\hline Peak Frequency & Daily Hours in Operation & One-way Travel Time \\
\hline
\end{tabular}

Operations and Connectivity:

Route 51 connects Pasco County and Wesley Chapel to downtown Tampa with a peak-hour, weekday limited-trip Express service. The line alternates trip patterns in the morning and afternoon peak periods, utilizing Interstates 75 and 275.

Origins and Destinations:

Two Park-and-Ride facilities in Pasco County at State Road 54 (75 minutes) and County Line $\mathrm{Rd}$ (60 minutes) are served by Route 51 . The New Tampa area has its only bus service at the Lowe's Park-and-Ride stop with a 42-minute travel time to downtown in peak service.

\begin{tabular}{|c|c|c|}
\hline \multicolumn{2}{|c|}{ Route 59: Westchase-Town 'N Country } & Type: Limited \\
\hline $25 \mathrm{~min}$ & 5 & $58 \mathrm{~min}$ \\
\hline Peak Frequency & Daily Hours in Operation & One-way Travel Time \\
\hline
\end{tabular}

Operations and Connectivity:

Route 59 runs from the Westchase business and residential areas in northwestern Hillsborough County to the future HSR station area. Non-HSR route connections are made at Northwest Transfer Center $(16,34,39,88)$ and Cypress St $(15,45,89)$. This is a limited trip, weekday peak-hour only service.

Origins and Destinations:

Westchase is served with a 58-minute travel time. The Town ' $N$ ' Country community is served with a 49-minute travel time. The St Matthews Park $n$ Ride in the southeastern most location within Town 'N' Country is connected with a 28-minute trip on Route 59. 


\begin{tabular}{|c|c|c|}
\hline \multicolumn{2}{|l|}{ Route 96: Downtown Purple Line } & Type: Circulator \\
\hline 10 min & 6 & 30 min \\
\hline Peak Frequency & Daily Hours in Operation & One-way Travel Time \\
\hline
\end{tabular}

Operations and Connectivity:

The Route 96 'In-Town Trolley', is a downtown CBD and streetcar connecting service that operates Monday through Friday in peak service (6:00am to 9:00am and 3:00pm to 6:00pm). It travels a pair of one-way loops through the CBD on Tampa St and Florida Ave and again on Harbour Island. Non-HSR serving route connections are made at Kennedy Blvd (46).

Origins and Destinations:

In addition to the CBD destinations, this circulator connects to the Tampa Convention Center and St Pete Times Forum in less than 15 minutes. 7 of the 8 large downtown hotels are within one city block of the In-Town Trolley Purple Line.

\begin{tabular}{|c|c|c|}
\hline \multicolumn{2}{|c|}{ Route 97: Downtown Green Line } & Type: Circulator \\
\hline 10 min & 8 & 30 min \\
\hline Peak Frequency & Daily Hours in Operation & One-way Travel Time \\
\hline
\end{tabular}

Operations and Connectivity:

Route 97 is the In-Town Trolley Green Line, a downtown circulator operating on Friday and Saturday from $6: 00 \mathrm{pm}$ to $2: 00 \mathrm{am}$. The one-way loop route pattern is moved one block to the west and extended to the east of downtown into the Channelside entertainment district. It also connects with the TECO Streetcar line allowing connections into Ybor City.

Origins and Destinations:

The Green Line route alignment is designed to serve all of the downtown hotels, Performing Arts Center, St Pete Times Forum, and nightlife in the Channelside area. All the destinations are connected in a travel time of less than 15 minutes with a 15-minute frequency near the proposed HSR station location. This line does not currently serve the Marion Transit Center directly, primarily due to the hours of service and typical trip purpose of the users. Connecting the Route 97 to local transit lines does not appear to be of high priority. 


\begin{tabular}{|c|c|c|}
\hline \multicolumn{2}{|l|}{ Route 200: Clearwater } & Type: Express \\
\hline 35 min & 6 & 30 min \\
\hline Peak Frequency & Daily Hours in Operation & One-way Travel Time \\
\hline
\end{tabular}

Operations and Connectivity:

Route 200 is an Inter-County express designed to connect the downtown Tampa transfer center to the Pinellas Suncoast Transit Authority system via the Highway 60/Courtney Campbell Causeway over Tampa Bay. This express service operates limited weekday only trips.

Origins and Destinations:

The area west of downtown Clearwater at the Eddie C. Moore Park-and-Ride complex provides the northernmost access to the PSTA system. Connections can be made here with the Greyhound Bus Terminal, PSTA Route 19 to St Petersburg, and Route 60 to downtown Clearwater. Additionally, there is a stop at Rocky Point on the Hillsborough County side of the Causeway.

\section{Premium Transit Capital Projects}

This section briefly summarizes several ongoing premium transit (such as light rail, commuter rail, bus rapid transit, streetcar) capital projects in the Tampa to Orlando FHSR corridor. Some projects have direct connectivity to HSR stations planned, while others do not directly serve stations, but greatly increase the capacity, speed, and connectivity of local transit networks. These projects represent the first implementation or extension of a particular transit mode type in an area that will have close proximity to HSR.

\section{Tampa - Streetcar Extension}

The Tampa TECO Electric Streetcar line Whiting Street Extension is a project that extends the only supporting systems' fixed guideway rail line. The extension will bring the streetcar service to the southern edge of the Tampa CBD and increase resident, employee, and visitor traffic from the downtown into the entertainment districts at Channelside and Ybor City. While future long-range plans bring the Streetcar into a circulation pattern extending it north near the HSR station location, a downtown rubber-wheeled trolley circulator is currently the highest quality connecting service between the future Intermodal area and the Streetcar Line. It is projected to open in December 2010/January 2011. 


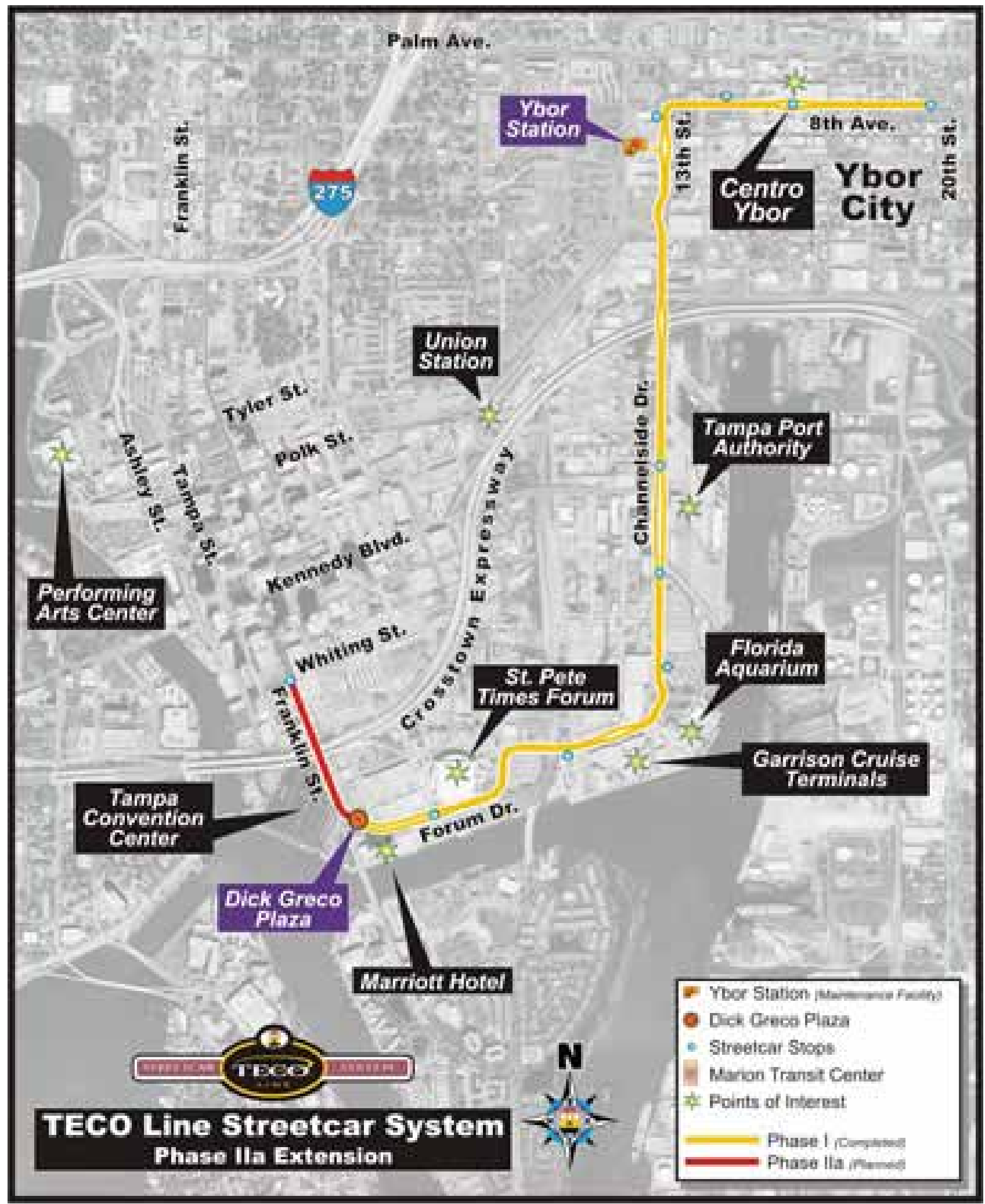

Map 4-4: TECO Line Streetcar System - Source: www.tecolinestreetcar.org 


\section{Tampa - HART Northwest and West Corridors AA}

A 2002 Tampa rail study has been updated and turned into a current Alternatives Analysis for submission to the federal New Starts process. Locally preferred alternatives have been reduced to two alignments. Both of the two lines originate at the future Tampa Intermodal Center and extend either to the Tampa International Airport into northwest Hillsborough County or north on Bruce B. Downs Boulevard, serving Tampa Palms and New Tampa. Preferred technologies have been identified as either Light Rail or Bus Rapid Transit. The analysis should conclude in 2011, assuming no local funding at this time. With local funding availability, the line was projected to open in 2018. However, a local referendum for a sales tax increase to fund the project's local match requirement was not realized and efforts are being made to identify potential alternative local financing sources. 


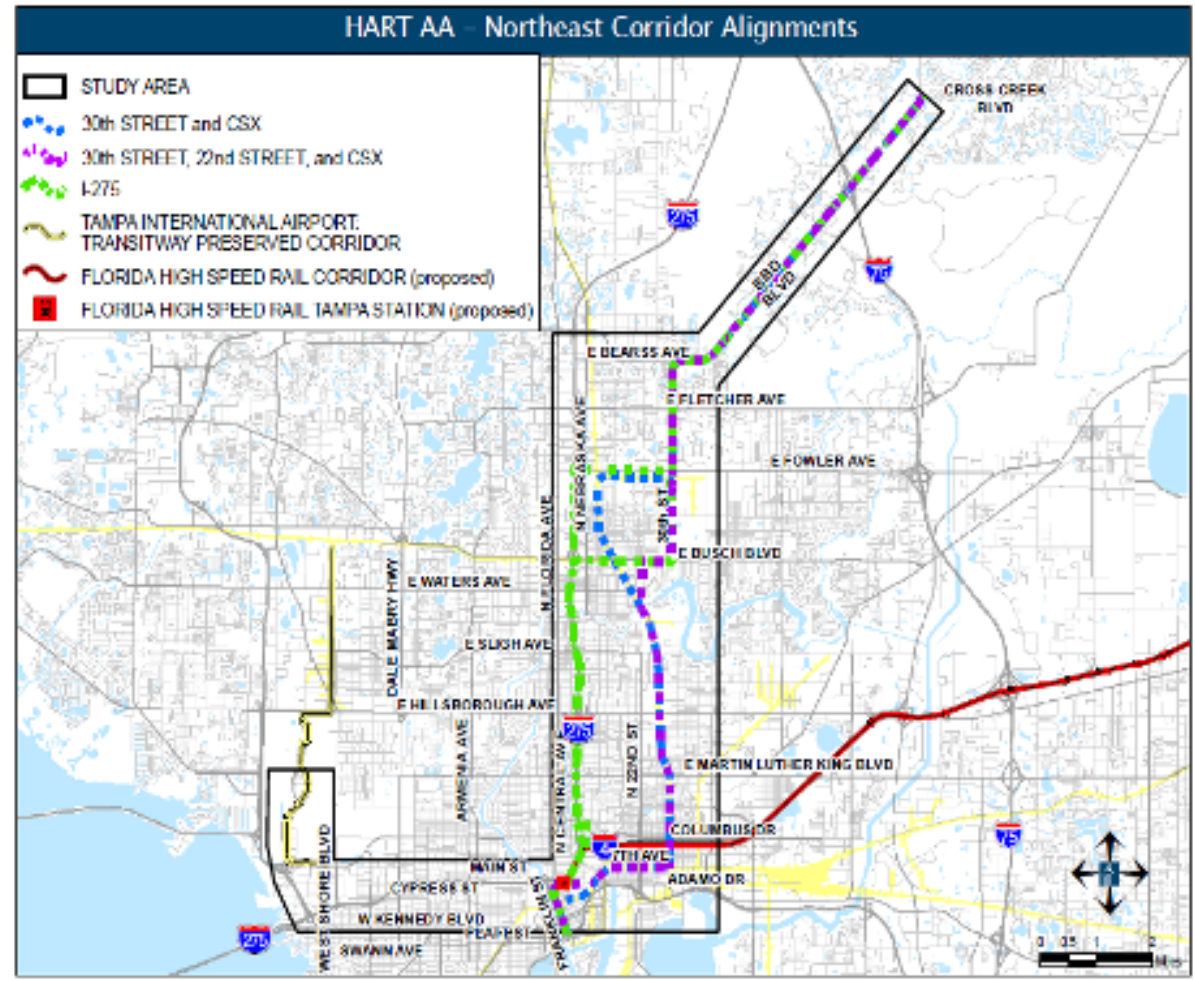

Map 4-5: HART AA - Northeast Corridor Alignment-Source: www.gohartaa.org

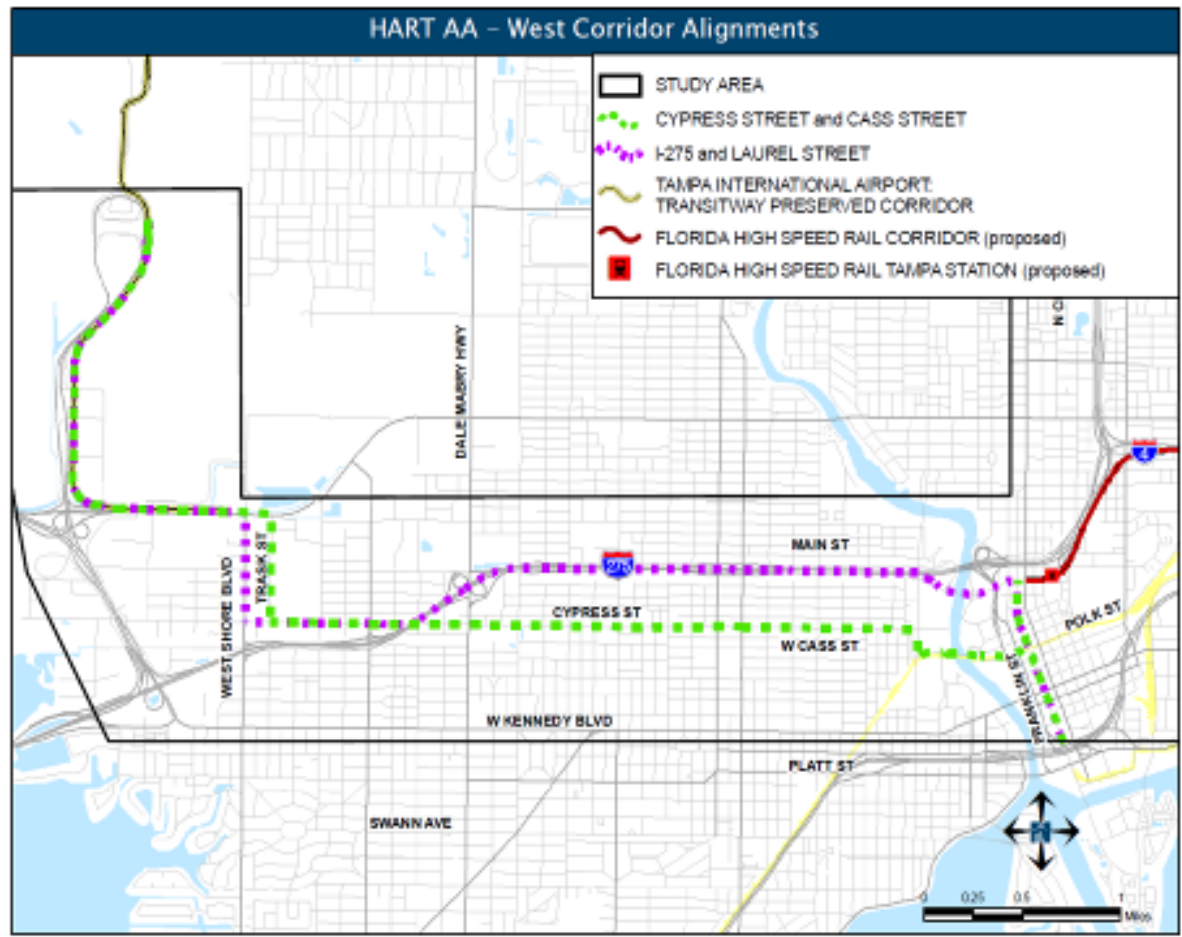

Map 4-6: HART AA - West Corridor Alignments - Source: www.gohartaa.org 


\section{Pinellas County - Alternatives Analysis}

As described on Pinellasontrack.com, the purpose of this Alternatives Analysis is to study implementing fixed-guideway transit service connecting major residential, employment, and activity centers in Pinellas County to Hillsborough County and future HSR services. TBARTA and FDOT in partnership with the Pinellas MPO and PSTA, are conducting an Alternatives Analysis to look at premium transit options connecting the major activity centers in Pinellas County-Clearwater, Gateway area, and St. Petersburg (Pinellas MPO, 2009). Connections to Hillsborough County will also be examined. The study will evaluate feasible alternatives and identify a preferred alternative consistent with the TBARTA Master Plan (TBARTA, 2009). The study will follow the Federal Transit Administration's New Starts Guidelines for Alternatives Analyses.

A fixed-guideway transit connection to HSR from Pinellas County would provide high-speed, high-capacity entry to the PSTA transit network serving St Petersburg, Clearwater, and other municipalities as well as the many commercial, cultural, and visitor attractions in the area. An Express Bus concept network, proposed BRT lines, and the local bus route system will all be accessible from the Tampa HSR station via this connection (Tindale-Oliver Associates, 2010). 


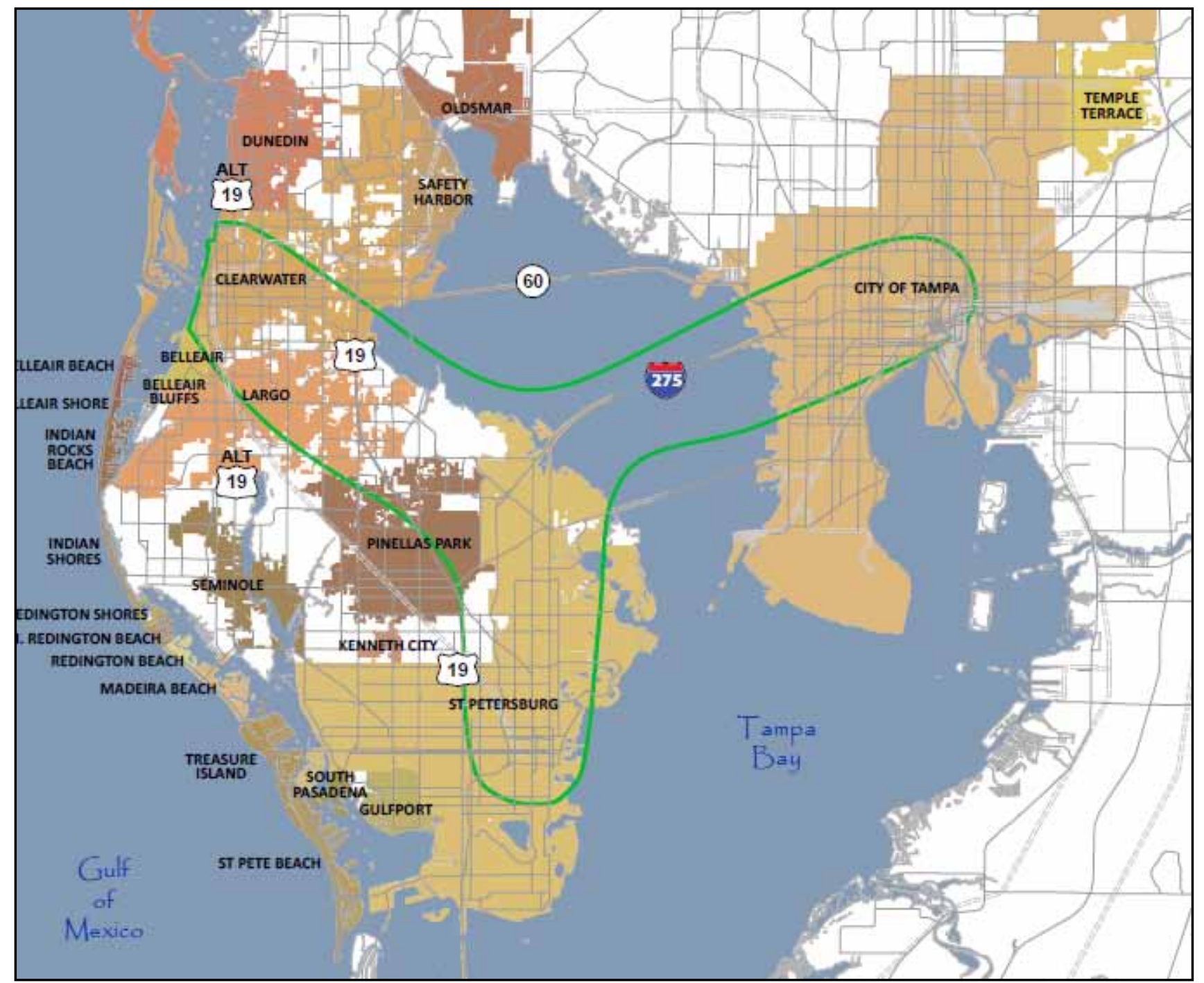

Map 4-7: Pinellas County Alternatives Analysis - Source: www.pinellasontrack.com 


\section{Metro Orlando - 'SunRail’ Commuter Rail System}

SunRail is a 61-mile Commuter Rail line designed to run north and south through cities that make up the greater Orlando area. The first phase of the line, from Debary in the north and Sand Lake Road to the south, will go into construction in 2011 and operation in 2013. A second phase is proposed on the southern end of the corridor, extending from Sand Lake to Poinciana in Osceola County. A 12-mile northern extension from DeBary to the DeLand Amtrak station completes the entire corridor and could be constructed by as early as 2015 . The first phase's 12 stations would be served with 30-minute peak frequencies in each direction, two-hour off peak service in each direction, with trains operated at an average speed of 45 miles per hour. The peak hour span of service is expected to be between 5:30am to 8:30am in the morning and 3:30pm to 6:30pm in the evening (FDOT, 2010).

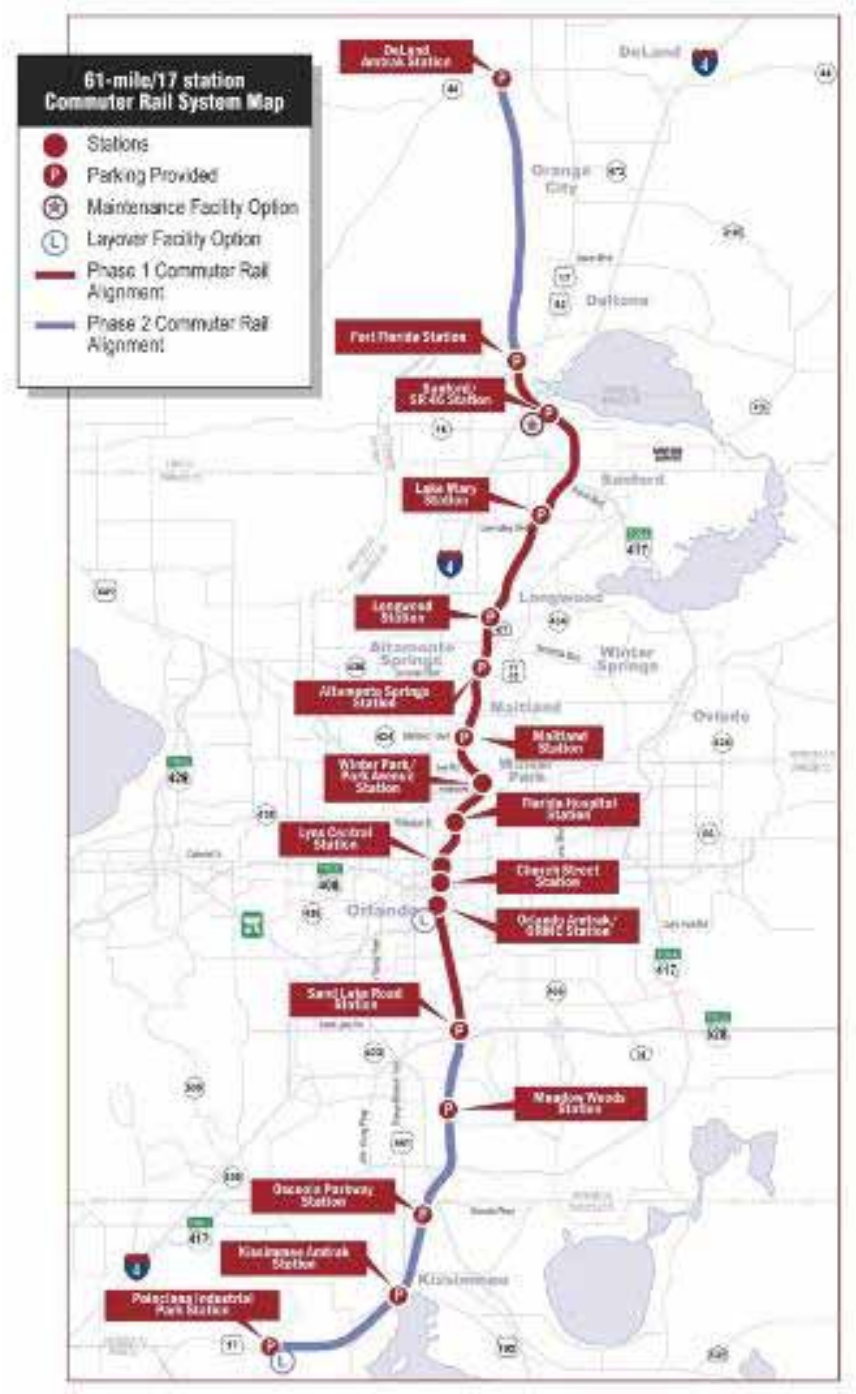

Map: 4-8: 61-mile/17 Station Commuter Rail System Map Source: www.cfnews13.com 


\section{Tampa - North-South and East-West Bus Rapid Transit (BRT)}

There are two BRT lines in development by HART. The first to go into service, a north-south line operating in Tampa on Fletcher Avenue and Nebraska Avenue, will consist of approximately 30 stations, spaced approximately a half-mile apart. It is expected to operate at a 10-minute peakhour frequency and utilize a limited amount of Transit Signal Priority in mixed traffic to maintain low travel times. The North/South line will originate at the future HSR station location. This line will go into operation in 2012/2013. The second BRT line in development is the east-west route, connecting East Tampa to the Tampa International Airport. It would operate with similar frequencies and stop spacing as the north-south line and connect to it by sharing a segment of Nebraska Avenue, allowing access to the future HSR station. The time for implementation of the east-west BRT line is 2015. 


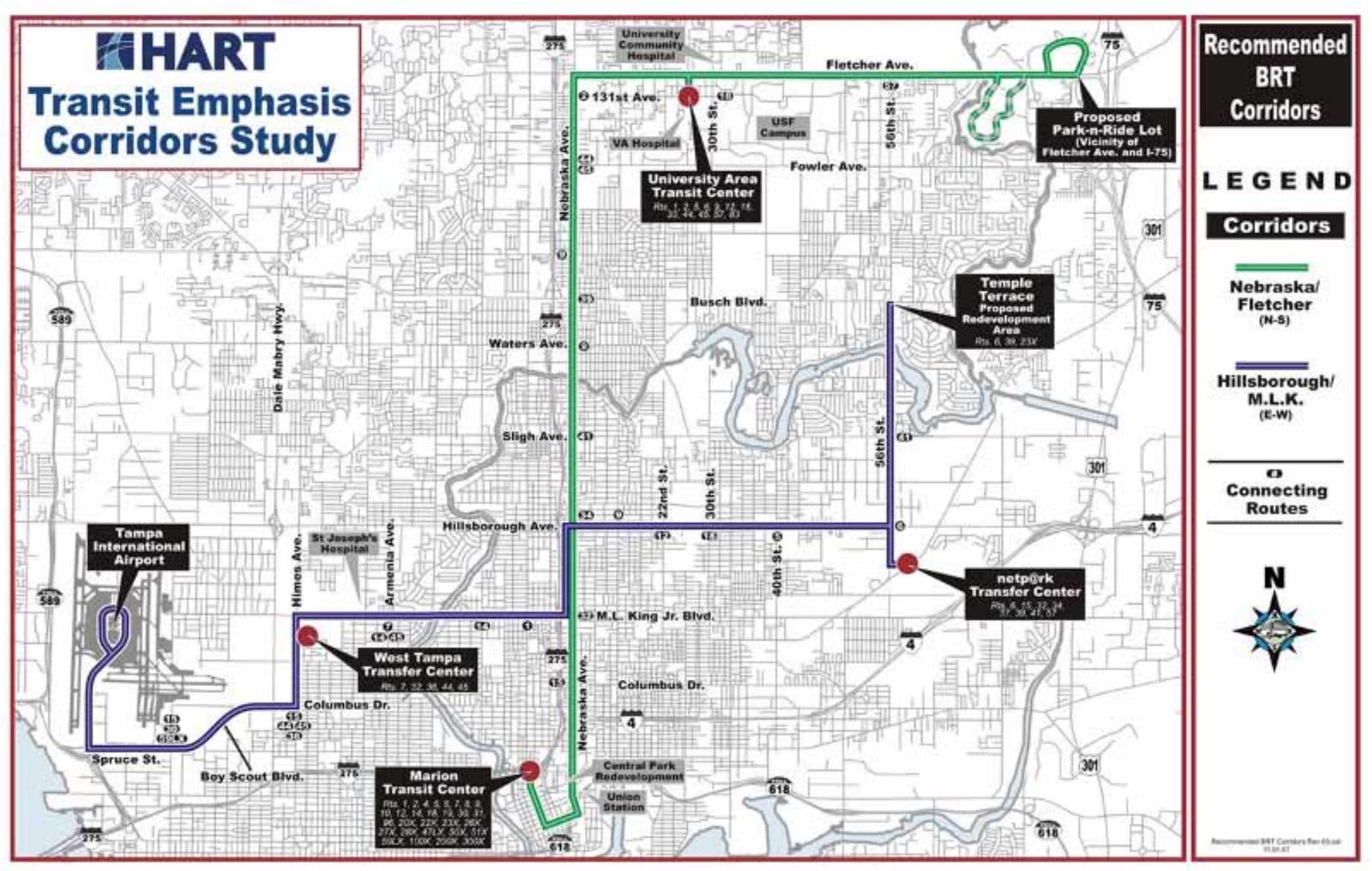

Map 4-9: HART Transit Emphasis Corridors Study - Source: www.gohart.org 


\section{Orlando - Lymmo BRT Expansion}

LYNX is currently studying an expansion of its downtown circulator BRT service, LYMMO. The existing LYMMO route is being considered to extend to areas to the north, center, and south of its present service area. One proposed alignment operates to the north and serves Florida Hospital, with another to the west serving Creative Village, the courthouse, and events center. An alternative mode of Streetcar is also being evaluated in the study. LYMMO currently operates using real-time information, dedicated bus lanes, and transit-only traffic signals. 


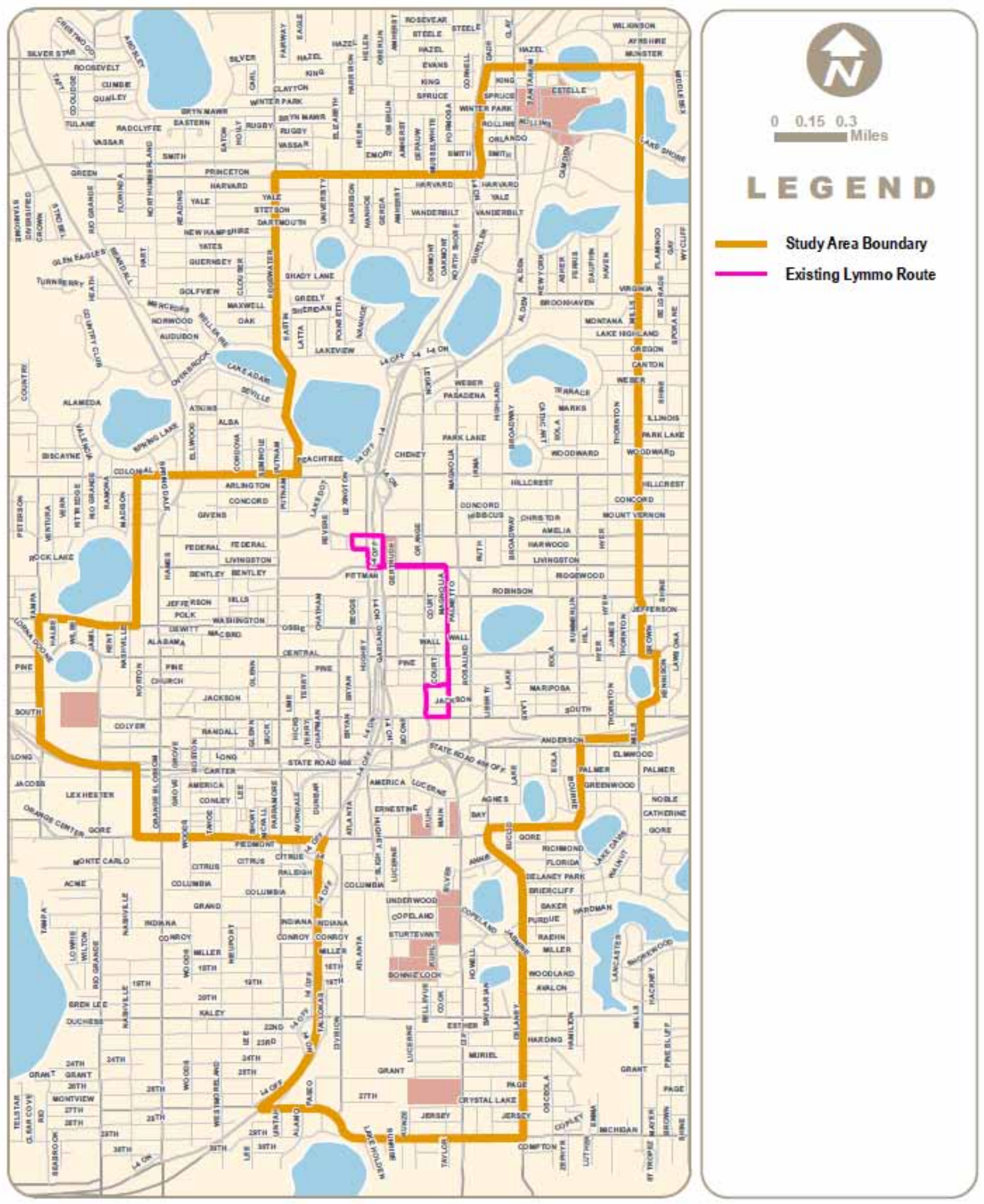

Map 4-10: Lymmo Expansion Study Area - Source: www.lymmostudy.com 


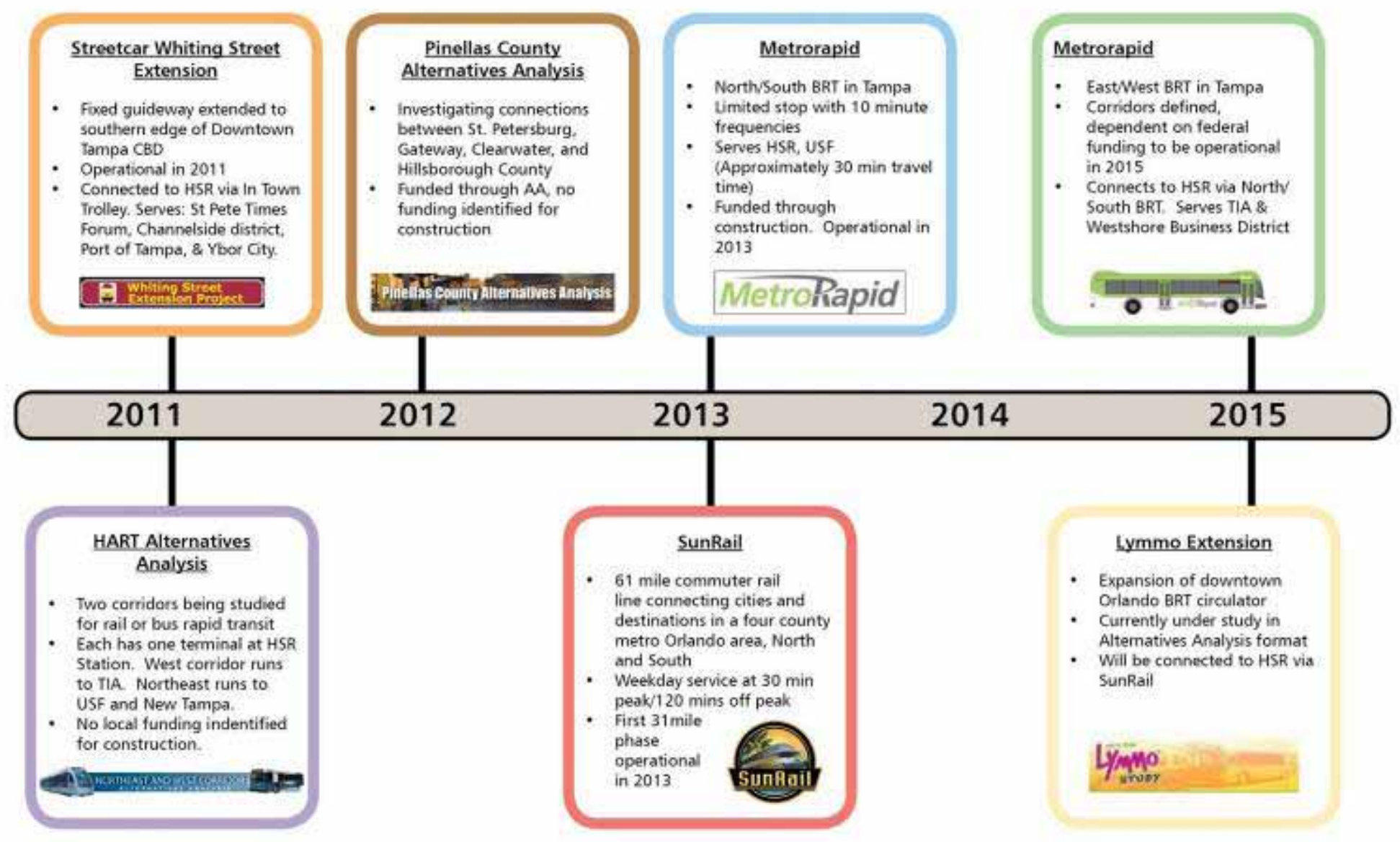

Figure 4-1 - Timeline of Various Premium Capital Projects 


\section{CHAPTER 5 \\ YEAR 2015 PUBLIC TRANSPORTATION SYSTEMS LEVEL OF SERVICE}

\section{YEAR 2015 PUBLIC TRANSPORTATION SYSTEMS LEVEL OF SERVICE}

This chapter is provided to understand the local transit agencies' priorities for service changes within the 2011 to 2015 timeline. The timeline has been developed from several sources including:

- Agency interviews in which philosophies about service planning were communicated

- One to two year short-range plans, which in the case of two of the three major service providers in the area were considering new revenues from November 2, 2010 funding referendums

- Ten-Year Transit Development Plans (TDPs), that project service needs and potential revenues over a mid-term horizon

The information for each transit property will include:

1) An agency's overall conceptual plans to change service within the next five years

2) If available, any cost constrained improvements will be described that were developed with an associated funding mechanism in place to support them

3) A cost unconstrained level of service, also called a Needs Plan

The value of this information lies in the ability to identify where efforts are focused at the local public transportation agency level and consider how these changes would affect service to HSR trip connections. Gaps in expected service levels can be explored with potential opportunities to improve HSR connecting lines and trips.

\section{Hillsborough Area Regional Transit Authority (HART)}

HART provides a mix of bus services to its Hillsborough County service area. HART is also the operator of the fixed guideway, 2.4 mile TECO electric streetcar line which connects the fringe of the downtown business district with the Tampa cruise port and other recreationally-based attractions (Hillsborough Area Regional Transit Authority, 2010). In November 2010, HART sought a new source of dedicated funding from a sales tax increase that failed at referendum. This process did, however, spur detailed discussion on what service changes would be made given a large increase in funding and the expectations for improvements that would accompany it. 
The planning efforts associated with the referendum envisioned sufficient revenue generation to pursue a New Starts federal application for funds to build a premium transit service that would be in service no sooner than 2018. It also involved what was termed a doubling of the bus system' which would happen in a much more rapid fashion, with a number of new and improved lines operating by 2015. Now, absent a funding mechanism to bring forward the service improvements, these changes constitute what will be the Needs Plan for HART.

HART's operating funding is largely dependent on ad valorem property tax revenues. In recent years, decreases in property values have continually put pressure on the agency to carefully assess performance and attempt to preserve service levels with less revenue. Without a new funding source, HART will make service changes over the next several years with several principles in mind.

For the next 2 years, the operating funding environment has been projected to be at best, flat after several years of revenue reductions. If this projection holds true, HART expects to be able to preserve current service levels through Year 2012. A primary goal for the agency is to protect core services, which are comprised of the top 15 performing bus routes in the system. During Year 2011, HART will consider eliminating certain express bus route trips or entire lines of service. This idea particularly holds true for express routes where a current local multi-stop route exists to service the same area. Late-night service, which over recent years was increased, will be scaled back as revenues dictate. The recent introduction of flex-route service in the Sun City area in South Hillsborough County and Brandon mark a shift in the agency service delivery strategy away from connector routes. Connector routes could be eliminated in favor of additional new flex service in communities such as Temple Terrace, Carrollwood, and Town ' $N$ ' Country where residential areas are not well served by local routes. The emphasis in service development for the system is to straighten out the local routes by keeping them out of residential neighborhoods and using the flex services as main line haul feeders.

2013 will mark the introduction of a new Bus Rapid Transit (BRT) service connecting the downtown and HSR station along the Nebraska Avenue and Fletcher Avenue corridors to the University of South Florida, as well as communities, businesses, and Telecom Park near Interstate 75. This service will overlay the high performing Route 2 with new limited stop, increased amenity, mixed traffic operating bus service.

The Needs Plan by Year 2015 includes a robust mix of new expresses, frequency improvements, weekend services, and flex zones. In a cost-unconstrained scenario, the following needs are identified:

Year 2011

- $\quad$ Bring 10 routes up to 30-minute frequencies or higher on weekends

- Move routes $7 \& 32$ to 30 -minute frequencies at all times

- Institute new weekend service on 6 routes, with 5 new flex routes in residential communities

- $\quad$ Expand express routes 20 and 27 
Year 2012

- 4 new express bus lines (1 direct HSR serving route from MacDill Air Force Base)

- 3 new local bus routes in western Hillsborough County (non-HSR serving)

- Service improvements to some HSR serving routes including 15-minute frequencies and additional weekend service

Year 2013

- $\quad$ MetroRapid HSR Serving BRT service (funded)

Year 2014

- One new non-HSR serving local route in North County

- New flex service in the airport area

- Frequency improvements and weekend service on 4 local routes

- Expansion of two HSR serving express lines, 50 and 59

Year 2015

- Weekend service improvements on 7 local routes

- One new Plant City to HSR express route

- Four new flex routes

- Expansion of two existing express routes, 23 and 28

Lakeland Area Mass Transit District (LAMTD), Winter Haven Area Transit (WHAT), and Polk County Transit Services (PCTS)

There are three public transit service providers in Polk County. Efforts have been ongoing to unite the three services under a single governing body. The Polk Transit Authority (PTA) would plan and operate all transit services for Polk County. The predominant reasons for doing this include better integrating services for a seamless public transit operation for the county as well as leveraging additional funding.

An unsuccessful November 2010 sales tax referendum, which would have created a new dedicated revenue stream from additional sales tax proceeds in lieu of a property tax levy, has left questions regarding what amount of public transportation will be present going into the future. Declining property tax revenues had led to a proposed service reduction, which would significantly lessen the amount of public transportation service present in the county. There is a concern over this issue being compounded with the release of the new Census data in the coming year that is expected to show urbanization in Polk County that will lead to the inability to use a portion of federal funding for operating expenses. The combined impact of declining ad valorem revenues and loss of ability to use existing federal funds for operating purposes has local officials planning for service cuts. 
Given the few routes that pass by the potential Kathleen Road station location and absence of service at the Williams DRI site, those cuts would be most likely impact non-HSR direct serving lines. Due to the substantial impact HSR is expected to bring to the county transportation system, plans are in place to redirect some service to either of the two locations HSR may be constructed. The Williams DRI site, Alternative \#1 from the TPO, had originally been proposed to receive 2 to 3 new transit routes directly connecting it to the City of Lakeland, Winter Haven, and the future Legoland Theme Park. Given the financially restrictive environment that currently faces the service providers, at this time one route is being proposed to serve the station. The alignment for 'Future USF Polytechnic Service' connects with Route 52 at the Plantation Square Shopping Center in Lakeland at one end of the line and Routes 12 and 50 at Neptune Road on the southern end. The Kathleen Road station could be fed by deviations on up to three existing routes, all of which connect into Lakeland's downtown central terminal.

In an unconstrained environment, the PTA would connect eastern Polk County locations to the WDW HSR station. A five year updated Needs Plan for the PTA consists of service restoration and frequency and span improvements, as well as seven new bus routes.

Year 2011

- Weekday and Saturday frequency improvement of two non-HSR serving routes to 30 minutes

- Weekday and Saturday span of service improvements from 5:00am to 10:00pm on weekdays and 7:00am to 9:00pm on weekends on 12 routes, including 3 Kathleen Road Station serving routes

- Restoration of previously cut service

Year 2012

- New flex -routing services in the county to feed the main line network

Year 2013

- 30-minute peak-service frequency on Routes 11, 12, 20, 22xl (express), 22xw (express), and 41.

- 60-minute all-day weekday service on Routes 40 and 44.

- 5:00am to 10:00pm weekday and 7:00am to 9:00pm Saturday span of service on 13 existing routes, all non-direct HSR serving

- Two new non-direct HSR serving routes. One would be on the Highway 27 corridor, while the other would connect Lake Wales, Lake Hamilton, and Haines City. 
Year 2014

- New Lakeland to Tampa connecting bus route

- New shuttle service between Polk State College and the University of South Florida campus at HSR station alternative \#1

- New service in Lake Miriam to Bartow

- A new route connecting USF at the Williams site to Auburndale

- A new Lakeland/Polk City/Auburndale bus route

- Modifications to Routes 32 and 54

\section{Central Florida Regional Transit Authority (LYNX)}

LYNX is the primary provider of public transportation services to a four-county metro-Orlando region. Beginning in 2008, a major restructuring of LYNX's fixed-route bus services was undertaken in response to a reduction in funding. This effort also allowed the agency to take a comprehensive look at strategic goals going forward and ensure the service redesign was going to meet the needs of the rider population into the future (Central Florida Regional Transportation Authority, 2010).

A Five-Year Service Plan was created with a primary goal of planning the development of premium transit, BRT, and other supporting services in a financially constrained environment. This redesign first required new service classifications as follows.

- Premium Service - Limited stop on major roadways, 15-minute headways

- Local Fixed-Route Service - Feeds into premium service routes on secondary roadways

- Flex-Route Service - Instituted in 2007. Zonal, neighborhood based feeder routes

- Deviated Fixed Routes - 3/4 mile deviations off fixed-route services

- Park-and-Ride Express Routes - Commuter service from parking lots to major employer sites

- Demand Response - Door-to-door service for the transportation disadvantaged

Primary corridors were identified to evaluate what is considered the functional core of the LYNX transit network. Those primary roadways host 17 routes that consume $50 \%$ of LYNX's operating budget. The corridors are:

- $\quad$ SR 436/Semoran Blvd

- US 17-92 from Lake Mary to Downtown Orlando

- US 441 from Apopka to Kissimmee

- SR 50 from Ocoee to Alafaya Trail

- Silver Star Road from Clark Road to US 441

- Hiawassee \& Kirkman Roads from Silver Star Road to International Drive

- US 192 from Lake County to Kissimmee

- $\quad$ I-4 and SR 528 from Disney to Orlando International Airport 
An enhanced system was then proposed for the horizon year of 2014, within current budgetary allowances and in light of the new strategic approach toward providing transit service. The enhanced system is a short-term, five-year goal for LYNX.

The characteristics of this new service plan are:

- Headways along the 14 Primary Corridors at a maximum of 15 minutes

- Access to proposed SunRail commuter stations

- Service to new regional developments (i.e. Lake Nona)

- Identification of candidate BRT corridors

- Identification of feeder services/corridors

BRT corridors identified for implementations are:

- $\quad$ SR 50 from Oakland to Alafaya Trail

- SR 436 from Apopka to Orlando International Airport (HSR-serving route)

- US 192 from US 27/Clermont to St Cloud

This significant restructuring of the LYNX service network should complement the coming HSR and Commuter Rail systems with a tiered supportive bus network. The stratifications proposed are high-level classifications that will be achieved through the annual revisions of service. Beginning in the implementation program for Fiscal Year 2011 are the following changes (Central Florida Regional Transportation Authority, 2010):

- Restructure Link 30 into two routes (due to length) and serve the LYNX Central Station

- Restructure Links 28 and 29 to serve as feeder routes to Link 30

- Restructure Links 48 and 49 to serve as feeder routes to Link 30

- Add new PickUp line service in Pine Hills \& St. Cloud

- Replace Link 405 (Apopka) with Pickupline service

- Implement service efficiencies on various routes to address running time concerns through interlining \& reducing excessive non-revenue service hours

- Add Sunday service on Link 10

- Improve existing Link 55 - West U.S. Highway 192 - Four Corners - add late evening service Monday through Saturday

- Add Saturday service on PickUp Line 621

In a financially unconstrained scenario, the LYNX 2009-2018 TDP describes the following changes in a Needs Plan.

Fiscal Year 2010

- Modify existing Link 21 to end at Universal Studios-Orlando

- Modify existing Link 8 to end at Prime Outlets

- Modify existing Link 42 to end at Prime Outlets

- Modify existing Link 43 to operate between the Florida Mall and Canadian 
- Court Transit Centers only (western leg served by new Link 439)

- Modify Link 111 - OIA - Canadian Court - Disney-Improve headways during all service periods, 7 days a week.

- Modify Link 103 - Improve headways during peak periods

- Add new International Drive Circulator Link - assumes eliminated portions of existing Links 8 \& 42

- $\quad$ Add new Link 439 - Turkey Lake Road - serves western portion of existing Link 43

- $\quad$ Add new Link 317 - South International Drive - serves portion of existing Link 42

- Eliminate existing Link 30 - Colonial Drive crosstown - replaced with Links 104 \& 105

- Add new Link 104 - West Colonial Drive

- Add new Link 105 - East Colonial Drive

- Eliminate existing Link 48 - West Colonial Drive/Park Promenade Plaza replace with new Link 403

- $\quad$ Add new Link 403 - Pine Hills/Balboa Drive

- Eliminate existing Link 49 - West Colonial Drive/Pine Hills Road - replace with new Links 110 \& 404

- Add new Link 110 - Pine Hills/Kirkman Road

- Add new Link 404 - Pine Hills/North Lane

- Eliminate existing Link 54 - Old Winter Garden Road - replace with new Link 308

- Add new Link 308 - Old Winter Garden Road

- Eliminate existing Link 37 - Park Promenade Plaza/Florida Mall - replace with new Links 110, 337 \& 438

- Add new Link 337 - South Hiawassee Road

- Add new Link 438 - Millennium /Prime Outlets/Florida Mall

- Eliminate existing Link 28 - East Colonial Drive/Azalea Park - replace with new Links 100, 105 \& 333

- Add new Link 333 - Southeast Orlando Connector

- Eliminate existing Link 29 - East Colonial Dr/Goldenrod - replace with new Links 100 \& 303

- $\quad$ Add new Link 303 - Goldenrod Road

- Eliminate existing Link 20 - Malibu/Pine Hills - replace with new Link 311

- Add new Link 311 - Silver Star Road/Universal Studios - Orlando

- Eliminate existing Link 24 - Millenia

- Modify existing Link 47 - Oveido - eliminate large end-of-the-line loop

- Add midday service on Link 200 - UCF/Waterford Lakes Express

- Add Link 18L - Osceola Limited Express 
Fiscal Year 2011

- Eliminate existing Link 34 - replace with new Links 419 \& 420

- $\quad$ Add new Link 419 - Sanford East - replaces portions of former Link 33

- Add new Link 420 - Sanford West

- Eliminate existing Link 45 - replace with new Link 322

- Add new Link 322 - Lake Mary Boulevard

- Add new Link 321 - Ronald Reagan Boulevard

- Eliminate existing Link 200 - Interstate 4/Volusia Express/Downtown Orlando

Fiscal Year 2012

- Eliminate existing Link 17 - North U.S. Highway 441/Apopka - replace with new Link 106

- Add new Link 106 - U.S Highway 441 North

- Eliminate existing Link 44 - Clarcona/Zellwood - replace with new Links 309 \& 406

- Add new Link 309 - North Hiawassee Road

- Add new Link 406 - Apopka/Plymouth/Zellwood

- Eliminate existing Link 39 - replace with new Links 102 \& 103 providing improved headways and service hours

- Eliminate existing Link 46 - replace with new Link 103 providing improved headways and service hours

- Eliminate existing Link 4 - South U.S. Highway 441/Kissimmee - replace with new

- Links 107 \& 108

- $\quad$ Add new Link 107 - U.S. Highway 441 South

- $\quad$ Add new Link 108 - U.S. Highway 441 - Osceola

- Modify existing Link 26 - Poinciana to serve downtown Kissimmee - portion not service by the new Link 108

- Eliminate existing Link 300 - Downtown Orlando/Hotel Plaza Boulevard - replace with new Link 3D-1

- Eliminate existing Link 301 - Pine Hill/Animal Kingdom - replace with new Link 3D-2

- Eliminate existing Link 302 - Rosemont/Magic Kingdom - replace with new Link 3D-3

- Eliminate existing Link 303 - Washington Shores/Disney-MGM Studios - replace with new Link 3D-4

- Eliminate existing Link 304 - Rio Grande/Vistana Resort - replace with new Link 3D-5

- Eliminate existing Link 305 - Metro West/All Star Resort - replace with new Link 3D-9

- Add new Link 3D-1 - Hotel Plaza Boulevard

- Add new Link 3D-2 - Animal Kingdom

- Add new Link 3D-3 - Magic Kingdom

- Add new Link 3D-4 - EPCOT/Pop Century Resort

- Add new Link 3D-5 - Vistana Resort

- Add new Link 3D-6 - EPCOT/Pop Century

- Add new Link 3D-7 - Caribe Royale 
- $\quad$ Add new Link 3D-8 - Gaylord Palms

- Add new Link 3D-9 - All Star Resorts

- Add new Link 265 - Washington Shores/Disney

- Add new Link 244 - Washington Shores/Canadian Court

- Improve Link 418 - Baldwin Park - add evening service Monday through Saturday

- Improve Link 403 - Pine Hills/Balboa Drive - improve weekday and Saturday evening headways and add Sunday late evening service

- Improve Link 404 - Pine Hills/North Lane - improve weekday and Saturday evening headways and add Sunday late evening service

- Improve Link 405 - Apopka/Park Avenue - improve weekday peak and midday headways, Saturday midday headways, and add late evening service on weekdays

- Improve Link 337 - South Hiawassee Road - improve weekday peak and midday headways and Saturday midday headways

- Improve Link 303 - Goldenrod Road - improve weekday peak and midday headways

Fiscal Year 2013

- Modify existing Link 18 - South Orange Avenue/Kissimmee - operate via Michigan Avenue/VCC/Osceola Square Mall

- Eliminate existing Link 12 - Buenaventura Lakes/Boggy Creek Road

- Add new Link 428 - East Osceola Parkway/Boggy Creek Road

- Add new Link 429 - Mill Run/Buenaventura Lakes

- Add new Link 415 - UCF/Avalon

- Improve existing Link 10 - East U.S Highway 192/St.Cloud - improve weekday and Saturday headways, and add Sunday service

- Improve existing Link 55 - West U.S. Highway 192 - Four Corners - add late evening service Monday through Saturday

- Improve existing Link 56 - West U.S. Highway 192/Magic Kingdom - add late evening service 7 days a week

- Eliminate existing Link 38 - Downtown Orlando/International Drive - replace with new Link 245

- Add new Link 245 - Orlando CBD/Canadian Court Transit Center

- Improve Link 50 - Downtown Orlando/Magic Kingdom - add late evening service 7 days a week

- Add new Link 223 - Downtown Orlando/OIA

- Add new Link 281 - Sanford Seminole Towne Center/Oveido Marketplace/UCF

- Improve Link 204 - Clermont Express Lake County Park and Ride/Downtown Orlando - add midday service

- Improve Link 336 - Lakemont - improve weekday peak and midday service Headways 
Fiscal Year 2014

- Eliminate existing Link 10 - east U.S. Highway 192/St. Cloud - replace with new Link 334, 433, and 434

- Add new Link 334 - St. Cloud/Kissimmee

- Add new Link 433 - St. Cloud/South

- $\quad$ Add new Link 434 - St. Cloud/East

- Eliminate existing Link 55 - West U.S. Highway 192/Four Corners - replace with new Link 112

- $\quad$ Add new Link 112 - U.S. Highway 192

- Eliminate existing Link 56 - West U.S. Highway 192/Magic Kingdom - replace with new Link 312

- Add new Link 312 - Kissimmee/Disney

- Eliminate existing Link 26 - Pleasant Hill Road/Poinciana - replace with new Link 335

- $\quad$ Add new Link 335 - Poinciana

- Improve Link 108 - U.S. Highway 441/Osceola - improve weekday peak and midday service headways - add late evening service 7 days a week

- $\quad$ Add new Link 432 - Kissimmee Circulator

- Improve Link 428 - East Osceola Parkway/Boggy Creek Road - improve weekday peak and midday headways - add new service on weekday late evening Saturday evening and late evening and Sunday evening

- Modify existing Link 57 - John Young Parkway to operate to the Downtown Kissimmee Commuter Rail Station

- Modify existing Link 18 - South Orange Avenue/Kissimmee to operate to the Downtown Kissimmee Commuter Rail Station

- Add new Link 261 - Osceola Parkway/Commuter Rail Station/Disney

- Improve Link 107 - U.S. Highway 441 South - improve weekday peak period headways and Sunday evening service

- Add new Link 316 - Palm Parkway

- Improve Link 245 - Orlando CBD/Canadian Court - add evening and late evening service 7 days a week

- Improve Link 300 - UCF - add Sunday late evening service

- Improve Link 309 - North Hiawassee Road - add Sunday midday and evening service

- Improve Link 311 - Silver Star Road/Universal Studios Orlando

The Lake Nona region in southeast Orange County is rapidly developing as a major site of employment, research, health care and recreation. Early in 2010, LYNX proposed a package of six fixed-route transit options to serve the area (Central Florida Regional Transportation Authority, 2010). The Lake Nona area enjoys a close location to the Orlando International Airport and associated HSR station. It is envisioned that this area will be a significant trip generator for HSR trips in the future and the selected transit service option should be developed 
appropriately to meet those emerging needs. Those service options under consideration include:

- One local service route from Orlando International Airport to Lake Nona via Narcoosee Road

- One commuter rail express option from the proposed Sand Lake SunRail station via OIA to Lake Nona

- Two downtown Orlando express service options with a total of 12 trips per day

- Two Kissimmee express bus options with a total of 12 trips per day

\section{PUBLIC TRANSPORTATION AND LONG-RANGE PLANS}

Beyond the 2015 line opening date, there is great potential for FHSR to have regional transportation benefit. Today's supporting transit networks have been conceived to be greatly expanded by transportation planning agencies into multi-county systems connected with commuter rail, light rail, BRT and other bus services to create an auto-independent environment for mobility. The transit networks envisioned will complement the Tampa to Orlando HSR corridor, as what has been termed a 'Super Region' in Central Florida develops with numerous transportation options (University of Pennsylvania, 2010). The built-out networks as planned for will require significant investment to realize, so it is difficult to precisely know when the phases of these supporting networks will be built, other than to understand which services are priorities to get constructed first as funding becomes available.

Long-range transportation and transit concept plans are in place or in the process of being updated for the regionally significant transit systems. The plans generally have a planning horizon of 20 years or greater. One positive aspect to these plans is that they have considered HSR as a future reality and in some cases included it in their outlooks. Short and mid range plans have not fully incorporated HSR considerations as the project has only had a funding source and project schedule since early 2009. Therefore, long range plans are more likely to have integrated HSR and incorporated supporting transit networks in connectivity plans.

\section{Metro Orlando Long Range Transit Plans}

\section{Commuter Rail}

While near term plans for the local transit system involve a restructuring of the existing network into a hierarchical set of bus systems of feeders and connecting services, long-term plans involve development of extensions of rail corridors and development of new transit modes. A northern and southern extension to the SunRail Commuter Rail corridor is envisioned. To the north, suburban communities north of DeBary up to Deland receive rail service through the SunRail line. A southern extension of SunRail achieves the planned 61.5-mile line build-out, extending the service south from the Sand Lake Station to Poinciana. SunRail extensions are planned to occur in the mid-to-long-range planning horizon. One scenario envisions a spur of the first phase of SunRail to connect with HSR at the Orlando International Airport. 


\section{Light Rail}

The blue line from the Orange County Convention Center (OCCC)HSR station area to Casselberry via downtown Orlando in Map 5-1 below is the preferred alignment for a future Light Rail line (Leftwich Consulting, 2009). The service would operate on Alden Road, beginning at the proposed OCCC Intermodal Center and would travel on Amelia Street to Orange Avenue to a redesigned Alden Road. It consists of up to 28 station alternatives that would connect pedestrians, bicycles and other transit facilities. The blue hatched area proceeding from the northern end of the line to Sanford is the evaluation area for an extension of the LRT line. The purple hatched area is a corridor for future southern LRT expansion. These additional LRT phases would extend the line into communities generally to the east of the SunRail line north and south.

Another proposed LRT line is the Orlando International Airport Connector that would be aligned east and west as illustrated by the central orange shaded area below (Leftwich Consulting, 2009). It has been designed to connect to the planned Central Florida North-South Light Rail Transit System (North-South LRT), the International Drive Resort Area and the Orlando International Airport. A preferred alignment for this service consists of extending from an eastern end at OIA, traveling west along N. Frontage Road to McCoy Road and then Sand Lake Road, where it could connect with SunRail. The alignment then would travel southwest and connect with the LRT at the western terminus at International Drive and the OCCC. This provides the best LRT and bus system alternative with potential for future growth and development. This line has not yet been included in the Metroplan Orlando Long-Range Transportation Plan.

\section{BRT and Circulators}

There are several candidate areas for premium bus transit services such as BRT and circulators. The downtown Orlando Lymmo BRT circulator system has a dashed line surrounding the areas considered for buildout of that successful system. Additional shaded areas below identify the following corridors for consideration of future services:

- South Orange/North Osceola Circulator - Bus or BRT

- UCF Circulator - Bus or BRT

- US 192 Circulator - Bus or BRT

- US 192 Circulator East Extension - Bus or BRT

- East-West Circulator - Bus or BRT

- Southwest Multi-Modal District - Bus or BRT

- I-Drive Circulator - Bus or BRT

- Osceola Parkway Corridor - Bus, BRT or LRT

- Narcoossee Corridor - Bus, BRT or LRT

- Seminole Way - Bus or BRT

- Altamonte Springs/Casselberry - Flex Services 

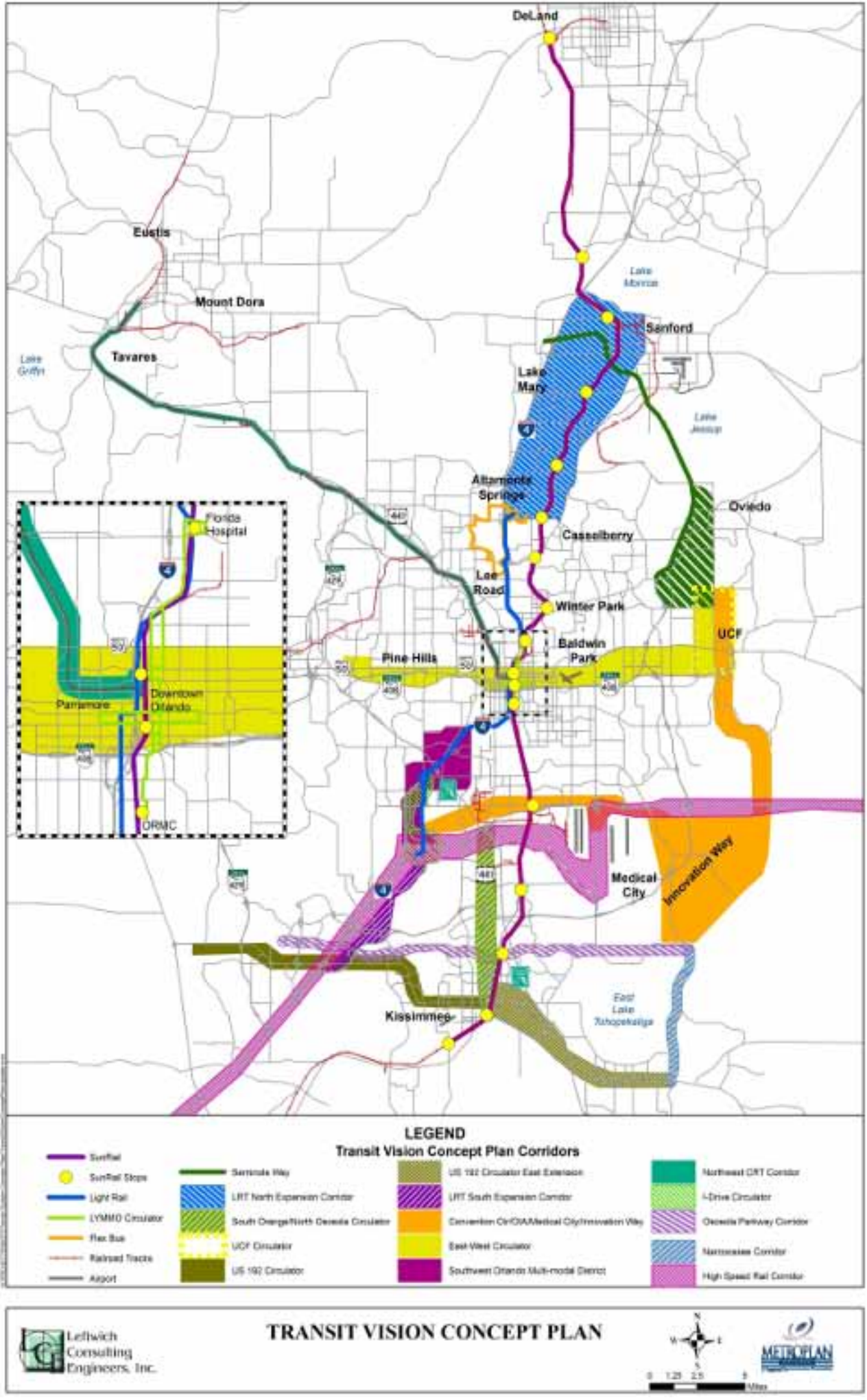

Map 5-1: Metro Orlando Transit Vision Concept Plan 2030 Source: Metroplan Orlando 


\section{Polk County Long Range Transit Plans}

The Polk County Transportation Planning Organization (TPO) is the lead transportation agency for Polk County. The TPO is currently leading an update to the local Mobility Vision Plan for the 2035 horizon year. It consists of a number of funded and unfunded bus routes and extensions as well as a commuter rail component that has been proposed but is unfunded. The funded bus routes consist of restoration of previously eliminated service, extensions to popular bus routes and new or expanded service into emerging population and employment centers.

Funded bus routes in the 2035 plan mirror many of the near and mid-range plans that are unfunded through those timeframes. The priority in Polk County is to build out the bus network and introduce higher capacity transit systems as demand warrants in the future. Public bus transportation connectivity to HSR is of significant importance here as there are no incremental premium services identified such as LRT. In addition, an unfunded commuter rail service is proposed to operate within the county.

Funded new bus routes and enhancements in the 2035 Mobility Plan that directly impact HSR service connectivity include (Polk County TPO, 2010):

- New Polk State College to University of South Florida Polytechnic shuttle

- New Lakeland Square to Kathleen via Kathleen Road bus route

- New Auburndale to University of South Florida Polytechnic route

- New Lakeland/Polk City/Auburndale route

- New Lakeland/Lakeland Square connection to High Speed Rail (at either of the two proposed station alternatives)

- Service restoration in Winter Haven that could potentially be extended to the Williams site station

Several new bus route needs were identified for the future system buildout in the 2035 plan.

- University of South Florida Polytechnic to Lakeland Square Mall

- University of South Florida Polytechnic to Winter Haven via Highway 540

- Lakeside Village to Lakeland Square via Harden and Florida

- Lakeside Village to University of South Florida Polytechnic

- Posner Park - SunRail Connector

- Tampa Bay Area Regional Transportation Authority Express I-4

- A new Bus Rapid Transit line from Lakeland Area Mass Transit Terminal to Lakeland Square Mall

- Lake Alfred/High Speed Rail Connection

- University of South Florida Polytechnic/High Speed Rail Connection

- Winter Haven/Auburndale/High Speed Rail Connection

Unfunded Commuter Rail needs identify potential for a service within existing rail right-of-way in the US 92 corridor and parallel to Polk Parkway. Any future commuter rail line would likely be an 
extension of either the Orlando or Tampa area service lines (Polk County MPO, 2009). Segments include:

- Osceola to Haines City

- Haines City to Auburndale

- Auburndale to Lakeland

- Lakeland to Hillsborough

- Auburndale to HSR Station 

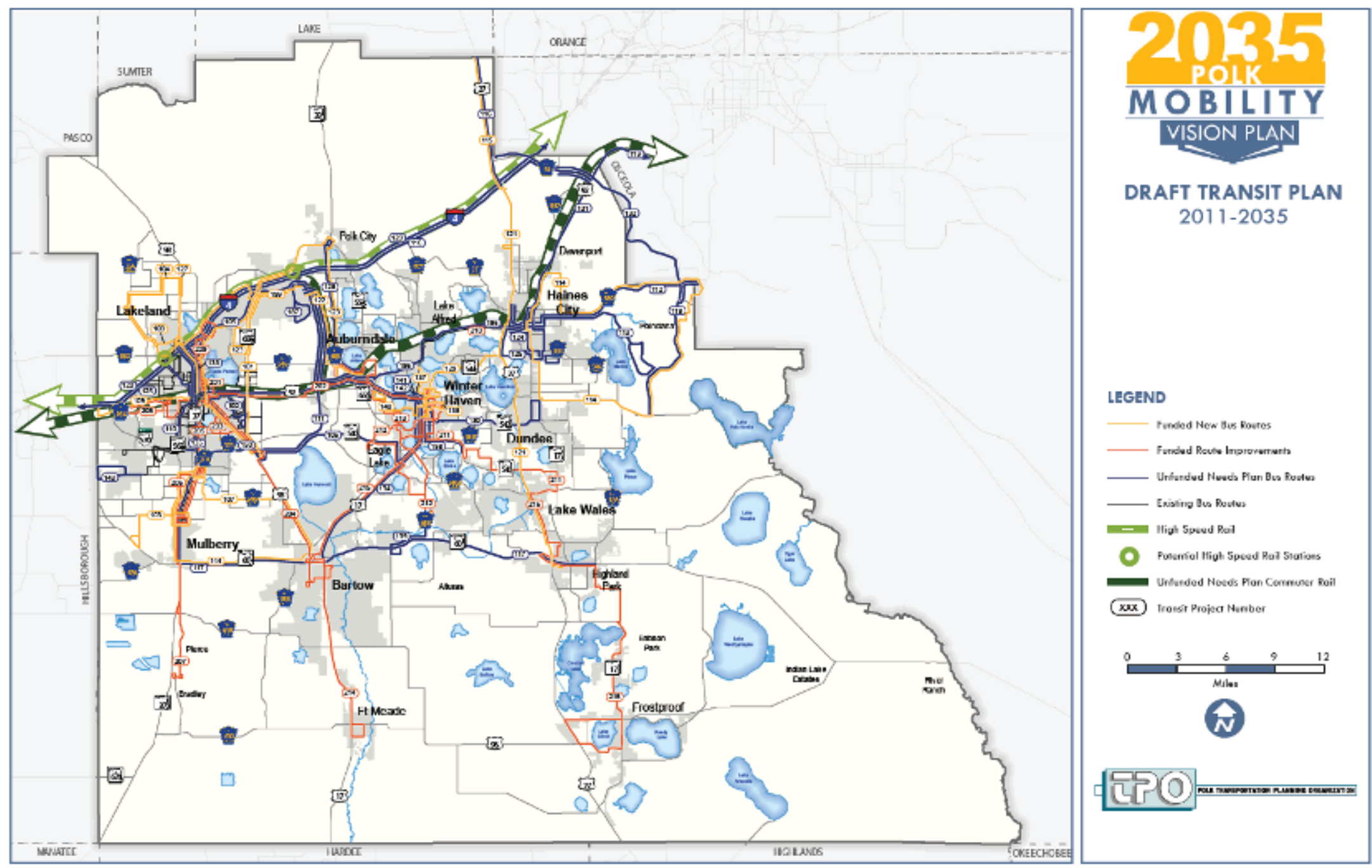

Map 5-2: Draft Polk County Transit Plan 2035 - Source: Polk County TPO 


\section{Tampa Bay Region Long Range Transit Plans}

The Tampa Bay Area Regional Transportation Authority (TBARTA) was created to develop and implement a Regional Transportation Master Plan for the seven-county West Central Florida region consisting of Citrus, Hernando, Hillsborough, Manatee, Pasco, Pinellas and Sarasota Counties. The TBARTA Master Plan focuses on providing guidance for transit solutions to serve all parts of the region. In 2009, local Metropolitan Planning Organizations (MPOs) adopted the TBARTA Master Plan into LRTPs with a 2035 horizon year (TBARTA, 2009).

The first priority phase of projects include several Tampa HSR station serving lines. In Map 5-3 below, two light blue lines identify alignments for Express Bus services to extend from neighboring counties, each with their own independent bus network. An express bus line from Wesley Chapel, a bedroom community of Tampa, would operate along Interstate 75 to downtown Tampa. This line could operate in future toll-managed HOV lanes or along highway shoulders through congested areas. The second express bus line would connect a planned Sarasota BRT line, through Bradenton to downtown Tampa. A southern extension to the City of Northport is also being evaluated by FDOT for feasibility.

Another premium transit corridor under evaluation is for a service to connect the University of South Florida to Wesley Chapel. The project is described as a "potential transit connection from Bruce B. Downs Boulevard north of Bearss Avenue near 37th Street (or northern terminus of the HART Alternatives Analysis) to the Wesley Chapel area in the vicinity of State Road 54." This corridor would link one of the two current preferred alignments that were considered for premium transit, each of which directly serves the HSR station in Tampa. The status of that project is likely being moved into a mid-to-long-range timeframe until local funding can be identified.

Other priority projects in the first phase of the TBARTA master plan include an Alternatives Analysis that would consider alignments connecting Tampa to Pinellas County with a premium transit option that operated across the Howard Frankland Bridge. The Tampa Westshore area is under evaluation for a transit connection from the HSR station in downtown Tampa to the Veterans Expressway at SR 60, continuing along the North Suncoast Parkway in Pasco County to end at US 98 in Citrus County.

Longer-range efforts include projects that would better integrate transportation in the region with an expansion of supporting rail and bus networks in an eight (8) county area. The Mid-Term Regional Network for the area would include (TBARTA, 2009):

- 116 miles of Short Distance Rail

- 12 miles of Bus Rapid Transit in Exclusive Lanes

- 42 miles of Bus Rapid Transit in Mixed Traffic

- 159 miles of Managed Lanes with Express Bus

- 226 miles of other Express Bus 
By 2050, the Long-Term Regional Network would contain (TBARTA, 2009).:

- 135 miles of short distance rail

- 115 miles of long distance rail

- 42 miles of bus rapid transit in mixed traffic

- 220 miles of managed lanes with express bus

- 217 miles of other express bus 


\section{Group 1Project Priorities w/ ongoing Regional Rail Projects}

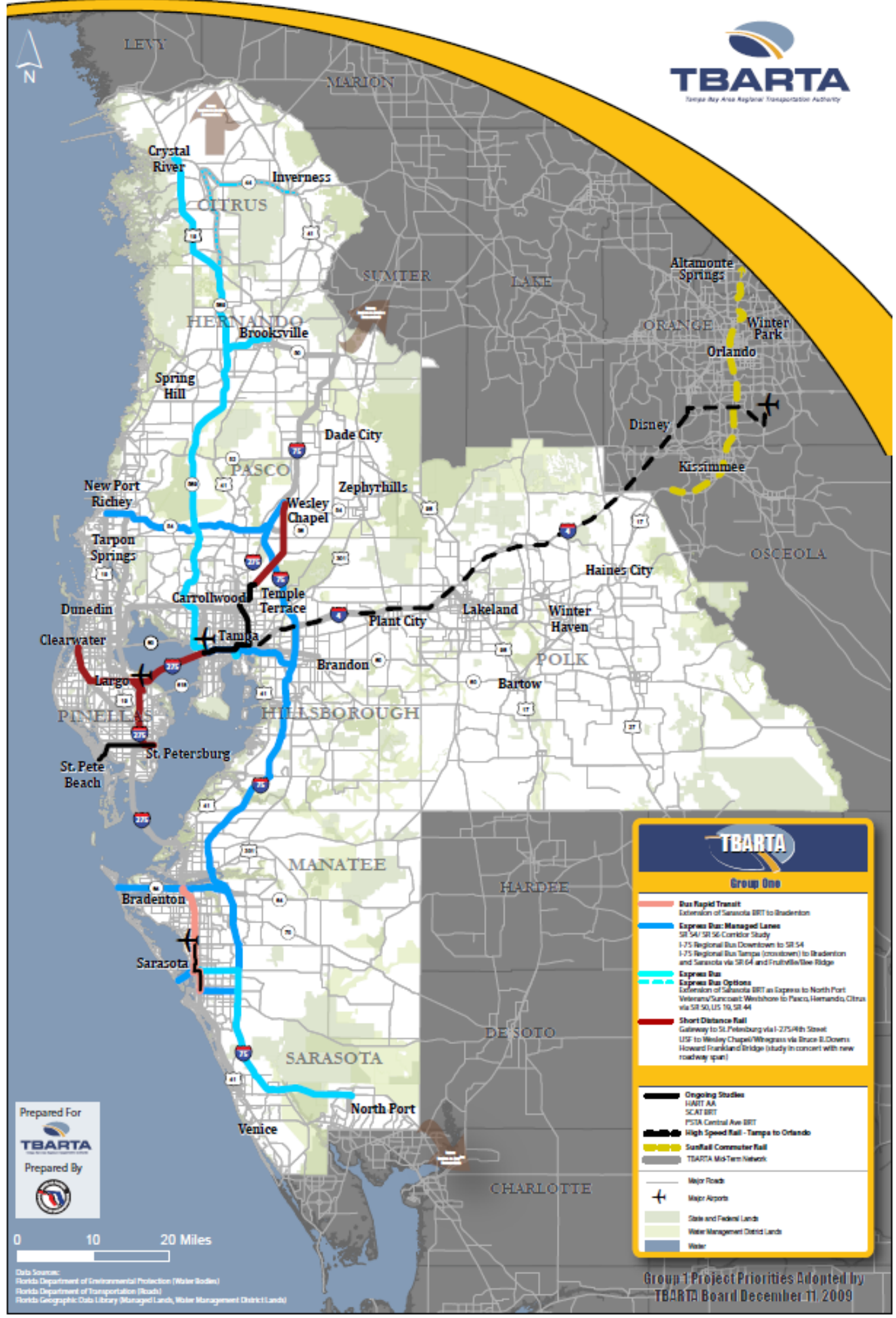

Map 5-3: Tampa Bay Region Initial Transit Projects - Source: TBARTA 


\section{Long-Term Supporting Network}

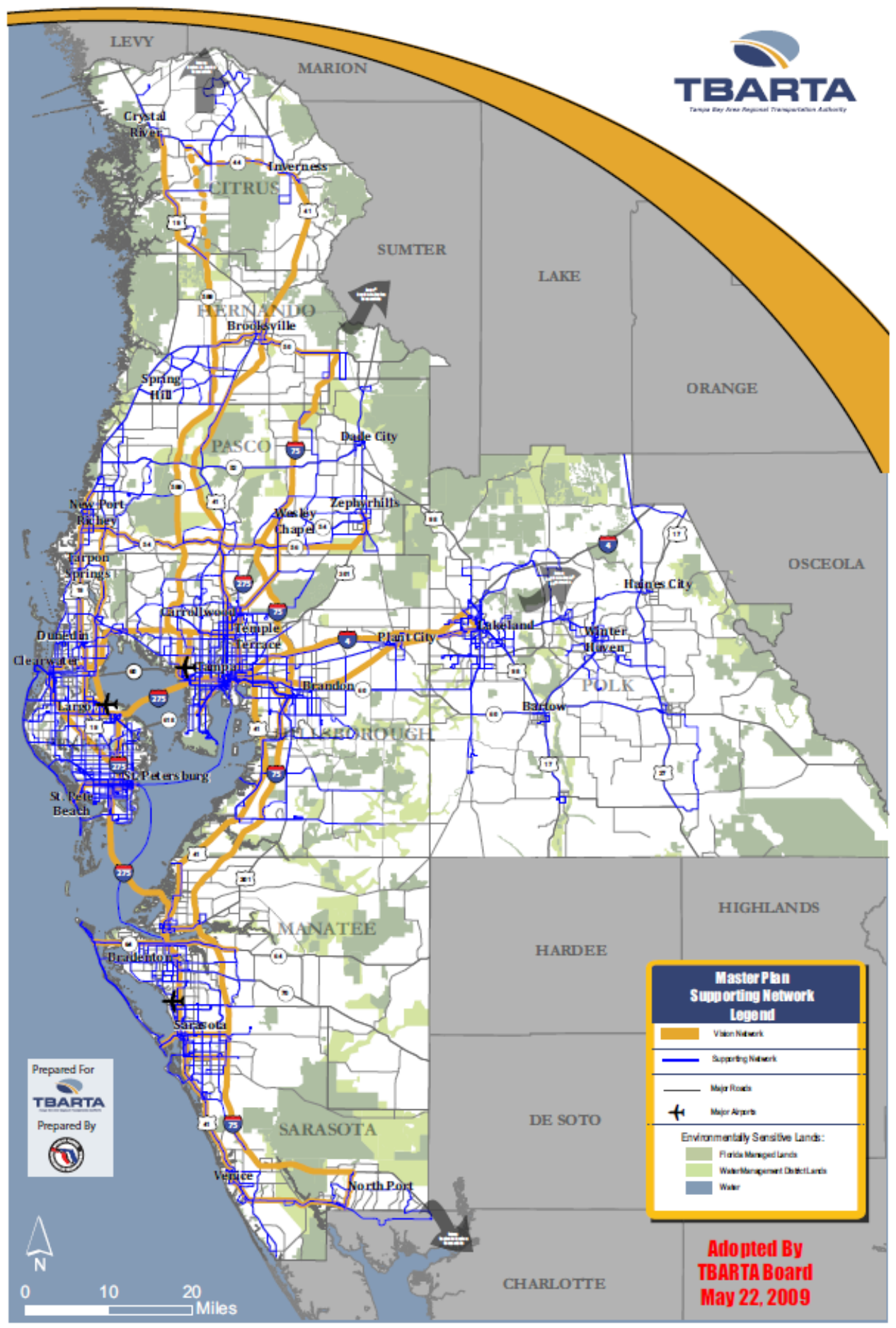

Map 5-4: Tampa Bay Region Long-Range Supporting Transit Network Source: TBARTA 


\section{ChAPTER 6 \\ APPLICATION OF METHODOLOGY \\ TO 2010 SERVICE LEVELS}

\section{APPLICATION OF METHODOLOGY TO 2010 SERVICE LEVELS}

In Chapter 3, a set of criteria were put forward with which to evaluate public transportation routes and determine how useful they would be to connect with HSR service. This chapter will apply those methods to current levels of service to proposed HSR station locations. By doing so, opportunities to enhance transit levels to HSR may be identified and addressed with suggested targeted improvements. What these methods do not consider however, are the vision and mission of the local public transportation service providers, as they do not exist exclusively to serve HSR. Therefore, the assessment of supporting mass transit service is intended only to cast light on the place where HSR and connecting public transit directly meet.

The first step of the process was to define major trip generators in each service area. These trip generators were identified from system marketing literature, interviews with agency officials and the location of existing predominant levels of service. These trip generators were then supplemented with the inclusion of service to cities and future anticipated trip generators. The next step was to identify a transit service line from the HSR stations that most frequently and quickly served that generator for each hour of the assumed HSR span of service, 7 days a week from 6:00am to 11:00pm. The 2010 transit schedules were used to identify lines with the highest frequency of vehicles stopping at the future stations. Schedules were also used to calculate travel times between HSR, the generators, and cities. This allowed the consideration of frequency, travel time, and span of service in the evaluation. Service-to-trip generators that required bus-to-bus transfers were excluded from consideration due to the degrading impact on travel time and large degree of inconvenience introduced for a HSR rider. Several generators and cities are not directly served from HSR with one bus connecting service. It is recognized that these destinations can still be served from HSR by local public transit; however, they do not meet the high quality connecting service definition that this evaluation intended to establish.

The next step was to calculate the equivalent auto trip travel time from the HSR station to those same generators and cities. This was accomplished with publically available engines furnished by Google and MapQuest. Once this information was compiled, a basic standard and associated color scheme were used in the following matrices. For each hour of the HSR operation, separately for weekday, Saturday, and Sunday:

- A HSR and generator connecting transit line that provided service with at least two (2) buses per hour (30-minute frequency) AND connected the two in a travel time equal or less than $200 \%$ of an equivalent auto trip time, was shaded green and considered a quality service for HSR connectivity. 
- A HSR and generator connecting transit line that provided service with at least 2 buses per hour (30-minute frequency) OR connected the two in a travel time equal or less than $200 \%$ of an equivalent auto trip time, was shaded yellow and could be considered for improvement to serve HSR and the generator.

- A HSR and generator connecting transit line that NEITHER provided service with at least 2 buses per hour (30- minute frequency) NOR connected the two in a travel time equal or less than $200 \%$ of an equivalent auto trip time, was shaded gray with an ' $x$ ' and could be considered for improvement to serve HSR and the generator.

There are several points to note in the following analysis. The abbreviation 'TT' was used to substitute for 'travel time'. There are no transit services currently operating to the potential Williams site HSR station. A future HSR station will be built at WDW and is expected to be well served by the Disney Transportation system. Two LYNX routes that operate near that station do not currently deviate into WDW, hence, Disney destinations were not evaluated. Minor route deviations are assumed for bus lines that serve within an immediate proximity to the future stations, but access roads remain to be built to feed them. The I Drive Trolley was not included in the evaluation, as it is a headway-based system. The service does not publish public schedules with which to determine travel times between locations, it only provides the frequency of arriving vehicles. Several significant generators along I-Drive are directly served by the two lines with a frequency of 30 minutes or less and a direct route path from HSR. Cities and trip generators that are currently not served by a single connecting bus route from HSR include:

Orlando

- Universal Studios

- Millenia Mall

- University of Central Florida

- Central Florida Fairgrounds

- Rollins College

- Winter Park

- Lake Buena Vista

- Florida Hospital

- Lake Nona/Burnham

- Maitland and several other cities

Polk County

- Publix Supermarkets Headquarters

- Lakeland Linder Regional Airport

- Cypress Gardens/Legoland

- Bartow

- Winter Haven

- Haines City

- Florida Southern College 
Tampa

- Lowry Park Zoo

- Hard Rock Hotel and Casino

- Westfield Citrus Park Mall

- Tampa Bay Rays Stadium (St Petersburg) 


\begin{tabular}{|c|c|c|c|c|c|c|c|c|c|c|c|c|c|c|c|c|c|c|c|}
\hline $\begin{array}{l}\text { Origin/Destination From Orlando } \\
\text { International Airport Highspeed } \\
\text { Rail Station }\end{array}$ & $\begin{array}{c}\text { Travel Time } \\
\text { by } \\
\text { Automobile } \\
\text { (minutes) }\end{array}$ & $\begin{array}{l}\sum_{1} \\
8 \\
0 \\
0\end{array}$ & 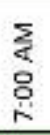 & $\begin{array}{l}\overline{3} \\
\text { d } \\
8 \\
\infty \\
\infty\end{array}$ & $\begin{array}{l}\overline{2} \\
4 \\
8 \\
0 \\
\alpha\end{array}$ & $\begin{array}{l}\sum \\
\vdots \\
8 \\
0 \\
0\end{array}$ & $\begin{array}{l}\sum_{1} \\
0 \\
0 \\
=\end{array}$ & 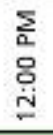 & $\begin{array}{l}\Sigma \\
\vdots \\
0 \\
\\
\end{array}$ & 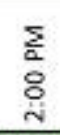 & $\begin{array}{l}\sum_{0} \\
8 \\
0 \\
m\end{array}$ & 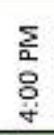 & $\begin{array}{l}\Sigma \\
\vdots \\
口 \\
\text { in }\end{array}$ & $\begin{array}{l}\Sigma \\
\vdots \\
8 \\
0 \\
\end{array}$ & $\frac{\Sigma}{0}$ & $\begin{array}{l}5 \\
\vdots \\
8 \\
\infty\end{array}$ & $\begin{array}{l}\sum \\
\vdots \\
\vdots \\
\vdots \\
\vdots\end{array}$ & $\begin{array}{l}\Sigma \\
\vdots \\
0 \\
\stackrel{0}{0} \\
\end{array}$ & 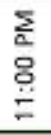 \\
\hline Florida Mall & 14 & \multicolumn{18}{|c|}{ Link 111: $30 \mathrm{~min} / 14 \mathrm{TT}$} \\
\hline Orlando Regional Medical Center & 20 & \multicolumn{18}{|c|}{ Link 11: $30 \mathrm{~min} / 32 \pi$} \\
\hline Cassellberry & 37 & $\begin{array}{c}\text { Link } \\
41: 30 \\
\text { min } \\
57 \pi\end{array}$ & & & & & & & & & & & & & & & & & \\
\hline Amway Arena & 24 & \multicolumn{18}{|c|}{$\begin{array}{l}\text { Link 41:30 minv64 } \pi \\
\text { Link } 11: 30 \mathrm{~min} / 40 \pi\end{array}$} \\
\hline Downtown Orlando & 22 & \multicolumn{18}{|c|}{ Link 11: $30 \mathrm{~min} / 40 \pi$} \\
\hline Altamonte Springs & 36 & \begin{tabular}{c|} 
Link \\
$41: 30$ \\
mini \\
$74 \pi$
\end{tabular} & \multicolumn{11}{|c|}{ Link 41: 30 minv83 $\pi$} & \multicolumn{6}{|c|}{ Link $41: 30 \min 74 \pi$} \\
\hline Apopka & 41 & $\begin{array}{c}\text { Link } \\
41: 30 \\
\text { mini } \\
108 \pi\end{array}$ & \multicolumn{11}{|c|}{ Link 41: $30 \mathrm{~min} / 120 \pi$} & \multicolumn{6}{|c|}{ Link 41: $30 \mathrm{~min} / 108 \mathrm{~T}$} \\
\hline
\end{tabular}

\begin{tabular}{|c|c|c|c|c|c|c|c|c|c|c|c|c|c|c|c|c|c|c|c|}
\hline $\begin{array}{l}\text { Origin/Destination From Orange } \\
\text { County Convention Center } \\
\text { Highspeed Rail Station }\end{array}$ & $\begin{array}{c}\text { Travel Time } \\
\text { by } \\
\text { Automobile } \\
\text { (minutes) }\end{array}$ & $\begin{array}{l}\sum_{1} \\
8 \\
0 \\
i\end{array}$ & 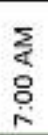 & $\begin{array}{l}\sum_{1} \\
8 \\
\infty \\
\infty\end{array}$ & $\begin{array}{l}\sum_{i} \\
8 \\
\delta\end{array}$ & 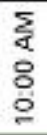 & $\begin{array}{l}\overline{2} \\
\vdots \\
0 \\
0 \\
=\end{array}$ & 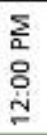 & $\begin{array}{l}\bar{\Sigma} \\
\stackrel{2}{\circ} \\
\stackrel{2}{-}\end{array}$ & $\underset{\substack{z \\
0 \\
i}}{i}$ & $\sum_{\substack{0 \\
0}}^{5}$ & 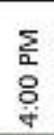 & 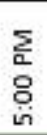 & 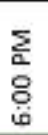 & $\frac{\sum}{8}$ & $\sum_{\substack{0 \\
\infty}}^{\infty}$ & $\begin{array}{l}\sum_{0} \\
\vdots \\
\dot{0} \\
i\end{array}$ & $\begin{array}{l}5 \\
\vdots \\
0 \\
0 \\
0\end{array}$ & $\begin{array}{l}\frac{5}{2} \\
8 \\
0 \\
\end{array}$ \\
\hline Sea World & \begin{tabular}{|c|}
5 \\
\end{tabular} & \multicolumn{18}{|c|}{ Link 8 or $50: 15 \mathrm{~min} / 5 \pi$} \\
\hline Downtown Orlando & 18 & \multicolumn{18}{|c|}{ Link 50: 30 minv $18 \pi$} \\
\hline Amway Arena & 20 & \multirow{2}{*}{\multicolumn{18}{|c|}{$\frac{\text { Link 50:30 min/18 } \pi}{\text { Link } 8: 15 \text { min/9 }}$}} \\
\hline Wet $n$ Wild & 7 & & & & & & & & & & & & & & & & & & \\
\hline Premium Outlets & 11 & \multicolumn{18}{|c|}{ Link 8: 15 min/17 $\pi$} \\
\hline Florida Mall & 11 & \multicolumn{18}{|c|}{ Link 111: $30 \mathrm{~min} / 19 \mathrm{TT}$} \\
\hline Prime Outlets & 12 & \multicolumn{18}{|c|}{ Link 8: $15 \mathrm{~min} / 22 \pi$} \\
\hline
\end{tabular}

Table 6-1: 2010 Weekday Levels of Public Transportation Service Connecting to HSR 


\begin{tabular}{|c|c|c|c|c|c|c|c|c|c|c|c|c|c|c|c|c|c|c|c|}
\hline \begin{tabular}{|c|} 
Origin/Destination From Orlando \\
Disney Highspeed Rail Station
\end{tabular} & $\begin{array}{c}\text { Travel Time } \\
\text { by } \\
\text { Automobile } \\
\text { (minutes) }\end{array}$ & $\begin{array}{l}\sum_{1} \\
8 \\
0 \\
0\end{array}$ & 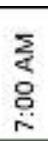 & $\begin{array}{l}\sum_{1} \\
8 \\
\dot{0} \\
\dot{\infty}\end{array}$ & \begin{tabular}{l}
$\sum_{1}$ \\
8 \\
\hdashline
\end{tabular} & $\begin{array}{l}\sum_{1} \\
8 \\
8 \\
0\end{array}$ & $\begin{array}{l}\sum_{1} \\
8 \\
0 \\
\\
\end{array}$ & 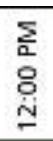 & $\begin{array}{l}\underset{2}{2} \\
\stackrel{8}{-}\end{array}$ & 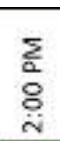 & $\sum_{0}$ & $\begin{array}{l}\sum_{0} \\
0 \\
0 \\
\dot{u}\end{array}$ & $\begin{array}{l}\sum_{a} \\
\text { i } \\
\text { in }\end{array}$ & $\begin{array}{l}\sum_{0} \\
\stackrel{0}{i} \\
i 0\end{array}$ & $\underset{\substack{0 \\
0}}{0}$ & $\sum_{\substack{0 \\
0}}$ & $\begin{array}{l}\sum_{0} \\
\stackrel{8}{8} \\
\dot{0}\end{array}$ & $\begin{array}{l}\Sigma \\
0 \\
0 \\
0\end{array}$ & $\begin{array}{l}\sum_{0} \\
8 \\
0 \\
\\
\end{array}$ \\
\hline Celebration & \begin{tabular}{|l|l|}
10 \\
\end{tabular} & \multicolumn{18}{|c|}{ Link 56:30 mirv10 Tा } \\
\hline Kissimmee & 23 & \multicolumn{18}{|c|}{ Link 56:30 min $37 \pi$} \\
\hline Downtown Orlando & 26 & \multicolumn{18}{|c|}{ Link 50: $30 \mathrm{~min} / 52 \pi$} \\
\hline Poinciana & 46 & \begin{tabular}{|c|} 
Link \\
$306:$ \\
1 bus \\
$46 \pi$
\end{tabular} & & & & & & & & & & & $\begin{array}{c}\text { Link } \\
306: \\
1 \text { bus/ } \\
46 \pi\end{array}$ & & & & & & \\
\hline
\end{tabular}

\begin{tabular}{|c|c|c|c|c|c|c|c|c|c|c|c|c|c|c|c|c|c|c|c|}
\hline $\begin{array}{c}\text { Origin/Destination From } \\
\text { Lakeland Kathleen Highspeed } \\
\text { Rail Station }\end{array}$ & $\begin{array}{l}\text { Travel Time } \\
\text { by } \\
\text { Automobile } \\
\text { (minutes) }\end{array}$ & $\begin{array}{l}\sum_{1} \\
8 \\
8 \\
0\end{array}$ & 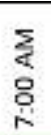 & 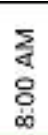 & $\begin{array}{l}\sum_{\alpha} \\
\text { \& } \\
\text { \& }\end{array}$ & $\begin{array}{l}5 \\
\vdots \\
8 \\
0 \\
0\end{array}$ & \begin{tabular}{l}
$\bar{z}$ \\
$\vdots$ \\
0 \\
\hdashline
\end{tabular} & 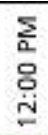 & 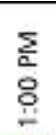 & $\begin{array}{l}\Sigma \\
\stackrel{2}{0} \\
i \\
i\end{array}$ & $\sum_{\frac{1}{2}}$ & 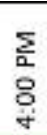 & $\begin{array}{l}\Sigma \\
\text { ¿ } \\
\text { 品 }\end{array}$ & 竞 & $\sum_{\substack{0 \\
0}}^{10}$ & $\sum_{0}^{\infty}$ & $\begin{array}{l}\Sigma \\
\vdots \\
0 \\
\vdots\end{array}$ & $\begin{array}{l}\vdots \\
\vdots \\
0 \\
0 \\
0\end{array}$ & $\begin{array}{l}\frac{\Sigma}{2} \\
\frac{\rho}{0} \\
=\end{array}$ \\
\hline PCQUSF campus & 19 & \multicolumn{13}{|c|}{ Route $51: 30$ min/19 $\frac{1}{1}$} & \multicolumn{5}{|c|}{$x$} \\
\hline Lakeland Regional Med Center & 7 & \multirow{2}{*}{\multicolumn{13}{|c|}{ Route 51: $30 \mathrm{~min} / 10 \pi$}} & \multicolumn{5}{|c|}{$x$} \\
\hline Lakeland Square Mall & 4 & & \multicolumn{11}{|c|}{ Route $51: 30 \mathrm{~min} / 23 \pi$} & & \multicolumn{5}{|c|}{$x$} \\
\hline
\end{tabular}

\begin{tabular}{|c|c|c|c|c|c|c|c|c|c|c|c|c|c|c|c|c|c|c|c|}
\hline $\begin{array}{c}\text { Origin/Destination From Tampa } \\
\text { Highspeed Rail Station }\end{array}$ & $\begin{array}{c}\text { Travel Time } \\
\text { by } \\
\text { Automobile } \\
\text { (minutes) }\end{array}$ & $\begin{array}{l}5 \\
4 \\
0 \\
0 \\
0\end{array}$ & $\begin{array}{l}\Sigma \\
\alpha \\
8 \\
1 \\
1\end{array}$ & $\begin{array}{l}5 \\
\alpha \\
8 \\
\infty \\
\end{array}$ & $\begin{array}{l}5 \\
\vdots \\
8 \\
0 \\
\end{array}$ & $\begin{array}{l}\overline{3} \\
8 \\
\stackrel{8}{0} \\
\end{array}$ & $\begin{array}{l}\sum \\
\vdots \\
0 \\
0 \\
\end{array}$ & 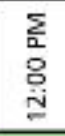 & $\begin{array}{l}\overline{2} \\
8 \\
8 \\
\end{array}$ & $\begin{array}{l}\bar{z} \\
\text { a } \\
\dot{0} \\
\dot{d} \\
\end{array}$ & 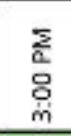 & $\begin{array}{l}5 \\
0 \\
0 \\
0 \\
0 \\
\end{array}$ & $\begin{array}{l}\text { 文 } \\
\text { o } \\
\text { in }\end{array}$ & $\begin{array}{l}\bar{\Sigma} \\
8 \\
8 \\
0 \\
0\end{array}$ & $\begin{array}{l}\sum_{0}^{2} \\
\stackrel{0}{0} \\
i\end{array}$ & 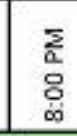 & $\begin{array}{l}\bar{z} \\
0 \\
0 \\
0 \\
\sigma \\
0\end{array}$ & $\begin{array}{l}\overline{2} \\
\vdots \\
8 \\
0 \\
\end{array}$ & $\begin{array}{l}\sum \\
\frac{2}{8} \\
\\
\end{array}$ \\
\hline Downtown Tampa CBD & 7 & \multicolumn{3}{|c|}{$\begin{array}{l}\text { Route 96: } \\
15 \mathrm{~min} / 7 \mathrm{~min} \pi\end{array}$} & \multicolumn{6}{|c|}{ Route $30: 15 \mathrm{~min} / 7 \mathrm{\pi}$} & \multicolumn{2}{|c|}{$\begin{array}{l}\text { Route 96: } \\
15 \text { minv7 Tा }\end{array}$} & \multirow{2}{*}{\multicolumn{2}{|c|}{$\begin{array}{l}\text { Route } 30: \\
15 \text { min/7 } \pi \\
\end{array}$}} & \multicolumn{5}{|c|}{ Route $30: 30 \mathrm{~min} / 7 \pi$} \\
\hline University of Tampa & 7 & \multicolumn{11}{|c|}{ Route $30: 15 \mathrm{~min} / 11 \mathrm{TT}$} & & & \multicolumn{5}{|c|}{ Route $30: 30 \mathrm{~min} / 11 \mathrm{~T}$} \\
\hline Tampa General Hospital & 12 & \multirow{2}{*}{\multicolumn{13}{|c|}{$\begin{array}{l}\text { Route } 19: 30 \mathrm{~min} / 17 \mathrm{~T} \\
\text { Route } 8.30 \mathrm{~min} / 12 \pi\end{array}$}} & & & & & $17 \pi$ \\
\hline Channelside & 12 & \multicolumn{9}{|c|}{ Route 8: $30 \mathrm{~min} / 12 \mathrm{~T}$} & & & & & \multirow{2}{*}{\multicolumn{5}{|c|}{$\begin{array}{l}\text { Route } 8: 60 \mathrm{~min} / 12 \mathrm{~T} \\
\text { Route } 8.60 \mathrm{~min} / 13 \mathrm{~T}\end{array}$}} \\
\hline Port of Tampa & 13 & \multicolumn{13}{|c|}{ Route $8: 30 \mathrm{~min} / 13 \pi$} & \multicolumn{3}{|c|}{ Route 8: $60 \mathrm{~min} / 13 \pi$} & & \\
\hline St. Pete Times Forum & 9 & \multicolumn{9}{|c|}{ Route $96: 15 \mathrm{~min} / 9 \mathrm{TT}$} & \multicolumn{4}{|c|}{$\begin{array}{l}\text { Route } 96: \\
15 \text { mini } 9 \pi\end{array}$} & \multicolumn{5}{|c|}{ Route 19:60 min/9 TT } \\
\hline Ybor city & 5 & \multicolumn{13}{|c|}{ Route 8:30 min/10 ता } & \multicolumn{5}{|c|}{ Route $8: 60 \mathrm{~min} / 10 \pi$} \\
\hline Busch Gardens & 17 & \multirow{2}{*}{\multicolumn{13}{|c|}{$\begin{array}{l}\text { Route } 5: 30 \mathrm{~min} / 34 \pi \\
\text { Route } 30: 15 \mathrm{~min} / 23 \pi\end{array}$}} & \multicolumn{5}{|c|}{ Route $5: 60 \mathrm{~min} / 34 \pi$} \\
\hline Westshore Plaza & 10 & & & & & & & & & & & & & & \multicolumn{5}{|c|}{ Route $30: 30 \mathrm{~min} / 23 \mathrm{~T}$} \\
\hline Tampa International Airport & 14 & \multicolumn{13}{|c|}{ Route $30: 15 \mathrm{~min} 38 \mathrm{~T}$} & \multicolumn{5}{|c|}{ Route $30: 30 \mathrm{~min} / 38 \pi$} \\
\hline University of South Florida & 18 & \multicolumn{13}{|c|}{ Route 5: $30 \mathrm{~min} / 44 \pi$} & \multicolumn{5}{|c|}{ Route $5=60 \mathrm{~min} / 44 \pi$} \\
\hline Westfield Brandon Mall & 18 & \multicolumn{13}{|c|}{ Route $8: 30 \mathrm{~min} / 70 \pi$} & \multicolumn{5}{|c|}{ Route 8.60 min/67 11} \\
\hline St. Joseph's Hospital & 9 & \multicolumn{13}{|c|}{ Route $7.30 \mathrm{~min} / 18 \pi$} & \multicolumn{5}{|c|}{$x \quad x$} \\
\hline Raymond James Stadium & 9 & \multirow{2}{*}{\multicolumn{13}{|c|}{ Route $7: 30 \mathrm{~min} / 26 \pi$}} & \multirow{2}{*}{\multicolumn{5}{|c|}{$\mathrm{x}$}} \\
\hline MacDill Airforce Base & 22 & & & & & & & Route & $60 n$ & $\sqrt{521}$ & & & & & & & & & \\
\hline
\end{tabular}

Table 6-1 Cont'd: 2010 Weekday Levels of Public Transportation Service Connecting to HSR 


\section{Observations for Weekday Service}

Where LYNX does provide connecting services, on weekdays they tend to meet the criteria as a quality option for a HSR rider. Several of the links have 15 or 30 minute frequencies that operate through the entire span of service on weekdays. Midday and evening frequencies generally match those offered during of peak hour, providing passengers with a simpler understanding of when vehicles will arrive to a connecting HSR rider.

The nature of the existing LYNX bus network design appears to accommodate the sprawling geography of the service area and connects many lines that operate south of downtown Orlando into the Central Transfer Terminal to meet routes that operate north of downtown. Because all three Orlando HSR stations will be built considerably south of downtown, they will connect better with southern service area generators than with northern ones. Link 41, a candidate for a future premium bus service, is a route that serves portions of the northern service area from future HSR.

A HSR to SunRail connection will be of great importance for the following this reason. Whereas, bus services tend to be split north and south of downtown, SunRail operates along a northsouth spine connecting many communities to HSR that currently aligned bus service cannot without transfers and high travel times. There are several options for how this connection could be made: a direct deviation of the existing SunRail alignment into OIA from Sand Lake Rd or a dedicated fixed guideway or bus shuttle service.

Similarly, many western Polk County transit routes connect at the downtown transfer terminal in Lakeland. Existing bus routes for serving the Kathleen Road site tend to be relatively short with low round trip travel times. The benefit to this is a direct connection from HSR where service exists, however a challenge is that shorter routes would conceivably serve fewer generators and a higher rate of transfers are required to reach the majority of the service area. Evening and night service in Polk County is minimal and public transit connections become difficult after 6:00pm.

HART benefits from a single, centrally located HSR station where a majority of its transit network already operates. Many generators located north and south of downtown can be served with a single HSR/bus connection with somewhat mixed degrees of quality on weekdays. HART tends to operate with more peak-hour frequency variation and decreases in frequency in evening and late-night service. The increased choices for route connectivity may present challenges to a HSR rider, particularly after 6:00 pm when buses arrive less frequently in some cases.

In the service design, most east-west traveling bus routes do not serve the HSR station location. There are a limited number of generators that require bus-to-bus transfers to be reached in the areas served by these routes. 


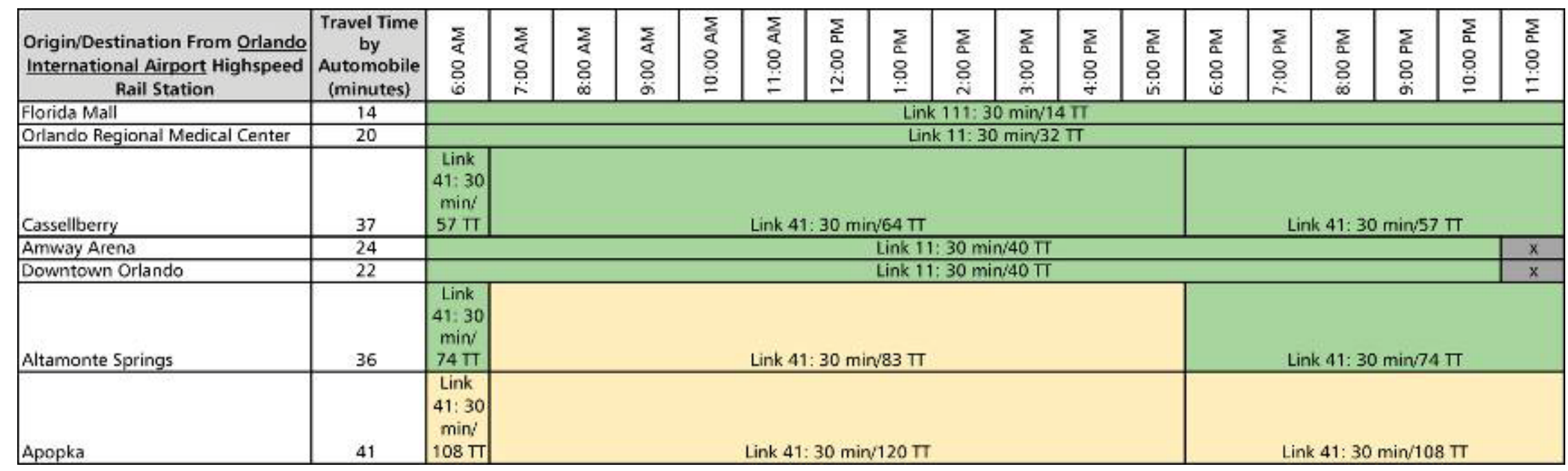

\begin{tabular}{|c|c|c|c|c|c|c|c|c|c|c|c|c|c|c|c|c|c|c|c|}
\hline $\begin{array}{c}\text { Origin/Destination From Orange } \\
\text { County Convention Center } \\
\text { Highspeed Rail Station }\end{array}$ & $\begin{array}{c}\text { Travel Time } \\
\text { by } \\
\text { Automobile } \\
\text { (minutes) }\end{array}$ & $\begin{array}{l}\sum_{1} \\
8 \\
0 \\
0\end{array}$ & $\begin{array}{l}\sum_{1} \\
8 \\
\\
i\end{array}$ & $\begin{array}{l}\sum_{4} \\
8 \\
\varnothing \\
\infty\end{array}$ & $\begin{array}{l}\sum \\
4 \\
8 \\
0 \\
\end{array}$ & $\begin{array}{l}\overline{3} \\
\vdots \\
8 \\
8 \\
0\end{array}$ & $\begin{array}{l}\overline{3} \\
4 \\
8 \\
0 \\
=\end{array}$ & \begin{tabular}{l}
$\Sigma$ \\
$\vdots$ \\
0 \\
$\stackrel{2}{0}$ \\
\cline { 1 - 1 }
\end{tabular} & $\begin{array}{l}\bar{\Sigma} \\
\stackrel{0}{8} \\
\stackrel{-}{-}\end{array}$ & $\begin{array}{l}\sum_{0} \\
8 \\
\\
i\end{array}$ & $\sum_{\substack{a \\
0\\
}}$ & $\begin{array}{l}5 \\
8 \\
\\
\end{array}$ & $\begin{array}{l}\sum_{0} \\
8 \\
\text { in } \\
\end{array}$ & 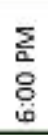 & $\frac{\sum}{8}$ & $\sum_{0}$ & 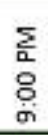 & 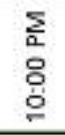 & $\begin{array}{l}\frac{5}{2} \\
0 \\
0 \\
\\
\end{array}$ \\
\hline Sea World & \begin{tabular}{|c|}
5 \\
\end{tabular} & \multicolumn{18}{|c|}{ Link 8 or $50: 30 \mathrm{~min} / 5 \pi$} \\
\hline Downtown Orlando & 18 & \multirow{2}{*}{\multicolumn{18}{|c|}{ Link 50:30 min/18 Tा }} \\
\hline Amway Arena & 20 & \multicolumn{13}{|c|}{ Link $50: 30 \mathrm{~min} / 20 \pi$} & & & & & \\
\hline Wet $n$ Wild & 7 & \multicolumn{16}{|c|}{ Link 8: 30 min/ $12 \pi$} & \multicolumn{2}{|c|}{$\begin{array}{c}\text { Link 8: } \\
60 \mathrm{~min} / 12 \mathrm{~T}\end{array}$} \\
\hline Premium Outiets & 11 & \multicolumn{16}{|c|}{ Link 8: 30 minv $16 \pi$} & \multicolumn{2}{|c|}{$\begin{array}{c}\text { Link 8: } \\
60 \text { min/16 Tा }\end{array}$} \\
\hline Florida Mall & 11 & \multicolumn{18}{|c|}{ Link 111: 30 min/19 $\pi$} \\
\hline Prime Outlets & 12 & \multicolumn{16}{|c|}{ Link $8.30 \mathrm{~min} / 16 \pi$} & \multicolumn{2}{|c|}{$\begin{array}{c}\text { Link 8: } \\
60 \mathrm{~min} / 16 \mathrm{TI}\end{array}$} \\
\hline
\end{tabular}

Table 6-2: 2010 Saturday Levels of Public Transportation Service Connecting to HSR 


\begin{tabular}{|c|c|c|c|c|c|c|c|c|c|c|c|c|c|c|c|c|c|c|c|}
\hline $\begin{array}{l}\text { Origin/Destination From Orlando } \\
\text { Disney Highspeed Rail Station }\end{array}$ & \begin{tabular}{|c} 
Travel Time \\
by \\
Automobile \\
(minutes) \\
\end{tabular} & 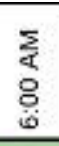 & 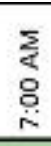 & 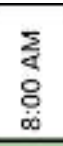 & $\begin{array}{l}\sum_{4} \\
8 \\
0 \\
\dot{\alpha}\end{array}$ & $\begin{array}{l}\vdots \\
8 \\
0 \\
0 \\
\end{array}$ & $\begin{array}{l}\bar{a} \\
8 \\
0 \\
\end{array}$ & $\begin{array}{l}\Sigma \\
\text { D } \\
\text { o } \\
\text { d }\end{array}$ & $\begin{array}{l}\underset{2}{2} \\
\stackrel{8}{8} \\
\\
\end{array}$ & 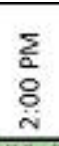 & $\begin{array}{l}\sum_{0} \\
8 \\
0 \\
\end{array}$ & $\begin{array}{l}\bar{z} \\
8 \\
\\
\dot{y} \\
\end{array}$ & $\begin{array}{l}\sum_{0} \\
\text { O̦ } \\
\text { in }\end{array}$ & $\begin{array}{l}\sum_{0} \\
8 \\
i \\
\end{array}$ & $\begin{array}{l}\sum_{0} \\
8 \\
\\
\end{array}$ & $\begin{array}{l}\sum_{1} \\
8 \\
0 \\
\infty \\
\end{array}$ & $\begin{array}{l}\sum_{0} \\
0 \\
0 \\
\dot{0}\end{array}$ & $\begin{array}{l}\Sigma \\
0 \\
0 \\
0 \\
0\end{array}$ & $\begin{array}{l}\Sigma \\
\vdots \\
0 \\
\\
\end{array}$ \\
\hline Celebration & 10 & \multicolumn{18}{|c|}{ Link 56: $30 \mathrm{~min} / 10 \pi$} \\
\hline Kissimmee & $\frac{23}{36}$ & \multirow{3}{*}{\multicolumn{18}{|c|}{ Link 50:30 min/52 Tा }} \\
\hline \begin{tabular}{|l} 
Downtown Orlando \\
Poinciana
\end{tabular} & 26 & & & & & & & & & & & & & & & & & & \\
\hline Poinciana & 46 & & & & & & & & & & & & & & & & & & \\
\hline
\end{tabular}

\begin{tabular}{|c|c|c|c|c|c|c|c|c|c|c|c|c|c|c|c|c|c|c|c|}
\hline $\begin{array}{c}\begin{array}{c}\text { Origin/Destination From } \\
\text { Lakeland Kathleen Highspeed } \\
\text { Rail Station }\end{array} \\
\end{array}$ & $\begin{array}{c}\begin{array}{c}\text { Travel Time } \\
\text { by } \\
\text { Automobile } \\
\text { (minutes) }\end{array} \\
\end{array}$ & $\begin{array}{l}5 \\
\frac{3}{2} \\
8 \\
0 \\
0 \\
\end{array}$ & $\begin{array}{l}\sum_{1}^{5} \\
0 \\
0 \\
i \\
\end{array}$ & 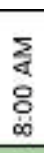 & $\begin{array}{l}\frac{2}{4} \\
8 \\
8 \\
\delta\end{array}$ & $\begin{array}{l}\sum_{1} \\
8 \\
0 \\
0\end{array}$ & 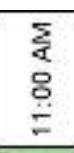 & 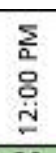 & $\begin{array}{l}\Sigma \\
\stackrel{\Sigma}{0} \\
\stackrel{0}{0} \\
\end{array}$ & $\begin{array}{l}\sum_{0} \\
8 \\
\\
\end{array}$ & 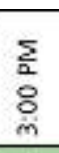 & $\begin{array}{l}\sum_{0} \\
0 \\
0 \\
\dot{4} \\
\end{array}$ & $\begin{array}{l}\sum_{0} \\
\text { o } \\
\text { in } \\
\end{array}$ & 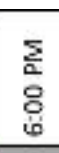 & $\begin{array}{l}5 \\
0 \\
0 \\
i\end{array}$ & 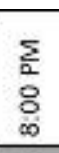 & $\begin{array}{l}\sum_{0} \\
\vdots \\
\vdots \\
\vdots\end{array}$ & $\begin{array}{l}\frac{5}{2} \\
\circ \\
0 \\
0\end{array}$ & $\begin{array}{l}\frac{\Sigma}{2} \\
0 \\
0 \\
\\
\end{array}$ \\
\hline PCOUSF campus & 19 & $x$ & \multirow{2}{*}{\multicolumn{11}{|c|}{ Route 51:30 min/19 }} & \multicolumn{6}{|c|}{$x$} \\
\hline Lakeland Regional Med Center & 7 & $x$ & \multirow{2}{*}{\multicolumn{11}{|c|}{$\begin{array}{l}\text { Route } 51: 30 \mathrm{~min} / 10 \pi \\
\text { Route } 51: 30 \mathrm{~min} / 23 \pi\end{array}$}} & \multirow{2}{*}{\multicolumn{6}{|c|}{$\frac{x}{x}$}} \\
\hline Lakeland Square Mall & 4 & $x$ & & & & & & & & & & & & & & & & & \\
\hline
\end{tabular}

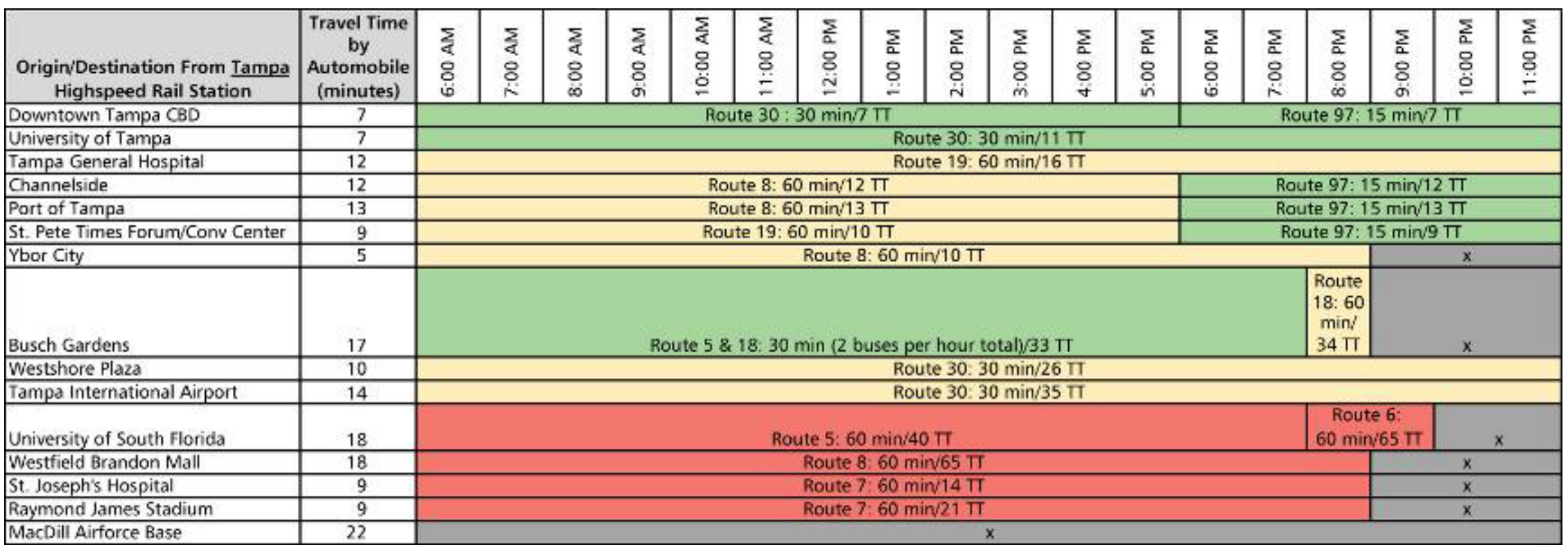

Table 6-2 Cont'd:: 2010 Saturday Levels of Public Transportation Service Connecting to HSR 


\section{Observations for Saturday Service}

On Saturdays, LYNX maintains a relatively high level of service on the routes connecting generators to HSR that operate with a 30-minute frequency, while retaining similar or improved travel times due to lighter traffic on weekends. Service from Orlando International Airport to downtown Orlando is cut after 10:00pm and could be a challenge to connect for late night arriving passengers via HSR. Night service on Link 8 is reduced to 60 minutes, reducing the number of arriving buses available on the last trips of Saturday service.

Polk County transit offers the same level of service on Saturdays as they do on weekdays.

HART operates several of its routes at 60-minute frequencies on Saturdays, reducing the number of available connecting buses for HSR. Connections to Busch Gardens on Saturdays can be made via Routes 5 and 18, providing the first example of multiple route availability for a destination. Service availability is reduced after 9:00pm as many routes go out of service after this time. 


\begin{tabular}{|c|c|c|c|c|c|c|c|c|c|c|c|c|c|c|c|c|c|c|c|}
\hline $\begin{array}{c}\text { Origin/Destination From } \\
\text { Orlando International Airport } \\
\text { Highspeed Rail Station }\end{array}$ & \begin{tabular}{|c}
$\begin{array}{c}\text { Travel Time } \\
\text { by }\end{array}$ \\
Automobile \\
(minutes)
\end{tabular} & $\begin{array}{l}\sum_{\alpha} \\
8 \\
0 \\
0\end{array}$ & $\begin{array}{l}\sum \\
\vdots \\
0 \\
0 \\
1\end{array}$ & $\begin{array}{l}\sum_{\alpha} \\
0 \\
0 \\
\infty \\
0\end{array}$ & $\begin{array}{l}\sum \\
\alpha \\
8 \\
\vdots \\
\alpha\end{array}$ & $\begin{array}{l}\vdots \\
< \\
\\
0 \\
0\end{array}$ & 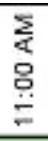 & 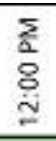 & 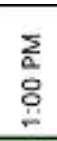 & 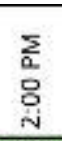 & 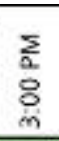 & $\begin{array}{l}\sum_{0} \\
0 \\
0 \\
\dot{j} \\
\end{array}$ & $\begin{array}{l}\sum_{0} \\
\stackrel{2}{0} \\
\text { in } \\
\end{array}$ & $\begin{array}{l}\sum_{0} \\
8 \\
0 \\
0\end{array}$ & 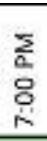 & $\begin{array}{l}\sum_{0} \\
\varnothing \\
\varnothing \\
\infty\end{array}$ & $\begin{array}{l}\Sigma \\
\frac{2}{2} \\
\delta \\
\alpha\end{array}$ & $\begin{array}{l}\text { 중 } \\
\text { 음 } \\
0\end{array}$ & 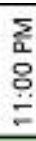 \\
\hline Florida Mall & 14 & \multicolumn{18}{|c|}{ Link 111: $30 \mathrm{~min} / 14 \mathrm{TT}$} \\
\hline Orlando Regional Med Center & 20 & \multicolumn{18}{|c|}{ Link $11: 30$ min/32 $\pi$} \\
\hline Cassellberry & 37 & \multicolumn{18}{|c|}{ Link $41: 60 \mathrm{~min} / 55 \pi$} \\
\hline Amway Arena & 24 & \multicolumn{17}{|c|}{ Link 11: $30 \mathrm{~min} / 40 \pi$} & $\bar{x}$ \\
\hline Downtown Orlando & 22 & \multirow{2}{*}{\multicolumn{17}{|c|}{$\frac{\text { Link 11: } 30 \mathrm{~min} / 40 \pi}{\text { Link } 41: 60 \mathrm{~min} / 74 \pi}$}} & $\bar{x}$ \\
\hline Altamonte Springs & 36 & \multirow{2}{*}{\multicolumn{18}{|c|}{$\frac{\text { Link 41:60 min/74 }}{\text { Link 41: } 60 \mathrm{~min} / 110 \pi}$}} \\
\hline Apopka & 41 & & & & & & & & & & & & & & & & & & \\
\hline
\end{tabular}

\begin{tabular}{|c|c|c|c|c|c|c|c|c|c|c|c|c|c|c|c|c|c|c|c|}
\hline $\begin{array}{c}\text { Origin/Destination From } \\
\text { Orange County Convention } \\
\text { Center Highspeed Rail Station }\end{array}$ & $\begin{array}{c}\text { Travel Time } \\
\text { by } \\
\text { Automobile } \\
\text { (minutes) }\end{array}$ & $\begin{array}{l}\sum_{1} \\
8 \\
0 \\
0\end{array}$ & $\begin{array}{l}\sum_{1} \\
8 \\
0 \\
i\end{array}$ & $\begin{array}{l}\sum_{1} \\
\vdots \\
o \\
0 j \\
0\end{array}$ & 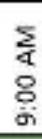 & $\begin{array}{l}\sum \\
8 \\
0 \\
0 \\
\end{array}$ & $\begin{array}{l}\sum_{5} \\
8 \\
0 \\
=\end{array}$ & $\begin{array}{l}\frac{2}{0} \\
8 \\
i \\
\end{array}$ & $\begin{array}{l}\underset{2}{0} \\
\stackrel{0}{0} \\
\stackrel{0}{-}\end{array}$ & $\begin{array}{l}\sum_{0} \\
\stackrel{2}{0} \\
\stackrel{i}{N}\end{array}$ & 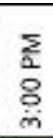 & $\begin{array}{l}\sum_{0} \\
\stackrel{0}{0} \\
\dot{j}\end{array}$ & 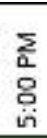 & $\frac{2}{8}$ & $\begin{array}{l}\frac{\Sigma}{0} \\
\stackrel{8}{0} \\
\dot{\sim}\end{array}$ & 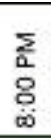 & 这 & 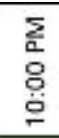 & $\begin{array}{l}\overline{2} \\
8 \\
8 \\
=\end{array}$ \\
\hline Sea World & 5 & \multicolumn{18}{|c|}{ Link 8 or $50: 30$ minis $\pi$} \\
\hline Downtown Orlando & 18 & \multirow{2}{*}{\multicolumn{18}{|c|}{$\begin{array}{l}\text { Link 50:30 min/18 Tा } \\
\text { Link 50: } 30 \mathrm{~min} / 20 \mathrm{TT}\end{array}$}} \\
\hline Amway Arena & 20 & & & & & & & & & & & & & & & & & & \\
\hline Wet $n$ Wild & 7 & \multicolumn{16}{|c|}{ Link 8: $30 \mathrm{~min} / 12 \pi$} & \multicolumn{2}{|c|}{$\begin{array}{c}\text { Link 8: } \\
60 \min / 12 \pi\end{array}$} \\
\hline Premium Outlets & 11 & \multicolumn{16}{|c|}{ Link 8: $30 \mathrm{~min} / 16 \pi$} & \multicolumn{2}{|c|}{$\begin{array}{l}\text { Link 8: } \\
60 \text { min/16 } \pi\end{array}$} \\
\hline Florida Mall & 11 & \multicolumn{18}{|c|}{ Link 111: $30 \mathrm{~min} / 19 \mathrm{TT}$} \\
\hline Prime Outlets & 12 & \multicolumn{16}{|c|}{ Link 8: $30 \mathrm{~min} / 16 \pi$} & \multicolumn{2}{|c|}{$\begin{array}{l}\text { Link 8: } \\
60 \mathrm{~min} / 16 \pi\end{array}$} \\
\hline
\end{tabular}

Table 6-3: 2010 Sunday Levels of Public Transportation Service Connecting to HSR 


\begin{tabular}{|c|c|c|c|c|c|c|c|c|c|c|c|c|c|c|c|c|c|c|c|}
\hline $\begin{array}{l}\text { Origin/Destination From } \\
\text { Orlando Disney Highspeed Rail } \\
\text { Station }\end{array}$ & $\begin{array}{c}\text { Travel Time } \\
\text { by } \\
\text { Automobile } \\
\text { (minutes) }\end{array}$ & $\begin{array}{l}\sum_{1} \\
8 \\
8 \\
0\end{array}$ & 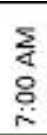 & $\begin{array}{l}\sum_{\alpha} \\
8 \\
8 \\
\text { id }\end{array}$ & $\begin{array}{l}\sum_{1} \\
8 \\
8 \\
0\end{array}$ & 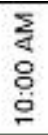 & 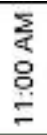 & \begin{tabular}{l}
$\sum_{0}$ \\
8 \\
0 \\
\hdashline
\end{tabular} & $\begin{array}{l}\bar{z} \\
\stackrel{0}{0} \\
\stackrel{0}{-}\end{array}$ & 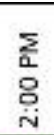 & 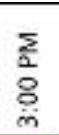 & 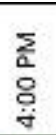 & 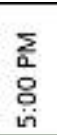 & 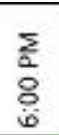 & 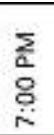 & 蛋 & 离 & $\begin{array}{l}\bar{\Sigma} \\
\vdots \\
0 \\
0 \\
\end{array}$ & $\begin{array}{l}\overline{2} \\
0 \\
8 \\
- \\
=\end{array}$ \\
\hline Celebration & 10 & \multicolumn{18}{|c|}{ Link 56:30 minv10 $\pi$} \\
\hline Kissimmee & 23 & \multicolumn{18}{|c|}{ Link 56: $30 \mathrm{~min} / 37 \mathrm{TT}$} \\
\hline Downtown Orlando & 26 & \multicolumn{18}{|c|}{ Link $50: 30 \mathrm{~min} / 52 \pi$} \\
\hline Poinciana & 46 & \multicolumn{18}{|c|}{$x$} \\
\hline
\end{tabular}

\begin{tabular}{|c|c|c|c|c|c|c|c|c|c|c|c|c|c|c|c|c|c|c|c|}
\hline $\begin{array}{l}\text { Origin/Destination From } \\
\text { Lakeland Kathleen Highspeed } \\
\text { Rail Station }\end{array}$ & $\begin{array}{c}\text { Travel Time } \\
\text { by } \\
\text { Automobile } \\
\text { (minutes) }\end{array}$ & $\begin{array}{l}5 \\
4 \\
8 \\
0\end{array}$ & $\begin{array}{l}\sum \\
1 \\
8 \\
0 \\
i\end{array}$ & 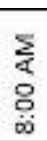 & 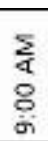 & $\begin{array}{l}\sum_{1} \\
8 \\
0 \\
0\end{array}$ & $\begin{array}{l}\frac{5}{6} \\
8 \\
8 \\
=\end{array}$ & $\begin{array}{l}\overline{2} \\
0 \\
8 \\
0 \\
\end{array}$ & $\underset{\substack{\Sigma \\
0}}{\stackrel{0}{0}}$ & 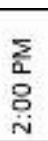 & $\sum_{\substack{2\\
}}$ & 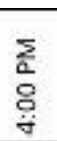 & 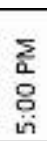 & $\sum_{i 0}^{\sum_{0}^{2}}$ & 产 & 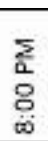 & 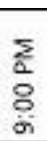 & $\begin{array}{l}\overline{2} \\
\stackrel{0}{O} \\
\stackrel{0}{0} \\
\dot{0}\end{array}$ & $\begin{array}{l}\overline{2} \\
\frac{1}{8} \\
\frac{1}{-}\end{array}$ \\
\hline PCCUSF campus & 19 & \multicolumn{18}{|c|}{$\frac{x}{x}$} \\
\hline Lakeland Regional Med Center & 7 & \multicolumn{18}{|c|}{$x$} \\
\hline Lakeland Square Mall & 4 & \multicolumn{18}{|c|}{$x$} \\
\hline
\end{tabular}

\begin{tabular}{|c|c|c|c|c|c|c|c|c|c|c|c|c|c|c|c|c|c|c|c|}
\hline $\begin{array}{c}\text { Origin/Destination From } \\
\text { Tampa Highspeed Rail Station }\end{array}$ & $\begin{array}{l}\text { Travel Time } \\
\text { by } \\
\text { Automobile } \\
\text { (minutes) }\end{array}$ & $\begin{array}{l}\sum_{d} \\
8 \\
0 \\
0\end{array}$ & 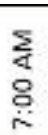 & $\begin{array}{l}\sum_{\alpha} \\
\varnothing \\
\dot{\phi} \\
\dot{\alpha}\end{array}$ & 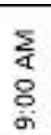 & $\begin{array}{l}\sum \\
\vdots \\
8 \\
0 \\
0\end{array}$ & $\begin{array}{l}\frac{5}{1} \\
8 \\
0 \\
=\end{array}$ & $\begin{array}{l}\overline{2} \\
8 \\
8 \\
\text { i }\end{array}$ & $\begin{array}{l}\bar{z} \\
\text { on } \\
\stackrel{0}{-}\end{array}$ & 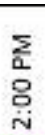 & 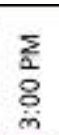 & 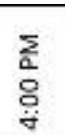 & 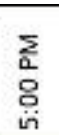 & $\begin{array}{l}\sum_{0}^{2} \\
\stackrel{8}{0}\end{array}$ & $\begin{array}{l}\bar{z} \\
\text { a } \\
\text { o } \\
\dot{\sim}\end{array}$ & 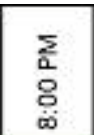 & $\begin{array}{l}\bar{z} \\
0 \\
0 \\
0 \\
0\end{array}$ & $\begin{array}{l}\overline{2} \\
\text { 응 } \\
\dot{0}\end{array}$ & $\begin{array}{l}\overline{2} \\
\frac{1}{8} \\
8 \\
\frac{1}{7}\end{array}$ \\
\hline Downtown Tampa CBD & 7 & \multicolumn{18}{|c|}{ Route $30: 30 \mathrm{~min} / 7 \pi$} \\
\hline University of Tampa & 7 & \multirow{2}{*}{\multicolumn{18}{|c|}{ Route $30: 30 \mathrm{~min} / 11 \mathrm{TI}$}} \\
\hline Tampa General Hospital & 12 & Route $19: 60$ min/16 $\pi$ & & & & & & & & & & & & & & & & & \\
\hline Channelside & 12 & \multirow{2}{*}{\multicolumn{14}{|c|}{ Route $8: 60 \mathrm{~min} / 12 \mathrm{TT}$}} & \multicolumn{4}{|c|}{$x$} \\
\hline Port of Tampa & 13 & \multicolumn{13}{|c|}{ Route $8: 60 \mathrm{~min} / 13 \mathrm{TT}$} & & \multicolumn{4}{|c|}{$\bar{x}$} \\
\hline St. Pete Times Forum/Conv Cnt & 9 & \multicolumn{18}{|c|}{ Route $19: 60 \mathrm{~min} / 10 \mathrm{TT}$} \\
\hline Ybor City & 5 & \multicolumn{14}{|c|}{ Route $8: 60 \mathrm{~min} / 10 \pi$} & \multicolumn{4}{|c|}{$\mathrm{x}$} \\
\hline Busch Gardens & 17 & $\begin{array}{l}\text { Route } \\
5: 60 \\
\text { minv } \\
33 \mathrm{TT}\end{array}$ & & & & Rout & $\& 18$ & $30 \mathrm{mi}$ & & ger 1 & r tota & $33 \pi$ & & & & \begin{tabular}{|c|} 
Route \\
18: 60 \\
min \\
$34 \pi$
\end{tabular} & & $\mathrm{x}$ & \\
\hline Westshore Plaza & 10 & \multicolumn{18}{|c|}{ Route $30: 30 \mathrm{~min} / 26 \pi$} \\
\hline Tampa International Airport & 14 & \multicolumn{18}{|c|}{ Route $30: 30 \mathrm{~min} / 35 \mathrm{TT}$} \\
\hline University of South Florida & 18 & \multicolumn{14}{|c|}{ Route 5: $60 \mathrm{~min} / 40 \mathrm{~T}$} & $\begin{array}{r}\text { Rout } \\
60 \mathrm{mir}\end{array}$ & 65 & \multicolumn{2}{|c|}{$x$} \\
\hline Westfield Brandon Mall & 18 & \multicolumn{14}{|c|}{ Route $8: 60 \mathrm{~min} / 65 \mathrm{TT}$} & \multicolumn{4}{|c|}{$x$} \\
\hline St. Joseph's Hospital & 9 & \multirow{2}{*}{\multicolumn{14}{|c|}{$\begin{array}{l}\text { Route } 7: 60 \mathrm{~min} / 14 \pi \\
\text { Route } 7: 60 \mathrm{~min} / 21 \pi\end{array}$}} & \multicolumn{4}{|c|}{$\bar{x}$} \\
\hline Raymond James Stadium & 9 & & & & & & & & & & & & & & & & & $\bar{x}$ & \\
\hline MacDill Airforce Base & 22 & \multicolumn{18}{|c|}{$x$} \\
\hline
\end{tabular}

Figure 6 -3 cont'd: 2010 Sunday Levels of Public Transportation Service Connecting to HSR 


\section{Observations for Sunday Service}

LYNX maintains service levels from Saturday through Sunday with the exception of Link 41, which has a reduced frequency to 60 minutes.

There is no Sunday public transportation service at either potential HSR station in Polk County.

HART has a mixed level of service to the generators on Sunday. Notably, Route 97 is not in operation, diminishing the downtown and entertainment district connectivity on Sundays. 


\section{CHAPTER 7 \\ OPPORTUNITIES TO ENHANCE HSR CONNECTIVITY}

\section{INTRODUCTION}

This chapter summarizes some of the ideas explored in this study with respect to policy and service opportunities to increase HSR connections to local transit systems.

\section{PLANNING POLICY}

\section{Update Land Use Plans and Create Transit Supportive Policies}

A review of existing land uses will provide some indication of the opportunity for success of Transit Oriented Development and other public transportation supportive policies. With the introduction of the HSR stations, there is an opportunity to channel development in the surrounding area with a focus on reducing transportation impacts.

\section{Increase Biking and Pedestrian Accessways to Local Transit Service and HSR Stations}

Transit trips are more likely to incorporate bike and pedestrian segments within an end-to-end trip. Improvement of pedestrian and bicycle facilities will encourage these less intensive modes of access to bus and rail networks.

\section{Explore Public/Private Partnerships to Increase Levels of Service}

There may be opportunities for public/private partnerships to help pay for connecting lines where high levels of service would be desired. With multiple tourist destinations in each of the three major service areas, there is potential to develop new lines connecting to HSR where costs of providing the service might be shared.

\section{Incorporate HSR as a Mode into Modeling Tools}

Planning projections should consider transit specific modeling tools to focus on non-highway mode ridership projections. HSR connections provide an opportunity for new growth in transit agency use. 


\section{SERVICE POLICY}

\section{Consider the Creation of Service Standards for High-Use HSR Connecting Routes}

A uniform service standard for high-use HSR connecting bus services would convey the image of a reliable and easily understood option for travelers. This could consist of matching the HSR span of service, at minimum on weekdays, to ensure a bus route is always available for a connecting rider. A 30-minute minimum frequency is suggested on routes that exceed 20 passengers per revenue hour to minimize passenger wait times between a train to bus transfer.

\section{Stagger Route Schedules}

Local transit agencies could explore staggering the times of arriving HSR station routes to ensure a consistent level of service throughout an hour. One benefit to this would be a more even distribution of vehicles using the access roads around a station, eliminating potential bus stacking entering and exiting the site. Additionally, HSR trip generators served by more than one bus route could in effect, increase the amount of frequency over an hour with multiple route options that do not all connect at the same time in a station.

\section{Transfer Wait Time Allowance}

Local transit agencies have varying transfer wait time allowances. This means, a bus may stay up to several minutes after its scheduled depart time from designated locations in order to allow transfers to take place. Typically, a connecting ride is running behind schedule and there are passengers on the late vehicle wanting to transfer to another route. In order to accommodate an early or late arriving bus with passengers attempting to transfer onto a HSR train, wait times could be adjusted to facilitate a higher successful transfer percentage.

\section{Coordinate Service Planning}

Future efforts to standardize connecting services could evolve into a formal committee to coordinate service planning at the local level. Currently, there is a limited amount of interagency planning taking place, simply because there are few elements which unite the HSR supporting transit properties. HSR will induce a degree of commonality between the agencies, particularly as the Central Florida area grows into a Super Region. There is an opportunity to create a HSR connecting service scheduling coordination committee, or other group made up of transit agencies in order to increase local system use with a single brand or service at the trip ends. 


\section{Target HSR Station Serving Routes for Frequency, Span, and Days of Service Improvements}

The analysis in Chapter 6 revealed opportunities to enhance local service with improvements to increase frequencies, span, and days of service operations on routes with a significant number of potential HSR trip generators. These routes could be the primary candidates for improvements should funds become available to do so.

\section{Extend or Deviate Nearby Bus Routes into HSR Stations}

There are likely to be a number of significant route changes at the transit agencies before the 2015 opening date of FHSR Phase I. Analysis of existing services provides some insight into what may be operating at that time for making connections. With minor deviations, non-HSR connected routes could serve the stations directly. For example, at HART, many east-west operating lines do not directly connect to the Marion Transit Center. One candidate route for a southern deviation into the future HSR station could be Route 15. Bringing this route south into the HSR station from Columbus Drive would provide a direct connection to the Hard Rock Hotel and Casino. At LYNX, an extension of Route 21 into the OCCC HSR station would connect Dr. Phillips Hospital, Universal Studios Theme Park, Valencia Community College, and the Citrus Bowl.

\section{Consider Enhancement of Existing Lines and New Express Bus Services to Emerging Generators and Unserved Communities}

The following maps and descriptions detail opportunities for enhancing existing services and suggest alignments for new express bus lines to connect generators and cities to HSR. 


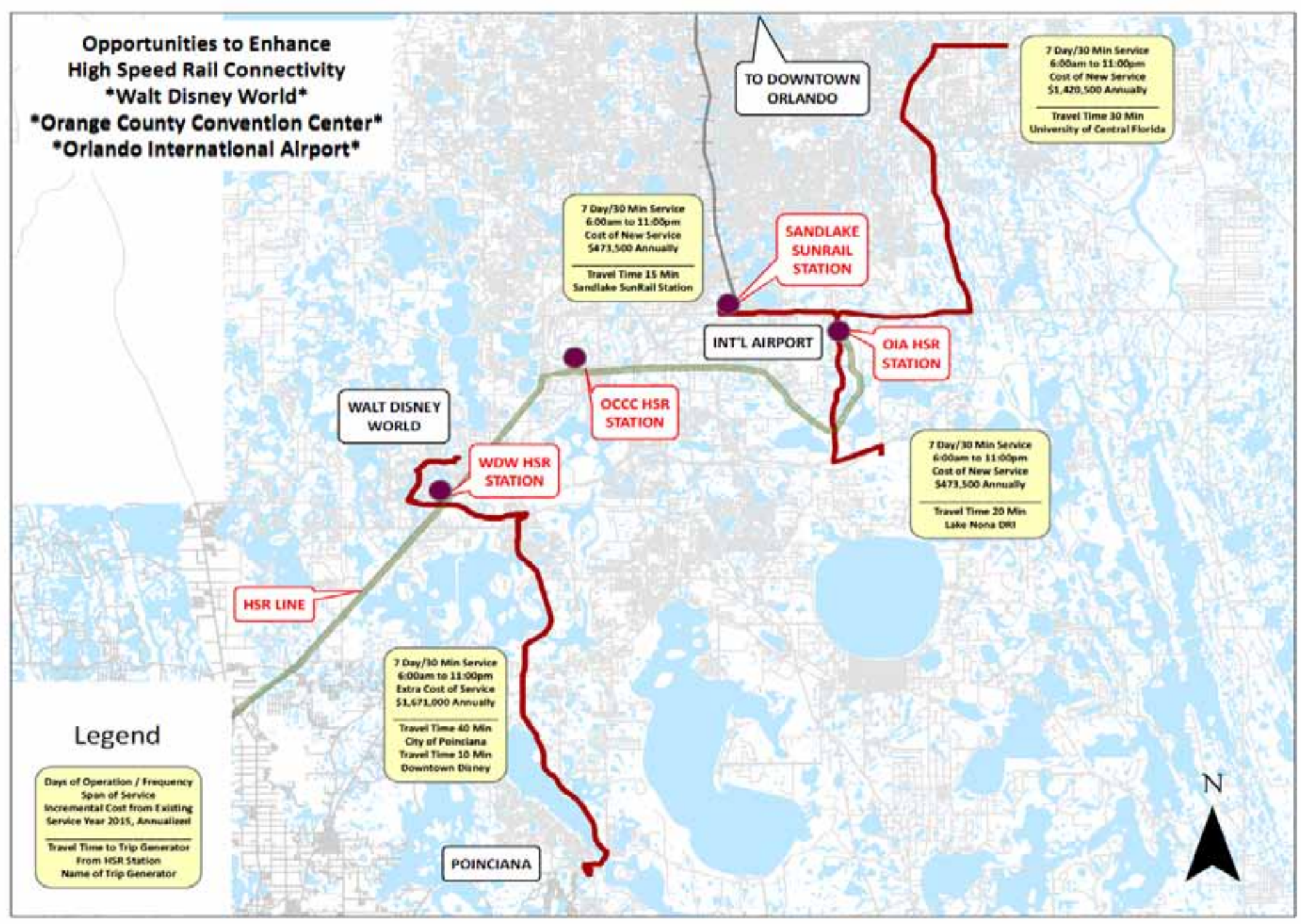

Map 7-1: Opportunities to Enhance High Speed Rail Connectivity *Walt Disney World* *Orange County Convention Center** Orlando International Airport* 


\section{Metro Orlando}

Connecting HSR to the Downtown Disney transfer station, the Lake Nona DRI, and the University of Central Florida with a new service is proposed in the map above. HSR span match and a 30-minute frequency would provide a very competitive and reliable level of service for HSR riders to consider when choosing their connecting mode to these locations. Assuming current service levels and absent a confirmed SunRail to HSR Connector service, a shuttle between OIA and SunRail is proposed, thereby opening up the area north of downtown Orlando to HSR with high capacity and short travel times. 


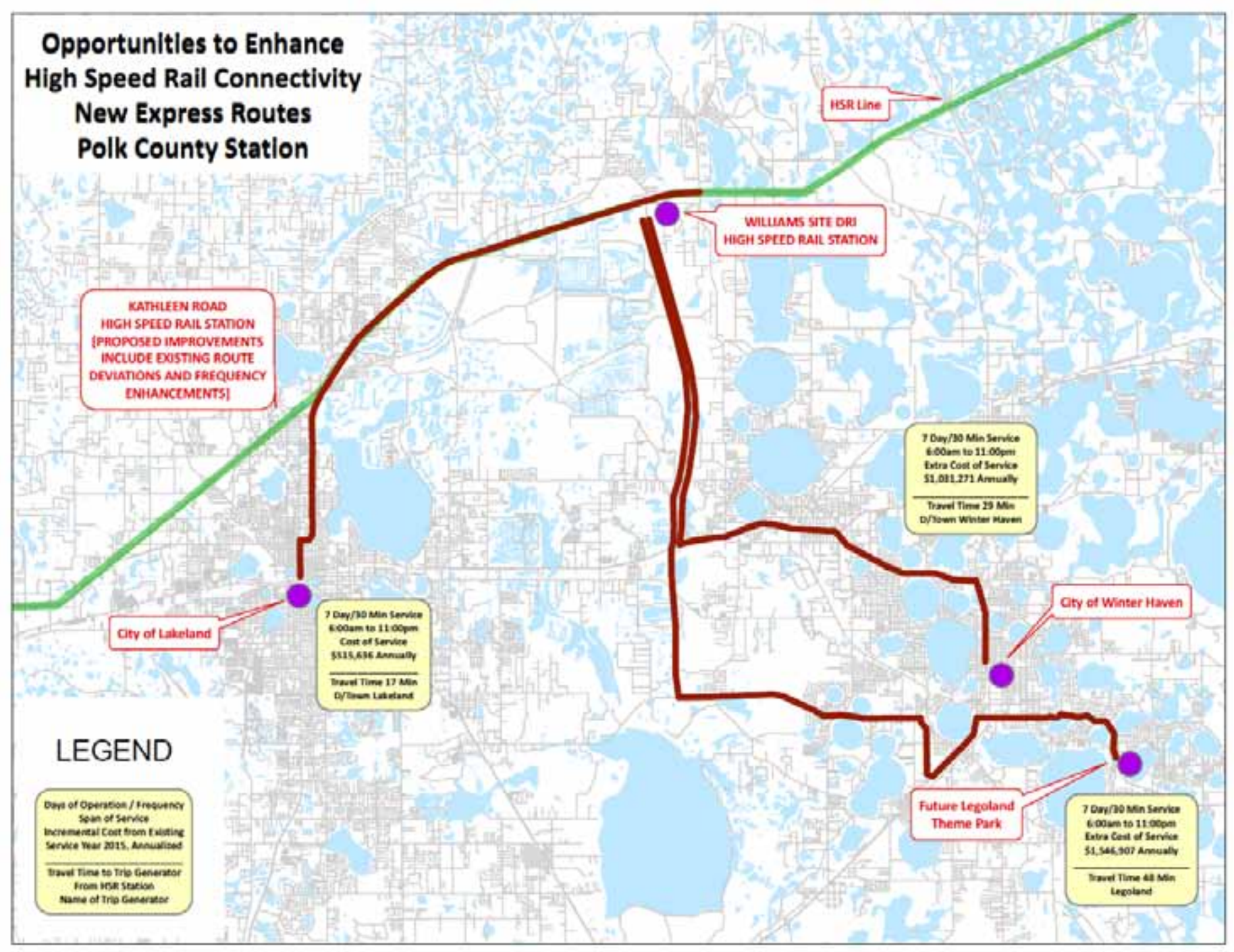

Map 7-2: Opportunities to Enhance High Speed Rail Connectivity with New Express Routes - Polk County Station 


\section{Polk County}

Given Polk County's existing transit network and funding outlook, it would be challenging to provide high levels of service to all corners of the county. However, there are opportunities to target improvements through modifications of existing service and implementing express bus routes to major cities and trip generators.

The Kathleen Road HSR station site has 3 local bus routes, the 50, 51, and 56, which are candidates for deviation into the transfer center. Additionally, Route 12 operates as an express connecting the cities of Lakeland and Winter Haven. Opportunities for route enhancements to improve HSR connectivity include:

- Route 12 - Lakeland/Winter Haven - Increase operating frequency from 60 to 30 minutes and modify span of service to match HSR. Approximate annual operating cost = $\$ 705,000$

- Route 50 - Kathleen/Providence - Deviate route into HSR station. Increase operating frequency from 60 to 30 minutes and modify span of service to match HSR. Approximate annual operating cost $=\$ 720,000$

- Route 51 - North 98/Duff Rd - Deviate route in to HSR station. Modify span of service to match HSR. Approximate annual operating cost $=\$ 380,000$

- Route 56 - Kathleen/Mall Hill Dr - Deviate route into HSR station. Increase operating frequency from 60 to 30 minutes and modify span of service to match HSR. Approximate annual operating cost $=\$ 705,000$

The Williams DRI site currently has no service to the proposed HSR station and has a limited number of new fixed routes proposed in existing five year plans. Opportunities beyond the multistop local routes planned for implementation are found in the potential for two new express services. One new express bus line would connect to downtown Lakeland in a 17-minute travel time with no other stops from HSR. The Polk County map details two potential alignments for an express service to the east. One alignment is direct to the City of Winter Haven and the other directly connects the future Legoland Theme Park. These services are somewhat duplicative and therefore a single express, connecting HSR through Winter Haven to Legoland, may be ideal for serving riders in the area if a private or public/private Legoland service is not developed in the future. 


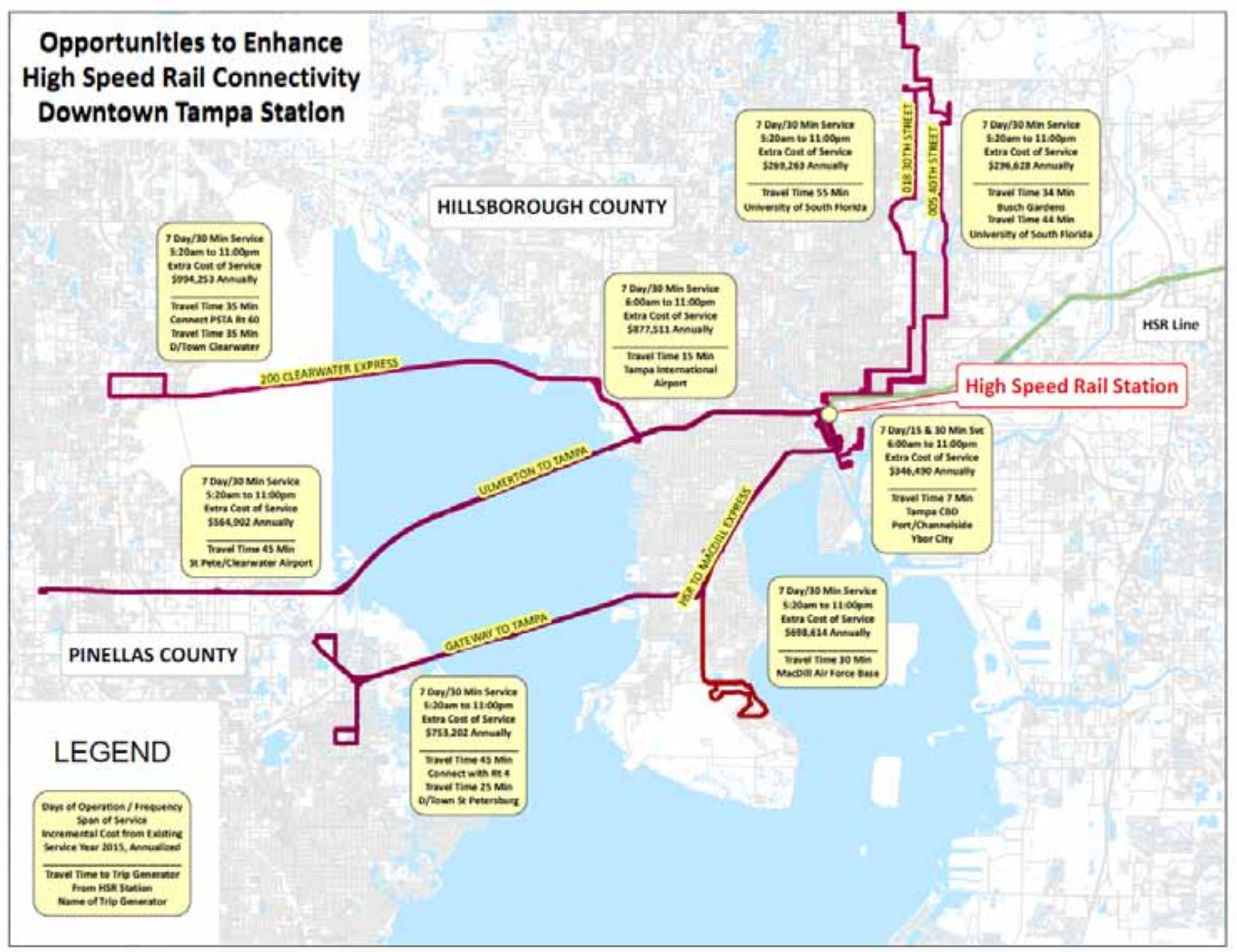

Map 7-3: Opportunities to Enhance High Speed Rail Connectivity Downtown Tampa Station 


\section{Tampa Bay}

The Tampa Bay HSR station connectivity could be enhanced by increasing the levels of service on three existing Express Routes that traverse the Bay. The 100x, 200x and 300x bring together two large metropolitan areas and open up the PSTA transit network to Tampa. Opportunities to increase levels to a matching span of service and increased frequency are uncovered in Chapter 6 and Map 7.3. A future Express Bus network in Pinellas County would connect these cross bay Expresses with major trip generators in St Petersburg, Clearwater, and other municipalities. An ongoing Alternatives Analysis in Pinellas County might result in replacing these Expresses with a single rail line across the Howard Frankland Bridge to HSR.

Two alternative alignments for service to USF and Busch Gardens could be improved with an increased span of service and improved frequency via HART Routes 5 and 18. A Tampa International Airport Express Bus Route is identified in Map 7.3 with associated operating costs. An increase in downtown, Channelside, and Ybor City connecting service levels is described as well as a dedicated express service to MacDill Air Force Base with HSR matching span and a 30-minute vehicle frequency.

\section{Deploy Traveler Information Systems that Inform Riders of Real-Time Arrival and Departure Times}

Traveler information systems are an important component of a transit system that provides riders assurance of adherence to published schedules. The ability of a quality customer information system to meet the needs of riders from the point of origin to final destination and at all points in-between, makes a system a more attractive experience to draw in new users. TCRP 48 summarized studies that found shorter wait times were reported by well over half of individuals surveyed at stations and stops with real-time bus information where frequencies had not actually changed (Schweiger, 2003). There is an opportunity to provide real-time bus arrivals and departures at HSR stations to facilitate connections.

Given the widespread availability of mobile technology, never before have transit users had the capabilities to plan and manage travel across multiple public transportation systems in such a dynamic way. FHSR and local transit providers will have the opportunity to fully develop an endto-end traveler information solution that will guide decision making. Riders have a need for unique types of information at separate times during the three stages of transit travel trip planning, trip commencement, and while en-route.

With the more widespread adoption of mobile technologies in recent years, information that could previously only be retrieved on a personal computer with a fixed data line can now be retrieved with any number of mobile devices. System maps with real-time bus locations and estimated times of arrival that can be viewed on mobile devices are now standard features offered by many transit agencies. To access such information at stations, passengers need either a laptop with a wireless connection, connected PDA, or Smartphone with a data plan. Other options to access this information without needing a data plan include the ability to text 
message a stations ID number to a service and have an estimated arrival time returned, a service currently provided by Tri-Met in Portland.

\section{Consider Bus Specifications to Serve the Needs of HSR Travelers}

A standard transit coach is typically designed with the most fundamental elements of service operation in mind. Interior seating is laid out in order to maximize the number of passengers that can stand or be seated and travel safely. Common amenities are things such air conditioning, basic cash or pass fare collection, padded seating, and low floors for easy ingress and egress. There is uniformity in the bus construction to allow for ease of maintaining major vehicle systems. Exterior bus painting may tend to be more modest in selection of colors and design that cross a number of body panels as vehicle striping is more costly and laborious to perform when elaborate paint schemes are used. Function generally prevails over form in operating an urban transit system.

By contrast, the impression of maintaining a quality connection between HSR and local transit goes beyond the bus schedules and destinations served. The premium transit experience should not end when a rider transfers from rail onto bus. A composite transit vehicle from other bus modes can be envisioned that meets the unique needs of a HSR traveler.

A premium bus transit mode, Bus Rapid Transit (BRT), offers enhanced specifications for a vehicle, that might help to maintain the quality HSR ride experience that may attract increased ridership:

- Train-like ride experience

- Level HSR Station boarding

- Wider passageway and access

- Onboard amenities such as wireless internet connectivity

BRT buses are designed for commuters and higher capacities than may be necessary for HSR express connector services. This will serve the business and commuter traveler well. However, they lack space for baggage or luggage that will be required for the expected predominant HSR passenger, a tourist or leisure rider. An airport shuttle bus, such as the Miami-Dade Transit operated 'Airport Flyer', is an example of a bus with specifications to serve the intercity visitor that may travel with baggage. The buses feature overhead luggage space for travelers to place their belongings, similar to the overhead storage found in an airplane. 


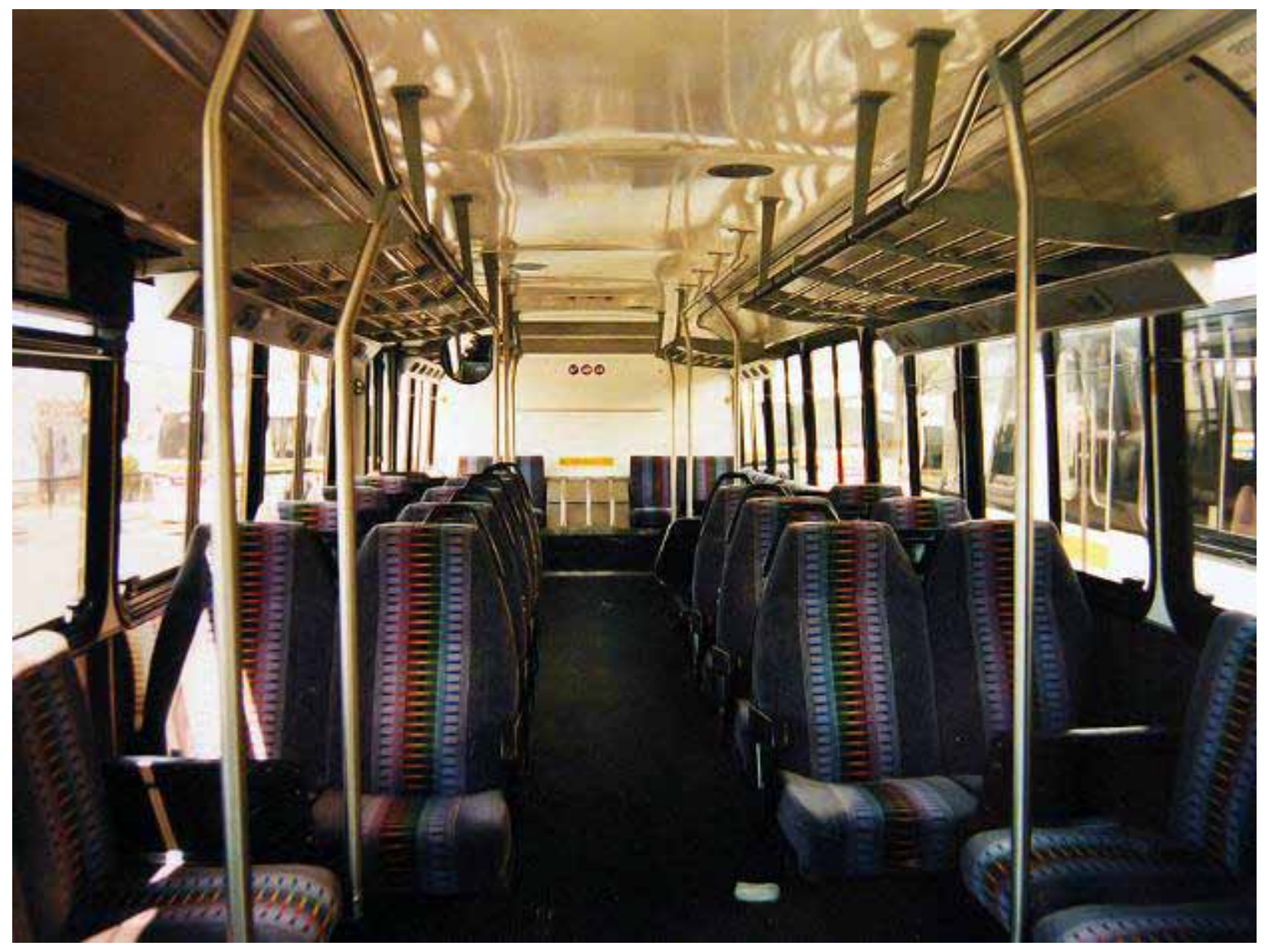

Figure 7-1 - Interior of a Public Transit Vehicle with Overhead Storage

\section{Integrate Fare Collection Across Transportation Systems}

Local transit systems offer a cost competitive advantage for HSR-connecting services. All day ride fares among the transit systems connecting to HSR range typically do not exceed four dollars.

In the Tampa to Orlando HSR corridor there are 4 local transit operators, each with an independently operated fare collections system, fare structure, and policy. The integration of fare collection is being pursued through state legislation that requires any new fare collection system to utilize open source encoding on fare media. This will allow for interoperability from a technical standpoint but does not address the myriad issues associated with how to divide revenues and manage any backend clearinghouse required to create a single form of fare payment.

A short term goal to ensure a seamless travel trip across modes is to offer a local system transit pass to a passenger at the point of sale of an HSR fare. This end-to-end trip booking may require the customer to buy two additional transit fares in order to travel all systems in two cities and might unduly burden or confuse a patron with multiple fare media. The benefit of this 
arrangement is that a patron would have all of the required travel fares purchased and in hand in advance of the trip.

Another option would be to work with the local transit operators to accept the flash of a HSR ticket or stub to demonstrate that they were a paying customer of the HSR system and ride transit services for that system at no cost. A bus operator would press a predefined key on the farebox that would record a HSR rider boarding to monitor that rider type. The reimbursement of the fare from HSR to the agency could take place post trip through a periodic reconciliation of fares through a pre-negotiated arrangement.

Longer term, there are models for a universal payment system that could be candidates for implementation to serve HSR. LYNX has demonstrated this via the ORANGES project, which allowed for multiple agency fee payments related to transportation in the Orlando area. SunPass is an effective toll and parking fee payment system that eases user involvement and smart card systems for transit agencies could be implemented to include HSR acceptance. 


\section{REFERENCES}

Albalate, D., Bel, G., High Speed Rail: Lessons for Policy Makers from Experiences Abroad. University of Barcelona, Spain (2010)

Central Florida Regional Transportation Authority, "LYNX Transit Development Plan Annual Update and Progress Report for Fiscal Year 2011" Orlando, FL (2010)

Central Florida Regional Transportation Authority, "Transit Services for the Lake Nona/Medical City Area Proposal", Orlando, FL (March, 2010)

Facchinetti-Mannone, V., Location of High Speed Rail Stations in French Medium Size City and Their Mobility and Territorial Implications. University of Burgundy, France (2010)

Florida Department of Transportation, "2060 Florida Transportation Plan", Tallahassee, FL (2010)

Florida Department of Transportation, "Florida Intercity Passenger Rail Vision Plan", Tallahassee, FL (2006)

Florida Department of Transportation, "Quality Time, Central Florida Commuter Rail”, Retrieved from http://www.sunrail.com/Files/Brochures/Brochure QualityTime.pdf (November 8, 2010)

Florida Department of Transportation, Florida Rail Enterprise, "FLHSR Fact Sheet", Retrieved from http://www.floridahighspeedrail.org (Webpage accessed December 15, 2010)

Gernert, B., "Williams Co. Offers High Speed Rail Station Location", Retrieved from http://blog.winterhavenfl.com/2010/02/16/williams-co-offers-high-speed-rail-station-location/ on September 19, 2010.

Hillsborough Area Regional Transit Authority, "2010-2019 Transit Development Plan Update" Tampa, FL (September, 2009)

Jackovics, T., "Proposed Rail Complex Could Be Catalyst for Development" Retrieved from http://www2.tbo.com/content/2010/jul/25/na-proposed-rail-complex-could-be-catalyst-for-dev/ on September 2, 2010

Leftwich Consulting, "2030 Long Range Transportation Plan”, Prepared for Metroplan Orlando, Orlando, FL (2009)

Leigh Fisher Associates, Coogan, M., Marketsense, "Improving Public Transportation Access to Large Airports", TCRP Report 62. Transportation Research Board, Washington, DC (2000) 
Leigh Fisher Associates, Coogan, M., Marketsense, "Strategies for Improving Public Transportation Access to Large Airports", TCRP Report 83. Transportation Research Board, Washington, DC (2002)

Pinellas County Metropolitan Planning Organization, "2035 Pinellas County Long Range Transportation Plan" (2009)

Polk County Transportation Planning Organization, "2035 Polk Mobility Vision Plan”, Bartow, FL (2010)

Schweiger, C., "Real-Time Bus Arrival Information Systems: A Synthesis of Transit Practice", TCRP Synthesis 48. Transportation Research Board, 2003

Shin, D., Recent Experience of and Prospects for High-Speed Rail in Korea: Implications of a Transport System and Regional Development from a Global Perspective, University of California, Institute of Urban and Regional Development, Berkeley, CA (2005)

Studiale, J., "Local Planning Efforts and the Benefits of High Speed Rail"; City of Lakeland, FL, Retrieved from http://www.floridahighspeedrail.org/nov-2010-forum-docs/tuesday-nov-9presentations/110910 KathleenStation PPT-web.pdf (November 21, 2010)

Tampa Bay Area Regional Transportation Authority, Tampa Bay Area Regional Transportation Authority Master Plan (2009)

Tindale-Oliver and Associates, "Polk Consolidated Transit Development Plan 2008-2017", Prepared for the Polk County Transportation Planning Organization, Bartow, FL (2007)

Tindale-Oliver and Associates, "PSTA 2011-2020 Transit Development Plan", Prepared for the Pinellas Suncoast Transit Authority, St. Petersburg, FL (2010)

U.S. Department of Transportation, Federal Railroad Administration, Florida Department of Transportation, "Florida High Speed Rail - Tampa to Orlando, Final Environmental Impact Statement" (May, 2010)

U.S. Department of Transportation, Federal Railroad Administration, "Florida High Speed Rail Tampa to Orlando, Record of Decision", Washington, DC (2010)

University of California at Irvine, Institute of Transportation Studies, "Thinking Ahead in HighSpeed Rail in Southern California", Irvine, CA (Summer 2010)

University of Pennsylvania, City Planning 702 Design Studio, "Connecting for Global Competitiveness: Florida's Super Region", Prepared for the Tampa Bay Partnership and Central Florida Partnership (Spring, 2010) 
University of South Florida, Center for Urban Transportation Research, "Best Practices in Service Planning", Prepared for the Florida Department of Transportation, Tallahassee, FL (2009)

University of South Florida, Center for Urban Transportation Research, "Florida Transit Handbook", Prepared for the Florida Department of Transportation, Tallahassee, FL (2010)

Urbitran Associates, Inc., Multisystems, Inc., SG Associates, Inc., Cervero, R., "Guidelines for Enhancing Suburban Mobility Using Public Transportation", TCRP Report 55. Transportation Research Board (Washington, DC 1999) 
This page intentionally left blank 


\section{APPENDIX A}




\begin{tabular}{|c|c|c|c|c|c|c|c|}
\hline $\begin{array}{l}\text { Route } \\
\text { Number }\end{array}$ & Route Description & $\begin{array}{l}\text { Weekday- } \\
\text { Span of } \\
\text { Service }\end{array}$ & $\begin{array}{l}\text { Weekday- } \\
\text { Frequency } \\
\text { (Peak/ Off- } \\
\text { Peak) }\end{array}$ & $\begin{array}{c}\text { Saturday - Span } \\
\text { of Service }\end{array}$ & $\begin{array}{c}\text { Saturday - } \\
\text { Frequency } \\
\text { (Peak/ Off- } \\
\text { Peak) }\end{array}$ & $\begin{array}{c}\text { Sunday - Span of } \\
\text { Service }\end{array}$ & $\begin{array}{c}\text { Sunday - } \\
\text { Frequency } \\
\text { (Peak/ Off- } \\
\text { Peak) }\end{array}$ \\
\hline \multicolumn{8}{|c|}{ Lynx (Orlando) } \\
\hline 1 & $\begin{array}{c}\text { Winter } \\
\text { Park/Altamonte } \\
\text { Springs }\end{array}$ & $\begin{array}{l}\text { 5:10 am - } \\
9: 30 \mathrm{pm}\end{array}$ & 60 & $5: 10 \mathrm{am}-9: 05 \mathrm{pm}$ & 60 & $\mathrm{n} / \mathrm{a}$ & $\mathrm{n} / \mathrm{a}$ \\
\hline 3 & Lake Margaret & $\begin{array}{l}\text { 4:30 am - } \\
9: 57 \mathrm{pm}\end{array}$ & 60 & $4: 30 \mathrm{am}-9: 57 \mathrm{pm}$ & 60 & $4: 15 \mathrm{am}-8: 35 \mathrm{pm}$ & 60 \\
\hline 4 & $\begin{array}{c}\text { South US } \\
441 / \text { Kissimmee }\end{array}$ & $\begin{array}{l}4: 15 \mathrm{am}- \\
2: 05 \mathrm{am}\end{array}$ & $30 / 15$ & $\begin{array}{c}4: 45 \mathrm{am}-11: 35 \\
\mathrm{pm}\end{array}$ & 30 & $\begin{array}{c}4: 39 \mathrm{am}-10: 05 \\
\mathrm{pm}\end{array}$ & 30 \\
\hline 6 & Dixie Belle & $\begin{array}{l}4: 21 \mathrm{am} \mathrm{-} \\
9: 11 \mathrm{pm}\end{array}$ & 60 & $4: 21 \mathrm{am}-9: 11 \mathrm{pm}$ & 60 & $\mathrm{n} / \mathrm{a}$ & $\mathrm{n} / \mathrm{a}$ \\
\hline 7 & $\begin{array}{c}\text { S Orange } \\
\text { Ave/Florida Mall }\end{array}$ & $\begin{array}{l}4: 15 \mathrm{am}- \\
12: 50 \mathrm{am}\end{array}$ & 60 & $\begin{array}{c}4: 15 \text { am - } 12: 50 \\
\text { am }\end{array}$ & 60 & $5: 15 \mathrm{am}-8: 35 \mathrm{pm}$ & 60 \\
\hline 8 & $\begin{array}{l}\text { W. Oak Ridge } \\
\text { Rd/Int'I Dr. }\end{array}$ & $\begin{array}{l}4: 45 \mathrm{am}- \\
3: 10 \mathrm{am}\end{array}$ & 15 & $\begin{array}{c}4: 45 \mathrm{am}-10: 05 \\
\mathrm{pm}\end{array}$ & $15 / 30$ & $\begin{array}{c}4: 45 \text { am - 10:05 } \\
\text { pm }\end{array}$ & $15 / 30$ \\
\hline 9 & $\begin{array}{c}\text { Winter } \\
\text { Park/Rosemont }\end{array}$ & $\begin{array}{l}5: 40 \mathrm{am}- \\
12: 29 \mathrm{am}\end{array}$ & $60 / 90$ & $5: 40 \mathrm{am}-9: 59 \mathrm{pm}$ & $60 / 90$ & $5: 40 \mathrm{am}-7: 55 \mathrm{pm}$ & 60 \\
\hline 10 & $\begin{array}{l}\text { East US 192/ST } \\
\text { Cloud }\end{array}$ & $\begin{array}{l}4: 00 \mathrm{am}- \\
11: 11 \mathrm{pm}\end{array}$ & 60 & $\begin{array}{c}\text { 4:00 am - 11:11 } \\
\mathrm{pm}\end{array}$ & 60 & $\mathrm{n} / \mathrm{a}$ & $\mathrm{n} / \mathrm{a}$ \\
\hline 11 & $\begin{array}{c}\text { S Orange } \\
\text { Ave/Orlando INTL } \\
\text { Airport }\end{array}$ & $\begin{array}{l}5: 00 \mathrm{am}- \\
12: 35 \mathrm{am}\end{array}$ & $30 / 60$ & $\begin{array}{c}5: 00 \mathrm{am}-10: 35 \\
\mathrm{pm}\end{array}$ & $30 / 60$ & 5:45 am - 9:05 pm & 60 \\
\hline 13 & $\begin{array}{c}\text { University of Central } \\
\text { Florida }\end{array}$ & $\begin{array}{l}4: 30 \mathrm{am}- \\
12: 05 \mathrm{am}\end{array}$ & 60 & $\begin{array}{c}4: 30 \mathrm{am}-12: 05 \\
\mathrm{am}\end{array}$ & 60 & $5: 23 \mathrm{am}-9: 35 \mathrm{pm}$ & 60 \\
\hline 14 & Calvary Towers & $\begin{array}{l}\text { 6: } 15 \mathrm{am} \mathrm{-} \\
8: 35 \mathrm{pm}\end{array}$ & 60 & $6: 15 \mathrm{am}-8: 35 \mathrm{pm}$ & 60 & $6: 15 \mathrm{am}-6: 35 \mathrm{pm}$ & 60 \\
\hline 15 & $\begin{array}{c}\text { Curry Ford Rd/VCC } \\
\text { East }\end{array}$ & $\begin{array}{l}4: 45 \mathrm{am}- \\
1: 05 \mathrm{am}\end{array}$ & $30 / 60$ & $\begin{array}{c}\text { 4:45 am - 11:05 } \\
\text { pm }\end{array}$ & $30 / 60$ & $\begin{array}{c}5: 15 \mathrm{am}-10: 05 \\
\mathrm{pm}\end{array}$ & 60 \\
\hline 17 & $\begin{array}{l}\text { North US } \\
\text { 441/Apopka }\end{array}$ & $\begin{array}{l}4: 45 \mathrm{am}- \\
1: 35 \mathrm{am}\end{array}$ & $30 / 60$ & $\begin{array}{c}4: 45 \underset{\mathrm{pm}}{\mathrm{am}}-10: 35 \\
\text { a }\end{array}$ & $30 / 60$ & $4: 45 \mathrm{am}-8: 35 \mathrm{pm}$ & 60 \\
\hline 18 & $\begin{array}{c}\text { S Orange } \\
\text { Ave/Kissimmee }\end{array}$ & $\begin{array}{l}5: 10 \mathrm{am}- \\
11: 20 \mathrm{pm}\end{array}$ & 60 & $\begin{array}{c}5: 10 \mathrm{am}-11: 20 \\
\mathrm{pm}\end{array}$ & 60 & $\mathrm{n} / \mathrm{a}$ & $\mathrm{n} / \mathrm{a}$ \\
\hline 20 & Malibu/Pine Hills & $\begin{array}{l}4: 51 \mathrm{am}- \\
10: 14 \mathrm{pm}\end{array}$ & 60 & $\begin{array}{c}4: 51 \mathrm{am}-10: 14 \\
\mathrm{pm}\end{array}$ & 60 & $5: 00 \mathrm{am}-8: 31 \mathrm{pm}$ & 60 \\
\hline 21 & Carver Shores & $\begin{array}{l}4: 16 \mathrm{am}- \\
2: 05 \mathrm{am}\end{array}$ & $30 / 60$ & 4:16 am - 2:05 am & $30 / 60$ & $\begin{array}{c}4: 42 \mathrm{am}-10: 05 \\
\mathrm{pm}\end{array}$ & 60 \\
\hline 23 & $\begin{array}{c}\text { Winter Park/Springs } \\
\text { Village }\end{array}$ & $\begin{array}{l}5: 15 \mathrm{am}- \\
8: 44 \mathrm{pm}\end{array}$ & 60 & $5: 15 \mathrm{am}-8: 44 \mathrm{pm}$ & 60 & $\mathrm{n} / \mathrm{a}$ & $\mathrm{n} / \mathrm{a}$ \\
\hline 24 & Millenia & $\begin{array}{l}\text { 6:05 am - } \\
6: 26 \mathrm{pm}\end{array}$ & 60 & $6: 05 a m-6: 26 p m$ & 60 & $6: 35 \mathrm{am}-6: 20 \mathrm{pm}$ & 60 \\
\hline
\end{tabular}




\begin{tabular}{|c|c|c|c|c|c|c|c|}
\hline $\begin{array}{l}\text { Route } \\
\text { Number }\end{array}$ & Route Description & $\begin{array}{c}\text { Weekday- } \\
\text { Span of } \\
\text { Service }\end{array}$ & $\begin{array}{l}\text { Weekday- } \\
\text { Frequency } \\
\text { (Peak/ Off- } \\
\text { Peak) }\end{array}$ & $\begin{array}{c}\text { Saturday - Span } \\
\text { of Service }\end{array}$ & $\begin{array}{l}\text { Saturday - } \\
\text { Frequency } \\
\text { ( Peak/ Off- } \\
\text { Peak) }\end{array}$ & $\begin{array}{c}\text { Sunday - Span of } \\
\text { Service }\end{array}$ & $\begin{array}{c}\text { Sunday - } \\
\text { Frequency } \\
\text { (Peak/ Off- } \\
\text { Peak) }\end{array}$ \\
\hline 26 & $\begin{array}{l}\text { Pleasant Hill } \\
\text { Rd/Poinciana }\end{array}$ & $\begin{array}{l}\text { 5:30 am - } \\
9: 49 \mathrm{pm}\end{array}$ & 60 & $5: 30 \mathrm{am}-9: 44 \mathrm{pm}$ & 60 & $\mathrm{n} / \mathrm{a}$ & $n / a$ \\
\hline 28 & $\begin{array}{c}\text { E Colonial } \\
\text { DR/Azalea Park }\end{array}$ & $\begin{array}{l}4: 15 \mathrm{am}- \\
1: 05 \mathrm{am}\end{array}$ & $30 / 60$ & 4:45 am - 10:05 pm & 60 & 4:45 am - 8:05 pm & 60 \\
\hline 29 & $\begin{array}{c}\text { E Colonial } \\
\text { DR/Goldenrod }\end{array}$ & $\begin{array}{l}4: 30 \mathrm{am}- \\
1: 35 \mathrm{am}\end{array}$ & $30 / 60$ & $\begin{array}{c}\text { 5: } 15 \text { am - 10:35 } \\
\text { pm }\end{array}$ & 60 & $5: 15$ am - 8:35 pm & 60 \\
\hline 30 & $\begin{array}{l}\text { Colonial DR } \\
\text { Crosstown }\end{array}$ & $\begin{array}{l}4: 45 \mathrm{am}- \\
11: 45 \mathrm{pm}\end{array}$ & $30 / 60$ & $\begin{array}{c}\text { 4:30 am - 11:37 } \\
\text { pm }\end{array}$ & $30 / 60$ & 5:45 am - 9: $19 \mathrm{pm}$ & 60 \\
\hline 31 & LYMMO & $\begin{array}{c}\text { 6:00 am - } \\
\text { 10:00 pm } \\
\text { (M-Th)/ 6:00 } \\
\text { am - 12:00 } \\
\text { am (Friday) }\end{array}$ & every $5 / 10$ & $\begin{array}{c}\text { 10:00 am - 12:00 } \\
\text { am }\end{array}$ & every $5 / 10$ & $\begin{array}{c}\text { 10:00 am - 10:00 } \\
\text { pm }\end{array}$ & every $5 / 10$ \\
\hline 34 & Sanford/Goldsboro & $\begin{array}{l}\text { 5:15 am - } \\
\text { 9:05 pm }\end{array}$ & 60 & 5:15 am - 9:05 pm & 60 & $\mathrm{n} / \mathrm{a}$ & $\mathrm{n} / \mathrm{a}$ \\
\hline 36 & Lake Richmond & $\begin{array}{l}4: 45 \mathrm{am}- \\
12: 20 \mathrm{am}\end{array}$ & $30 / 60$ & $4: 45$ am - 9:20 pm & $30 / 60$ & $6: 15 \mathrm{am}-8: 05 \mathrm{pm}$ & 60 \\
\hline 37 & $\begin{array}{l}\text { Park Promenade/ } \\
\text { Florida Mall }\end{array}$ & $\begin{array}{l}4: 45 \mathrm{am} \mathrm{-} \\
10: 58 \mathrm{pm}\end{array}$ & 30 & $\begin{array}{c}5: 20 \mathrm{am}-10: 25 \\
\mathrm{pm}\end{array}$ & 30 & $5: 20 \mathrm{am}-9: 57 \mathrm{pm}$ & 60 \\
\hline 38 & $\begin{array}{c}\text { Downtown } \\
\text { Orlando/Int'I Dr. }\end{array}$ & $\begin{array}{l}\text { 6:00 am - } \\
9: 20 \mathrm{am} / \\
2: 00 \mathrm{pm}- \\
5: 50 \mathrm{pm}\end{array}$ & 15 & $\begin{array}{c}6: 00 \mathrm{am}-9: 20 \\
\mathrm{am} / 2: 00 \mathrm{pm}- \\
5: 50 \mathrm{pm}\end{array}$ & 15 & $\begin{array}{c}\text { 6:15 am - 9:05 } \\
\text { am/ 2:15 pm - } \\
\text { 5:35 pm }\end{array}$ & 30 \\
\hline 40 & $\begin{array}{c}\text { Americana } \\
\text { Blvd/Universal } \\
\text { Orlando }\end{array}$ & $\begin{array}{l}\text { 4:00 am - } \\
1: 35 \mathrm{am}\end{array}$ & $45 / 60$ & 4:00 am - 1:35 am & $45 / 60$ & 4:45 am- 8: 35 pm & 60 \\
\hline 41 & State Road 436 & $\begin{array}{l}4: 15 \mathrm{am}- \\
12: 26 \mathrm{am}\end{array}$ & 30 & $\begin{array}{c}4: 15 \text { am - } 12: 26 \\
\text { am }\end{array}$ & 30 & $\begin{array}{c}4: 58 \mathrm{am}-11: 21 \\
\mathrm{pm}\end{array}$ & 60 \\
\hline 42 & $\begin{array}{l}\text { Int'I Dr/Orlando Int'I } \\
\text { Airport }\end{array}$ & $\begin{array}{l}4: 36 \mathrm{am}- \\
12: 25 \mathrm{am}\end{array}$ & $25 / 30$ & $\begin{array}{c}4: 36 \text { am - } 12: 25 \\
\text { am }\end{array}$ & $25 / 30$ & 5: 16 am - 11:06 & 60 \\
\hline 44 & Hiawassee/Zellwood & $\begin{array}{c}\text { 5:07 am - } \\
\text { 9:10 pm }\end{array}$ & 60 & 5:07 am - 9:10 pm & 60 & $\mathrm{n} / \mathrm{a}$ & $\mathrm{n} / \mathrm{a}$ \\
\hline 45 & Lake Mary & $\begin{array}{l}\text { 5:06 am - } \\
\text { 7:57 pm/ } \\
\text { 5:27 am - }\end{array}$ & 60 & $\begin{array}{c}\text { 5:06 am - 7:57 } \\
\mathrm{pm} / 5: 27 \mathrm{am}- \\
7: 57 \mathrm{pm}\end{array}$ & 60 & $\mathrm{n} / \mathrm{a}$ & $\mathrm{n} / \mathrm{a}$ \\
\hline
\end{tabular}




\begin{tabular}{|c|c|c|c|c|c|c|c|}
\hline $\begin{array}{l}\text { Route } \\
\text { Number }\end{array}$ & Route Description & $\begin{array}{l}\text { Weekday- } \\
\text { Span of } \\
\text { Service }\end{array}$ & $\begin{array}{l}\text { Weekday- } \\
\text { Frequency } \\
\text { (Peak/ Off- } \\
\text { Peak) }\end{array}$ & $\begin{array}{c}\text { Saturday - Span } \\
\text { of Service }\end{array}$ & $\begin{array}{l}\text { Saturday - } \\
\text { Frequency } \\
\text { (Peak/ Off- } \\
\text { Peak) }\end{array}$ & $\begin{array}{c}\text { Sunday - Span of } \\
\text { Service }\end{array}$ & $\begin{array}{c}\text { Sunday - } \\
\text { Frequency } \\
\text { (Peak/ Off- } \\
\text { Peak) }\end{array}$ \\
\hline $46 W$ & $\begin{array}{l}\text { W. SR 46/Seminole } \\
\text { Towne Center }\end{array}$ & $\begin{array}{l}\text { 6: } 15 \mathrm{am}- \\
8: 59 \mathrm{pm}\end{array}$ & 60 & $6: 55 \mathrm{am}-9: 21 \mathrm{pm}$ & 60 & $6: 20 \mathrm{am}-7: 59 \mathrm{pm}$ & 60 \\
\hline 48 & $\begin{array}{l}\text { W Colonial Dr/Park } \\
\text { Promenade Plaza }\end{array}$ & $\begin{array}{l}4: 14 \mathrm{am}- \\
12: 16 \mathrm{am}\end{array}$ & $30 / 60$ & $\begin{array}{c}4: 45 \text { am - 10:05 } \\
\text { pm }\end{array}$ & 60 & 4:45 am - 8:05 pm & 60 \\
\hline 49 & $\begin{array}{l}\text { W Colonial Dr/ } \\
\text { Pine Hills }\end{array}$ & $\begin{array}{l}4: 30 \mathrm{am}- \\
12: 45 \mathrm{am}\end{array}$ & $30 / 60$ & $\begin{array}{c}5: 15 \text { am }-10: 35 \\
\text { pm }\end{array}$ & 60 & 5:15 am - 8:35 pm & 60 \\
\hline 50 & $\begin{array}{l}\text { DowntownOrlando/ } \\
\text { Magic Kingdom }\end{array}$ & $\begin{array}{l}5: 15 \mathrm{am}- \\
1: 05 \mathrm{am}\end{array}$ & 30 & $5: 15$ am - 1:05 am & 30 & 5:15 am - 1:05 am & 30 \\
\hline 51 & $\begin{array}{l}\text { Conway/Orlando } \\
\text { Intl Airport }\end{array}$ & $\begin{array}{l}5: 15 \mathrm{am}- \\
10: 20 \mathrm{pm}\end{array}$ & 60 & $\begin{array}{c}5: 15 \text { am - 10:20 } \\
\text { pm }\end{array}$ & 60 & 5:15 am - 9:05 pm & 60 \\
\hline 54 & $\begin{array}{c}\text { Old Winter Garden } \\
\text { Rd }\end{array}$ & $\begin{array}{l}\text { 5:25 am - } \\
8: 22 \mathrm{pm}\end{array}$ & 60 & $5: 25 \mathrm{am}-8: 22 \mathrm{pm}$ & 60 & $\mathrm{n} / \mathrm{a}$ & $\mathrm{n} / \mathrm{a}$ \\
\hline 55 & $\begin{array}{c}\text { West US 192/Four } \\
\text { Corners }\end{array}$ & $\begin{array}{l}5: 30 \mathrm{am}- \\
10: 10\end{array}$ & 30 & $5: 30 \mathrm{am}-10: 10$ & 30 & $5: 30$ am - 10:13 & 30 \\
\hline 56 & $\begin{array}{c}\text { West US 192/Magic } \\
\text { Kingdom }\end{array}$ & $\begin{array}{l}5: 45 \mathrm{am}- \\
11: 30 \mathrm{pm}\end{array}$ & 30 & $\begin{array}{c}5: 45 a m-11: 30 \\
p m\end{array}$ & 30 & $\begin{array}{c}5: 45 a m-11: 30 \\
p m\end{array}$ & 30 \\
\hline 57 & J ohn Young Parkway & $\begin{array}{l}\text { 5:00 am - } \\
\text { 8:54 pm }\end{array}$ & 60 & 5:00 am - 8:54 pm & 60 & $\mathrm{n} / \mathrm{a}$ & $\mathrm{n} / \mathrm{a}$ \\
\hline 58 & $\begin{array}{l}\text { Shingle Creek } \\
\text { Circulator }\end{array}$ & $\begin{array}{l}\text { 6:44 am - } \\
9: 43 \mathrm{am} / \\
1: 44 \mathrm{pm}- \\
11: 43 \mathrm{pm}\end{array}$ & 30 & $\begin{array}{c}6: 44 \text { am - 9:43 } \\
\text { am/ 1:44 pm - } \\
11: 43 \mathrm{pm}\end{array}$ & 30 & $\begin{array}{c}6: 44 \text { am - 9:43 } \\
\text { am/ 1:44 pm - } \\
11: 43 \mathrm{pm}\end{array}$ & 30 \\
\hline 102 & $\begin{array}{c}\text { Orange Ave/South } \\
\text { US } 17 / 92\end{array}$ & $\begin{array}{l}4: 30 \mathrm{am}- \\
12: 35 \mathrm{am}\end{array}$ & $15 / 60$ & $\begin{array}{c}5: 00 \text { am }-11: 50 \\
p m\end{array}$ & $30 / 60$ & $\begin{array}{c}\text { 5:00 am - 10:50 } \\
\text { pm }\end{array}$ & 30 \\
\hline 103 & $\begin{array}{l}\text { North US } 17-92 \\
\text { Sanford }\end{array}$ & $\begin{array}{l}\text { 5:00 am - } \\
8: 58 \mathrm{pm}\end{array}$ & $15 / 30 / 40$ & 5:10 am - 9:04 pm & $30 / 40$ & 5:05 am - 8:13 pm & 60 \\
\hline 125 & $\begin{array}{l}\text { Silver Star Rd } \\
\text { Crosstown }\end{array}$ & $\begin{array}{l}4: 23 \mathrm{am}- \\
1: 24 \mathrm{am}\end{array}$ & $20 / 30 / 60$ & 4:30 am - 1:07 am & $30 / 60$ & $4: 25 a m-8: 22 p m$ & $30 / 60$ \\
\hline 200 & $\begin{array}{c}\text { Volusia } \\
\text { County/Downtown } \\
\text { Orlando }\end{array}$ & $\begin{array}{l}\text { 6:00 am- } \\
\text { 8:05 am/ } \\
\text { 4:00 pm - } \\
6: 35 \mathrm{pm}\end{array}$ & $30 / 45$ & $\mathrm{n} / \mathrm{a}$ & $\mathrm{n} / \mathrm{a}$ & $\mathrm{n} / \mathrm{a}$ & $\mathrm{n} / \mathrm{a}$ \\
\hline
\end{tabular}




\begin{tabular}{|c|c|c|c|c|c|c|c|}
\hline $\begin{array}{l}\text { Route } \\
\text { Number }\end{array}$ & Route Description & $\begin{array}{l}\text { Weekday- } \\
\text { Span of } \\
\text { Service }\end{array}$ & $\begin{array}{l}\text { Weekday- } \\
\text { Frequency } \\
\text { (Peak/ Off- } \\
\text { Peak) }\end{array}$ & $\begin{array}{c}\text { Saturday - Span } \\
\text { of Service }\end{array}$ & $\begin{array}{l}\text { Saturday - } \\
\text { Frequency } \\
\text { (Peak/ Off- } \\
\text { Peak) }\end{array}$ & $\begin{array}{c}\text { Sunday - Span of } \\
\text { Service }\end{array}$ & $\begin{array}{c}\text { Sunday - } \\
\text { Frequency } \\
\text { (Peak/ Off- } \\
\text { Peak) }\end{array}$ \\
\hline 300 & $\begin{array}{c}\text { Downtown Disney } \\
\text { Direct }\end{array}$ & $\begin{array}{l}\text { 6:30 am - } \\
7: 20 \mathrm{am} / \\
4: 55 \mathrm{pm}- \\
6: 00 \mathrm{pm}\end{array}$ & $\begin{array}{l}1 \text { trip am/ } \\
1 \text { trip pm }\end{array}$ & $\begin{array}{c}\text { 6:30 am - 7:20 } \\
\mathrm{am} / 4: 55 p m-6: 00 \\
p m\end{array}$ & $\begin{array}{l}1 \text { trip am/ } \\
1 \text { trip pm }\end{array}$ & $\begin{array}{c}\text { 6: } 30 \mathrm{am}-7: 20 \\
\mathrm{am} / 4: 55 p m-6: 00 \\
p m\end{array}$ & $\begin{array}{l}1 \text { trip am/ } \\
1 \text { trip pm }\end{array}$ \\
\hline 301 & $\begin{array}{l}\text { 3D-Pine Hills/Animal } \\
\text { Kingdom }\end{array}$ & $\begin{array}{l}\text { 6:05 am - } \\
7: 36 \mathrm{am} / \\
2: 20 \mathrm{pm}- \\
6: 20 \mathrm{pm}\end{array}$ & $\begin{array}{l}1 \text { trip am/ } \\
1 \text { trip pm }\end{array}$ & $\begin{array}{c}\text { 6:05 am - 7:36 } \\
\mathrm{pm} / 2: 20 \mathrm{pm}- \\
6: 20 \mathrm{pm}\end{array}$ & $\begin{array}{l}1 \text { trip am/ } \\
1 \text { trip pm }\end{array}$ & $\begin{array}{c}\text { 6:05 am - 7:36 } \\
\mathrm{pm} / 2: 20 \mathrm{pm}- \\
6: 20 \mathrm{pm}\end{array}$ & $\begin{array}{l}1 \text { trip am/ } \\
1 \text { trip pm }\end{array}$ \\
\hline 302 & $\begin{array}{c}\text { 3D-Rosemont/Magic } \\
\text { Kingdom }\end{array}$ & $\begin{array}{l}\text { 5:55 am - } \\
7: 47 \mathrm{am} / \\
2: 10 \mathrm{pm}- \\
6: 26 \mathrm{pm}\end{array}$ & $\begin{array}{l}1 \text { trip am/ } \\
1 \text { trip pm }\end{array}$ & $\begin{array}{c}5: 55 \mathrm{am}-7: 47 \\
\mathrm{am} / 2: 10 \mathrm{pm}- \\
6: 26 \mathrm{pm}\end{array}$ & $\begin{array}{l}1 \text { trip am/ } \\
1 \text { trip pm }\end{array}$ & $\begin{array}{c}\text { 5:55 am - 7:47 } \\
\text { am/ 2:10 pm - } \\
6: 26 \mathrm{pm}\end{array}$ & $\begin{array}{l}1 \text { trip am/ } \\
1 \text { trip pm }\end{array}$ \\
\hline 303 & $\begin{array}{c}\text { 3D-Washington } \\
\text { Shores/Disney MGM }\end{array}$ & $\begin{array}{l}\text { 6: } 15 \mathrm{am}- \\
7: 20 \mathrm{am} / \\
2: 30 \mathrm{pm}- \\
6: 00 \mathrm{pm}\end{array}$ & $\begin{array}{l}1 \text { trip am/ } \\
1 \text { trip pm }\end{array}$ & $\begin{array}{c}\text { 6:15 am - 7:20 } \\
\mathrm{am} / 2: 30 \mathrm{pm}- \\
\text { 6:00 pm }\end{array}$ & $\begin{array}{l}1 \text { trip am/ } \\
1 \text { trip pm }\end{array}$ & $\begin{array}{c}\text { 6:15 am - 7:20 } \\
\mathrm{am} / 2: 30 \mathrm{pm}- \\
\text { 6:00 pm }\end{array}$ & $\begin{array}{l}1 \text { trip am/ } \\
1 \text { trip pm }\end{array}$ \\
\hline 304 & $\begin{array}{c}\text { 3D-Rio } \\
\text { Grande/Vistana }\end{array}$ & $\begin{array}{l}6: 11 \mathrm{am}- \\
7: 35 \mathrm{am} / \\
2: 20 \mathrm{pm}- \\
6: 25 \mathrm{pm}\end{array}$ & $\begin{array}{l}1 \text { trip am/ } \\
1 \text { trip pm }\end{array}$ & $\begin{array}{l}6: 11 \mathrm{am}-7: 35 \mathrm{am} / \\
2: 20 \mathrm{pm}-6: 25 \mathrm{pm}\end{array}$ & $\begin{array}{l}1 \text { trip am/ } \\
1 \text { trip pm }\end{array}$ & $\begin{array}{l}6: 11 \mathrm{am}-7: 35 \mathrm{am} / \\
2: 20 \mathrm{pm}-6: 25 \mathrm{pm}\end{array}$ & $\begin{array}{l}1 \text { trip am/ } \\
1 \text { trip pm }\end{array}$ \\
\hline 305 & $\begin{array}{l}\text { 3D- Metro West/All } \\
\text { Star Resorts }\end{array}$ & $\begin{array}{l}\text { 6:09 am - } \\
\text { 7:19 am }\end{array}$ & am only & 6:09 am - 7:19 am & am only & 6:09 am - 7:19 am & am only \\
\hline 306 & $\begin{array}{c}\text { Downtown Disney } \\
\text { Direct }\end{array}$ & $\begin{array}{c}\text { 6: } 15 \mathrm{am}- \\
\text { 7:00 am/ } \\
\text { 5:20 pm - } \\
6: 05 \mathrm{pm}\end{array}$ & $\begin{array}{l}1 \text { trip am/ } \\
1 \text { trip pm }\end{array}$ & $\begin{array}{c}\text { 6:15 am - 7:00 } \\
\text { am/ 5:20 pm - } \\
\text { 6:05 pm }\end{array}$ & $\begin{array}{l}1 \text { trip am/ } \\
1 \text { trip pm }\end{array}$ & $\begin{array}{c}\text { 6:15 am - 7:00 } \\
\text { am/ 5:20 pm - } \\
\text { 6:05 pm }\end{array}$ & $\begin{array}{l}1 \text { trip am/ } \\
1 \text { trip pm }\end{array}$ \\
\hline 313 & Veterans Hospital & $\begin{array}{l}5: 52 \mathrm{am} \mathrm{-} \\
7: 35 \mathrm{pm}\end{array}$ & 60 & 5:52 am - 7:35 pm & 60 & $\mathrm{n} / \mathrm{a}$ & $\mathrm{n} / \mathrm{a}$ \\
\hline 319 & Richmond Heights & $\begin{array}{l}4: 20 \mathrm{am}- \\
1: 05 \mathrm{am}\end{array}$ & $20 / 60$ & $4: 20$ am - 1:05 am & $20 / 60$ & 4:45 am - 8:05 pm & 60 \\
\hline 405 & Apopka Circulator & $\begin{array}{l}4: 45 \mathrm{am}- \\
12: 51 \mathrm{am}\end{array}$ & 60 & $4: 35 \mathrm{am}-8: 51 \mathrm{pm}$ & 60 & $4: 35 \mathrm{am}-7: 51 \mathrm{pm}$ & 60 \\
\hline 426 & Poinciana Circulator & $\begin{array}{l}5: 25 \mathrm{am}- \\
10: 11 \mathrm{pm}\end{array}$ & 60 & $\begin{array}{c}5: 25 \text { am - 10:11 } \\
\text { pm }\end{array}$ & 60 & $\mathrm{n} / \mathrm{a}$ & $\mathrm{n} / \mathrm{a}$ \\
\hline
\end{tabular}




\begin{tabular}{|c|c|c|c|c|c|c|c|}
\hline $\begin{array}{l}\text { Route } \\
\text { Number }\end{array}$ & Route Description & $\begin{array}{l}\text { Weekday- } \\
\text { Span of } \\
\text { Service }\end{array}$ & $\begin{array}{l}\text { Weekday- } \\
\text { Frequency } \\
\text { ( Peak/ Off- } \\
\text { Peak) }\end{array}$ & $\begin{array}{c}\text { Saturday - Span } \\
\text { of Service }\end{array}$ & $\begin{array}{l}\text { Saturday - } \\
\text { Frequency } \\
\text { (Peak/ Off- } \\
\text { Peak) }\end{array}$ & $\begin{array}{c}\text { Sunday - Span of } \\
\text { Service }\end{array}$ & $\begin{array}{c}\text { Sunday - } \\
\text { Frequency } \\
\text { (Peak/ Off- } \\
\text { Peak) }\end{array}$ \\
\hline 434 & $\begin{array}{l}\text { State Rd } 434 \\
\text { Crosstown }\end{array}$ & $\begin{array}{l}\text { 5:30 am - } \\
9: 50 \mathrm{pm}\end{array}$ & 60 & 5:30 am - 9:50 pm & 60 & $\mathrm{n} / \mathrm{a}$ & $\mathrm{n} / \mathrm{a}$ \\
\hline 443 & Lee Rd Crosstown & $\begin{array}{l}\text { 4:57 am - } \\
8: 18 \mathrm{pm}\end{array}$ & 60 & 4:57 am - 8:18 pm & 60 & $6: 25 \mathrm{am}-6: 23 \mathrm{pm}$ & 60 \\
\hline 601 & South Poinciana & $\begin{array}{l}\text { 6:15 am - } \\
7: 25 \mathrm{pm}\end{array}$ & 60 & $6: 15$ am - 7:25 pm & 60 & $\mathrm{n} / \mathrm{a}$ & $\mathrm{n} / \mathrm{a}$ \\
\hline 603 & Southwest Poinciana & $\begin{array}{l}\text { 6: } 15 \mathrm{am}- \\
6: 25 \mathrm{pm}\end{array}$ & 120 & $6: 15$ am - 6:25 pm & 120 & $\mathrm{n} / \mathrm{a}$ & $\mathrm{n} / \mathrm{a}$ \\
\hline 611 & Ocoee & $\begin{array}{l}\text { 5:40 am - } \\
\text { 7:50 pm }\end{array}$ & 60 & $5: 40 \mathrm{am}-7: 50 \mathrm{pm}$ & 60 & $\mathrm{n} / \mathrm{a}$ & $\mathrm{n} / \mathrm{a}$ \\
\hline 612 & Winter Garden & $\begin{array}{l}\text { 5:45 am - } \\
7: 25 \mathrm{pm}\end{array}$ & $60 / 90$ & $6: 00 \mathrm{am}-7: 10 \mathrm{pm}$ & 60 & $\mathrm{n} / \mathrm{a}$ & $\mathrm{n} / \mathrm{a}$ \\
\hline 621 & Bithlo & $\begin{array}{l}\text { 5:40 am - } \\
\text { 7:40 pm }\end{array}$ & 90 & $\mathrm{n} / \mathrm{a}$ & $\mathrm{n} / \mathrm{a}$ & $\mathrm{n} / \mathrm{a}$ & $\mathrm{n} / \mathrm{a}$ \\
\hline 622 & Oviedo & $\begin{array}{l}\text { 6:20 am - } \\
7: 30 \mathrm{pm}\end{array}$ & 60 & $6: 20 \mathrm{am}-7: 30 \mathrm{pm}$ & 60 & $\mathrm{n} / \mathrm{a}$ & $\mathrm{n} / \mathrm{a}$ \\
\hline 631 & $\begin{array}{c}\text { Buena Ventura } \\
\text { Lakes }\end{array}$ & $\begin{array}{l}\text { 6: } 15 \mathrm{am}- \\
7: 25 \mathrm{pm}\end{array}$ & 60 & $\mathrm{n} / \mathrm{a}$ & $\mathrm{n} / \mathrm{a}$ & $\mathrm{n} / \mathrm{a}$ & $\mathrm{n} / \mathrm{a}$ \\
\hline 641 & $\begin{array}{c}\text { Williamsburg } \\
\text { Circulator (pickup } \\
\text { line) }\end{array}$ & $\begin{array}{l}\text { 6:05 am - } \\
\text { 7: } 15 \mathrm{pm}\end{array}$ & 60 & $6: 05 \mathrm{am}-7: 15 \mathrm{pm}$ & 60 & $\mathrm{n} / \mathrm{a}$ & $\mathrm{n} / \mathrm{a}$ \\
\hline
\end{tabular}




\begin{tabular}{|c|c|c|c|c|c|c|c|}
\hline $\begin{array}{l}\text { Route } \\
\text { Number }\end{array}$ & Route Description & $\begin{array}{c}\text { Weekday- Span } \\
\text { of Service }\end{array}$ & $\begin{array}{l}\text { Weekday- } \\
\text { Frequency } \\
\text { ( Peak/ Off- } \\
\text { Peak) }\end{array}$ & $\begin{array}{c}\text { Saturday - Span } \\
\text { of Service }\end{array}$ & $\begin{array}{c}\text { Saturday - } \\
\text { Frequency } \\
\text { ( Peak/ Off- } \\
\text { Peak) }\end{array}$ & $\begin{array}{l}\text { Sunday } \\
\text { - Span } \\
\text { of } \\
\text { Service }\end{array}$ & $\begin{array}{c}\text { Sunday - } \\
\text { Frequency } \\
\text { (Peak/ Off- } \\
\text { Peak) }\end{array}$ \\
\hline & \multicolumn{7}{|l|}{$\begin{array}{l}\text { Citrus Connection } \\
\text { (Lakeland) }\end{array}$} \\
\hline 10 & Shuttle & $\begin{array}{c}7: 15 \text { am - 6:40 } \\
\text { pm }\end{array}$ & 60 & $\begin{array}{c}8: 15 \text { am - 5:40 } \\
\text { pm }\end{array}$ & 60 & $\mathrm{n} / \mathrm{a}$ & $\mathrm{n} / \mathrm{a}$ \\
\hline 11 & $\begin{array}{l}\text { East Main/Combee } \\
\text { Road }\end{array}$ & $\begin{array}{c}6: 15 \text { am - 7:10 } \\
\text { pm }\end{array}$ & 60 & $\begin{array}{c}\text { 8: } 15 \text { am - 6: } 10 \\
p m\end{array}$ & 60 & $\mathrm{n} / \mathrm{a}$ & $\mathrm{n} / \mathrm{a}$ \\
\hline 12 & $\begin{array}{c}\text { Lakeland to Winter } \\
\text { Haven }\end{array}$ & $\begin{array}{c}6: 15 \text { am - 7:10 } \\
\text { pm }\end{array}$ & 60 & $\begin{array}{c}\text { 7: } 15 \text { am - 4: } 10 \\
\text { pm }\end{array}$ & $60 / 120$ & $\mathrm{n} / \mathrm{a}$ & $\mathrm{n} / \mathrm{a}$ \\
\hline 20 & $\begin{array}{c}\text { Grove Park/Crystal } \\
\text { Lake }\end{array}$ & $\begin{array}{c}6: 15 \text { am - 7:05 } \\
\text { pm }\end{array}$ & 60 & $\begin{array}{c}\text { 8: } 15 \text { am - 6:05 } \\
\text { pm }\end{array}$ & 60 & $\mathrm{n} / \mathrm{a}$ & $\mathrm{n} / \mathrm{a}$ \\
\hline 21 & Edgewood & $\begin{array}{c}6: 45 \text { am - 6:28 } \\
\text { pm }\end{array}$ & $60 / 120$ & $\begin{array}{c}\text { 7:45 am - 5:28 } \\
\text { pm }\end{array}$ & $60 / 120$ & $\mathrm{n} / \mathrm{a}$ & $\mathrm{n} / \mathrm{a}$ \\
\hline $22 X L$ & Bartow Express & $\begin{array}{c}\text { 6:05 am - 7:05 } \\
\text { pm }\end{array}$ & $30 / 50 / 25 / 90 / 45$ & $\begin{array}{c}\text { 7: } 15 \text { am - 6: } 10 \\
\text { pm }\end{array}$ & 60 & $\mathrm{n} / \mathrm{a}$ & $\mathrm{n} / \mathrm{a}$ \\
\hline 30 & Cleveland Heights & $\begin{array}{c}6: 45 a m-6: 35 \\
p m\end{array}$ & $60 / 120$ & $\begin{array}{c}8: 45 a m-4: 35 \\
p m\end{array}$ & $60 / 120$ & $\mathrm{n} / \mathrm{a}$ & $\mathrm{n} / \mathrm{a}$ \\
\hline 31 & $\begin{array}{l}\text { South Florida/Lake } \\
\text { Miriam }\end{array}$ & $\begin{array}{c}5: 45 \text { am - 7:40 } \\
\text { pm }\end{array}$ & 30 & $\begin{array}{c}\text { 7: } 15 \text { am - 6: } 10 \\
\text { pm }\end{array}$ & 30 & $\mathrm{n} / \mathrm{a}$ & $\mathrm{n} / \mathrm{a}$ \\
\hline 32 & Medulla Loop & $\begin{array}{c}5: 55 \text { am - 5:36 } \\
\text { pm }\end{array}$ & 90 & $\begin{array}{c}\text { 7:55 am - 4:36 } \\
\text { pm }\end{array}$ & 90 & $\mathrm{n} / \mathrm{a}$ & $\mathrm{n} / \mathrm{a}$ \\
\hline 33 & $\begin{array}{c}\text { South Florida/Carter } \\
\text { Road }\end{array}$ & $\begin{array}{c}6: 20 a m-5: 47 \\
p m\end{array}$ & 30 & $\begin{array}{c}8: 20 a m-4: 47 \\
p m\end{array}$ & 30 & $\mathrm{n} / \mathrm{a}$ & $\mathrm{n} / \mathrm{a}$ \\
\hline 37 & South Lakeland & $\begin{array}{c}6: 08 \text { am - 6:28 } \\
p m\end{array}$ & $60 / 90$ & $\begin{array}{c}8: 08 \text { am - 5:28 } \\
\text { pm }\end{array}$ & $60 / 90$ & $\mathrm{n} / \mathrm{a}$ & $\mathrm{n} / \mathrm{a}$ \\
\hline 40 & Ariana/Beacon & $\begin{array}{c}6: 45 a m-6: 10 \\
p m\end{array}$ & 60 & $\begin{array}{c}\text { 7:45 am - 5: } 10 \\
\mathrm{pm}\end{array}$ & 60 & $\mathrm{n} / \mathrm{a}$ & $\mathrm{n} / \mathrm{a}$ \\
\hline 41 & Central Avenue & $\begin{array}{c}5: 45 \text { am - 7:35 } \\
\text { pm }\end{array}$ & 60 & $\begin{array}{c}\text { 7:45 am- 5:35 } \\
\text { pm }\end{array}$ & 60 & $\mathrm{n} / \mathrm{a}$ & $\mathrm{n} / \mathrm{a}$ \\
\hline 42 & West Memorial & $\begin{array}{c}\text { 6:05 am - 7: } 10 \\
\mathrm{pm}\end{array}$ & $40 / 30$ & $\begin{array}{c}\text { 7: } 15 \text { am - 6: } 10 \\
\mathrm{pm}\end{array}$ & 30 & $\mathrm{n} / \mathrm{a}$ & $\mathrm{n} / \mathrm{a}$ \\
\hline 50 & Kathleen/Providence & $\begin{array}{c}5: 45 \text { am - 7:35 } \\
\text { pm }\end{array}$ & 60 & $\begin{array}{c}7: 45 a m-5: 35 \\
p m\end{array}$ & 60 & $\mathrm{n} / \mathrm{a}$ & $\mathrm{n} / \mathrm{a}$ \\
\hline
\end{tabular}




\begin{tabular}{|c|c|c|c|c|c|c|c|}
\hline $\begin{array}{l}\text { Route } \\
\text { Number }\end{array}$ & Route Description & $\begin{array}{c}\text { Weekday- Span } \\
\text { of Service }\end{array}$ & $\begin{array}{l}\text { Weekday- } \\
\text { Frequency } \\
\text { (Peak/ Off- } \\
\text { Peak) }\end{array}$ & $\begin{array}{c}\text { Saturday - Span } \\
\text { of Service }\end{array}$ & $\begin{array}{l}\text { Saturday - } \\
\text { Frequency } \\
\text { (Peak/ Off- } \\
\text { Peak) }\end{array}$ & $\begin{array}{l}\text { Sunday } \\
\text { - Span } \\
\text { of } \\
\text { Service }\end{array}$ & $\begin{array}{l}\text { Sunday - } \\
\text { Frequency } \\
\text { (Peak/ Off- } \\
\text { Peak) }\end{array}$ \\
\hline 52 & $\begin{array}{l}\text { North Florida } \\
\text { Avenue }\end{array}$ & $\begin{array}{c}\text { 6:15 am - 7:05 } \\
\text { pm }\end{array}$ & 30 & $\begin{array}{c}\text { 7:15 am - 6:05 } \\
\text { pm }\end{array}$ & 30 & $\mathrm{n} / \mathrm{a}$ & $\mathrm{n} / \mathrm{a}$ \\
\hline 53 & Lakeside Village & $\begin{array}{c}\text { 6:45 am - 6:40 } \\
\mathrm{pm}\end{array}$ & 60 & $\begin{array}{c}\text { 7:45 am- 5:40 } \\
\text { pm }\end{array}$ & 60 & $\mathrm{n} / \mathrm{a}$ & $\mathrm{n} / \mathrm{a}$ \\
\hline 56 & $\begin{array}{c}\text { Kathleen/Mall Hill } \\
\text { Dr. }\end{array}$ & $\begin{array}{c}\text { 6: } 15 \text { am - 7: } 10 \\
\text { pm }\end{array}$ & 60 & $\begin{array}{c}\text { 7:15 am- 6:10 } \\
\text { pm }\end{array}$ & 60 & $\mathrm{n} / \mathrm{a}$ & $\mathrm{n} / \mathrm{a}$ \\
\hline 57 & Kidron/Flightline & $\begin{array}{c}\text { 6:15 am - } \\
\text { 9:05am/ 3:15 pm } \\
-6: 05 p m\end{array}$ & 60 & $\begin{array}{c}8: 15 \mathrm{am}-11: 05 \\
\mathrm{am} / 3: 15 \mathrm{pm}- \\
5: 05 \mathrm{pm}\end{array}$ & 60 & $\mathrm{n} / \mathrm{a}$ & $\mathrm{n} / \mathrm{a}$ \\
\hline
\end{tabular}




\begin{tabular}{|c|c|c|c|c|c|c|c|}
\hline $\begin{array}{l}\text { Route } \\
\text { Number }\end{array}$ & $\begin{array}{c}\text { Route } \\
\text { Description } \\
\text { WHAT } \\
\text { TRANSI T }\end{array}$ & $\begin{array}{c}\text { Weekday- Span } \\
\text { of Service }\end{array}$ & $\begin{array}{l}\text { Weekday- } \\
\text { Frequency } \\
\text { ( Peak/ Off- } \\
\text { Peak) }\end{array}$ & $\begin{array}{c}\text { Saturday - Span } \\
\text { of Service }\end{array}$ & $\begin{array}{c}\text { Saturday - } \\
\text { Frequency } \\
\text { ( Peak/ Off- } \\
\text { Peak) }\end{array}$ & $\begin{array}{l}\text { Sunday - } \\
\text { Span of } \\
\text { Service }\end{array}$ & $\begin{array}{c}\text { Sunday - } \\
\text { Frequency } \\
\text { (Peak/ Off- } \\
\text { Peak) }\end{array}$ \\
\hline 12 & $\begin{array}{l}\text { Winter Haven to } \\
\text { Lakeland }\end{array}$ & $\begin{array}{c}\text { 6: } 15 \text { am - 7:10 } \\
\text { pm }\end{array}$ & 60 & $\begin{array}{c}\text { 7: } 15 \text { am - 4: } 10 \\
\text { pm }\end{array}$ & 60 & $\mathrm{n} / \mathrm{a}$ & $\mathrm{n} / \mathrm{a}$ \\
\hline $40-44$ & South/Southwest & $\begin{array}{c}\text { 5:45 am - 7:05 } \\
\text { pm }\end{array}$ & 90 & $\begin{array}{c}\text { 7:50 am - 3:50 } \\
\mathrm{pm}\end{array}$ & $120 / 180$ & $\mathrm{n} / \mathrm{a}$ & $\mathrm{n} / \mathrm{a}$ \\
\hline 50 & Auburndale & $\begin{array}{c}\text { 5:45 am - 7:05 } \\
\text { pm }\end{array}$ & 90 & $\begin{array}{c}6: 50 \mathrm{am}-2: 50 \\
p m\end{array}$ & $120 / 180$ & $\mathrm{n} / \mathrm{a}$ & $\mathrm{n} / \mathrm{a}$ \\
\hline 15 & $\begin{array}{l}\text { Winter Haven to } \\
\text { Haines City }\end{array}$ & $\begin{array}{c}\text { 6: } 15 \mathrm{am}-7: 10 \\
\mathrm{pm}\end{array}$ & 60 & $\begin{array}{c}\text { 7:15 am - 3:10 } \\
\text { pm }\end{array}$ & $120 / 180$ & $\mathrm{n} / \mathrm{a}$ & $\mathrm{n} / \mathrm{a}$ \\
\hline $22 \times w$ & $\begin{array}{c}\text { Bartow/Winter } \\
\text { Haven }\end{array}$ & $\begin{array}{c}6: 15 \text { am - 7:10 } \\
\text { pm }\end{array}$ & 60 & $\begin{array}{c}\text { 8: } 15 \text { am - 4: } 10 \\
p m\end{array}$ & $120 / 180$ & $\mathrm{n} / \mathrm{a}$ & $\mathrm{n} / \mathrm{a}$ \\
\hline 30 & $\begin{array}{c}\text { Cypress Gardens } \\
\text { Blvd }\end{array}$ & $\begin{array}{c}6: 28 \text { am - 7: } 10 \\
p m\end{array}$ & 60 & $\begin{array}{c}\text { 7: } 15 \text { am - 4:15 } \\
\mathrm{pm}\end{array}$ & $60 / 120$ & $\mathrm{n} / \mathrm{a}$ & $\mathrm{n} / \mathrm{a}$ \\
\hline
\end{tabular}




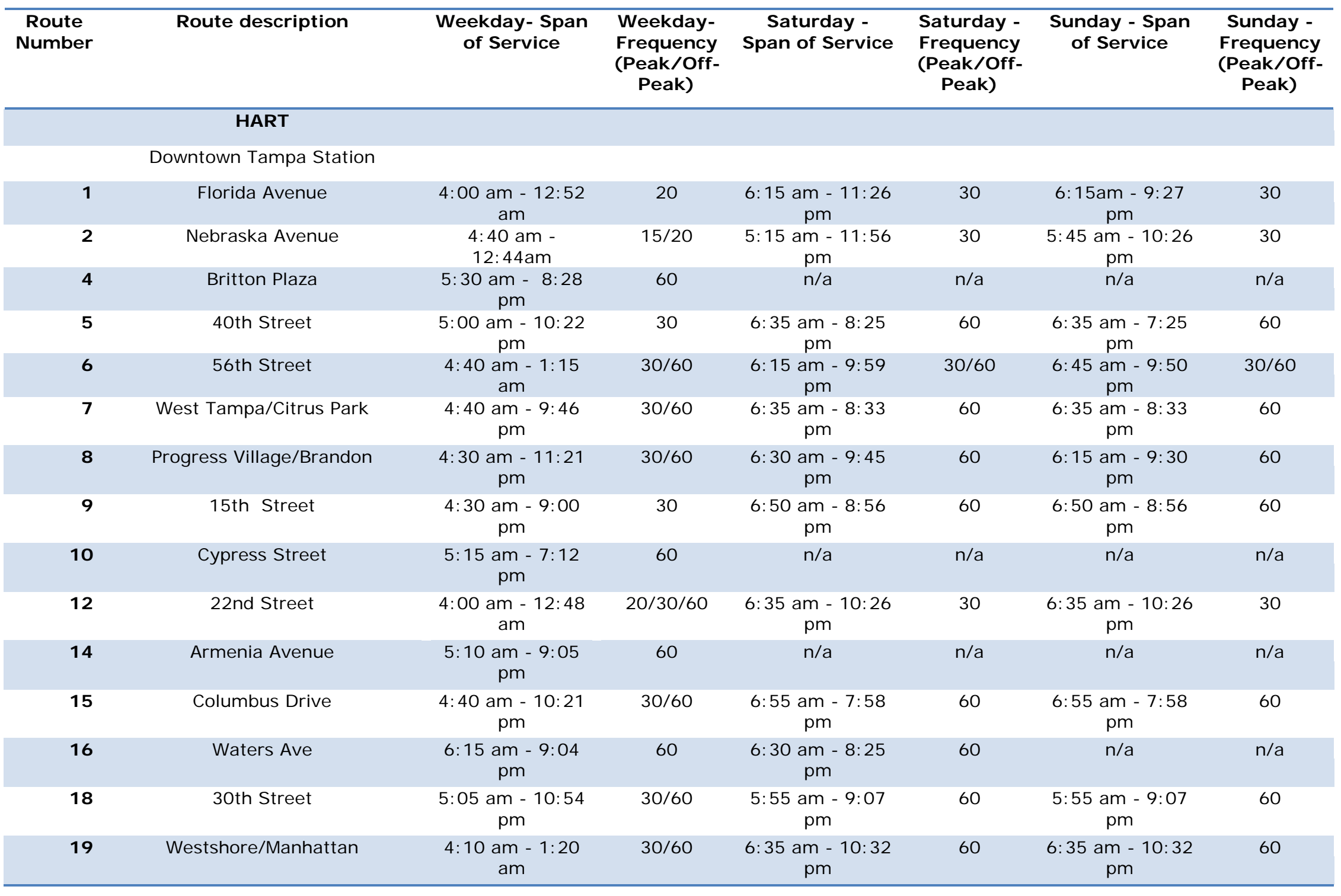




\begin{tabular}{|c|c|c|c|c|c|c|c|}
\hline $\begin{array}{l}\text { Route } \\
\text { Number }\end{array}$ & Route description & $\begin{array}{l}\text { Weekday- Span } \\
\text { of Service }\end{array}$ & $\begin{array}{l}\text { Weekday- } \\
\text { Frequency } \\
\text { (Peak/ Off- } \\
\text { Peak) }\end{array}$ & $\begin{array}{c}\text { Saturday - } \\
\text { Span of Service }\end{array}$ & $\begin{array}{c}\text { Saturday - } \\
\text { Frequency } \\
\text { (Peak/ Off- } \\
\text { Peak) }\end{array}$ & $\begin{array}{c}\text { Sunday - Span } \\
\text { of Service }\end{array}$ & $\begin{array}{c}\text { Sunday - } \\
\text { Frequency } \\
\text { (Peak/ Off- } \\
\text { Peak) }\end{array}$ \\
\hline 30 & Town 'N Country & $\begin{array}{c}4: 40 \text { am - } 1: 14 \\
\text { am }\end{array}$ & $15 / 30$ & $\begin{array}{c}6: 35 \text { am - 11:17 } \\
\text { pm }\end{array}$ & 30 & $\begin{array}{c}6: 35 \text { am - 11:17 } \\
\text { pm }\end{array}$ & 30 \\
\hline 31 & South Hillsborough County & $\begin{array}{c}\text { 6:00 am - 8:09 } \\
\text { pm }\end{array}$ & 120 & $\mathrm{n} / \mathrm{a}$ & $\mathrm{n} / \mathrm{a}$ & $\mathrm{n} / \mathrm{a}$ & $\mathrm{n} / \mathrm{a}$ \\
\hline 32 & Dr. Martin Luther King, Jr. Blvd & $\begin{array}{c}4: 35 \text { am - } 12: 28 \\
a m\end{array}$ & $30 / 60$ & $\begin{array}{c}\text { 7:05 am - 11:00 } \\
\text { pm }\end{array}$ & 60 & $\begin{array}{c}\text { 7:05 am - 11:00 } \\
\text { pm }\end{array}$ & 60 \\
\hline 33 & $\begin{array}{c}\text { Dale Mabry Highway/Fletcher } \\
\text { Ave }\end{array}$ & $\begin{array}{c}4: 45 \text { am }-11: 06 \\
p m\end{array}$ & 30 & $\begin{array}{c}\text { 6:00 am -10:21 } \\
\mathrm{pm}\end{array}$ & 45 & $\begin{array}{c}6: 30 \text { am }-7: 51 \\
\text { pm }\end{array}$ & 45 \\
\hline 34 & Hillsborough Ave & $\begin{array}{l}\text { 4:30 am - } \\
12: 45 a m\end{array}$ & $30 / 60$ & $\begin{array}{c}6: 30 \mathrm{am}-10: 23 \\
\mathrm{pm}\end{array}$ & 30 & $\begin{array}{c}\text { 7:00 am - 9:53 } \\
\text { pm }\end{array}$ & 60 \\
\hline 36 & Dale Mabry/Himes Ave & $\begin{array}{c}\text { 5:05 am - 10:23 } \\
\text { pm }\end{array}$ & $30 / 60$ & $\begin{array}{c}\text { 6: } 00 \mathrm{am}-8: 55 \\
\mathrm{pm}\end{array}$ & 60 & $\begin{array}{c}\text { 6: } 00 \mathrm{am}-8: 55 \\
\mathrm{pm}\end{array}$ & 60 \\
\hline 37 & Grand Regency Plaza & $\begin{array}{c}\text { 5:05 am - 8:55 } \\
\text { pm }\end{array}$ & $30 / 60$ & $\begin{array}{c}6: 40 \mathrm{am}-7: 29 \\
\mathrm{pm}\end{array}$ & 60 & $\mathrm{n} / \mathrm{a}$ & $\mathrm{n} / \mathrm{a}$ \\
\hline 39 & Busch Blvd & $\begin{array}{c}\text { 5:05 am - 6:53 } \\
\mathrm{pm}\end{array}$ & 30 & $\begin{array}{c}\text { 7:00 am - 7:40 } \\
\text { pm }\end{array}$ & 30 & $\begin{array}{c}\text { 7:00 am - 8: } 35 \\
\text { pm }\end{array}$ & 60 \\
\hline 41 & Sligh Ave & $\begin{array}{c}\text { 5:05 am - 7:51 } \\
\mathrm{pm}\end{array}$ & 60 & $\mathrm{n} / \mathrm{a}$ & $\mathrm{n} / \mathrm{a}$ & $\mathrm{n} / \mathrm{a}$ & $\mathrm{n} / \mathrm{a}$ \\
\hline 45 & Rome Av & $\begin{array}{c}4: 30 \underset{\mathrm{pm}}{\mathrm{am}}-10: 25 \\
\text { p }\end{array}$ & 30 & $\begin{array}{c}\text { 6: } 35 \text { am - 8:48 } \\
\text { pm }\end{array}$ & 60 & $\begin{array}{c}\text { 6: } 35 \text { am - 8: } 48 \\
p m\end{array}$ & 60 \\
\hline 46 & Davis Islands/West Brandon & $\begin{array}{c}\text { 6:02 am - 7:00 } \\
\text { pm }\end{array}$ & 60 & $\mathrm{n} / \mathrm{a}$ & $\mathrm{n} / \mathrm{a}$ & $\mathrm{n} / \mathrm{a}$ & $\mathrm{n} / \mathrm{a}$ \\
\hline 57 & UATC/Temple Terrace/Netpark & $\begin{array}{c}4: 35 \mathrm{am}-10: 26 \\
\mathrm{pm}\end{array}$ & 60 & $\mathrm{n} / \mathrm{a}$ & $\mathrm{n} / \mathrm{a}$ & $\mathrm{n} / \mathrm{a}$ & $\mathrm{n} / \mathrm{a}$ \\
\hline 87 & Southshore Connector & $\begin{array}{c}\text { 7:20 am - 8:02 } \\
\text { pm }\end{array}$ & $\begin{array}{l}70 / 100 / \\
170 / 175\end{array}$ & $\mathrm{n} / \mathrm{a}$ & $\mathrm{n} / \mathrm{a}$ & $\mathrm{n} / \mathrm{a}$ & $\mathrm{n} / \mathrm{a}$ \\
\hline 88 & Town 'N Country Connector & $\begin{array}{c}6: 00 \mathrm{am}-9: 10 \\
\mathrm{am} / 3: 30 \mathrm{pm}- \\
6: 40 \mathrm{pm}\end{array}$ & 40 & $\mathrm{n} / \mathrm{a}$ & $\mathrm{n} / \mathrm{a}$ & $\mathrm{n} / \mathrm{a}$ & $\mathrm{n} / \mathrm{a}$ \\
\hline 89 & South Tampa Connector & $\begin{array}{c}5: 30 \mathrm{am}-8: 20 \\
\mathrm{pm}\end{array}$ & 60 & $\mathrm{n} / \mathrm{a}$ & $\mathrm{n} / \mathrm{a}$ & $\mathrm{n} / \mathrm{a}$ & $\mathrm{n} / \mathrm{a}$ \\
\hline
\end{tabular}




\begin{tabular}{|c|c|c|c|c|c|c|c|}
\hline $\begin{array}{l}\text { Route } \\
\text { Number }\end{array}$ & Route description & $\begin{array}{l}\text { Weekday- Span } \\
\text { of Service }\end{array}$ & $\begin{array}{l}\text { Weekday- } \\
\text { Frequency } \\
\text { (Peak/ Off- } \\
\text { Peak) }\end{array}$ & $\begin{array}{c}\text { Saturday - } \\
\text { Span of Service }\end{array}$ & $\begin{array}{c}\text { Saturday - } \\
\text { Frequency } \\
\text { (Peak/ Off- } \\
\text { Peak) }\end{array}$ & $\begin{array}{c}\text { Sunday - Span } \\
\text { of Service }\end{array}$ & $\begin{array}{c}\text { Sunday - } \\
\text { Frequency } \\
\text { (Peak/ Off- } \\
\text { Peak) }\end{array}$ \\
\hline $20 x$ & Lutz & $\begin{array}{l}6: 15 \text { am }-7: 34 \\
a m / \quad 4: 30 p m \\
-5: 55 p m\end{array}$ & $40 / 45$ & $\mathrm{n} / \mathrm{a}$ & $\mathrm{n} / \mathrm{a}$ & $\mathrm{n} / \mathrm{a}$ & $\mathrm{n} / \mathrm{a}$ \\
\hline $22 x$ & Dover/Brandon & $\begin{array}{c}6: 20 \mathrm{am}-7: 44 \\
\mathrm{am} / 4: 45 \mathrm{pm}- \\
6: 12 \mathrm{pm}\end{array}$ & 30 & $\mathrm{n} / \mathrm{a}$ & $\mathrm{n} / \mathrm{a}$ & $\mathrm{n} / \mathrm{a}$ & $\mathrm{n} / \mathrm{a}$ \\
\hline $23 x$ & Temple Terrace & $\begin{array}{c}6: 35 \mathrm{am}-7: 44 \\
\mathrm{am} / 4: 30 \mathrm{pm}- \\
5: 57 \mathrm{pm}\end{array}$ & $40 / 45$ & $\mathrm{n} / \mathrm{a}$ & $\mathrm{n} / \mathrm{a}$ & $\mathrm{n} / \mathrm{a}$ & $\mathrm{n} / \mathrm{a}$ \\
\hline $24 x$ & FishHawk/Riverview/MacDill & $\begin{array}{c}5: 10 \mathrm{am}-7: 15 \\
\mathrm{am} / 2: 58 \mathrm{pm}- \\
6: 20 \mathrm{pm}\end{array}$ & $5 / 10 / 20 / 30$ & $\mathrm{n} / \mathrm{a}$ & $\mathrm{n} / \mathrm{a}$ & $\mathrm{n} / \mathrm{a}$ & $\mathrm{n} / \mathrm{a}$ \\
\hline $25 L X$ & South Brandon/MacDill A.F.B. & $\begin{array}{c}5: 30 \mathrm{am}-7: 15 \\
\mathrm{am} / 2: 58 \mathrm{pm}- \\
6: 27 \mathrm{pm}\end{array}$ & $15 / 10$ & $\mathrm{n} / \mathrm{a}$ & $\mathrm{n} / \mathrm{a}$ & $\mathrm{n} / \mathrm{a}$ & $\mathrm{n} / \mathrm{a}$ \\
\hline 27LX & South Brandon & $\begin{array}{c}6: 10 \mathrm{am}-7: 50 \\
\mathrm{am} / 4: 40 \mathrm{pm}- \\
6: 14 \mathrm{pm}\end{array}$ & $20 / 30$ & $\mathrm{n} / \mathrm{a}$ & $\mathrm{n} / \mathrm{a}$ & $\mathrm{n} / \mathrm{a}$ & $\mathrm{n} / \mathrm{a}$ \\
\hline $28 X$ & East County & $\begin{array}{c}6: 20 \mathrm{am}-7: 41 \\
\mathrm{am} / 4: 40 \mathrm{pm}- \\
6: 05 \mathrm{pm}\end{array}$ & $30 / 35$ & $\mathrm{n} / \mathrm{a}$ & $\mathrm{n} / \mathrm{a}$ & $\mathrm{n} / \mathrm{a}$ & $\mathrm{n} / \mathrm{a}$ \\
\hline 35LX & Brandon/South Shore & $\begin{array}{c}10: 15 \text { am - 5:11 } \\
\text { pm }\end{array}$ & $75 / 90$ & $\mathrm{n} / \mathrm{a}$ & $\mathrm{n} / \mathrm{a}$ & $\mathrm{n} / \mathrm{a}$ & $\mathrm{n} / \mathrm{a}$ \\
\hline 47LX & South Shore & $\begin{array}{c}5: 45 \text { am - 7:47 } \\
\mathrm{am} / 4: 40 \mathrm{pm}- \\
6: 27 \mathrm{pm}\end{array}$ & $45 / 30$ & $\mathrm{n} / \mathrm{a}$ & $\mathrm{n} / \mathrm{a}$ & $\mathrm{n} / \mathrm{a}$ & $\mathrm{n} / \mathrm{a}$ \\
\hline $50 x$ & Citrus Park/Carrollwood & $\begin{array}{c}\text { 6:15 am - 7:47 } \\
\mathrm{am} / 4: 45 \mathrm{pm}- \\
6: 09 \mathrm{pm}\end{array}$ & 30 & $\mathrm{n} / \mathrm{a}$ & $\mathrm{n} / \mathrm{a}$ & $\mathrm{n} / \mathrm{a}$ & $\mathrm{n} / \mathrm{a}$ \\
\hline $51 X$ & New Tampa & $\begin{array}{c}6: 01 \mathrm{am}-7: 45 \\
\mathrm{am} / 4: 45 \mathrm{pm}- \\
6: 29 \mathrm{pm}\end{array}$ & $26 / 30$ & $\mathrm{n} / \mathrm{a}$ & $\mathrm{n} / \mathrm{a}$ & $\mathrm{n} / \mathrm{a}$ & $\mathrm{n} / \mathrm{a}$ \\
\hline 59LX & Westchase/Town 'N Country & $\begin{array}{c}\text { 5:00 am - 7:43 } \\
\mathrm{am} / 4: 45 \mathrm{pm}- \\
7: 23 \mathrm{pm}\end{array}$ & $25 / 30$ & $\mathrm{n} / \mathrm{a}$ & $\mathrm{n} / \mathrm{a}$ & $\mathrm{n} / \mathrm{a}$ & $\mathrm{n} / \mathrm{a}$ \\
\hline $200 x$ & Clearwater & $\begin{array}{l}5: 20 \mathrm{am}-9: 29 \\
\mathrm{am} / 4: 40 \mathrm{pm}-\end{array}$ & $50 / 35$ & $\mathrm{n} / \mathrm{a}$ & $\mathrm{n} / \mathrm{a}$ & $\mathrm{n} / \mathrm{a}$ & $\mathrm{n} / \mathrm{a}$ \\
\hline
\end{tabular}


Appendix A 2010 Public Transportation Services LeVels by Transit Agency

\begin{tabular}{|c|c|c|c|c|c|c|c|}
\hline $\begin{array}{l}\text { Route } \\
\text { Number }\end{array}$ & Route description & $\begin{array}{l}\text { Weekday- Span } \\
\text { of Service }\end{array}$ & $\begin{array}{l}\text { Weekday- } \\
\text { Frequency } \\
\text { (Peak/ Off- } \\
\text { Peak) }\end{array}$ & $\begin{array}{c}\text { Saturday - } \\
\text { Span of Service }\end{array}$ & $\begin{array}{l}\text { Saturday - } \\
\text { Frequency } \\
\text { ( Peak/ Off- } \\
\text { Peak) }\end{array}$ & $\begin{array}{l}\text { Sunday - Span } \\
\text { of Service }\end{array}$ & $\begin{array}{c}\text { Sunday - } \\
\text { Frequency } \\
\text { (Peak/ Off- } \\
\text { Peak) }\end{array}$ \\
\hline $100 x$ & PSTA Route (Clearwater) & $\begin{array}{c}5: 20 \text { am - 7:40 } \\
\text { pm }\end{array}$ & 30 & $\mathrm{n} / \mathrm{a}$ & $\mathrm{n} / \mathrm{a}$ & $\mathrm{n} / \mathrm{a}$ & $\mathrm{n} / \mathrm{a}$ \\
\hline $300 x$ & PSTA Route (St. Petersburg) & $\begin{array}{c}6: 00 \text { am - 7:55 } \\
\text { pm }\end{array}$ & $30 / 120$ & $\mathrm{n} / \mathrm{a}$ & $\mathrm{n} / \mathrm{a}$ & $\mathrm{n} / \mathrm{a}$ & $\mathrm{n} / \mathrm{a}$ \\
\hline 96 & Purple Line & $\begin{array}{c}6: 00 \mathrm{am}-9: 00 \\
\mathrm{am} / 3: 00 \mathrm{pm}- \\
6: 00 \mathrm{pm}\end{array}$ & 15 & $\mathrm{n} / \mathrm{a}$ & $\mathrm{n} / \mathrm{a}$ & $\mathrm{n} / \mathrm{a}$ & $\mathrm{n} / \mathrm{a}$ \\
\hline 97 & $\begin{array}{c}\text { Green Line (Friday and Saturday } \\
\text { only) }\end{array}$ & $\begin{array}{c}\text { FRIDAY \& } \\
\text { SATURDAY ONLY: } \\
\text { 6:00 pm - 2:00 } \\
\text { am }\end{array}$ & 15 & $\begin{array}{c}6: 00 \mathrm{pm}-2: 00 \\
\mathrm{am}\end{array}$ & 15 & $\mathrm{n} / \mathrm{a}$ & $\mathrm{n} / \mathrm{a}$ \\
\hline
\end{tabular}


This page intentionally left blank 


\section{APPENDIX B}




\section{Agency Interviews}

\section{HART}

Coordination meetings were held between CUTR project staff and HART Planning Staff. To kick off, there was a discussion about HART's current level of service from the intermodal HSR station to major trip generators in the service area. HART has a preliminary service implementation plan in the event a November referendum for a new source of dedicated revenue was successful (note: The referendum was unsuccessful). Service improvements were to include 10 new bus routes, with a number of them in the Westshore and Brandon areas, increased flex services, and frequency and span enhancements for existing service. Given that a significant number of existing routes already serve the future HSR location, HSR connectivity should be improved on current lines. HSR specific improvements on HART service have been designed for the Route 5, providing access to the Busch Gardens/University of South Florida areas.

A discussion was had about the planned premium transit options, Bus Rapid Transit (BRT) and Light Rail (LRT). HART's first BRT line, the North/South line, is planned for operation in late 2012 with 10-minute peak frequencies, ending at the HSR station. An east-west line and LRT to either the airport or Cross Creek areas will also serve the HSR intermodal station. Options for increased service from the HSR station to Tampa International Airport were described. HART will also be redesigning the downtown Tampa service, affecting the downtown circulator patterns. Increased service to leisure centers such as the Hard Rock casino, were thought to be candidates for public/private partnerships. At the conclusion of the meeting, CUTR requested HART's draft transition plan and operating costs.

Subsequent to the first meeting, HART is now in development of a revised 5-10 year plan, no longer a transitions plan that assumes new revenues. They will complete their Alternatives Analysis with no local funding identified. The transition plan that was created to implement new service assuming an increase in funding will now likely become the 10-year TDP Needs Plan. The only HSR serving route planned for improvements by 2015 is Route 8. Fiscal years 2011 and 2012 will maintain current service levels, assuming stable ad valorem revenues. Express routes may be eliminated in upcoming markups, along with late-night service. Service planning goals include replacing connector routes with flex services, straightening out non-linear routes, and using flex as feeder service.

\section{POLK}

A coordination meeting was held between CUTR project staff, Lakeland Area Mass Transit (LAMTD), and Polk County Transit Service (PCTS). Similar to HART, Polk County's transit providers have a five year plan to transition transit services in the event there is a successful funding referendum passed (note: The referendum was unsuccessful). That increased service would include two to three new routes serving the USF Polytechnic proposed HSR site. The transition plan is in a limited redesign and wherever the HSR station is ultimately located will influence at least a portion of where increased resources would be placed. 
In a financially unconstrained scenario, LAMTD would create service from the HSR station to roads 540 and 17 serving Legoland. A route was also suggested along 540 to the WDW station. PCTS would add service from northeast Polk County to the Disney station. If the HSR station for Polk County were placed at the Kathleen Road site, modifications would be made to the Routes 50 and 56 to serve it. A concern in Polk County is road network access to station sites and preferential transit bus access.

\section{LYNX}

Coordination meetings were held between CUTR project staff and LYNX. Areas of interest raised by LYNX included that only a limited amount of work has been put into looking at how their services would connect to the HSR stations. The development of an upcoming long-range strategic plan would begin to address HSR/LYNX interaction. About a year ago, LYNX began a five-year plan to address their core services and to set preliminary standards for service. This is a financially constrained plan, particularly for 2012 when an impact is expected to be felt from the loss of stimulus funds.

Consideration for service expansion within the financial plan is being given in the emerging Lake Nona DRI and International Airport. This is in part attributable to the construction of new medical and research facilities to the south of the airport. Connections to the planned SunRail commuter rail system are being discussed at 30-minute frequencies to existing routes, which could link the line to the airport.

A brainstorming discussion was had on areas that would be valuable to connect to HSR stations in a financially unconstrained situation. The airport would receive more services in this scenario, with new service to the south in the congested Boggy Creek area. A connection from the airport to Innovation Way to the University of Central Florida will be addressed in the strategic plan. The Orange County Convention Center/International Drive station would receive enhanced frequencies and span of existing services in this scenario. The WDW station market could be explored with services to the timeshares residences in the area, potentially provided through a public-private partnership. Service to the Dr. Phillips and Celebration areas would also be a priority for the HSR station.

Considerations for shared maintenance facilities and the differing sizes of LYNX buses requiring access to the stations for connecting the service were mentioned by LYNX. Upon conclusion of the meeting, it was agreed LYNX would provide CUTR with the work completed on their five

year service plan, the draft SunRail feeder plan, plans for the Lake Nona DRI, and operating cost data. 
This page intentionally left blank 